\title{
WestVirginiaUniversity
}

THE RESEARCH REPOSITORY @ WVU

Graduate Theses, Dissertations, and Problem Reports

2002

\section{Seepage in earth slopes with longitudinal drainage trenches}

Ricardo Constantino Kiriakidis L.

West Virginia University

Follow this and additional works at: https://researchrepository.wvu.edu/etd

\section{Recommended Citation}

Kiriakidis L., Ricardo Constantino, "Seepage in earth slopes with longitudinal drainage trenches" (2002). Graduate Theses, Dissertations, and Problem Reports. 1255.

https://researchrepository.wvu.edu/etd/1255

This Thesis is protected by copyright and/or related rights. It has been brought to you by the The Research Repository @ WVU with permission from the rights-holder(s). You are free to use this Thesis in any way that is permitted by the copyright and related rights legislation that applies to your use. For other uses you must obtain permission from the rights-holder(s) directly, unless additional rights are indicated by a Creative Commons license in the record and/ or on the work itself. This Thesis has been accepted for inclusion in WVU Graduate Theses, Dissertations, and Problem Reports collection by an authorized administrator of The Research Repository @ WVU. For more information, please contact researchrepository@mail.wvu.edu. 


\title{
Seepage In Earth Slopes With longitudinal Drainage Trenches
}

\author{
By \\ Ricardo C. Kiriakidis L. \\ Thesis submitted to the \\ College of Engineering and Mineral Resources \\ at West Virginia University \\ in partial fulfillment of the requirements for \\ the degree of \\ Master of Science
in
Civil Engineering
}

Hema J. Siriwardane Ph.D., P.E., Chair

Udaya Halabe Ph.D., P.E.

George Hall Ph.D., P.E.

Department of Civil and Environmental Engineering

\author{
Morgantown, West Virginia \\ 2002
}

Keywords: Longitudinal Trench Drains, Seepage 


\section{ABSTRACT \\ Seepage In Earth Slopes With Longitudinal Drainage Trenches \\ Ricardo C. Kiriakidis L.}

Slope stability is a serious problem that can cause damages in millions of dollars annually. Slope failures caused by seepage are very common in West Virginia and other states. Longitudinal drainage trenches along the face of the slope, instead of horizontal wells or regular French drains, could be an efficient solution to this problem. The stabilization method involves installing longitudinal drainage trenches in the direction of the slope inclination within the potential failure zone. These longitudinal drains could reduce the amount of water flowing through the slope and change the water flow-patterns thus greatly reducing the seepage force and increasing the stability of the treated slope.

The major objective of this study was to determine the effect of hydraulic conductivity on the effectiveness and efficiency of longitudinal drains and on the time to reach steady state seepage under controlled laboratory conditions. An apparatus capable of simulating different slope angles and trench spacing was utilized in this study. By using this apparatus it was possible to obtain data regarding flow pattern, pressure heads, saturation time, influence of slope angle $(\theta)$, the trench spacing $(\mathrm{W}=2 \mathrm{w})$ and seepage depth (h) under steady state and transient conditions for different values of hydraulic conductivity. Two different soil types with different values of hydraulic conductivity (k) were tested at three slope angles. For each of these slopes, three different values of trench spacing were tested. For each of these, tests were conducted at three seepage levels. Measurements of seepage removal rate were taken along the longitudinal direction of the trench under transient and steady state conditions. The piezometric pressures at selected locations in the soil slope were measured.

The results show that the longitudinal trench drains are very effective in removing the majority of seepage from the soil. While the observed transient time is a function of hydraulic conductivity of the soil, the transient time was relatively short. The short transient time suggests that the longitudinal drains become effective in a very short time for small drainage configurations (model conditions). The report contains laboratory data on the influence of different experimental parameters on the performance of longitudinal drainage trenches. 


\section{ACKNOWLEDGMENTS}

Thanks to all of those whose support made this project a reality. The author wishes to thank Dr. Hema J. Siriwardane, graduate adviser and committee chairman, for his invaluable guidance, which was the corner stone for this thesis. The author also wishes to thank Dr. George Hall for his constant flow of ideas and views. Thanks also go to Dr. Udaya Halabe for his participation in the committee and his keen eye for detail.

The financial support provided by the West Virginia Department of Transportation, Division of Highways for this project through a research contract to West Virginia University is gratefully acknowledged.

The author also would like to thank family and friends for their moral support and understanding. 


\section{TABLE OF CONTENTS}

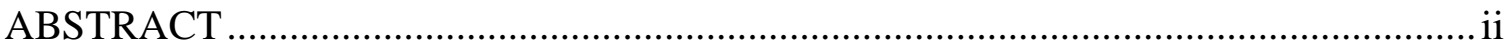

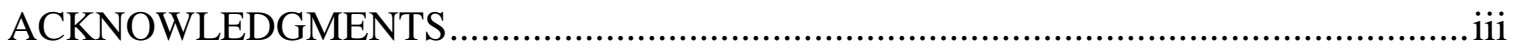

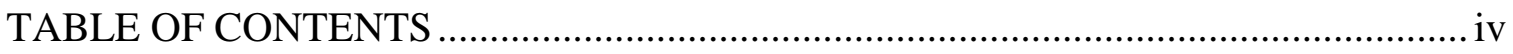

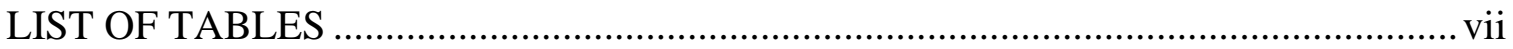

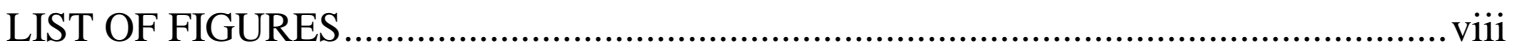

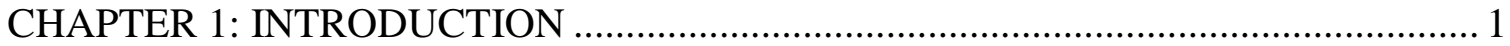

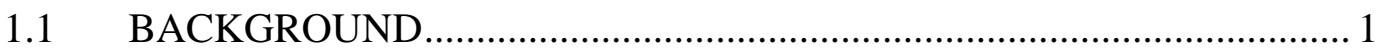

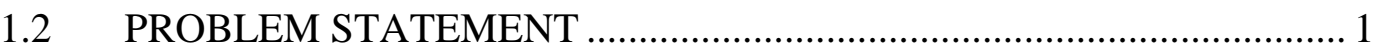

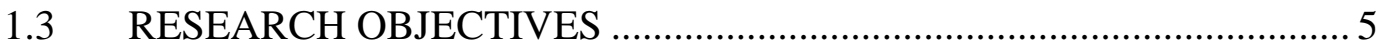

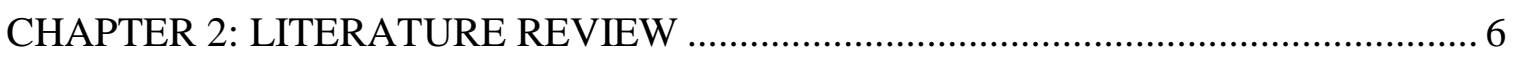

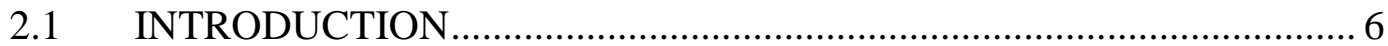

2.2 SEEPAGE

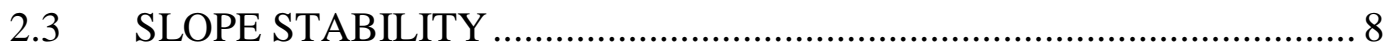

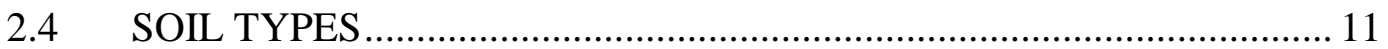

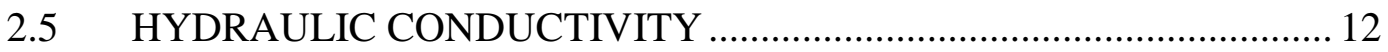

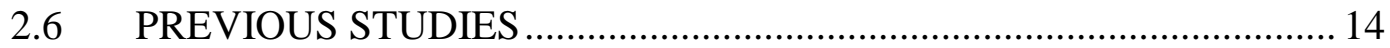

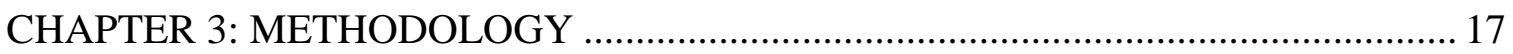

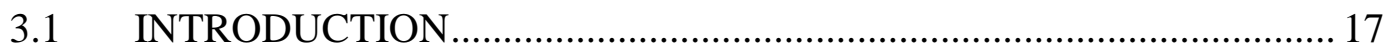

3.2 SELECTION OF SOIL SPECIMENS …............................................... 17

3.3 DESCRIPTION OF THE EXPERIMENTAL APPARATUS .................. 21

3.3.1 Piezometric Head .............................................................. 22

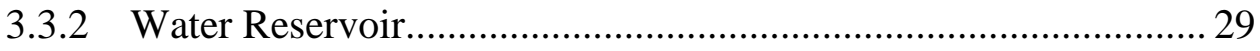

3.3.3 Longitudinal Drain ...................................................................... 31 
3.3.4 End Drain ...................................................................... 31

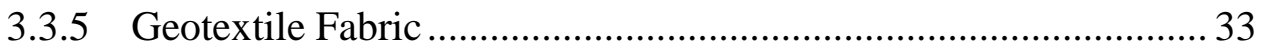

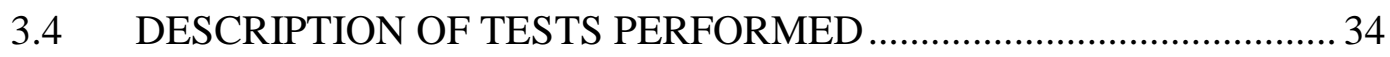

3.4.1 Placement of Soil .................................................................. 34

3.4.2 Saturation Period .................................................................. 35

3.4.3 Transient State Condition..................................................... 36

3.4.4 Steady State Condition .................................................... 36

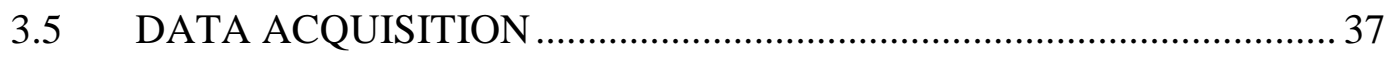

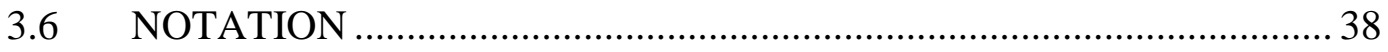

CHAPTER 4: RESULTS AND DISCUSSION FOR TRANSIENT STATE ................. 42

$4.1 \quad$ INTRODUCTION ................................................................... 42

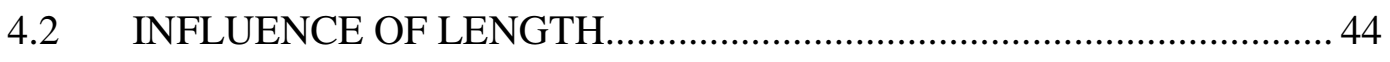

4.2.1 Transient State Condition..................................................... 44

4.2.2 Steady State Condition ................................................... 47

4.3 INFLUENCE OF INCLINATION ANGLE $(\phi) \ldots \ldots \ldots \ldots \ldots \ldots \ldots \ldots \ldots \ldots . . . . . . \ldots \ldots$

4.3.1 Transient State Condition.................................................. 49

4.3.2 Steady State Condition ................................................. 51

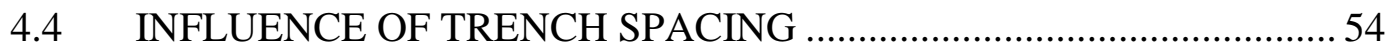

4.4.1 ... Transient State Condition..................................................... 54

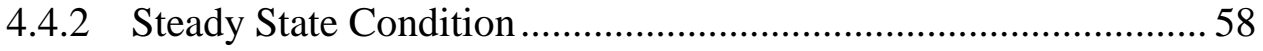

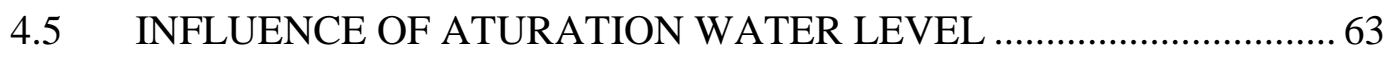

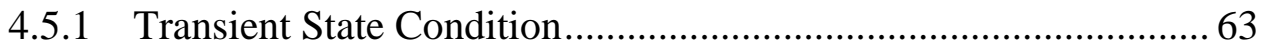

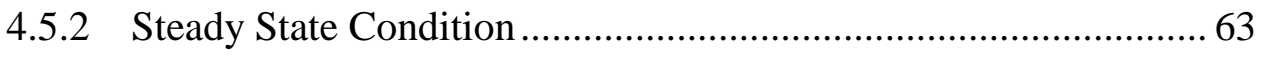




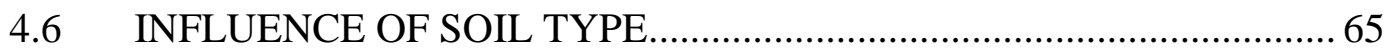

4.6.1 Transient State Condition................................................................ 65

4.6.2 Steady State Condition ……………………………………...... 71

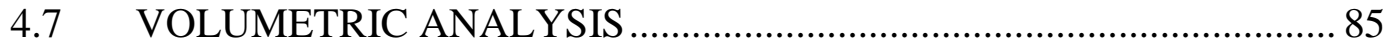

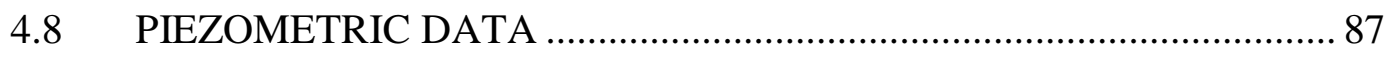

4.8.1 Transient State Condition......................................................... 87

4.8.2 Steady State Condition ............................................................. 94

CHAPTER 5: CONCLUSIONS AND RECOMMENDATIONS ................................... 98

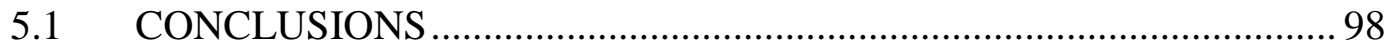

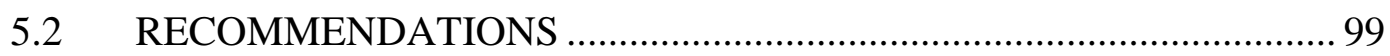

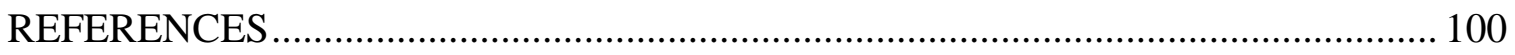

APPENDIX A: GRAIN SIZE AND HYDRAULIC CONDUCTIVITY FOR

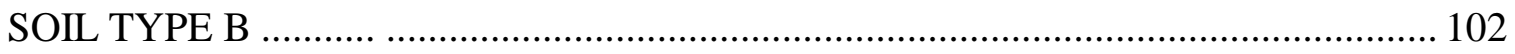

APPENDIX B: TRANSIENT CONDITION FOR SOIL TYPE B................................. 109

APPENDIX C: SEEPAGE REMOVAL FOR SOIL TYPE B....................................... 119

APPENDIX D: INFLUENCE OF SLOPE ANGLE FOR SOIL TYPE B........................ 132

APPENDIX E: INFLUENCE OF TRENCH SPACING FOR SOIL TYPE B ................ 142

APPENDIX F: INFLUENCE OF SATURATION DEPTH FOR SOIL TYPE B.......... 152

APPENDIX G: INFLUENCE OF SOIL TYPE ON TRANSIENT CONDITION......... 165

APPENDIX H: INFLUENCE OF SOIL TYPE UNDER STEADY STATE.................. 178

APPENDIX I: VARIATION OF PIEZOMETRIC HEAD............................................ 205

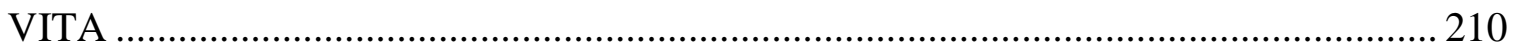




\section{LIST OF TABLES}

Table 2.1 Typical Values of Hydraulic Conductivity ............................................ 12

Table 3.1 Variation of Hydraulic Conductivity with Clay Content ........................ 18

Table $3.2 \quad$ Properties of Geotextile Fabric ........................................................ 33 


\section{LIST OF FIGURES}

Figure 1.1 Longitudinal trenches along the face of the slope

Figure 1.2 Flow pattern before and after installation of longitudinal drain trench....... 4

Figure 2.1 Constant Head Hydraulic Conductivity Apparatus .................................... 13

Figure 3.1 Variation of Hydraulic Conductivity with Clay Content (5\% to 25\%)..... 19

Figure 3.2 Variation of Hydraulic Conductivity with Clay Content (20\% to 30\%)... 20

Figure 3.3 Plan View of the Apparatus ............................................................... 23

Figure 3.4 Schematic Diagram of Longitudinal Drains............................................. 24

Figure 3.5 Piezometic Terminals Locations ……………..................................25

Figure 3.6 Panel of Piezometers ...................................................................... 27

Figure $3.7 \quad$ Close-up View of Piezometers ………………..................................... 28

Figure $3.8 \quad$ Side View of the Main Water Reservoir ................................................ 30

Figure 3.9 Picture of longitudinal Drain with Geotextile in Place ............................. 32

Figure 3.10 Surface Cracks on the soil Surface ............................................................. 39

Figure 3.11 Apparatus and Soil Specimen …………............................................. 40

Figure 3.12 Schematic of Water Profile Inside Soil Specimen .................................... 41

Figure 4.1 Influence of Length in Transient Condition for Soil Type B

with 8" Saturation Depth and 4:1 Slope Angle .......................................... 46

Figure 4.2 Influence of Length for Soil Type B with 8" Saturation Depth

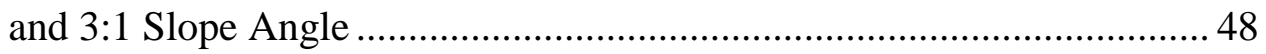

Figure 4.3 Influence of Angle on Transient Condition for soil Type B

with 8" Saturation Depth and 18" Half Trench Spacing ........................... 50 
Figure 4.4: Influence of Sloe Angle for Soil Type B with 8" Saturation Depth

and 18" Half Trench Spacing.....

Figure 4.5: Influence of Trench Spacing under Transient Condition

for Soil Type B with 8" Saturation Depth and Zero Slope Angle. 55

Figure 4.6: Influence of Trench Spacing under Transient Condition

for Soil Type B with 8" Saturation Depth and 4:1 Slope Angle 56

Figure 4.7: Influence of Trench Spacing under Transient Condition

for Soil Type B with 8" Saturation Depth and 2:1 Slope Angle.

Figure 4.8: Influence of Trench Width for soil Type B with 8" Saturation Depth

and Zero Slope Angle

Figure 4.9: Influence of Trench Spacing for soil Type B with 8" Saturation Depth

and 4:1 Slope Angle

Figure 4.10 Influence of Trench Spacing for soil Type B with 8" Saturation Depth

and 2:1 Slope Angle

Figure 4.11 Influence of Saturation Depth for soil Type B for 18” Half Trench

Spacing and 4:1 Slope Angle

Figure 4.12 Influence Soil Type under Transient Condition at D1

for 4:1 Slope Angle

Figure 4.13 Influence Soil Type under Transient Condition at D2

for 4:1 Slope Angle 68

Figure 4.14 Influence Soil Type under Transient Condition at D1

for 2:1 Slope Angle. 
Figure 4.15 Influence Soil Type under Transient Condition at D2

for 2:1 Slope Angle

70

Figure 4.16 Influence of Soil Type for 8" Saturation Depth

and 18" Half Trench Spacing.

Figure 4.17 Influence of Soil Type for 8" Saturation Depth

and 18" Half Trench Spacing

Figure 4.18 Influence of Soil Type for 8" Saturation Depth

and 18" Half Trench Spacing...... .75

Figure 4.19 Influence of Soil Type for 8" Saturation Depth

and 18" Half Trench Spacing 76

Figure 4.20 Influence of Soil Type for 8" Saturation Depth

and 12" Half Trench Spacing

Figure 4.21 Influence of Soil Type for 8" Saturation Depth

and 12" Half Trench Spacing....... 78

Figure 4.22 Influence of Soil Type for 8" Saturation Depth and 12" Half Trench Spacing 79

Figure 4.23 Influence of Soil Type for 8" Saturation Depth and 12" Half Trench Spacing 80

Figure 4.24 Influence of Soil Type for 8" Saturation Depth

and 6" Half Trench Spacing

Figure 4.25 Influence of Soil Type for 8" Saturation Depth

and 6" Half Trench Spacing 
Figure 4.26 Influence of Soil Type for 8" Saturation Depth

and 6" Half Trench Spacing

Figure 4.27 Influence of Soil Type for 8" Saturation Depth

and 6" Half Trench Spacing

Figure 4.28 Volumetric Analysis of All Drains for 8" Saturation Depth

and 4:1 Slope Angle 86

Figure 4.29 Variation of Piezometric Head at Cross-section X

for $\mathrm{w}=18$ inches and 4:1 Slope Angle

Figure 4.30 Variation of Piezometric Head at Cross-section X

for $\mathrm{w}=18$ inches and 2:1 Slope Angle

Figure 4.31 Variation of Piezometric Head at Cross-section X

for $\mathrm{w}=12$ inches and 4:1 Slope Angle

Figure 4.32 Variation of Piezometric Head at Cross-section X

for $\mathrm{w}=12$ inches and 2:1 Slope Angle

Figure 4.33 Variation of Piezometric Head at Cross-section X

for $\mathrm{w}=6$ inches and 4:1 Slope Angle

Figure 4.34 Variation of Piezometric Head at Cross-section X

for $\mathrm{w}=6$ inches and 2:1 Slope Angle

Figure 4.35 Influence of Trench Spacing on Piezometric Head at the Centerline

for 8" Saturation Depth and 4:1 Slope Angle 95

Figure 4.36 Piezometric Head at 12" from Tank for 8" Saturation Depth

and 4:1 Slope Angle 96 
Figure 4.37 Piezometric Head at 12" from Tank for 8" Saturation Depth

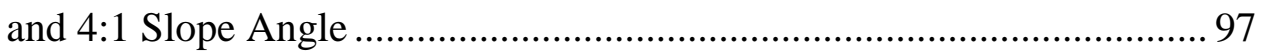




\section{CHAPTER 1}

\section{INTRODUCTION}

\subsection{BACKGROUND}

When building any type of structure, it is very important to check the terrain and its stability. A flat terrain is the best an engineer can hope for, because it simplifies many of the structural designs. With the increase in population and the growth of cities, the most desirable lands is scarce and more expensive. Also, the terrain varies from one state to the other. West Virginia is known for its beautiful mountains. Slopes are basically everywhere in this part of the country. Engineers have developed different ways to use slopes, but the common methods for stabilization of earth slopes, like retaining walls, tend to be expensive. The majority of failures in earth slopes are due to seepage forces. An effective method to extract water from earth slopes would be useful in reducing stability problems caused by seepage.

Not only the shape and size of the slopes determine their behavior but also the type of soil. Some types are more prone to slope failures (landslides) than others. Their consistency influences the seepage patterns. The material composition of the soil plays an important role, because it is that composition which controls factors such as hydraulic conductivity, swelling, settlement and more.

\subsection{PROBLEM STATEMENT}

Slope stability problems are very common in hilly terrain. Slopes fail when the driving forces exceed the resistance offered by shear strength of the soil. The most prominent driving force is the weight of soil. Other forces that cause the instability include seepage forces and loads placed on top of the soil slope. 
Commonly the additional driving forces that cause slope failures are attributed to seepage. In other words, earth slopes that are otherwise stable can fail under the influence of seepage forces. In such cases, slope stability can be improved by removing seepage forces. A reduction in seepage force can be accomplished by redirecting seepage through earth slopes. Cutoff trenches are typically used to intercept seepage flow in earth slopes.

An alternative method for capturing seepage through earth slopes is to install longitudinal drains as shown in Figure 1.1. However, the performance of longitudinal drains is relatively unknown. Promising results on the performance of longitudinal drains have been presented in a previous study (Staud 2000). The data in the previous study was limited to one soil type under steady state conditions.

The objective of the present study is to evaluate the performance of longitudinal drains for different soil types under both steady state and transient conditions. The ultimate objective of the present study is to develop an efficient method to stabilize earth slopes by removing seepage water from earth slopes. The experiments performed in this study consist of placing drain trenches along the longitudinal direction of the slope (Figure 1.1) as opposed to the common method of placing drain trenches perpendicular to the direction of slope. The goal of installing longitudinal drains is to reduce the water flow in earth slopes and to change the water flow pattern (Figure 1.2). In doing so the seepage force is reduced giving the earth slope more stability. It is also important to predict the transient behavior of longitudinal drains before such drains become fully functional in removal of seepage. 


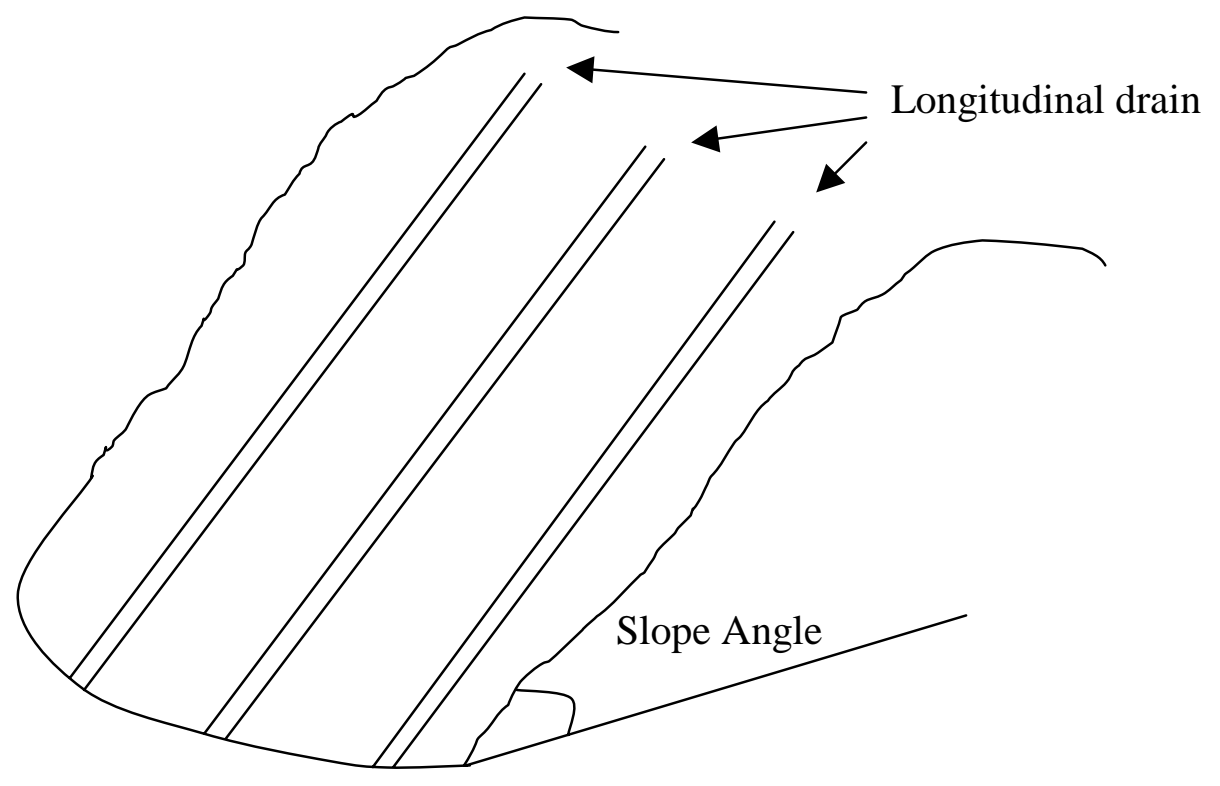

Figure 1.1: Longitudinal trenches along the face of the slope. 


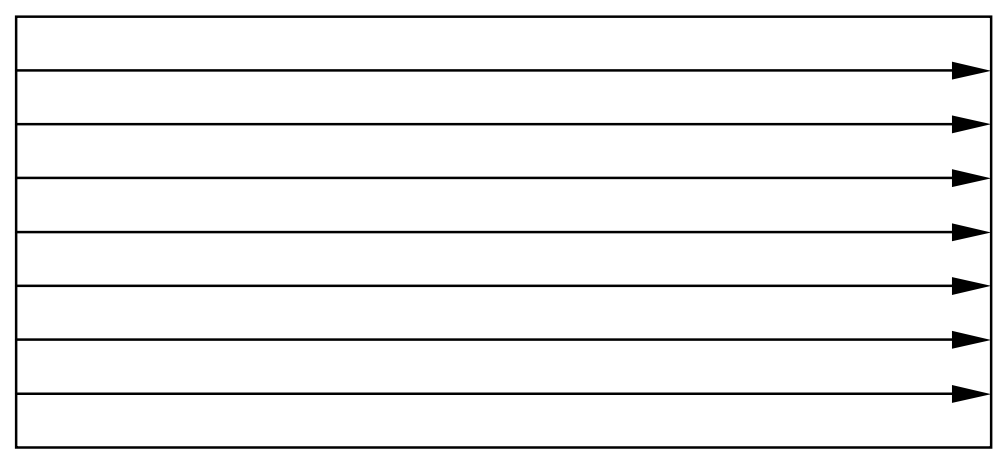

Before installing longitudinal trenches

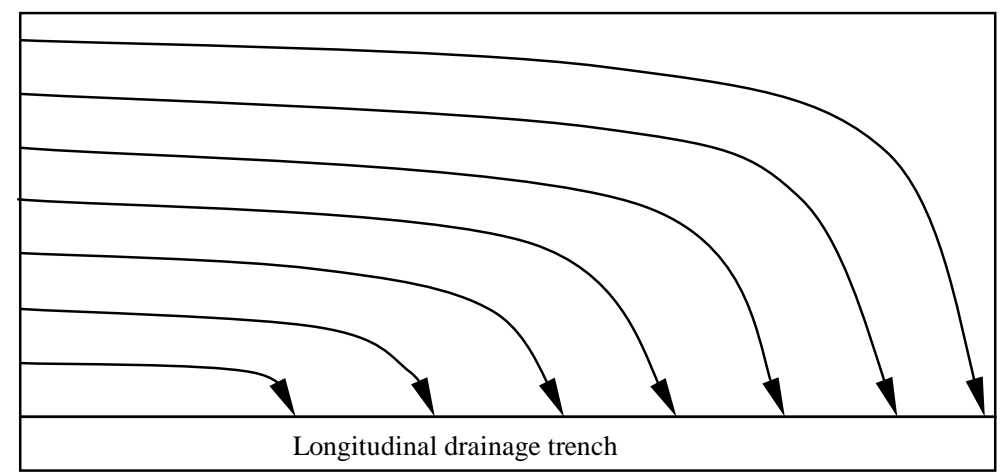

After installing longitudinal trenches

Figure 1.2: Flow pattern before and after installation of longitudinal drain trench. 


\subsection{RESEARCH OBJECTIVES}

The following specific objectives were identified.

1. Review existing literature related to seepage in earth slopes and existing methods for reducing seepage in earth slopes.

2. Use a laboratory model to study the effects of longitudinal drains on seepage patterns at steady state for different slope angles $(\theta)$, drain spacing $(\mathrm{w}=\mathrm{W} / 2)$, and seepage depths $(\mathrm{h})$.

3. Investigate transient behavior for different slope angles $(\theta)$ and drain spacing $(w)$ at a constant seepage depth $(\mathrm{h}=8$ inches $)$.

4. Evaluate flow behavior during construction time based on the transient study.

5. Evaluate and compare results for soil types with different hydraulic conductivities. 


\section{CHAPTER 2}

\section{LITERATURE REVIEW}

\section{$2.1 \quad$ INTRODUCTION}

A review of the literature indicated that there is hardly any technical information on the performance of longitudinal drains. Except for one technical paper by Stanic (1984) and a previous study at West Virginia University (Staud, 2000), no technical information is available in the literature on longitudinal drainage trenches. Therefore, the research study presented in this report is considered as unique and original.

A review of the basic principles involved with longitudinal drains was presented in a previous study (Staud, 2000). The four main aspects involved in this study of longitudinal drains are:

1. - Seepage.

2. - Slope Stability.

3. - Soil type.

4. - Steady state and transient condition.

These topics are discussed briefly in the following sections.

\subsection{SEEPAGE}

Soil consists of many individual grains of varying size. Because the individual grains that make up soil do not fit tightly together, voids form between the grains. These voids act as a semi-continuous conduit for the flow of water. Flow through these void spaces is called seepage or flow through porous media. One of the major destabilizing forces resulting in slope instability is the flow of water in porous media. As water, or any fluid, flows through soil it exerts a force on the soil particles through friction (Cedergren, 
1977). While the seepage forces in slopes only occasionally result in quick conditions, the forces usually have a destabilizing influence. The primary law governing flow through porous media is the Darcy's Law, which is given as:

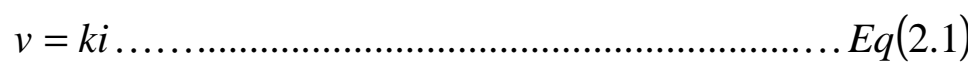

Where:

$$
\begin{aligned}
& \mathrm{v}=\text { Discharge velocity }- \text { the amount of water flowing in a } \\
& \text { unit time through a unit cross-sectional area }(\mathrm{ft} / \mathrm{s} \text { or } \mathrm{cm} / \mathrm{s}) \text {. } \\
& \mathrm{k}=\text { Hydraulic conductivity }(\mathrm{ft} / \mathrm{s} \text { or } \mathrm{cm} / \mathrm{s}) \text {. } \\
& \mathrm{i}=\quad \text { Hydraulic gradient }(\mathrm{ft} / \mathrm{ft} \text { or } \mathrm{cm} / \mathrm{cm}) \text {. }
\end{aligned}
$$

This form of Darcy's law states that flow rate through a porous media is equal to the hydraulic gradient multiplied by the cross sectional area and a parameter, $\mathrm{k}$, called the hydraulic conductivity. The hydraulic gradient is defined as the ratio of the difference in head across the specimen to the length of the soil specimen. The term head is defined in Bernoulli's energy equation for incompressible steady flow of a fluid as:

$$
\frac{v_{1}^{2}}{2 g}+\frac{p_{1}}{\rho_{w} g}+z_{1}=\frac{v_{2}^{2}}{2 g}+\frac{p_{2}}{\rho_{w} g}+z_{2}+h_{f}=\text { constant total head }
$$

Where:

$$
\begin{array}{ll}
\mathrm{v}= & \text { Velocity }(\mathrm{ft} / \mathrm{s} \text { or } \mathrm{cm} / \mathrm{s}) . \\
\mathrm{g}= & \text { Gravitational constant }\left(32.17 \mathrm{ft} / \mathrm{s}^{2} \text { or } 9.807 \mathrm{~m} / \mathrm{s}^{2}\right) \\
\mathrm{p}= & \text { Pressure }(\mathrm{psf} \text { or } \mathrm{kPa}) . \\
\rho_{\mathrm{w}}= & \text { Density of water }\left(\mathrm{lb} / \mathrm{ft}^{3} \text { or } \mathrm{kg} / \mathrm{m}^{3}\right) . \\
\mathrm{z}= & \text { Elevation }(\mathrm{ft} \text { or } \mathrm{m}) .
\end{array}
$$




$$
\mathrm{h}_{\mathrm{f}}=\quad \text { Head loss due to friction (ft or } \mathrm{m} \text { ). }
$$

Since the seepage velocity, $v$, is usually very small, the term $\left(v^{2} / 2 g\right)$ can be neglected. The head, at any point, can now be expressed as the sum of the head due to pressure and the head due to elevation.

$$
\frac{p}{\rho_{w} g}+z=\mathrm{h}
$$

The hydraulic conductivity, $\mathrm{k}$, is determined experimentally and relates how well a fluid moves through the spaces in the soil matrix. The hydraulic conductivity of a particular soil primarily depends on grain size distribution and porosity. Porosity is a term relating the void space as a percentage of the total volume of soil.

\subsection{SLOPE STABILITY}

Slopes can be defined as either man-made or natural. Because of the fact that the slope is at an angle, gravity tries to move the slope downward. Sudden change in the equilibrium condition can bring down the slope. The stability analysis of a slope is not an easy task. Evaluation of variables such as the soil stratification and its in-place shear strength parameters may prove to be a formidable task (Das, 1993).

Slopes failures can be divided into two groups, deep seated or shallow. A deep slide happens when the depth is a significant percentage (say 20\%) of the length. Shallow slides only involve a small percentage of the length. The stability of constructed or natural slopes depends on the balance of two groups of forces: all of the forces that are keeping the soil mass in its place of equilibrium, where the most important one is the shear strength of the soil, and all the forces trying to bring the soil down. Shear strength of a soil is determined experimentally and it is the maximum resistance of the material to 
shear deformation. The strength of soil in a slope can be improved by using a geotextiles layer reinforcing for added strength or piles for restraint or retention.

Because of gravity, the weight of the slope is a prominent driving force. Seepage forces and loads placed on the slope can also be factors in slope instability. The factor of safety against failures is defined as the ratio of soil shear strength to the shear stress developed at the potential failure surface. Designed slopes usually have calculated factors of safety greater than 1.2. For man-made or natural slopes the actual groundwater conditions in the slope may have to be estimated from limited observations. Because of this estimation, the factor of safety has to be kept higher to prevent catastrophic failures.

At the verge of failure the driving forces are equal to those due to the strength. Seepage is a main driving force responsible for failures. Most existing methods to reduce seepage are difficult to construct and are therefore expensive. One method is the use of horizontal wells for deep-seated failures. Horizontal wells are inserted into or below the failing soil mass to intercept the seepage. Another method to reduce seepage is the installation of cut-off trenches. Cut-off trenches are typically placed across the slope. They can collapse during excavation, if no bracing is used, especially if they reach the slip plane. Longitudinal trenches parallel to each other and in the direction of maximal slope inclination can be used (Stanic, 1984). These trenches are less likely to collapse during excavation.

A mass of rock, debris or earth moving as a mass down a slope is defined as a landslide (Cruden, 1991). Some common landslides move relatively slowly. As one of the major hazards, landslides account each year for significant property damage, direct and indirect. There are a number of factors, which can trigger landslides. Some of these 
are: sudden changes in the water table levels due to rainfall or even human drains; earthquakes; ocean waves against a cliff face; rapid increase in the shear stress or decrease in the strength of slope forming materials (Dai, Lee and Ngai, 2001). In addition, as development expands into unstable hill slope areas under the pressure of increasing population and urbanization, human activities such as deforestation or excavation of slopes for road cuts and building sites can cause landslides.

Landslides have caused large numbers of casualties and huge economic losses in mountainous areas of the world. The most disastrous landslides have claimed as many as 100,000 lives (Li and Wang, 1992). In December of 1999 an uncommon tropical storm hit the coastal area of Venezuela. Five days of rainfall and poorly designed drainage brought an enormous soil mass down from the adjacent mountains into the coast. This combined with December festivities claimed the lives of more than 5,000 people. Heavy rainfall hit northeastern Japan from the $26^{\text {th }}$ to $31^{\text {st }}$ of August 1998 . It triggered many landslides and debris flows especially in southern Japan, and killed 21 persons (Wang, Sassa and Wang, 2001). In the United States, landslides cause an estimated US \$ $1-2$ billion in economic losses and about $25-50$ deaths annually, thus exceeding the average losses due to earthquakes (Schuster and Fleming, 1986).

The fact that a landslide can travel larger distances than expected from simple frictional arguments has led many authors to hypothesize that fluids play a significant role in reducing solid friction (Kent 1996). The addition of fluids into granular soils can reduce the effective normal stress. Current understanding of granular avalanches suggests that they exhibit a constant coefficient of friction, close to the coefficient of friction of their particles in both the quasistatic flow and rapid flow (Legros 2001). 
It is important to notice that the majority of articles in landslides are always warning or investigating the role that fluids play in this type of catastrophes. Water has an enormous effect in slopes. Water always finds the easiest way to flow. Whenever water is introduced in a slope it will immediately try to flow to a point of lower pressure head, but in doing so it reduces stability of the slope and in some cases it causes localized avalanches.

As water, or any fluid, flows through soil it exerts a force on the soil particles through friction (Cedergren, 1977). This seepage force can most readily be demonstrated in quick sand. In quick sand the force of the water moving up into the sand from below equals the downward force of the soil particles and results in a dense viscous fluid. The same forces seen in quick sand are also found in slopes that have seepage. While the seepage forces in slopes usually do not result in quick conditions, the forces can have a destabilizing influence.

\subsection{SOIL TYPES}

The geotechnical properties of a soil, such as grain size distribution, Atterberg Limits, soil composition and hydraulic conductivity are important parameters of this work. Detailed information on soil classification methods can be found in the literature (Das, 1993). The hydraulic conductivity of sandy soils is relatively high and therefore water can be drained rapidly. Silty and clayey soils have very low hydraulic conductivity and as such it is more difficult to drain water from them. Drainage trenches are usually made up of gravel in view of their high hydraulic conductivity.

Generally, the Darcy's Law governs the flow of water through soils. In this study, sandy and clayey soils were used to investigate the effectiveness of longitudinal drains. 


\subsection{HYDRAULIC CONDUCTIVITY}

The void spaces or pores between soil grains allow water to flow through them. The amount of flow rate depends on the soil type and its hydraulic conductivity. The hydraulic conductivity of soils depends on several factors: fluid viscosity, grain size distribution, void ratio, roughness of mineral particles, and degree of soil saturation. The value of hydraulic conductivity (k) varies widely for different soils. Some typical values for saturated soils are show in table 2.1 (Das 1993).

Table 2.1: Typical values for hydraulic conductivities (Das, 1993).

\begin{tabular}{|l|c|c|}
\hline \multicolumn{1}{|c|}{ Soil Type } & cm/sec. & ft/min \\
\hline Clean gravel & $100-1.0$ & $200-2.00$ \\
\hline Coarse sand & $1.0-0.01$ & $2.0-0.02$ \\
\hline Fine sand & $0.01-0.001$ & $0.02-0.002$ \\
\hline Silty clay & $0.001-0.00001$ & $0.002-0.00002$ \\
\hline Clay & $<0.000001$ & $<0.000002$ \\
\hline
\end{tabular}

There are two standard laboratory tests, constant head test and falling head test to determine hydraulic conductivity of a soil in the laboratory. In this research work, hydraulic conductivity of soils was determined by using a constant head test. A schematic diagram of a constant head hydraulic conductivity apparatus is shown in Figure 2.1. Several units of such an apparatus was built and used in this research project. 


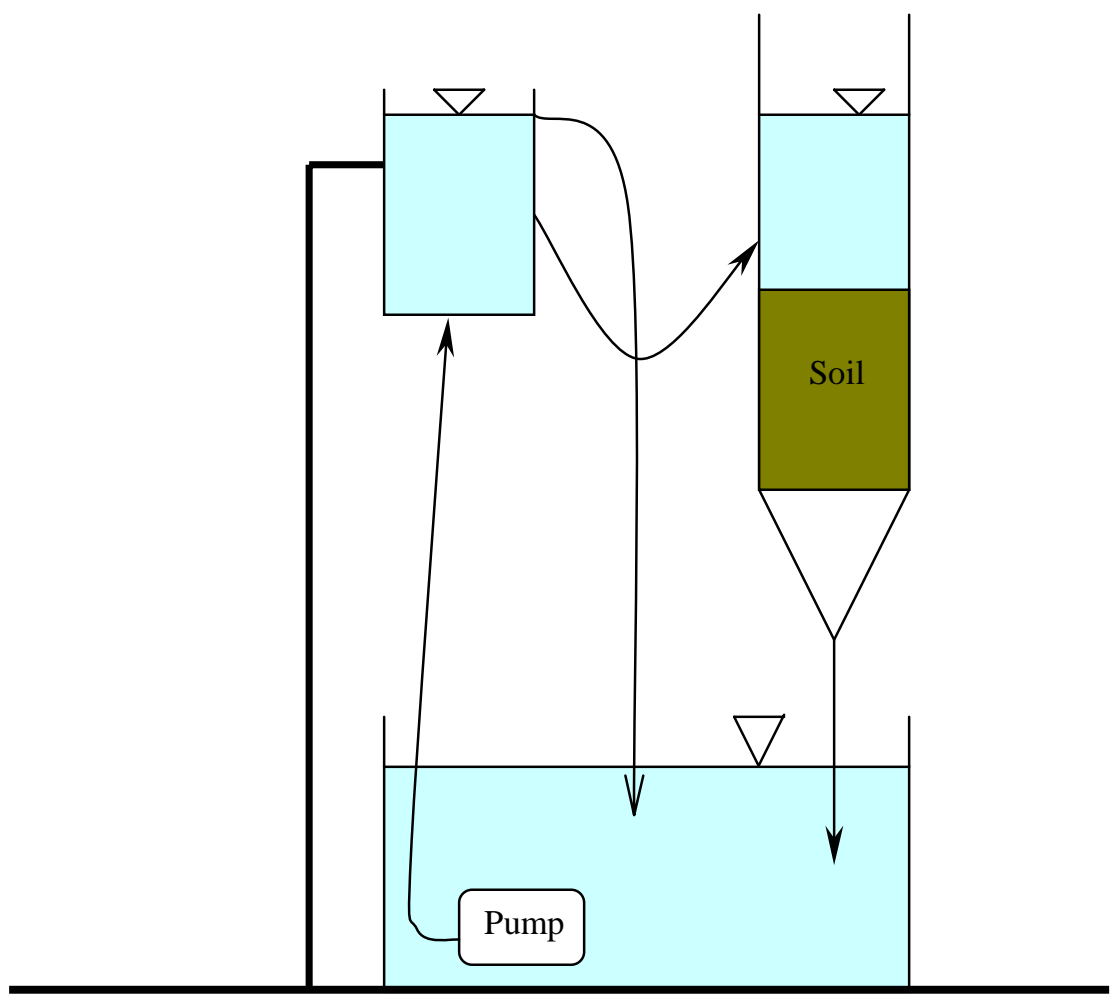

Figure 2.1: Constant Head Hydraulic Conductivity Apparatus. 
The primary law governing flow through porous media is the Darcy's Law. The flow volume can be expressed as:

$$
Q=A v t=A(k i) t
$$

Where,

$$
i=\frac{h}{L}
$$

The hydraulic conductivity, $\mathrm{k}$, can be expressed as:

$$
k=\frac{Q L}{A h t}
$$

Where:

$$
\begin{array}{ll}
\mathrm{Q}= & \text { Volume of water collected }(\mathrm{cc}) . \\
\mathrm{A}= & \text { Area of cross-section of specimen }\left(\mathrm{cm}^{2}\right) . \\
\mathrm{t}= & \text { Duration }(\mathrm{sec}) . \\
\mathrm{h}= & \text { Head }(\mathrm{cm}) . \\
\mathrm{L}= & \text { length of the specimen }(\mathrm{cm}) .
\end{array}
$$

\subsection{PREVIOUS STUDIES}

In 1984, Stanic published a paper about the influence of drainage trenches on slope stability. In 2000 Staud presented a thesis on seepage through earth slopes. These two papers are very related to the scope of this project.

Stanic (1984) studied the behavior of water flow in slopes, by analyzing the piezometric level along the slope. He used finite element analysis to study the effect of longitudinal drain systems on the factor of safety against sliding. Stanic (1984) made five major assumptions. First, the slope was assumed to be infinite in all directions with an 
inclination of $\beta$ with the horizontal. Second, the potential failure surface was assumed to be impermeable and at a constant depth below the surface. Third, the direction of seepage in the slope before the installation of drains was assumed to be parallel to the slope face and steady with respect to time. Fourth, the soil in the slope was assumed to be homogeneous and isotropic with respect to hydraulic conductivity. Fifth, the drains were assumed to be parallel to each other in the direction of maximal slope inclination and were assumed to extend to the failure surface

The model was tested at different drain spacing (w) and slope angles $(\theta)$. To determine the piezometric surface, the data collected in the finite element analysis was normalized, by dividing the piezometric level by the water level (h) before the drain installment. The data was processed to obtain the maximum level in the slope for different angles and drain spacing. According to Stanic (1984), as the ratio of drain spacing to depth, w/h, becomes smaller, the average and maximum piezometric level decreases. Using the results of the finite element analysis, Stanic (1984) concluded that based on the reduction in piezometric levels an increase in the factor of safety is obtained for different combinations of normalized drain spacing and slope angles.

Staud (2000) presented results on the performance of longitudinal drains under steady state conditions. This thesis is an extension of research work presented by Staud (2000). The objective of Staud's study was to determine how the longitudinal drain system works under laboratory conditions. In this study, a laboratory model was constructed to assess the flow patterns caused by a trench drain in a slope. The experimental variables include the trench spacing $(W=2 w)$, seepage depth $(h)$, and slope angle $(\theta)$. In the experimental program, four values of slope angle, three values of trench 
spacing and three values of seepage depth were considered. Each experiment was performed twice to ensure that the measurements are reproducible. The soil type for the experimental program was selected on the basis of hydraulic conductivity. The soil was placed in the experimental cell under dry conditions and the water was introduced at predetermined levels at the upstream end to maintain a constant head. Measurements of seepage volume were taken along the longitudinal direction of the trench after reaching steady state seepage conditions. The piezometric pressures at selected locations in the soil slope were measured.

The results show that a longitudinal trench drain system with appropriate drain spacing can be used to remove the majority of seepage from soil slope. Furthermore, the report contains laboratory data that provide quantitative information on the influence of different experimental parameters on the removal rate of seepage water (Staud 2000).

The previous work reported by Staud (2000) was limited to one soil type under steady state conditions. In the present study, two different soil types were used to investigate the influence of hydraulic conductivity on the performance of longitudinal drains. Moreover, experiments were conducted to determine the transient time period for longitudinal drains to become fully effective. 


\section{CHAPTER 3}

\section{METHODOLOGY}

\subsection{INTRODUCTION}

The objective of this research work was to determine the effectiveness of longitudinal drains in removing seepage from earth slopes. In order to reach this objective a series of experiments were conducted. The following steps describe the methodology used in this research work. These steps are:

1. - Selection of soil specimens.

2. - Use of the experimental apparatus.

3. - Details of the tests performed.

4. - Data acquisition.

5. - Notation

\subsection{SELECTION OF SOIL SPECIMENS}

The soil specimens used in this research were made in order to control their hydraulic conductivity. Since one of the objectives of this project was to study the effect permeability on longitudinal drains, samples with three different hydraulic conductivities

(in the order of $10^{-2}, 10^{-3}$ and $10^{-4} \mathrm{~cm} / \mathrm{s}$ ) were prepared. An important criterion was the reproducibility of the samples. A representative sample of each type of soil was saved with their respective mixtures in order to ascertain reproducibility of samples.

To generate the desired soil samples, Ohio River Sand, which has a hydraulic conductivity of in the order of $1 \mathrm{~cm} / \mathrm{s}$, was mixed with an amount of clay (kaolinite) according to the desired hydraulic conductivity. Ohio River sand was used because of its 
low cost and availability. Kaolinite clay was used to control the permeability of the sample. To reduce discrepancies, the river sand was sieved through Sieve \#20 $(0.85 \mathrm{~mm})$. The portion of sand passing $0.85 \mathrm{~mm}$ sieve has a hydraulic conductivity in the order of $10^{-}$ ${ }^{1} \mathrm{~cm} / \mathrm{s}$.

Samples containing different amounts of clay were tested to obtain a range of values for hydraulic conductivities. Different percentages of clay (by dry weight) were added to the sieved sand. Based on a number of experiments, the relationship between the hydraulic conductivity and clay content was established as shown in Table 3.1, Figure 3.1 and Figure 3.2.

Table 3.1 Variation of Hydraulic Conductivity with Clay Content.

\begin{tabular}{|c||c||c||}
\hline Soil Type & $\begin{array}{c}\text { Clay Content } \\
\%\end{array}$ & $\begin{array}{c}\text { Hydraulic Conductivity } \\
\text { cm/s }\end{array}$ \\
\hline \hline A & 5 & $2.00 \mathrm{E}-02$ \\
\hline & 10 & $9.75 \mathrm{E}-03$ \\
\hline B & 15 & $1.40 \mathrm{E}-03$ \\
\hline & 20 & $7.15 \mathrm{E}-04$ \\
\hline C & 25 & $2.83 \mathrm{E}-04$ \\
\hline & 30 & $6.21 \mathrm{E}-05$ \\
\hline
\end{tabular}

Because the desired hydraulic conductivities were in the order of $10^{-2} \mathrm{~cm} / \mathrm{s}$ to $10^{-4}$ $\mathrm{cm} / \mathrm{s}$, clay contents of $5 \%, 15 \%$ and $25 \%$ were selected for the soil mixtures used in this study. About 10 cubic feet of material was prepared for each of the three soil types. Each batch was thoroughly mixed, washed, dried and re-pulverized. This process was determined to be extremely important because it insured that the sample was homogeneous. 


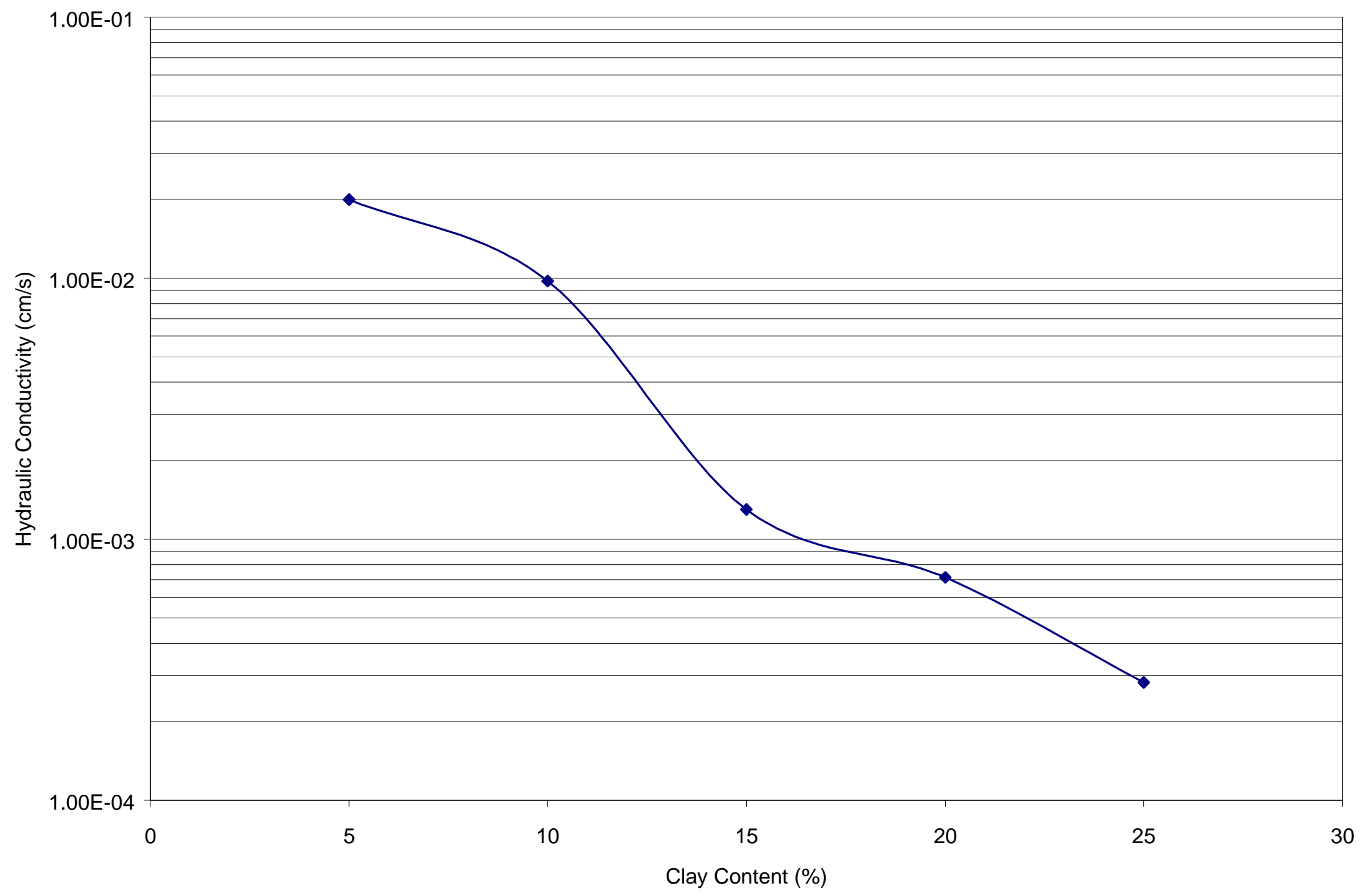

Figure 3.1: Variation of Hydraulic Conductivity with Clay Content (5\% to 25\%). 


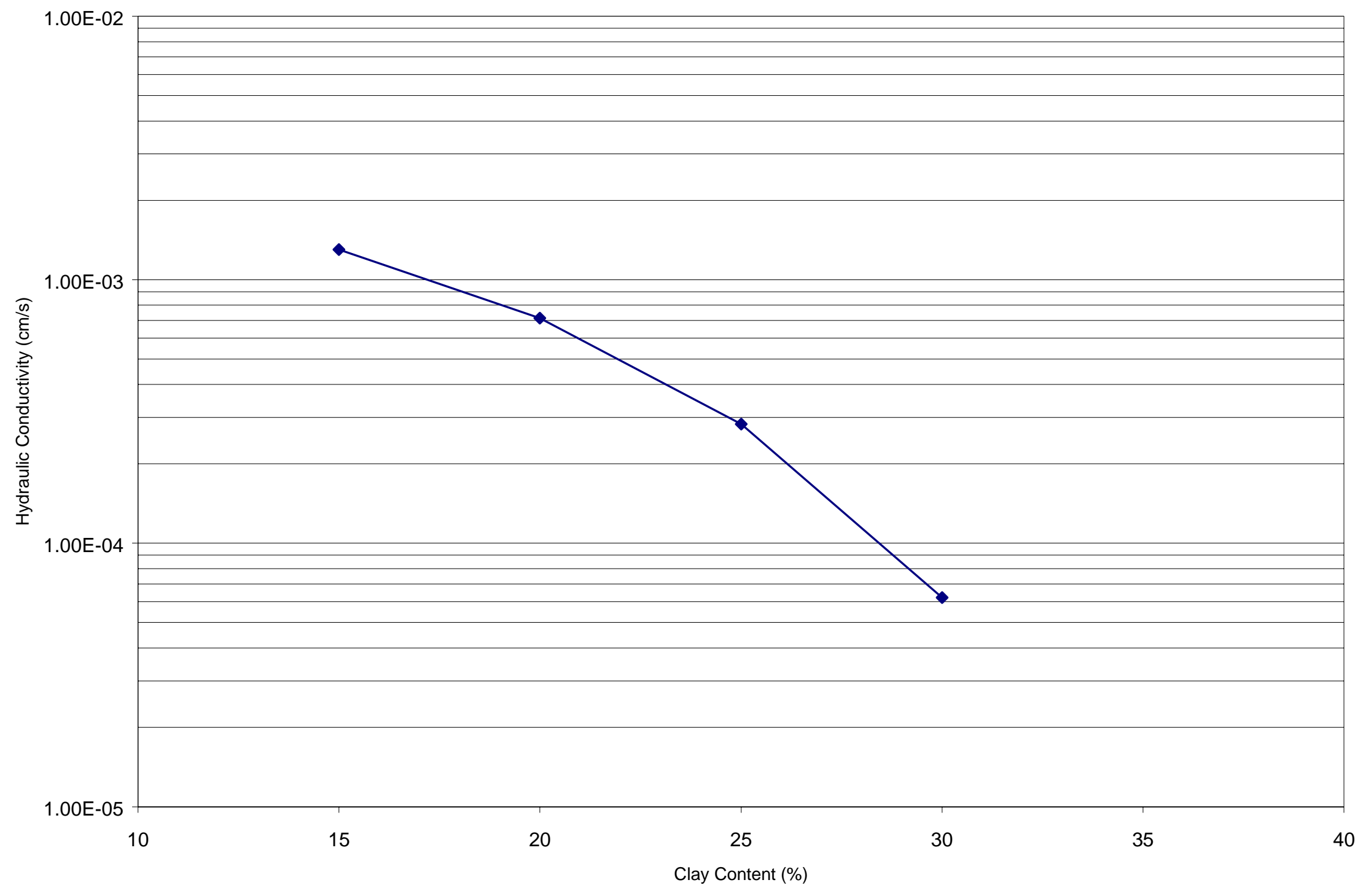

Figure 3.2: Variation of Hydraulic Conductivity with Clay Content (20\% to 30\%). 


\subsection{DESCRIPTION OF THE EXPERIMENTAL APPARATUS}

A schematic diagram of the experimental apparatus is shown in Figure 3.3. The base of the apparatus is made out of wood. It consists of six legs, three in front and three on the back. Each set of legs has a pivot point, which allows them to rotate when the slope of the model is changed. In order to change the slope of the model, the legs in the back are raised to a certain height depending on the desired slope angle. Each individual leg has perpendicular wood sections at the end to increase the contact area between the legs and the ground; these extensions give the apparatus more stability.

For the model (soil zone) itself a transparent plastic material (plexi-glass) was used. This plastic material has more than enough strength to withhold the soil. The fact that it is transparent is an important asset because it allows the user to make observations near the boundaries. The lower plate of the model is $1 / 2$ inch $(127 \mathrm{~mm})$ thick. The baseplate contains a series of holes, to which, the piezometric tubes are connected. A thin layer of sand was glued to the base-plate by using spray adhesive. The water reservoir, the sand model, the longitudinal drain and the end drain are located on top of the base plate. The walls at the narrow sides of the model are also made of $1 / 2$ inch $(127 \mathrm{~mm})$ thick plexi-glass. These two walls are perforated to allow water flow. One of the walls along the side is fixed. The other wall is perforated to simulate a longitudinal drain. It is made of $1 / 4$ inch $(63.5 \mathrm{~mm})$ thick plexi-glass. The second longitudinal wall does not have any perforations. This wall represents the centerline between two drains and it can be adjusted depending on the width needed for the experiment. The flow between two drains is assumed to be symmetrical about the centerline between two parallel longitudinal drains. Because of this symmetry, a no-flow boundary condition was used to simulate the 
dividing line between the two symmetrical halves (Figure 3.4.). Because of this symmetry, the model only represents half the slope between drains. The other half would be a mirror image of the existing one. That is why only one drain was used in the experimental set up.

\subsubsection{Piezometric Head}

Piezometric head is the pressure of a liquid at any point. In this research, the liquid used was water. The water flows freely through the soil in the model without any external pressure. Because no pressures are introduced in the system the water level at a particular point can be determined by a simply reading the piezometric head.

The model contains a series of piezometric terminals arranged in such a way that allows the measurement of a water profile in the longitudinal direction along the centerline. Figure 3.5 shows the locations of piezometers for each of the selected widths. The apparatus has different sets of piezometric terminals that allow the piezometric tubes to be connected according to the selected width. Because of the symmetry assumption made earlier in this chapter, the centerline coincides with the position of the adjustable wall. The wall is located in such a as to not cover the piezometric terminals.

The longitudinal or centerline profile consists of five piezometric terminals at $1 / 8$, $1 / 4,3 / 8,1 / 2$ and $3 / 4$ of the legth of the apparatus regardless of the width. The other two profiles $\mathrm{X}$ and $\mathrm{Y}$ on Figure 3.5 depend on the width of the soil zone. All the piezometric terminals perforate the base plate of the soil zone. Because of their small size they do not compromises the integrity of the apparatus. 


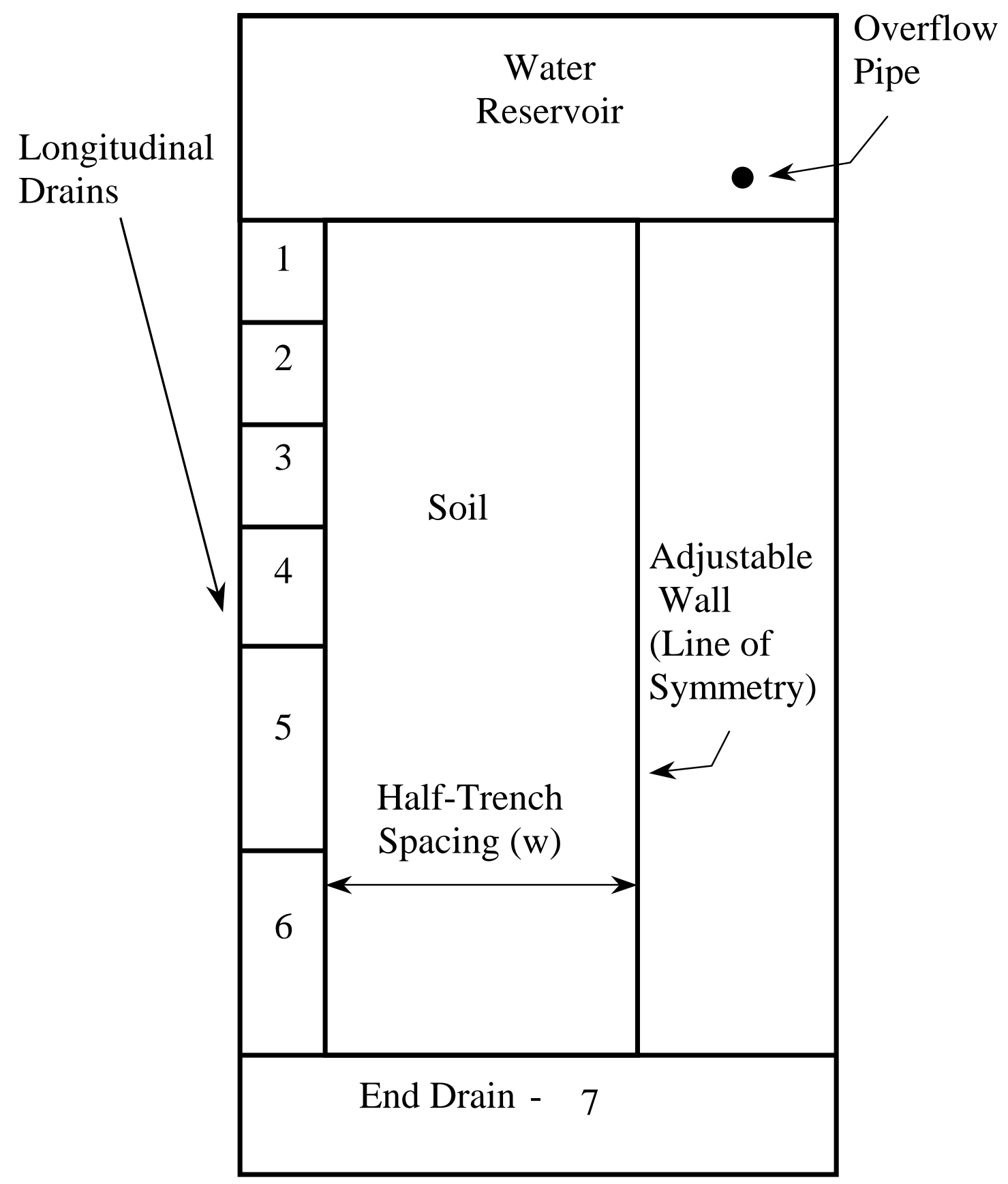

Figure 3.3: Plan View of the Apparatus. 


\section{Line of Symmetry}

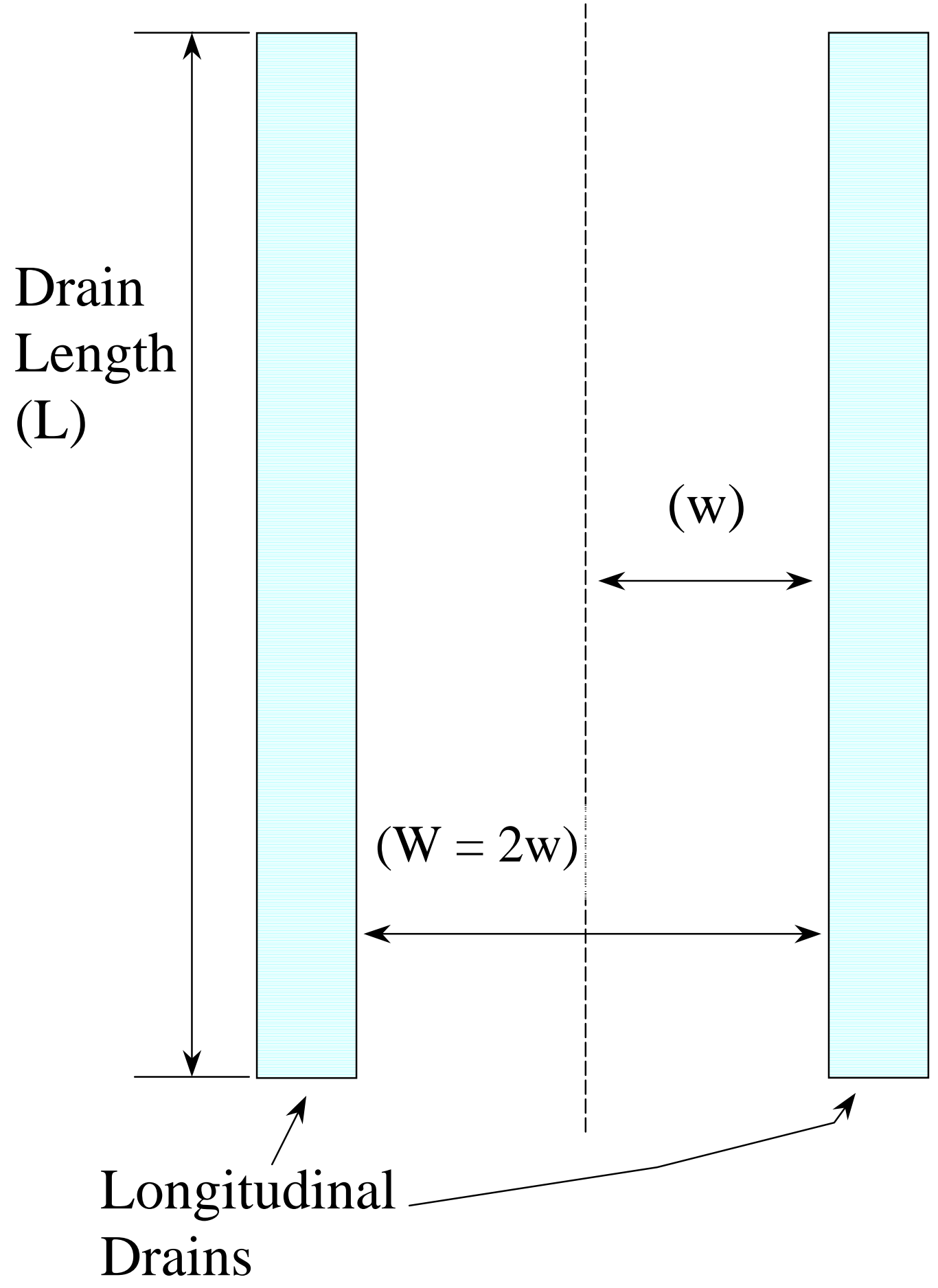

Figure 3.4: Schematic Diagram of Longitudinal Drains. 


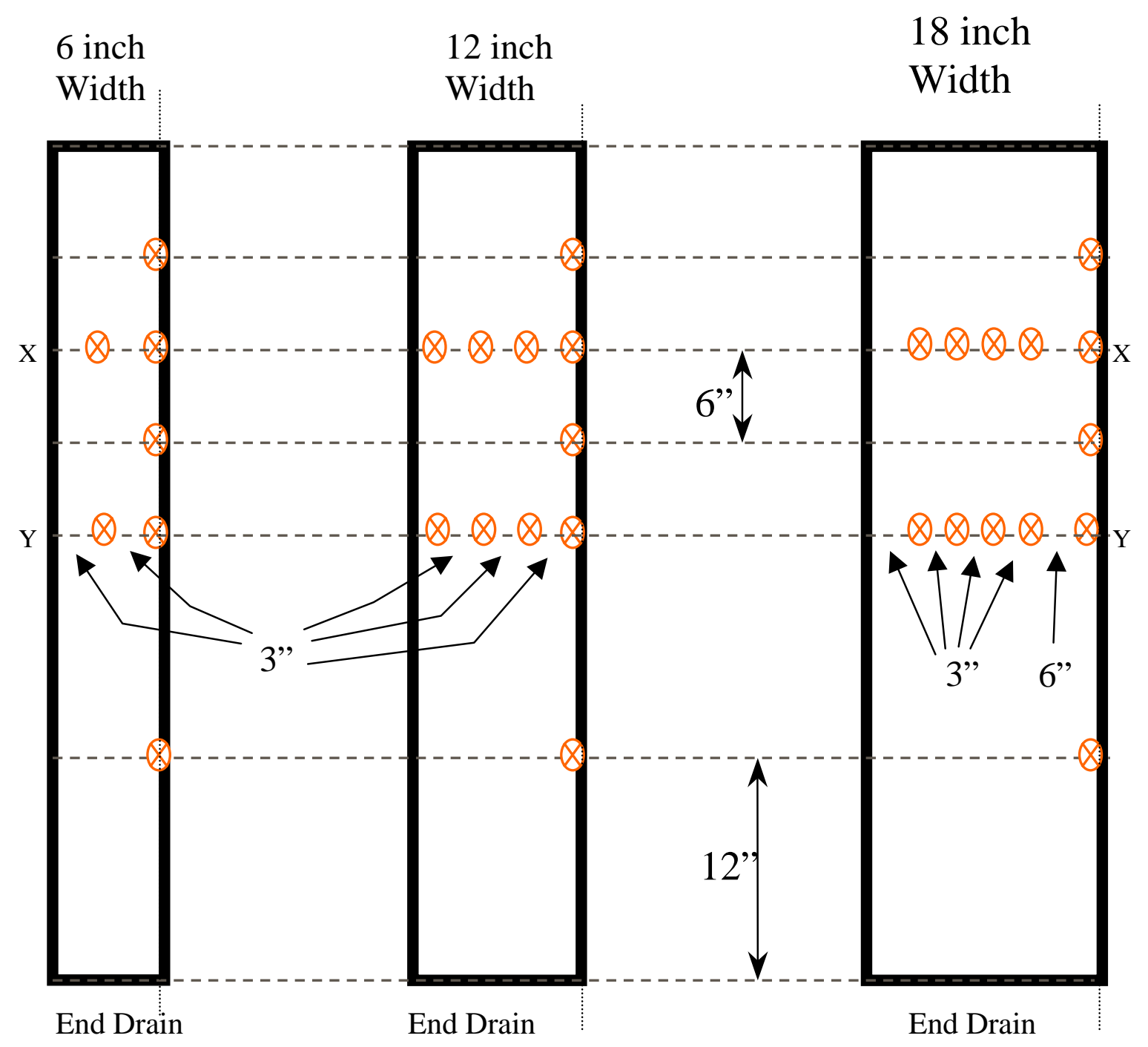

Note: Section $X$ is located at 12 inches from the top Section $\mathrm{Y}$ is located at 24 inches from the top

Figure 3.5: Piezometic Terminals Locations 
Using flexible tubing the piezometric terminals are connected to a series of piezometers. These piezometers are mounted on a wooden board. The piezometers are set in such a way that their lower end is at the same elevation as the model (when horizontal). This board consists of thirteen high accuracy glass tubing attached by plastic bracers. Beside each tube a metric ruler was attached in order to take readings. The glass tubbing has an inner diameterr of $\frac{1}{8}$ of an inch. The plastic tubbing has an outer diameterr of $1 / 8$ of an inch.

In order to prevent soil particles from entering the plastic tubing and clogging them, small squares of a fine metalic screen were glued to the surface of each terminal at the surface of the base plate. These small pieses were replaced after every other test to prevent them from clogging and thus interfering with their purpose.

Before starting every test the piezometers were filled with water. Once the soil was saturated, the plastic tubes were disconnected in order to drain the contents of the glass section. Once drained the tubes were reconnected to allow the actual pressure to build up the water column. Special effort was made to avoid air bubbles entering the system. A picture of the board containing the piezometers can be seen in Figure 3.6. and Figure 3.7. 


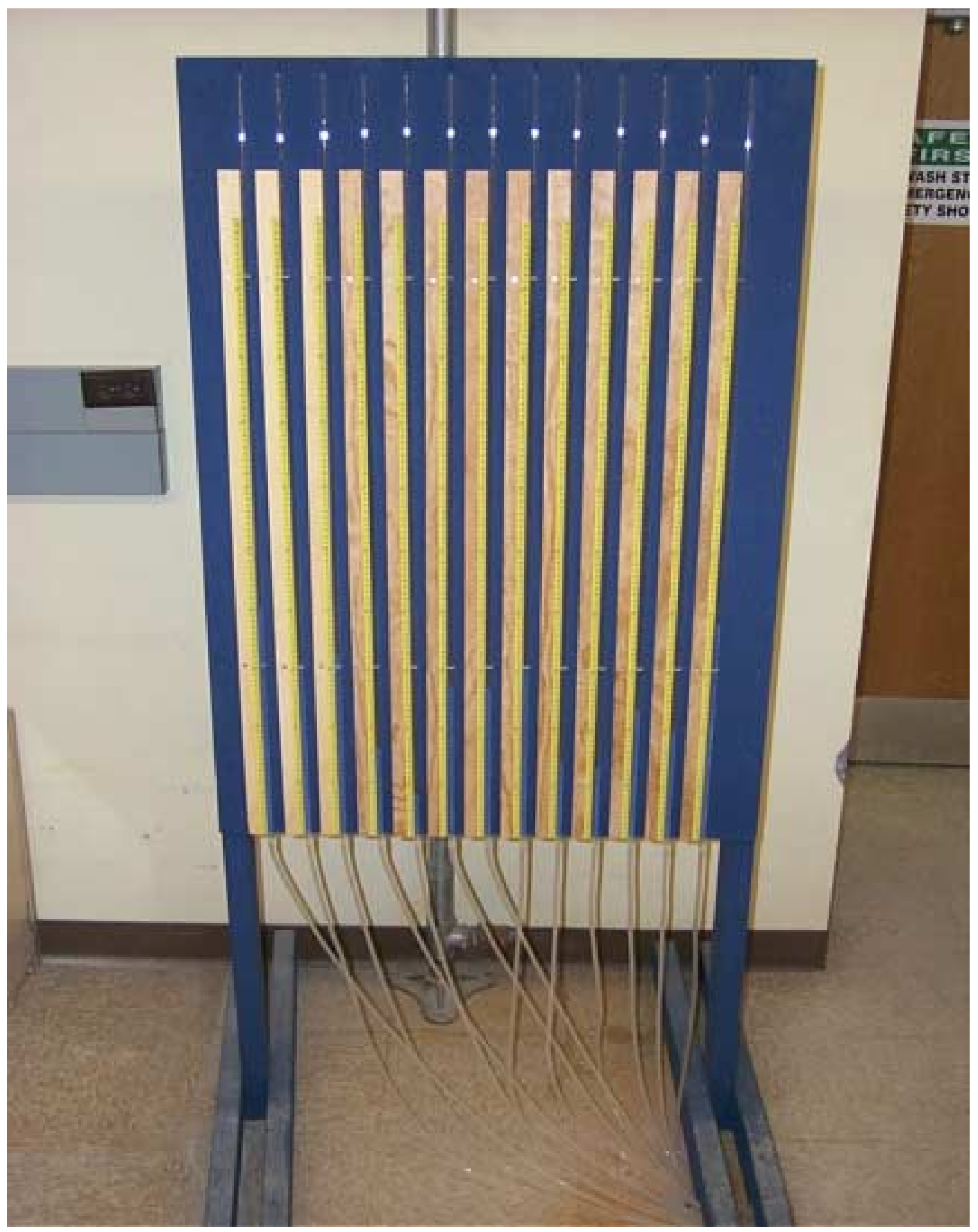

Figure 3.6: Panel of Piezometers. 


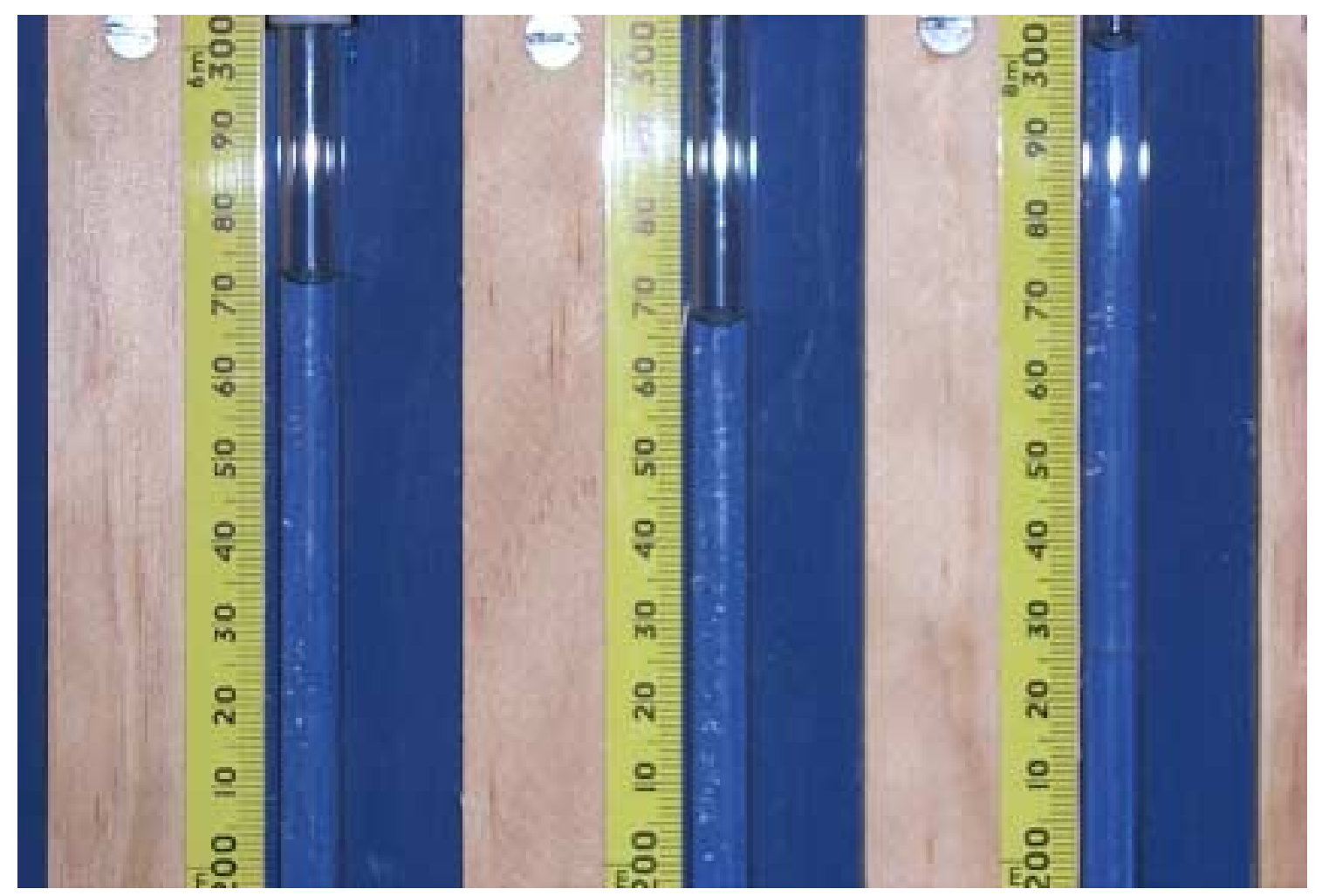

Figure 3.7: Close-up View of Piezometers. 


\subsubsection{Water Reservoir}

The water reservoir is located at the back of the soil zone. Its dimensions are 12 inches long, 24 inches wide and 10 inches deep $(30 \mathrm{~cm} \times 60 \mathrm{~cm} \times$ and $25 \mathrm{~cm})$. The reservoir supplies the water going through the soil and its overflow pipe can be adjusted to different heights in order to set the water level to the desired depth. The overflow pipe is a polyvinyl chloride (PVC) pipe, 1 inch $(2.5 \mathrm{~cm})$ in diameter attached to the bottom of the reservoir using a compression fitting. This pipe is connected to a secondary reservoir. This secondary reservoir collects the water from the drains and the overflow, and sends it back to the main reservoir by means of a submersible pump. The pump sends the water back through a $\frac{5}{8}$ inch $(1.6 \mathrm{~cm})$ tube forming a loop between the reservoirs.

The main reservoir is separated from the soil zone by a perforated plexi-glass wall. The holes are $3 / 8$ inch $(0.95 \mathrm{~cm})$ in diameter and are arranged in a matrix form, with $3 / 4$ inch $(1.9 \mathrm{~cm})$ spacing. Each hole is covered by a $1 / 2$ inch $(1.3 \mathrm{~cm})$ square section of geotextile fabric to prevent soil from washing back into the reservoir. By having separate square sections, instead of one continuous sheet, transverse flow through the fabric is eliminated. To prevent errors, and to provide free flow, the holes at the bottom of the wall are half circles instead of round.

Whenever the width of the soil zone was reduced, the section of perforated wall not contacting the soil was covered and sealed using a solid section of plexi-glass and silicone glue. Figure 3.8 shows a picture of the main water reservoir. 


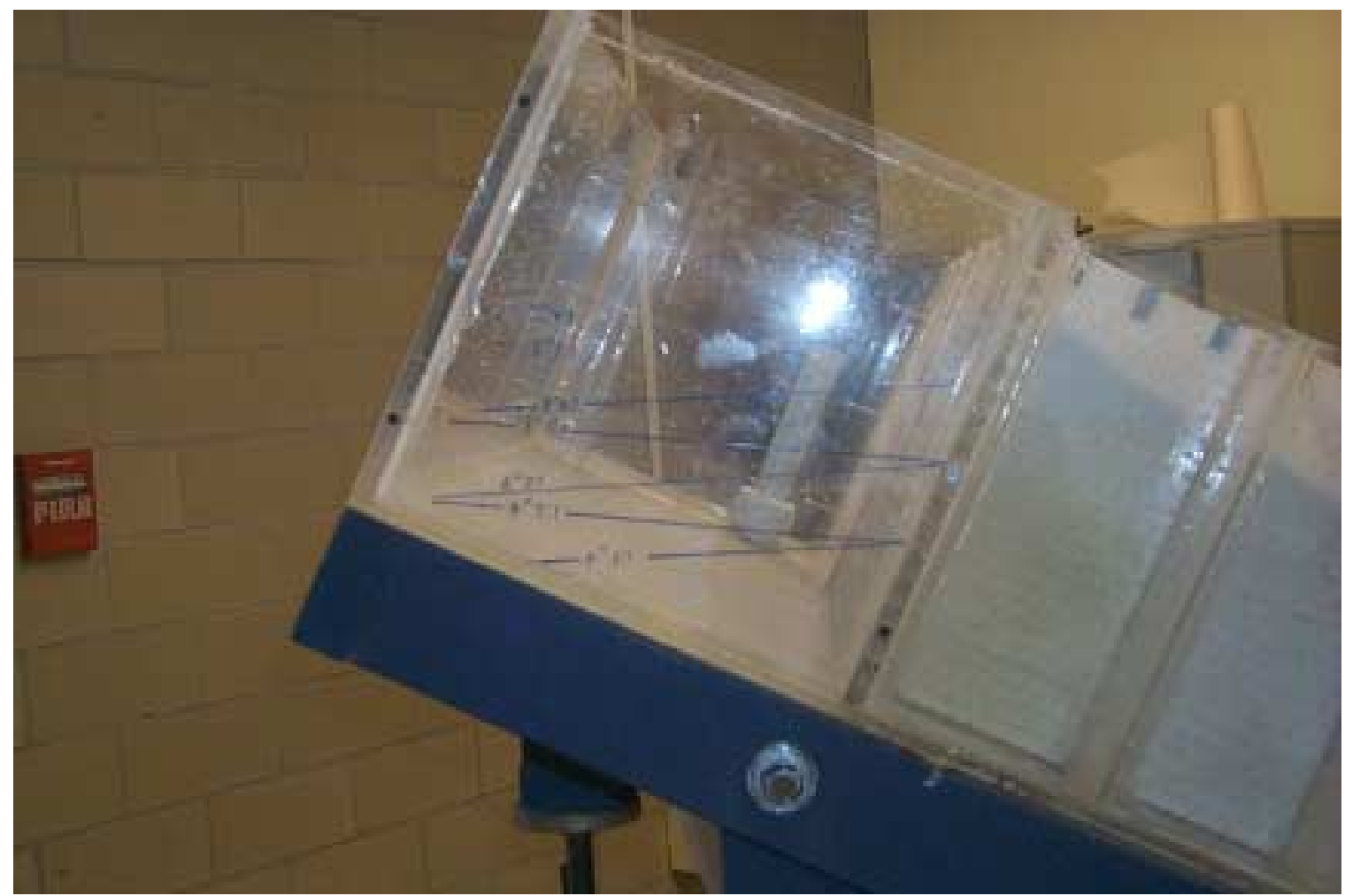

Note: water level indications for different slopes and flow depths are shown in the picture.

Figure 3.8: Side View of the Main Water Reservoir. 


\subsubsection{Longitudinal Drain}

As mentioned before the longitudinal drain runs along one of the long edges of the soil zone. It is divided into six independent sections, using $1 / 4$ inch $(0.64 \mathrm{~cm})$ thick plexi-glass walls (Figure 3.9). Each of the first four sections is 6 inches $(15 \mathrm{~cm})$ long, and the remaining two are 12 inches $(30 \mathrm{~cm})$ long. The reason for having independent sections of the drains is to determine the effectivenes of the drain with respect to the length of the soil zone. It was expected that the majority of the water was going to be drained in the first half of the soil zone. That is the reason why the first four drains are smaller than those on the second half.

To prevent any soil from entering the drain, a geotextile fabric was placed between the soil and the drain wall. Instead of using one continuous section, the fabric used was divided to each drain size, because the geotextile has an in-plane conductivity. A gap of approximately $1 / 4$ inch $(0.64 \mathrm{~cm})$ was left between the sections and then sealed using silicone glue to prevent water from one section entering another. The drains were labeled one through seven (Figure 3.3) starting from the one closest to the main reservoir. Each drain has a $\frac{5}{8}$ inch $(1.59 \mathrm{~cm})$ flexible tubing that connects the drain to a PCV pipe, which feeds the secondary reservoir.

\subsubsection{End Drain}

A perforated wall of plexi-glass similar to the one in the face of the water reservoir tank formed the end drain of the soil zone. Just like the longitudinal drains, the perforated wall of the end drain was covered with a section of the same fabric. The width of the fabric used was equal to the width of the soil zone. 


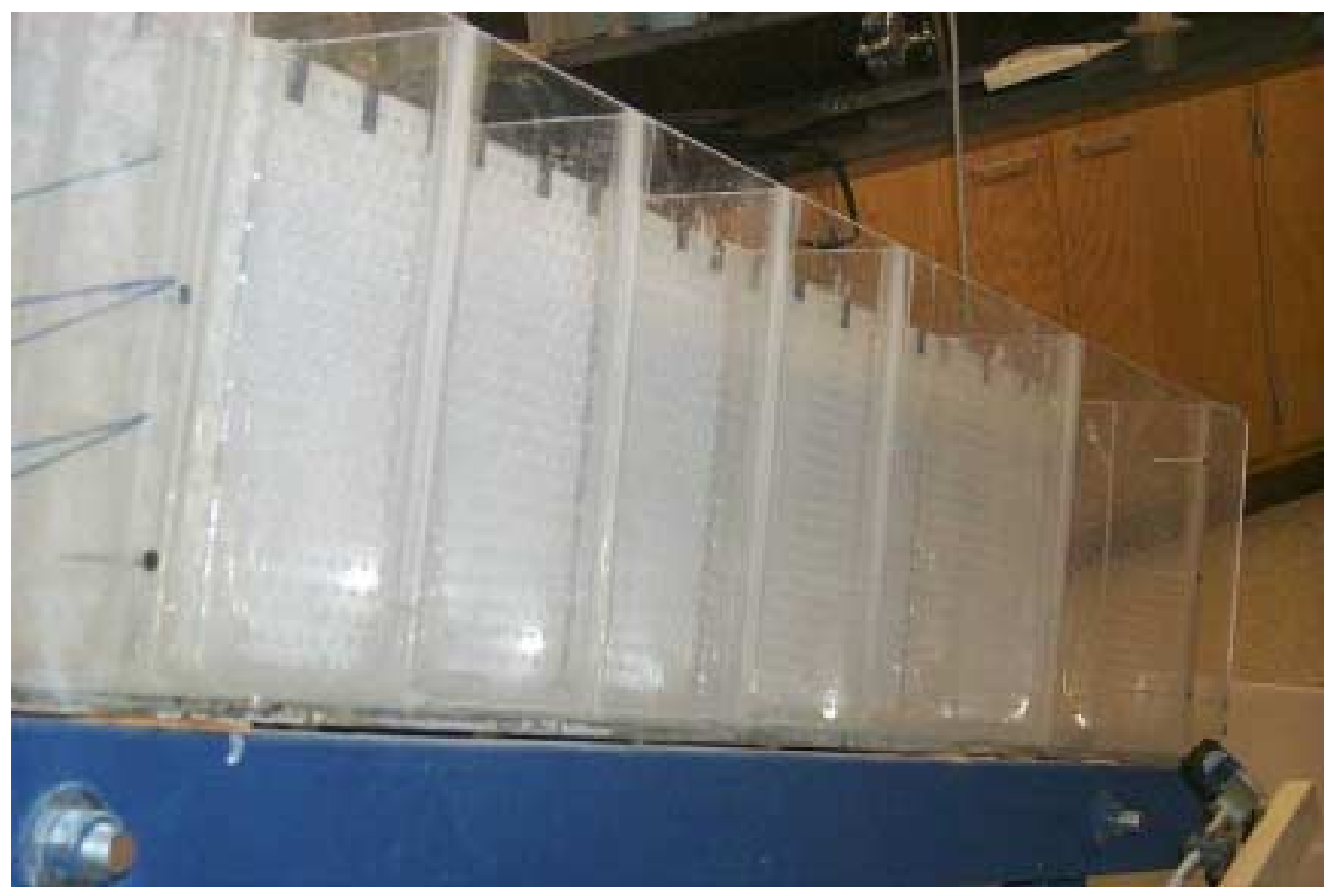

Figure 3.9: Picture of longitudinal Drain with Geotextile in Place. 


\subsubsection{Geotextile Fabric}

The geotextile fabric used in this study had a hydraulic conductivity at least one order of magnitude higher than that of the soil with the lowest (5\%) clay content. If the hydraulic conductivity of the fabric were to be smaller than that of the soil, all the data collected would be inaccurate since the objective is to collect date on seepage through soil. It is extremely important for the fabric to have a much lower resistance to water flow than the soil. The fabric used was Terrafix 400R from Terrafix ${ }^{\circledR}$. Fabric specifications are given in Table 3.2. The pieces of fabric used to cover the drains were changed after every other test to prevent clogging, while the tiny squares used in the water reservoir were changed at the beginning of every test. This was necessary to ensure that the soil mass was supplied with a constant flow of water. To reduce the amount of soil particles suspended in water a small filter was used. The filter consisted of an 8-inch $(20 \mathrm{~cm})$ section of PCV pipe filled with geosyntetic material. The same geosynthetic fabric was used. This is known as a "comet" filter in this research (Staud, 2000).

Table 3.2: Properties of Geotextile Fabric.

\begin{tabular}{|l|l|}
\hline Parameter & Value \\
\hline E.O.S $(\mu \mathrm{m})^{*}$ & 50 to 150 \\
\hline Hydraulic Conductivity k $(\mathrm{cm} / \mathrm{s})$ & $2.8 \times 10^{-1}$ \\
\hline
\end{tabular}

* Equivalent Opening Size. 


\subsection{DESCRIPTION OF THE TESTS PERFORMED}

The previously described apparatus was designed and utilized to represent seepage through real earth slopes. The beauty of this test is its simplicity. Once a soil sample was placed in the soil zone, water was introduced. Before proceeding with the test, it is necessary to allow enough time for the sample to saturate. Once saturated, drainage under transient state and steady state conditions were investigated. This section is divided in four steps, which follow the order in which they were performed.

1. - Placement of the Soil

2. - Saturation Period

3. - Transient State

4. - $\quad$ Steady State

\subsubsection{Placement of Soil}

After several preliminary tests, a new and simpler way for placing the soil was devised. A wooden frame was constructed to carry the load instead of a person. This frame holds a bucket at a constant height. Wheels were mounted at the bottom of the bucket so that it can be moved along the frame. The frame runs along the longitudinal direction of the model. Because it is much higher than the model in elevation, a flexible tube was connected to the bucket. The end of the tube was maintained at a distance no greater than $5 \mathrm{~cm}$ ( 2 inches) from the surface of the soil. The soil was placed in slow longitudinal motion, leaving only a thin layer of soil after each pass. This process was repeated until the soil zone was filled. During this process the bucket had to be refilled many times. 
When working with low hydraulic conductivity soils the process had to be modified. In this case, a layer of approximately $5 \mathrm{~cm}$ (2 inches) thick was placed and water was introduced into it. After it was saturated another layer was placed and the process was repeated until the soil zone was filled. The soil was placed in the soil zone while it was in a horizontal position. A more detailed description of the saturation process follows this section.

\subsubsection{Saturation Period}

For soils with high hydraulic conductivity, the initial saturation process was very simple. Once the soil was in place, the main reservoir was filled with water. This type of soil saturated very quickly when the water depth was set to $20 \mathrm{~cm}$ (8 inches). For this type of soil the saturation period varied from five to seven days depending on the width of the soil zone. During the saturation period the soil changes color, and it becomes a little darker than in its dry state. Because the walls are made of transparent plexi-glass, it is quite simple to determine when the soil is fully saturated, but piezometric tubes were also checked as verification.

In the case of soils with low permeability the saturation procedure had to be modified. When using this type of soil, it was noted that during saturation time, deep cracks appeared in the soil making the experiment unusable. Because of its low hydraulic conductivity, the water introduced was saturating the soil faster in the upward direction than in the longitudinal direction. Because the soils settled when saturated, the upstream section of soil settled causing cracks at the surface (Figure 3.10).

To prevent cracking, the soil was saturated in layers. A layer of every $5 \mathrm{~cm}(2$ inches) in thickness was allowed saturate before placing another layer. The water level 
was kept a few centimeters below the soil level. This process was repeated until the desired thickness was reached. This process was performed in the horizontal position of the model.

\subsubsection{Transient State Condition}

This part of the study is focused on drainage of water as soon as the drains were opened. During the saturation period, all drains except the end drain were closed. Once it was determined that the saturation period was completed, the drains were opened. As soon as the drains were opened, the flow data was collected in each drain. Data was collected for two to three days depending on the flow behavior. After collecting data for the steady state condition, the model was tilted to the next slope angle and the procedure was repeated. The transient state is a very important part of this study because it represents the drains immediately after construction. This data will indicate the time required for a drain to be fully functional.

\subsubsection{Steady State Condition}

After the drains were in place, and the transient state was completed, the flow in each of the drains reached a steady state condition. As soon as the flow remains stable and the piezometric data stops changing, the steady state condition is reached. Usually the last couple of readings taken during the transient state are almost steady, so they can be used for this part of the study.

Data collected during the steady state condition of the experiment indicates the real effectiveness of the drains with respect to length. It gives an idea of how well the drain works along the longitudinal direction. 


\subsection{DATA ACQUISITION}

For both the transient and steady state conditions, water was collected in each drain for ten minutes at each of the reading times. The water was collected in graduated cylinders in order to get an accurate reading. At the beginning of every reading, all the current piezometric data was recorded. The tests were run at three different water depths for each of the slopes. This process was repeated for each of the three widths studied.

Transient readings were taken only at the highest water level of 8 inches (20 $\mathrm{cm})$. As soon as the drains were opened, readings were recorded until variations stopped. After a few preliminary tests, the best times for starting to take readings were identified and defined as follows: at time zero (as soon as the drains are opened), $1 / 2 \mathrm{hr}, 1 \mathrm{hr}, 2 \mathrm{hr}$, $1 / 4$ day, $1 / 2$ day, 1 day, 2 days, and so on depending on the data. If the last few reading were stable, they were used for the steady state condition. Otherwise, data was taken until the steady state condition was reached. Once data was collected for transient and steady state conditions, the water level was lowered to the next one at 6 inches $(15 \mathrm{~cm})$.

After many tests, it was noted that the flow stabilized very quickly when lowering the water level. After a few hours, there were no variations in the flow. Steady state readings were taken and the water level was lowered once more to the final depth of 4 inches $(10 \mathrm{~cm})$.

After taking all the readings for the present slope, the apparatus was raised to the next inclination. The inclination was selected as horizontal or flat, 4:1 inclination, 3:1 inclination and 2:1 inclination. Once the apparatus was raised, the drains were closed and the water level was kept at 2 inches for at least a few hours. Then the water level was raised little by little in steps leaving few hours in between the steps. This process is very 
important because it prevents the soil from sliding. The implementation of this plan was adopted after a few failures occurred. Once the water level was at $20 \mathrm{~cm}$ ( 8 inches), the same readings were taken, and the whole process was repeated for each slope inclination.

As a quality control measure, at least two sets of data points were taken, and each test was repeated at least once. If the data sets were within a five percent difference, then it was considered as satisfactory.

\subsection{NOTATION}

The following notation is used to describe the experimental parameters used in this project.

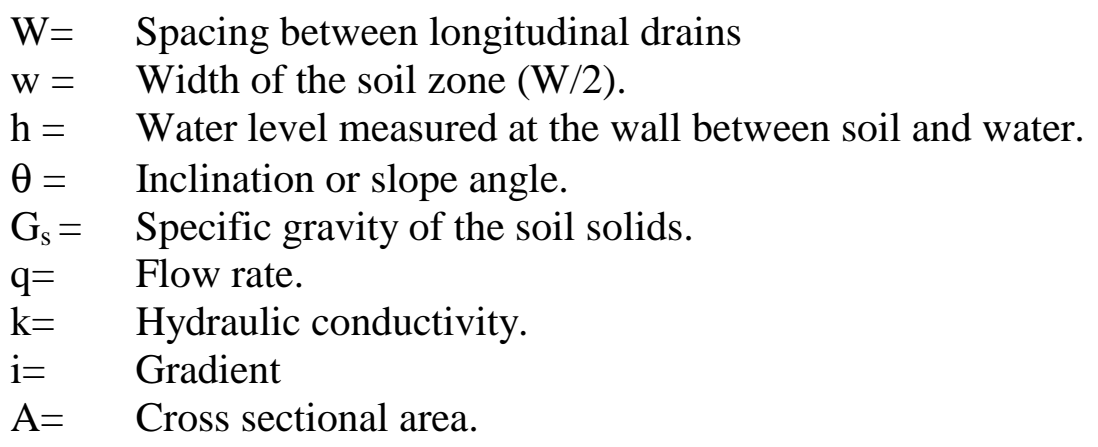

The following pictures show the whole apparatus, Figure 3.11, and an approximation to the water profile inside a soil specimen, Figure 3.12.

Because of the amount of experiments and data collected it was necessary to come up with a labeling system. The labels used were as follows: the first number represents the width of the soil zone (half trench spacing, w), the second number represents the water level (h), the third number is the slope angle $(\theta)$ and the last number is the experiment number. For example, the test labeled $12-6-3-18$ was a 12 inch $(30 \mathrm{~cm})$ width soil zone with a water level at 6 inches $(15 \mathrm{~cm})$ at a slope of $3: 1$ and the experiment number was 18 . 


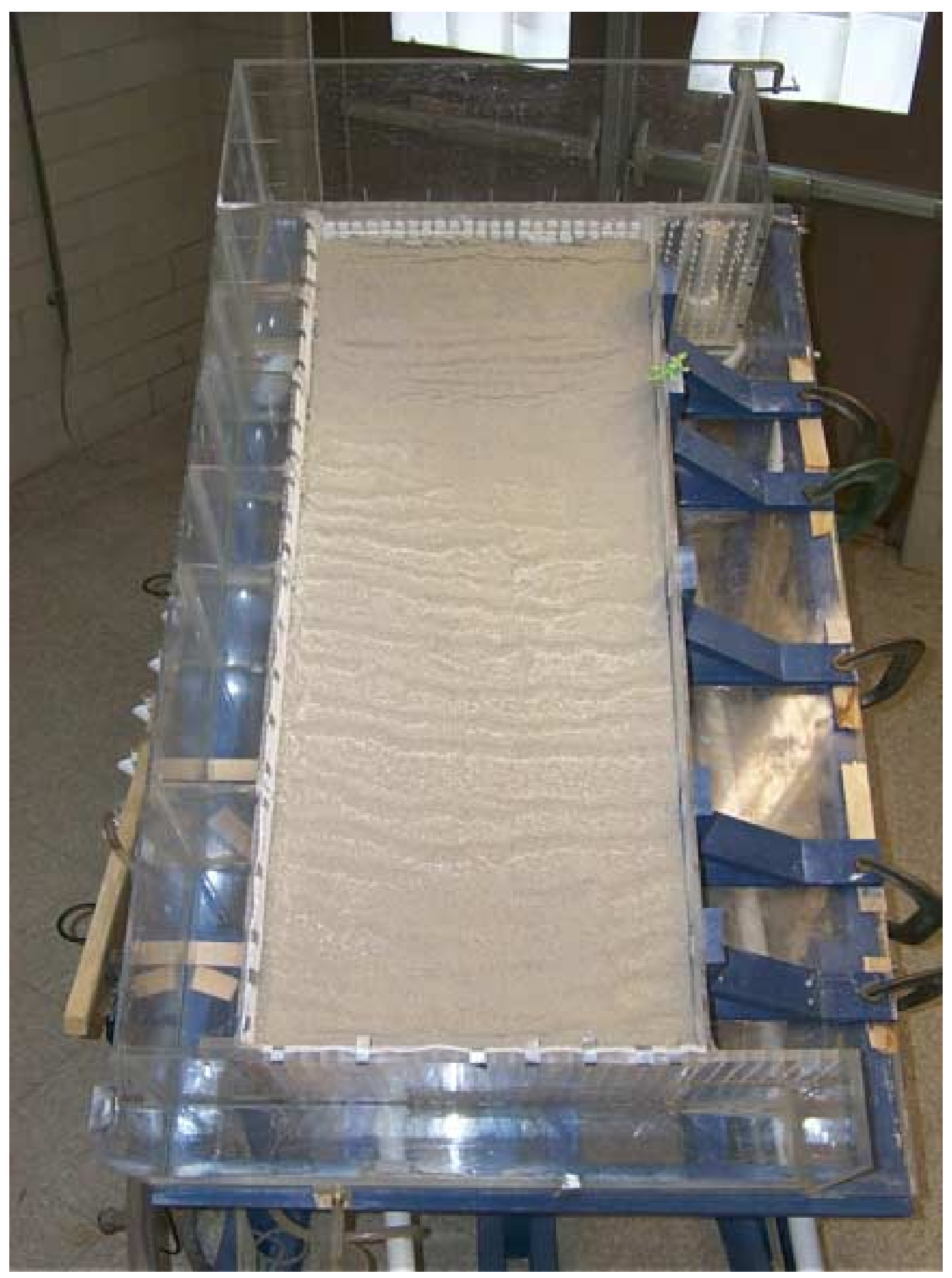

Figure 3.10: Surface Cracks on the Soil Surface. 


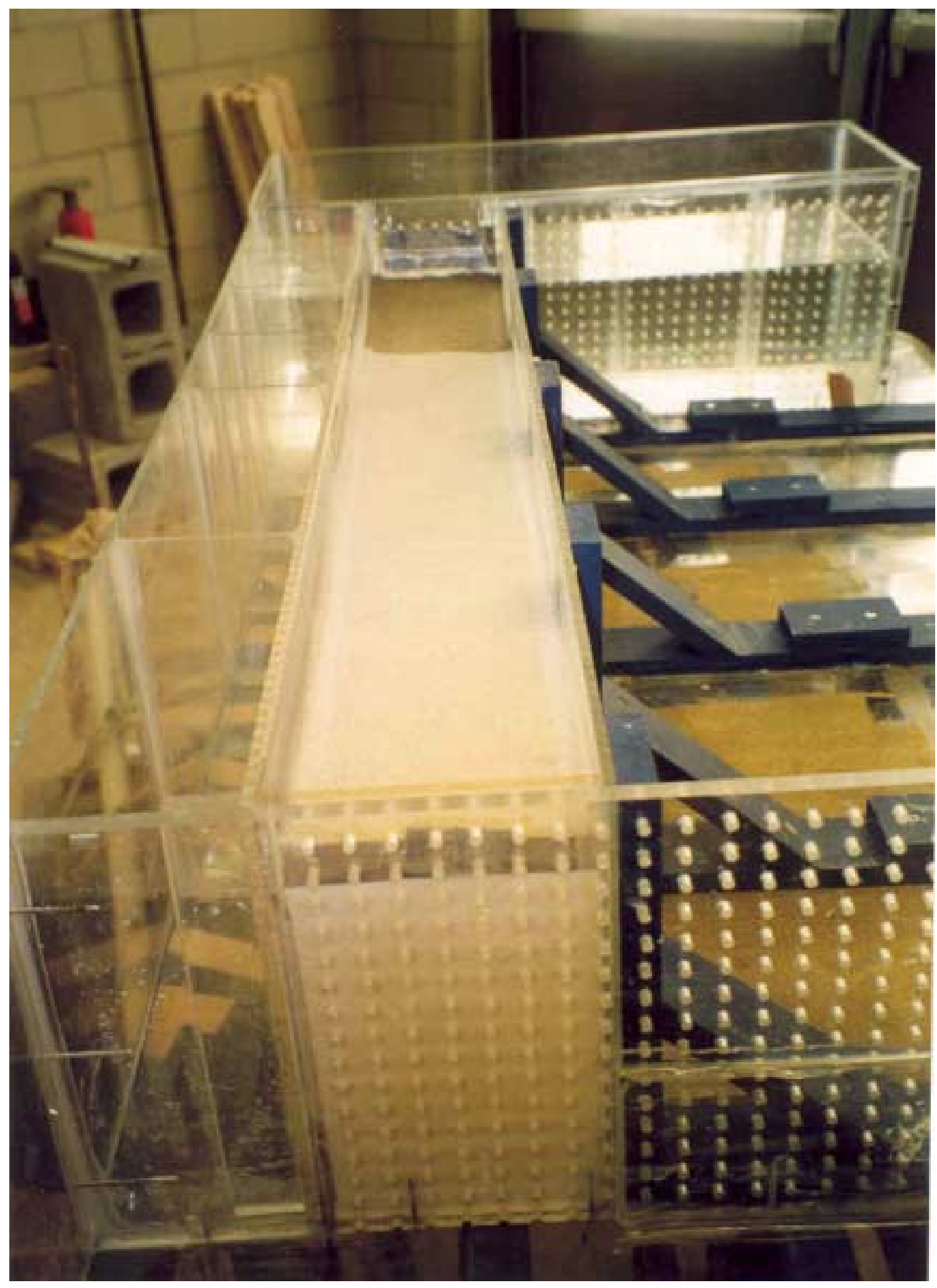

Figure 3.11: Apparatus and Soil Specimen. 


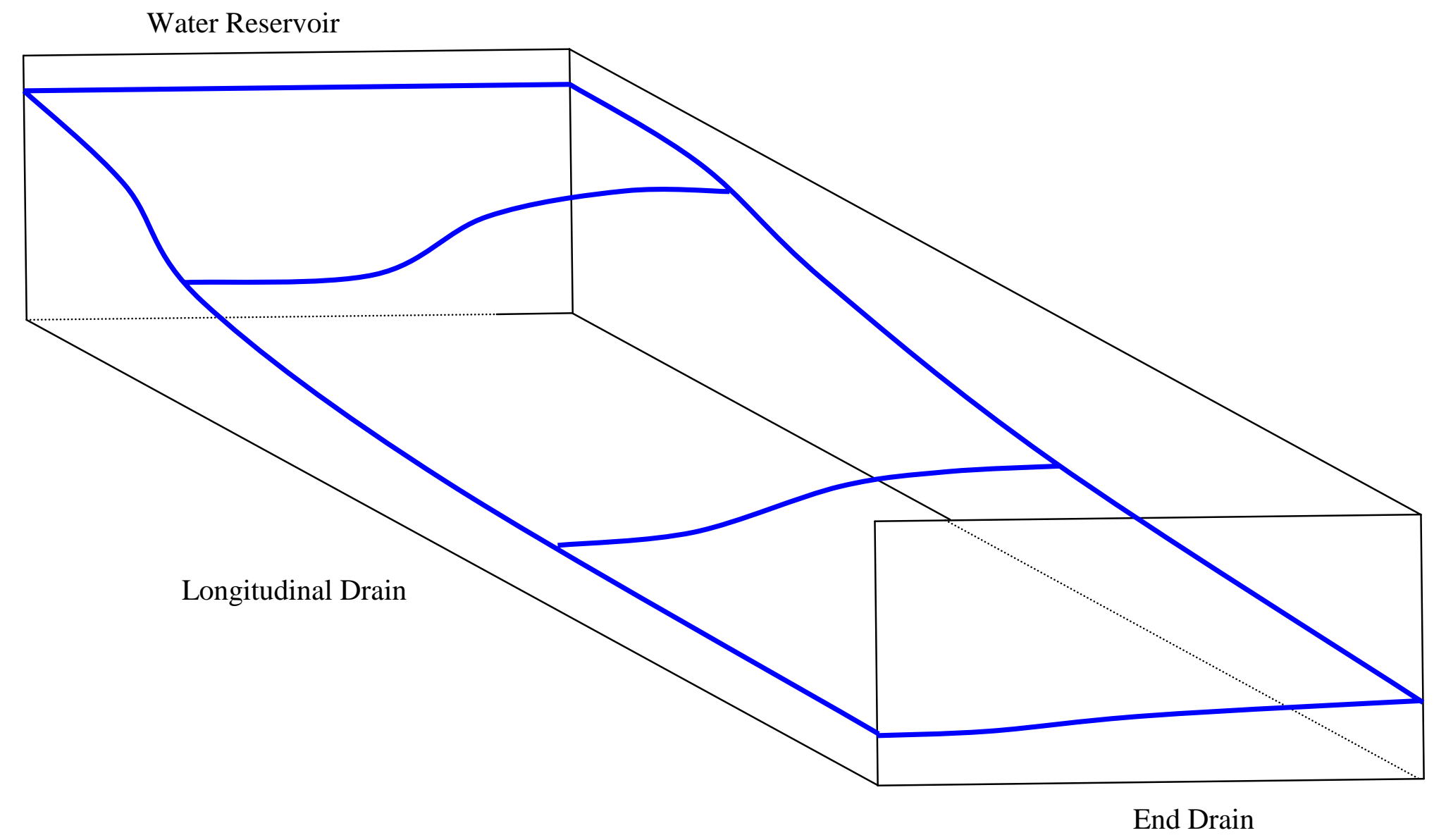

Figure 3.12: Schematic of Water Profile Inside Soil Specimen. 


\section{CHAPTER 4}

\section{RESULTS}

\subsection{INTRODUTION}

By using the model described in the previous chapter, an abundance of data on the performance of longitudinal drains was collected. All raw data was then processed and interpreted. Several graphs were prepared to facilitate and provide visual understanding of what is actually happening along the slope. The effectiveness of the drain and the influence of different factors affecting the flow are clearly shown throughout the chapter.

Every section in the chapter deals with two states: transient state and steady state conditions. It is important to remember that the model is based on the assumption that the flow is symmetrical between parallel longitudinal drains (Figure 3.4). The apparatus was configured at different slopes, different water levels and different widths. Different soils were used for each combination. These configurations are reviewed briefly in the following section.

Four different inclinations or slopes were used. These were: zero inclination or horizontal, 4:1 inclination, 3:1 inclination and 2:1 inclination. These numbers represent two sides of a triangle; the first number being the horizontal side and the second number being the vertical side, the apparatus itself would be the hypotenuse. The water level introduced into the soil was adjusted to three levels: 4 inches $(10 \mathrm{~cm}), 6$ inches $(15 \mathrm{~cm})$ and 8 inches $(20 \mathrm{~cm})$. The water level was measured at the perforated wall dividing the main water reservoir and the soil zone. Width was also adjusted to three different sizes: $15 \mathrm{~cm}$ (6 inches), $30 \mathrm{~cm}$ (12 inches) and $46 \mathrm{~cm}$ (18 inches).

Graduated cylinders were used to accurately collect water from each drain. The amount of water seeping though the slope would be the sum of the volumes of water 
collected by all seven drains. Water was collected in each drain for ten minutes when the readings were taken. The piezometric data was recorded at the beginning of each interval. For the transient study, readings were taken at time zero (as soon as the drains were opened), $1 / 2 \mathrm{hr}, 1 \mathrm{hr}, 2 \mathrm{hr}, 1 / 4$ day, $1 / 2$ day, 1 day, 2 days, and so on until the steady state condition was reached. Because the total volume of water collected is known, the volumes collected in each individual drain can be processed in order to investigate the influence of length on drain efficiency. In addition to the data collected using the model, representative samples of the soil were taken and tested for hydraulic conductivity, specific gravity, and grain size distribution.

One of the important aspects of this study is that all the experimental observations were duplicated. All data regarding the composition and type of soil is given in this chapter. The apparatus was described in the previous chapter. The proportions of sand and clay for each soil mix are presented in this chapter. The reproducibility of the experimental data is very important. In this study, each experiment was repeated at least once to make sure that the data is reproducible. 


\subsection{INFLUENCE OF LENGTH}

\subsubsection{Transient Condition}

The length of the drain has a great influence on its effectiveness. Figure 4.1 shows the variation of drainage (rate of seepage removal) with length for soil type B for a half trench spacing of 18 inches $(46 \mathrm{~cm})$ at 4:1 inclination angle. This figure as well as all the figures in the Appendix B show that the biggest changes in removal of seepage happen in the first $1 / 3$ of the apparatus (the first three drains). After this point the flow remains almost constant. Although the first three drains are the ones showing changes, these changes are in the order of only five percent. A small change such as this may seem insignificant, but depending on the total volume of water, a five percent transition should be examined closely. The most critical transient condition of flow happens during the first day. For this reason, results are shown in Figure 4.1 only for the time zero and day one. Some of the figures in Appendix B show trends for more time periods, and it is clearly seen that after the first day transient condition does not exist and the flow reaches steady state condition. The changes after the first day are in most cases lower than one percent. A small change such as this does not have great influence in the outcome.

In view of the limited data collected at the beginning of the transient condition, part of the transient condition may have been missed in the experiments. In future experiments, more data should be collected within the first few hours of the transient condition. Appendix B shows results for transient condition for soils with different hydraulic conductivities, different trench spacing and different slopes. These figures show the same trend, a big transition in the first three drains followed by an almost 
constant drainage. Other factors affecting the transient behavior will be explored in following sections of this chapter. 


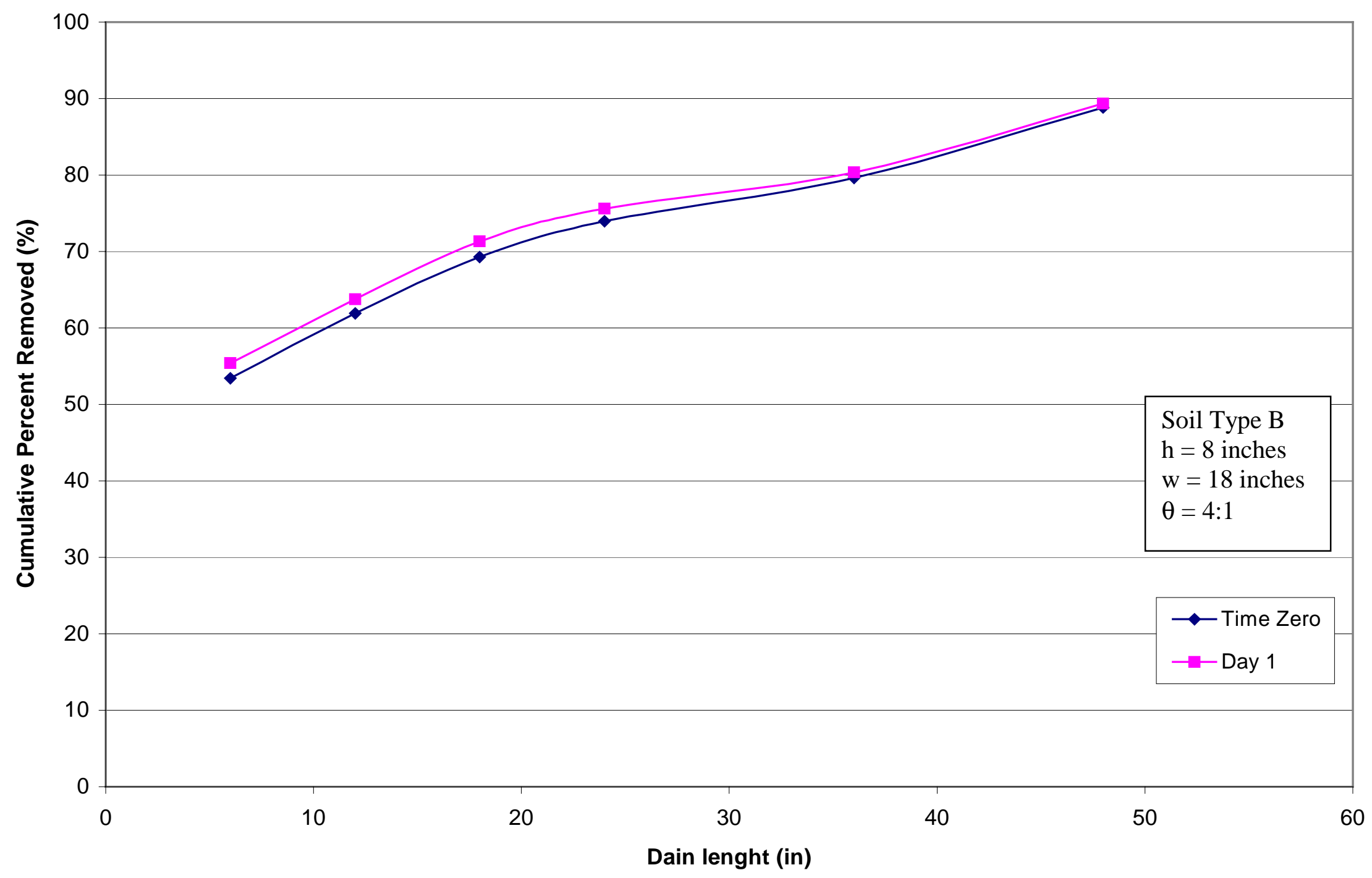

Figure 4.1: Influence of Length in Transient Condition for Soil Type B with 8" Saturation Depth and 4:1 Slope Angle. 


\subsubsection{Steady State Condition}

After completing all of the tests, it was observed that the first drain which is equal to 6 inches $(15 \mathrm{~cm})$ in length provided the biggest water removal. This is true for different combinations of water depth (h), inclination angle $(\theta)$, half trench spacing $(w)$, and soil type. As seen in the figures included in Appendix C, the first drain collects more than half of the total volume seeping through the soil. Figure 4.2 shows a typical representation in seepage removal as a function of longitudinal distance for soil type B. It can be easily seen that the amount of seepage water removed form the soil decreases as the drains move further downstream. In Figure 4.2, all three graphs show that the removal rate is almost eighty percent for the first drain (6 inches from the water reservoir). The next five drains removed approximately fifteen percent, leaving only a five percent seeping all the way to the end. For these conditions, the longitudinal drain is removing almost all the water flowing through the soil.

Appendix $\mathrm{C}$ shows results corresponding to steady state condition for different combinations of water depths, inclination angles and trench spacing. All these results show similar trends. 


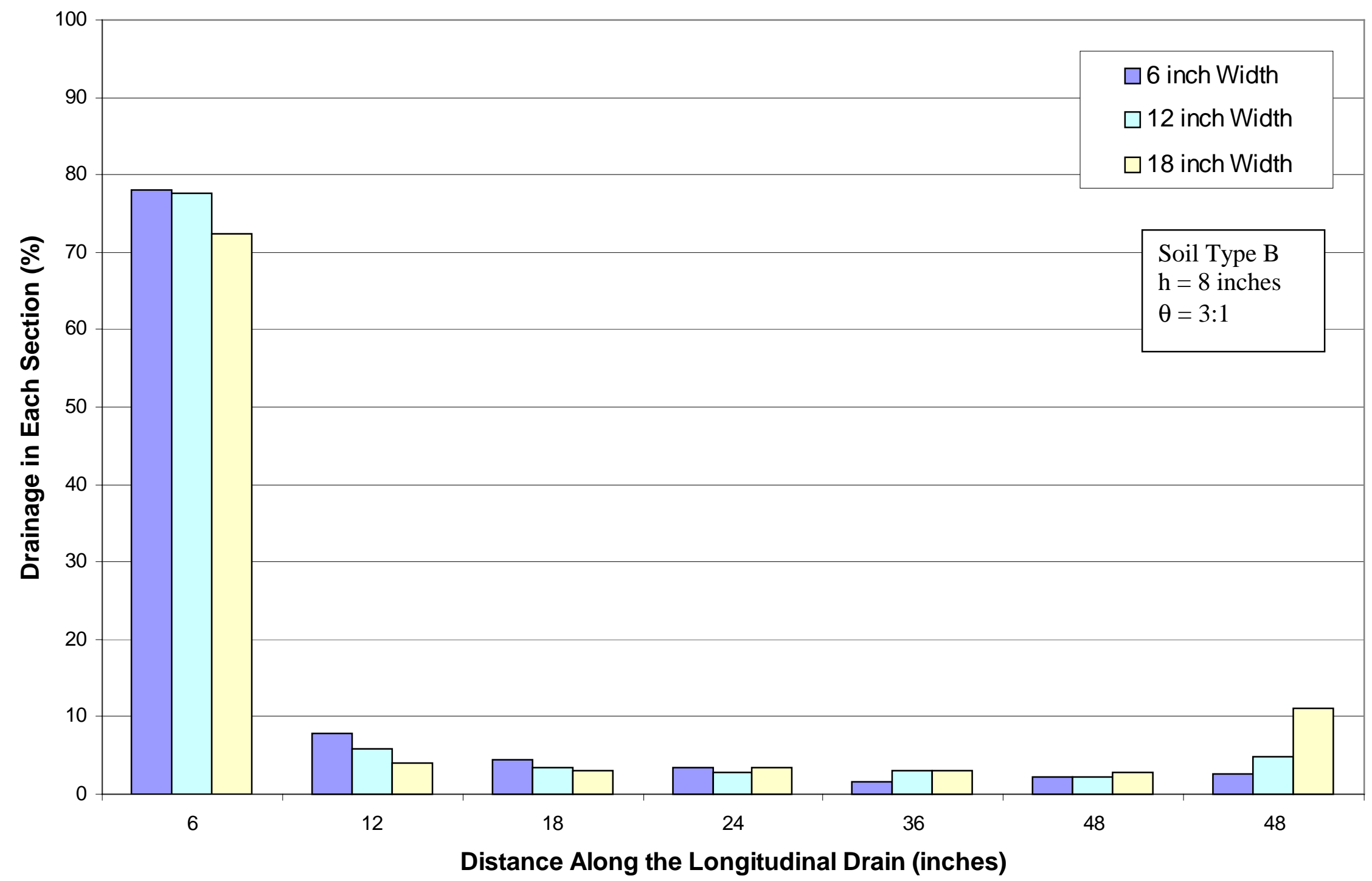

Figure 4.2: Influence of Length for Soil Type B with 8" Saturation Depth and 3:1 Slope Angle. 


\subsection{INFLUENCE OF SLOPE INCLINATION ANGLE $(\theta)$}

\subsubsection{Transient Condition}

The inclination of slope has an influence on the behavior of seepage water flow under transient conditions. As shown in Figure 4.3, the inclination angle does not have a big influence on the variations of flow. It can be seen that fluctuations do not increase because of the inclination angle. The increase in slope angle would increase the seepage rate. The more inclination the slope has the faster the water will try to reach steady state condition without fluctuating too much. Although the inclination angle increases the overall water flow, it does not increase the transition time. Throughout the experiments it was observed that the transition time is still within the first day. Only the results for time zero and day one are shown in Figure 4.3 because the fluctuations after the first day are very small.

As can be seen From Figure 4.3, the fluctuations in the flow are bigger in those cases with some inclination angle than that corresponding to zero slope. It is also noticeable that as the inclination becomes steeper, the difference in cumulative flow becomes smaller. This indicates that the steeper angles force the flow and constrict its fluctuations into a steady state condition quickly while lower slopes give more freedom to fluctuations. 


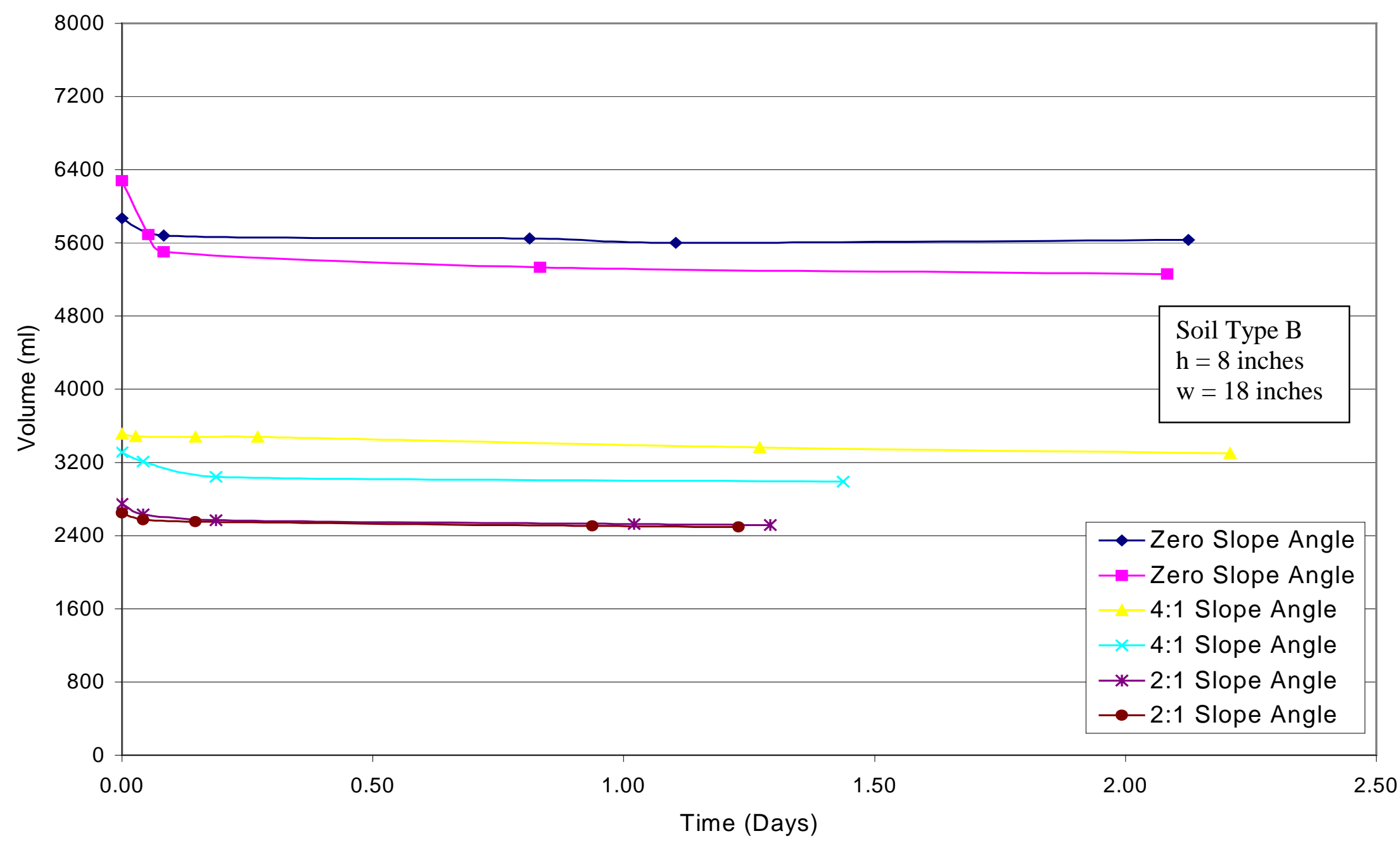

Figure 4.3: Influence of Angle on Transient Condition for soil Type B with 8" Saturation Depth and 18" Half Trench Spacing. 


\subsubsection{Steady State Condition}

Unlike in the transient state, the inclination angle, or slope, has a significant influence on the steady state condition. The effectiveness of the longitudinal drain is significantly affected by the slope inclination. The overall effectiveness of the drain decreases as the inclination angle increases. Figure 4.4 shows results corresponding to soil type B. This figure shows that for the zero slope the total amount of water removed was approximately ninety nine percent, where the majority was removed by the first drain $(80 \%)$. For the case of $4: 1$ slope, the overall removal was reduced to approximately ninety percent, almost ten percent lower than that of the zero inclination case. The first drain removed a volume less than that of the previous case (only 75\%). Between the horizontal case and the case of 4:1 slope, there is an approximate reduction of 10\% in the seepage removal rate. This means that there is more water flowing though soil when the slope is $4: 1$. As long as there is water flowing through soil slope, there can be slope stability problems associated with seepage. Between the cases of 3:1 slope and the case of 4:1 slope there is a difference of about $3 \%$ (the $3: 1$ slope case being $3 \%$ lower) in the seepage removal rate.

There is not a big difference between these two slopes (3:1 slope case and 4:1 slope case), yet the three percent is a consequence of the higher slope. For the 2:1 slope case, there is also a further reduction of approximately three percent in the seepage removal rate when compared to the previous case. The overall removal rate is close to eighty five percent, which is almost 15 percent lower than that of the horizontal case. Although the slope inclination does reduce the effectiveness of the longitudinal drain, it is still very effective. For the worst case (2:1 slope case), eighty five percent of the total 
amount of water flowing through the soil was removed through longitudinal drains. Appendix D contains results for different cases. These results show similar trends.

The inclination angle has little effect on drains four through six. As the inclination of the slope increases the effectiveness of these drains reduces. The volumes collected by these drains reduce dramatically as the slope inclination increases. 


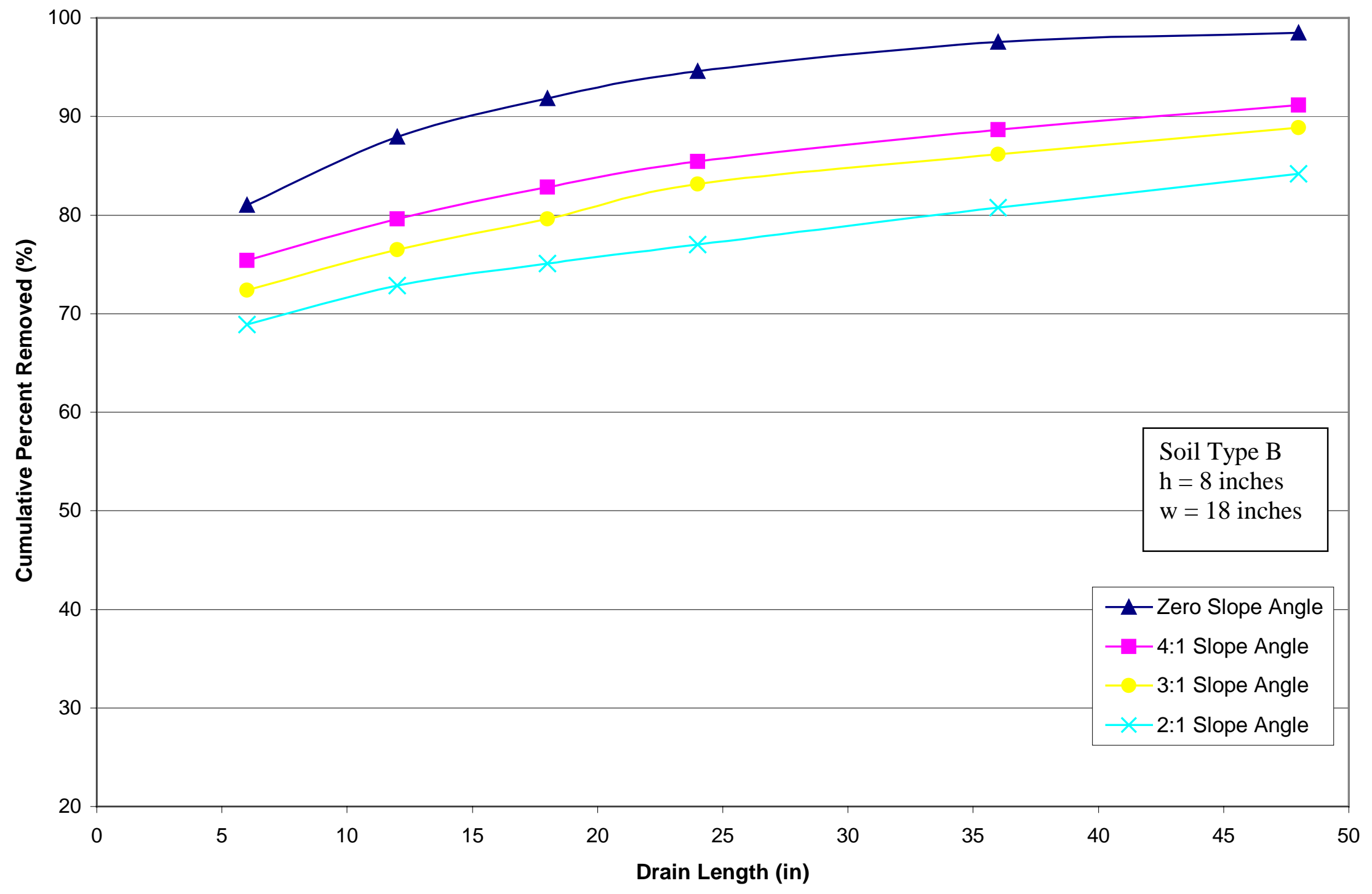

Figure 4.4: Influence of Sloe Angle for Soil Type B with 8" Saturation Depth and 18" Half Trench Spacing. 


\subsection{INFLUENCE OF TRENCH SPACING (w)}

\subsubsection{Transient Condition}

Figures 4.5 through 4.7 show the influence of trench spacing (w) on the transient state condition of the flow for the three different slope angles. In the horizontal case (Figure 4.5) the percentages of drainage collected at different trench spacing are close to each other, making it somewhat difficult to see different trends. The fluctuation of flow for each spacing is not greater than two percent for the first three drains. This gap slowly reduces as one approaches the end drain.

Figures 4.6 and 4.7 represent the influence the trench spacing (w) has on the transient behavior of flow going into the drains at 4:1 inclination and 2:1 inclination, respectively. Both of these figures represent data for soil type B with the water level set to 8 inches $(20 \mathrm{~cm})$. It can be seen from these two figures that the trench spacing has no significant influence on the fluctuations of flow. Regardless of the trench spacing gap between the flow trends remains almost constant.

It is important not to confuse the effectiveness of the drains, which definitely changes with trench spacing, with the transient fluctuations. In this section, the focus is on the changes the flow undergoes once the drains are activated. Once the drains are activated (opened), the flow pattern changes. The transient analysis focuses on how much the drainage change and how fast. The figures presented in this section show that the changes in flow remain within about two percent regardless of the trench spacing. 


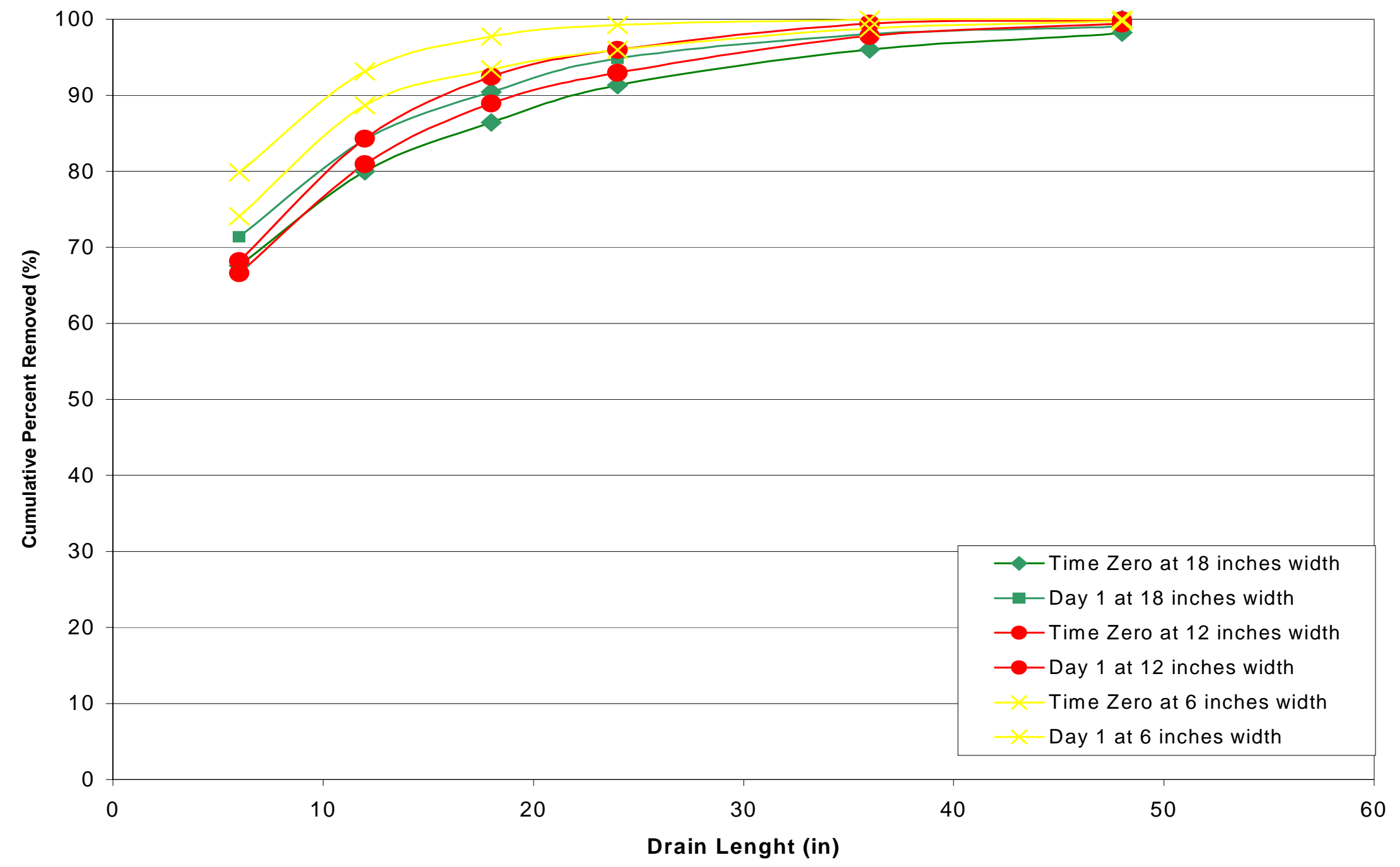

Figure 4.5: Influence of Trench Spacing under Transient Condition for Soil Type B with 8" Saturation Depth and Zero Slope Angle. 


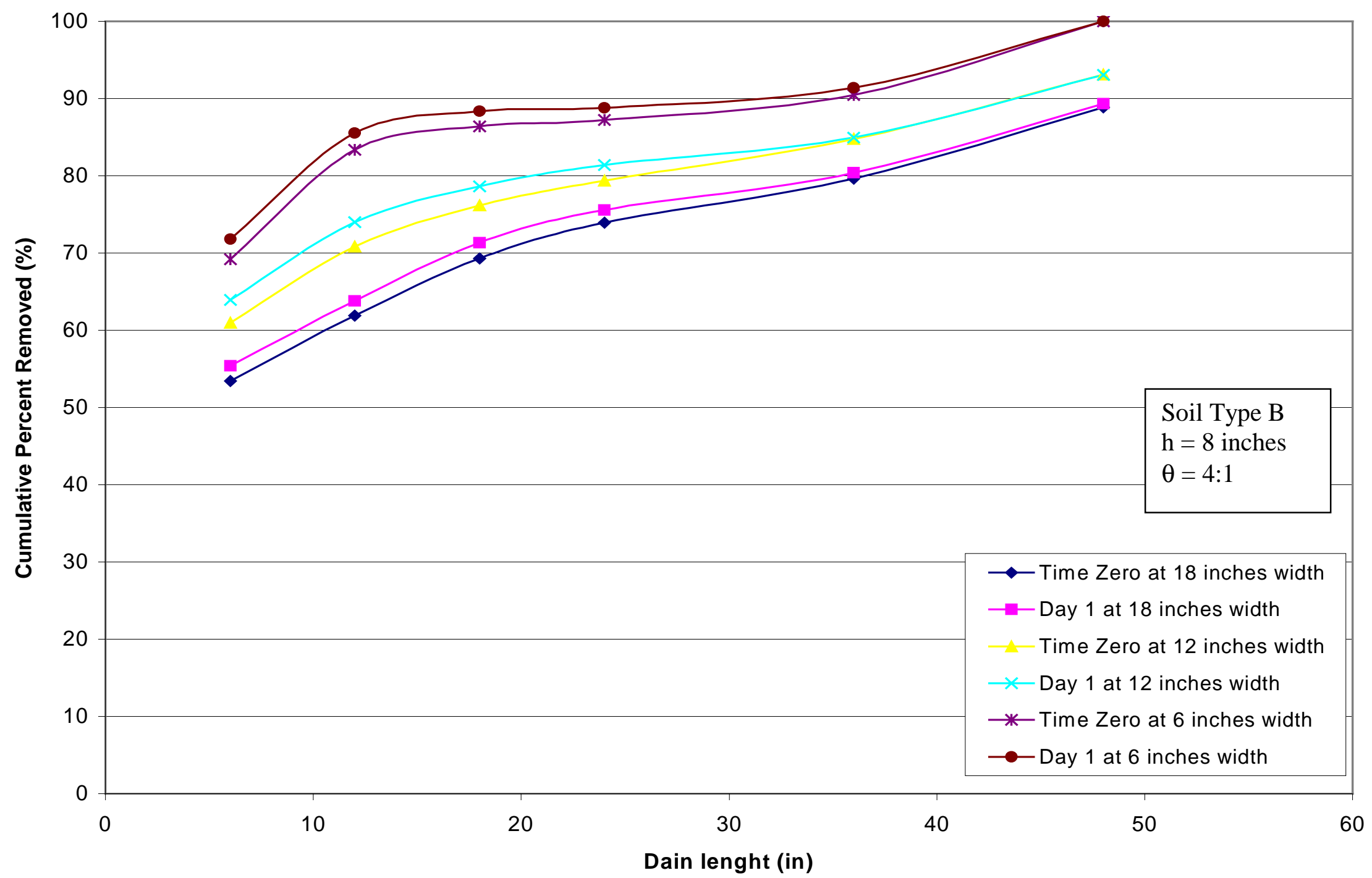

Figure 4.6: Influence of Trench Spacing under Transient Condition for Soil Type B with 8" Saturation Depth and 4:1 Slope Angle. 


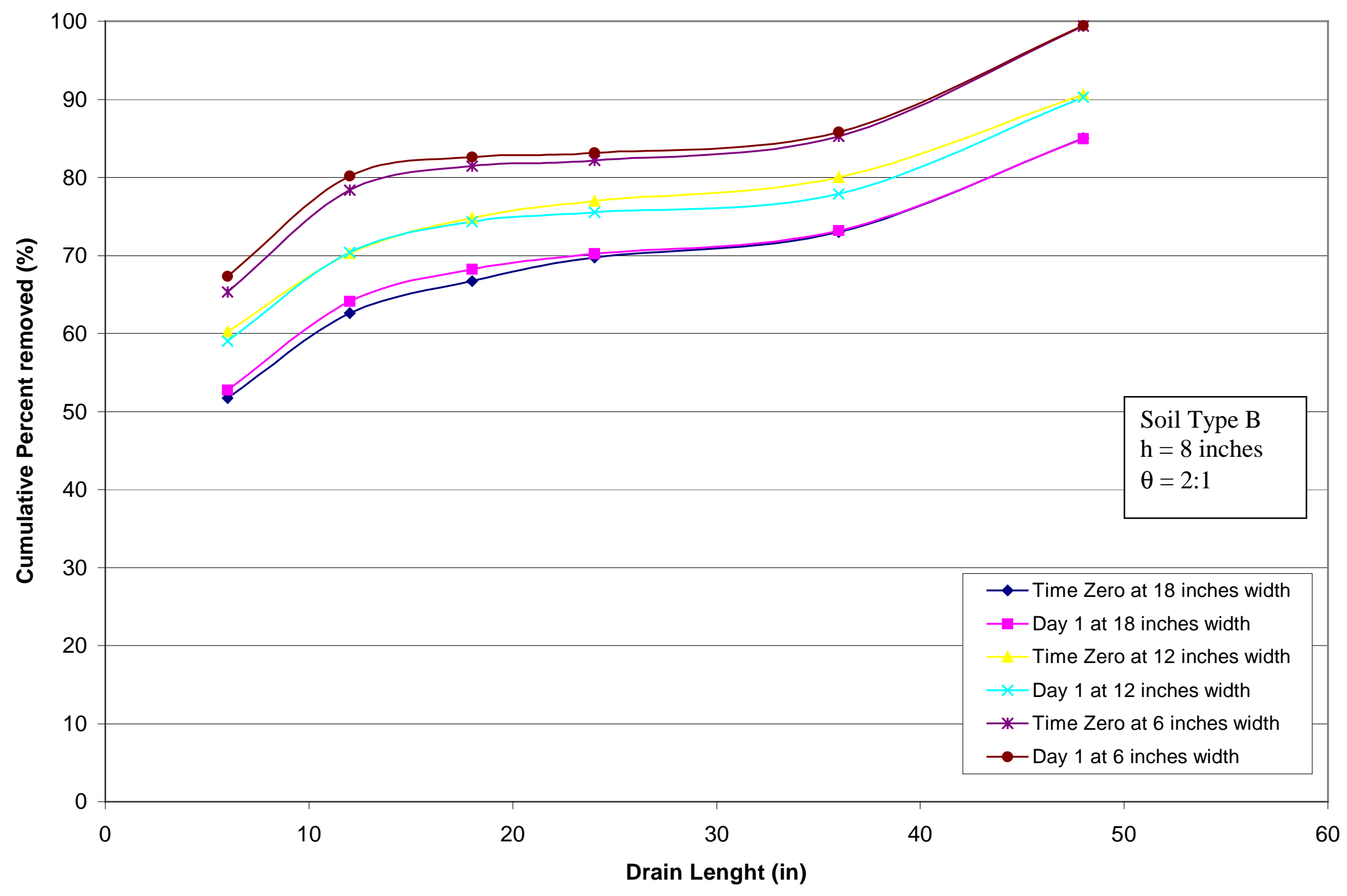

Figure 4.7: Influence of Trench Spacing under Transient Condition for Soil Type B with 8" Saturation Depth and 2:1 Slope Angle. 


\subsubsection{Steady State Condition}

Once the drainage through the drains stabilizes, the analysis of the influence of trench spacing was performed. Figures 4.8 through 4.10 show the cumulative percent of seepage water collected throughout the drains for three inclinations (horizontal, 4:1 and $2: 1$, respectively) for type soil $\mathrm{B}$ (hydraulic conductivity of $10^{-4} \mathrm{~cm} / \mathrm{s}$ ) and saturation water level of 8 inches $(20 \mathrm{~cm})$. For all three cases shown in these figures, the cumulative volumes collected increase as the trench spacing decreases. As expected the smaller the longitudinal drain spacing, the more effective they become. It is easier for the seepage water flow to be diverted, if the trench spacing is small.

For the soil represented in these graphs, the effectiveness of drains increases greatly depending on the trench spacing. In Figure 4.8, the flow rate into the first drain increases by about three percent when the spacing changed from 18 inches $(46 \mathrm{~cm})$ to 6 inches $(15 \mathrm{~cm})$ for the horizontal case. At 4:1 inclination (Figure 4.9), the effectiveness becomes more evident between the widths. The flow rate into the first drain increases by almost three percent when the spacing was changed from 18 inches $(46 \mathrm{~cm})$ to 12 inches $(30 \mathrm{~cm})$, and almost five percent when the spacing was change from 18 inches $(46 \mathrm{~cm})$ to 6 inches $(15 \mathrm{~cm})$. At 2:1 inclination (Figure 4.10), the effectiveness becomes even more evident between the widths. The flow rate into the first drain increases by almost eight percent when the spacing was changed from 18 inches $(46 \mathrm{~cm})$ to 12 inches $(30 \mathrm{~cm})$, and almost ten percent when the spacing was change from 18 inches $(46 \mathrm{~cm})$ to 6 inches $(15$ $\mathrm{cm})$.

Although the shorter the spacing between the longitudinal drains the more effective they become, it may not be feasible to do so in every case. Depending on 
economic factors, timetables and many others, the spacing of longitudinal drains may not be as small as desired. Once the effectiveness of the drain is determined, the engineer must evaluate all these factors and make the best decision.

Figures for different soil types, water levels and slope angles are shown in Appendix E. All these figures show similar trends. 


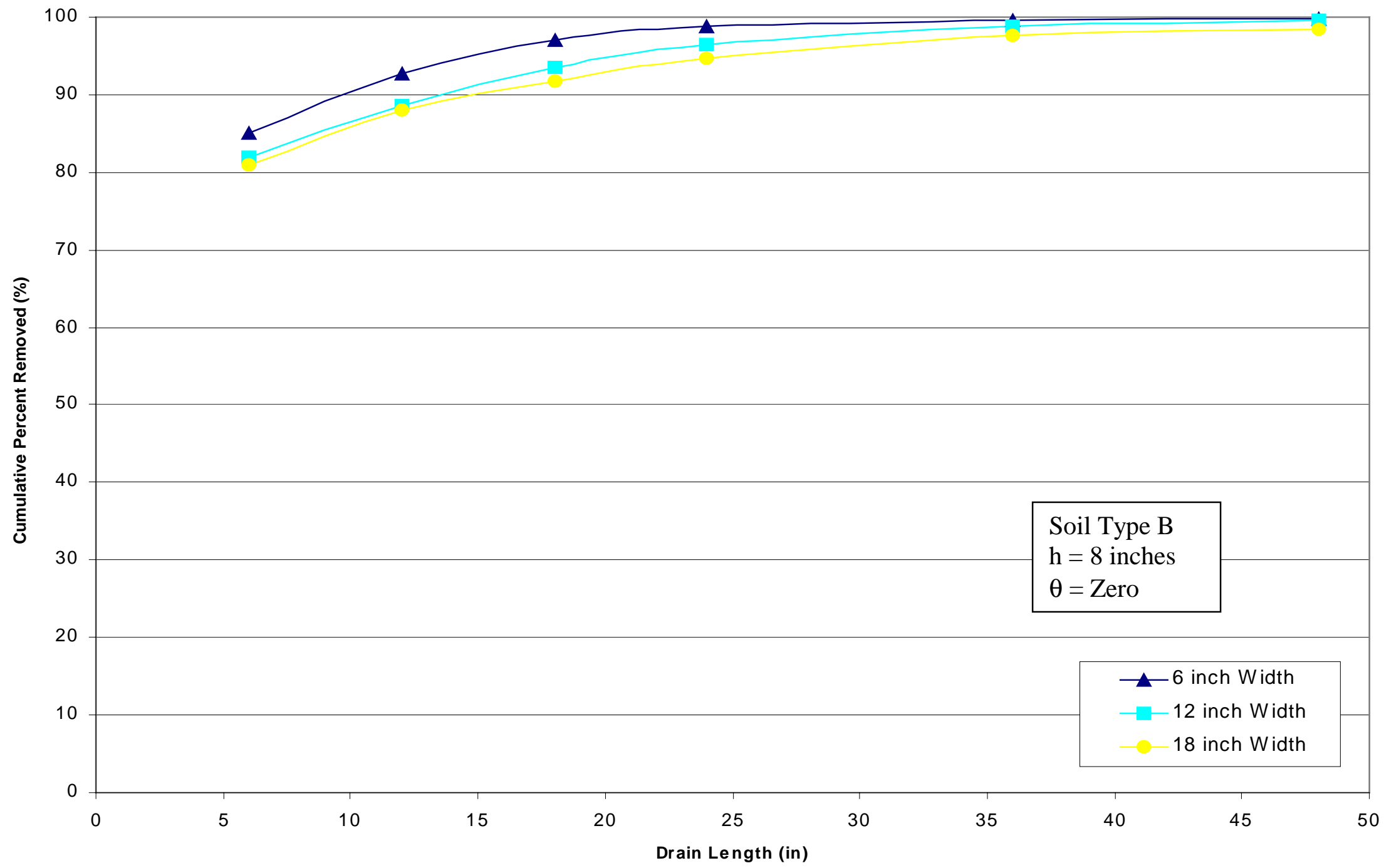

Figure 4.8: Influence of Trench Width for soil Type B with 8" Saturation Depth and Zero Slope Angle. 


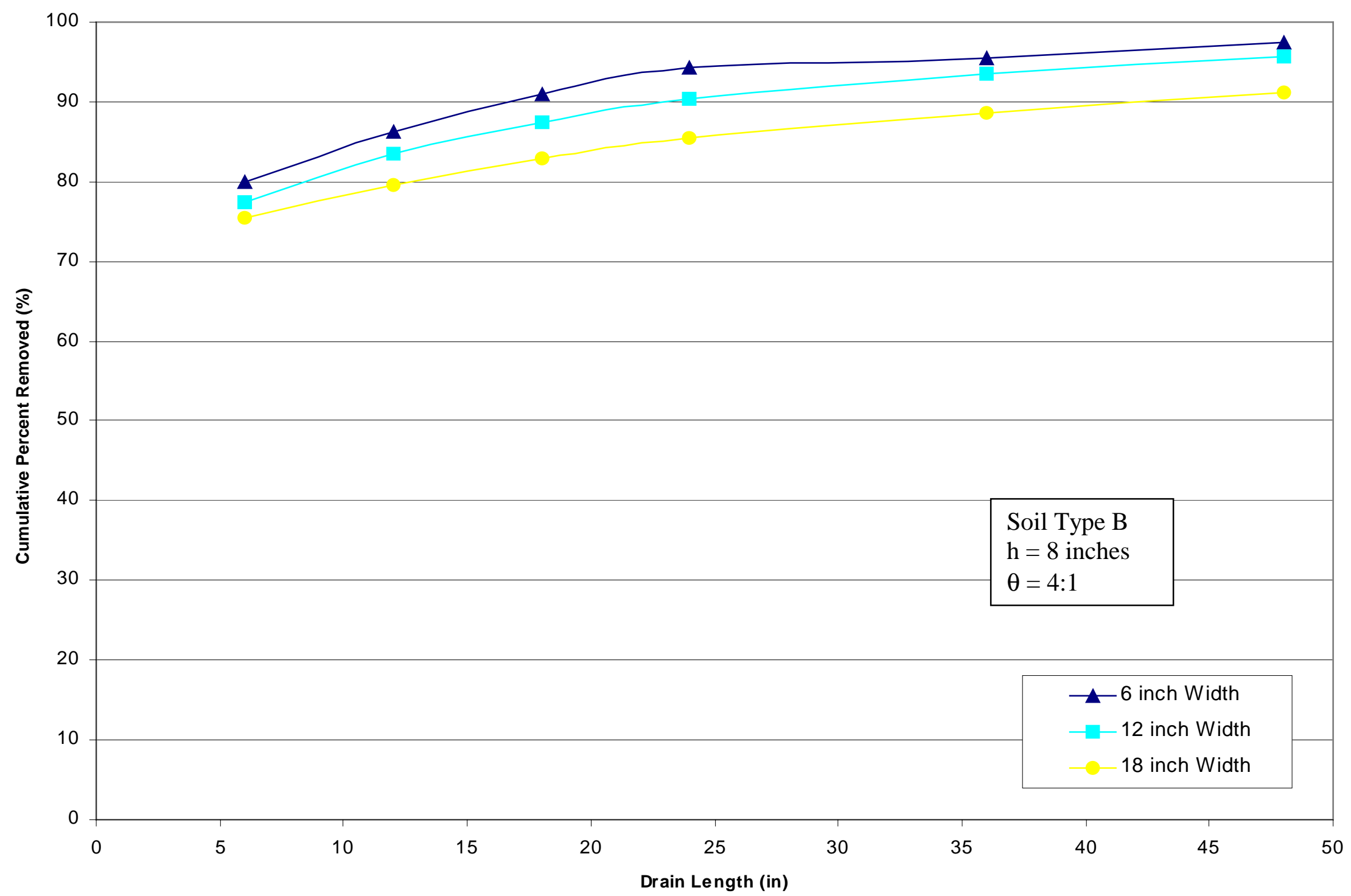

Figure 4.9: Influence of Trench Spacing for soil Type B with 8" Saturation Depth and 4:1 Slope Angle. 


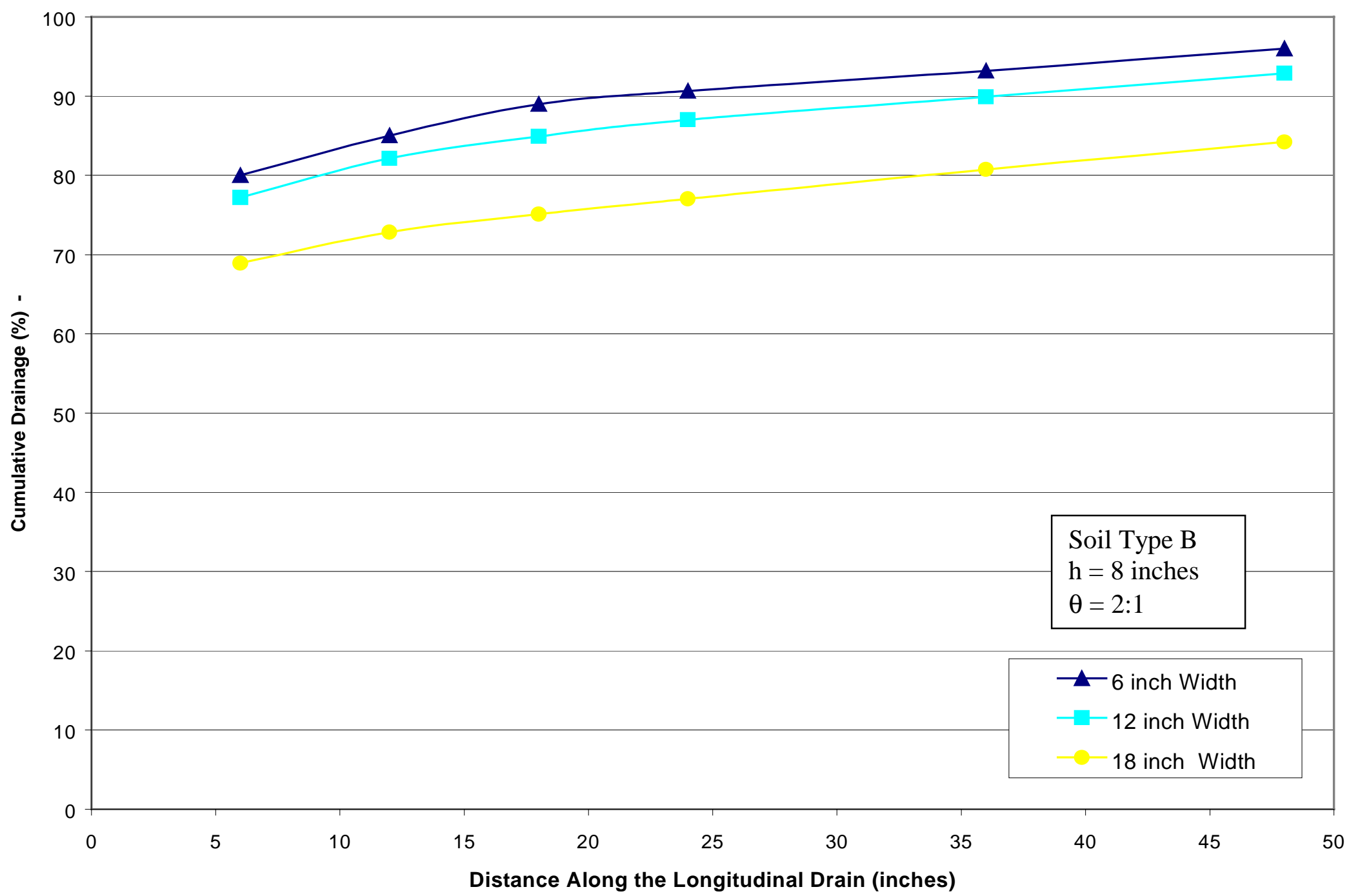

Figure 4.10: Influence of Trench Spacing for soil Type B with 8” Saturation Depth and 2:1 Slope Angle. 


\subsection{INFLUENCE OF SATURATION WATER LEVEL}

\subsubsection{Transient Condition}

Early in the experiments, it was found that the most critical water depth was 8 inches $(20 \mathrm{~cm})$. For this reason, the transient analysis was only performed for this water level. The influences of water levels in the transient fluctuations of flow were not considered in this study.

\subsubsection{Steady State Condition}

Water level (seepage depth) has significant effect on the effectiveness of the longitudinal drain. Figure 4.11 shows the cumulative volume of seepage water collected at 4:1 slope. Other figures showing the effect of water level for different slope angles and trench spacing can be found in Appendix F. The effectiveness of the longitudinal drain is closely related to the water level. The rate of removal of seepage water increases as the water level increases. The volume of water flowing through the soil is much larger when the water level is set at 8 inches $(20 \mathrm{~cm})$ than when it is set to 4 inches $(10 \mathrm{~cm})$. Because the volume is larger the seepage rate also increases.

In Figure 4.11 the total removal of seepage water approaches seventy eight percent for 4 inches $(10 \mathrm{~cm})$ water depth and ninety one percent for 8 inches $(20 \mathrm{~cm})$ of water depth. The overall effectiveness increases almost eight percent between 4 inches $(10 \mathrm{~cm})$ and 6 inches $(15 \mathrm{~cm})$ water levels. This increase is close to thirteen percent when the water level is increased from 4 inches $(10 \mathrm{~cm})$ to 8 inches $(20 \mathrm{~cm})$. These trends show that the effectiveness of longitudinal drains increases as the water level in the soil is increased. Once again the biggest increase can be seen in the first three drains. 


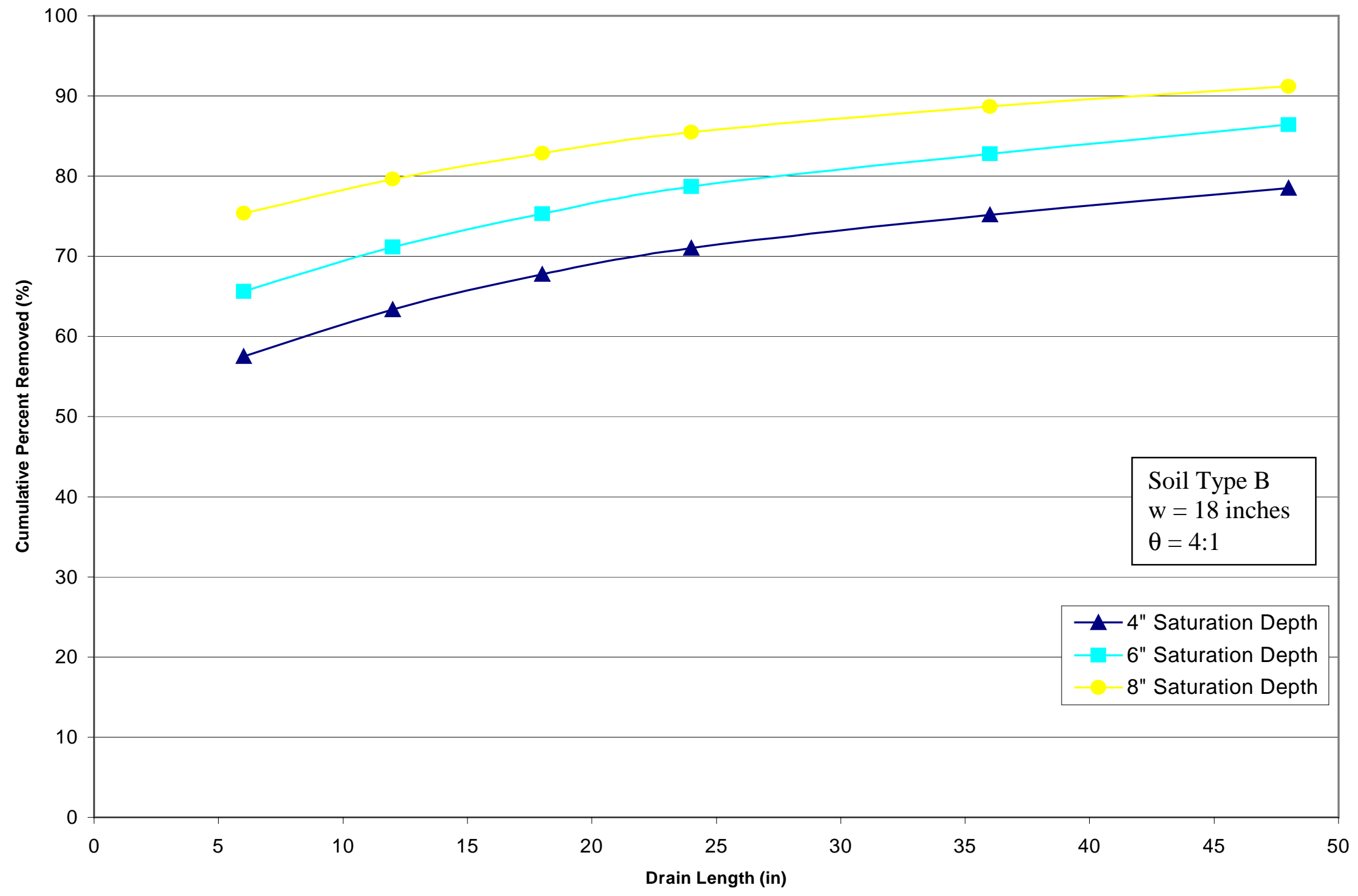

Figure 4.11: Influence of Saturation Depth for soil Type B for 18” Half Trench Spacing and 4:1 Slope Angle. 


\subsection{INFLUENCE OF SOIL TYPE}

\subsubsection{Transient Condition}

At present time, transient condition data is only available for the 12 inches (30 $\mathrm{cm}$ ) trench spacing. The soil type does not have a significant influence on the transitional behavior of the flow patterns. Because the amount of water flowing is smaller and slower in soil with low hydraulic conductivity than that of higher permeability samples, the changes in flow seem to be more evident in low permeability samples. The overall transitional time is still close to one day. The fluctuations corresponding to soil type B are smaller, and occur slower than those for soil type C. Figure 4.12 to 4.15 shows two groups trend lines of volumetric quantities collected at drains one and two for soil types $\mathrm{B}$ and $\mathrm{C}$ at 4:1 inclination angle and 2:1 inclination angle. All four figures show that for soil type $\mathrm{C}$ the flow undergoes its major change earlier than that for soil type $\mathrm{B}$, but in spite of this the flow does not reach a steady state until later. For both type of soils the transition ends after the first day.

Another effect that can be seen is the small "hump" that occurs on the low permeability soil at the first few hours. In all figures for soil type C, flow drops suddenly and then increases toward steady state flow rate. Once the drains are activated, the flow quickly reduces, for both type of soils, but soon after, soil type B begins to stabilize forming a smooth curve while soil $\mathrm{C}$ jumps up forming a hump in the curve.

These effects can be further studied once the current experiments are completed. The figures presented in this section are of importance. However, it is important to note that without the ability to see the combined effects of soil type with soil zone width the 
results are inconclusive at this point. During previous sections it was shown that inclination angle and width affect the effectiveness of the drain. The soil type seems to make the drainage pattern more interesting. For the cases completed so far, the combined effects of slope inclination and soil type can be seen in Figures 4.12 to 4.15 and in Appendix G. 


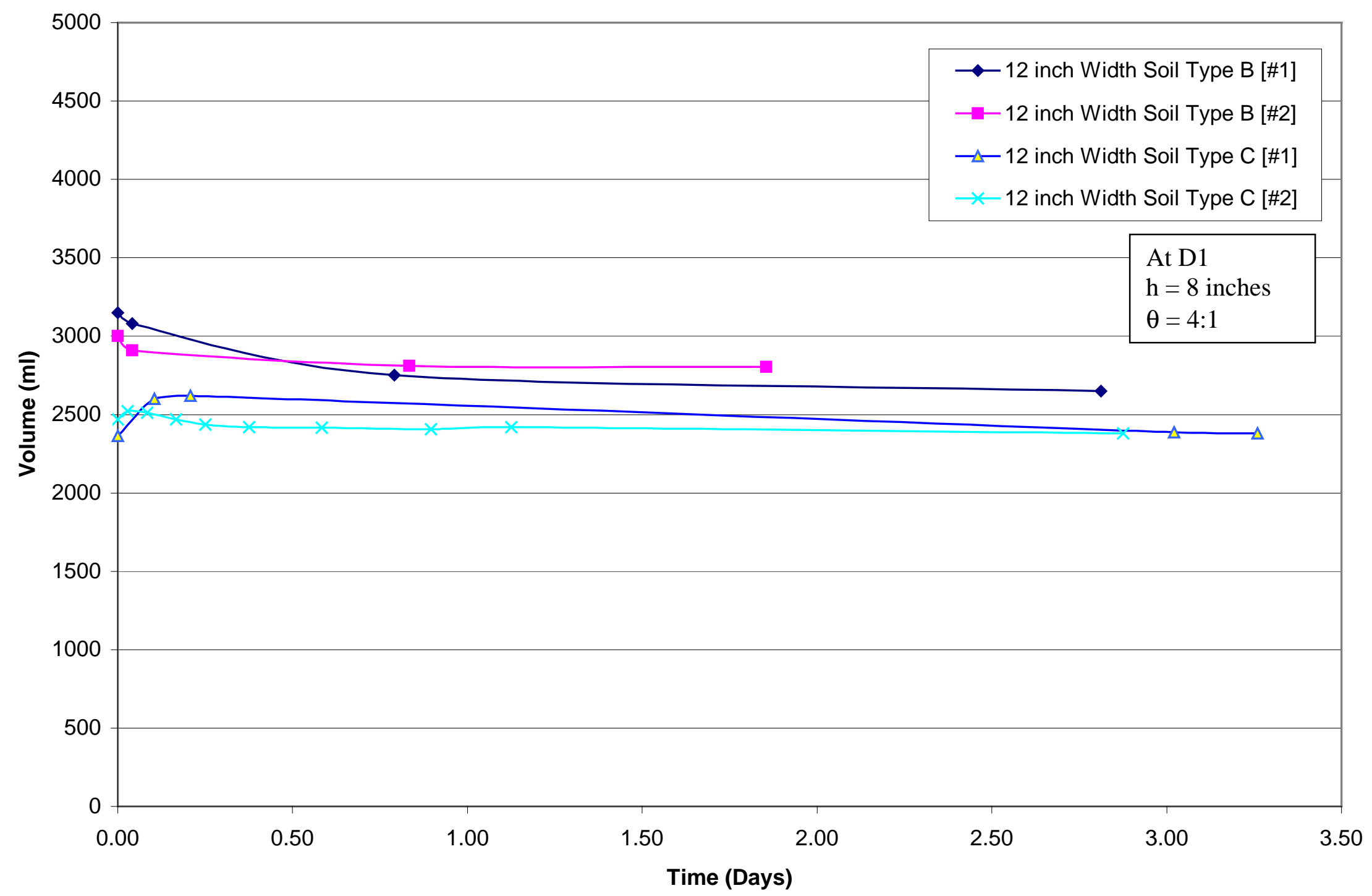

Figure 4.12: Influence of Soil Type under Transient Condition at D1 for 4:1 Slope Angle. 


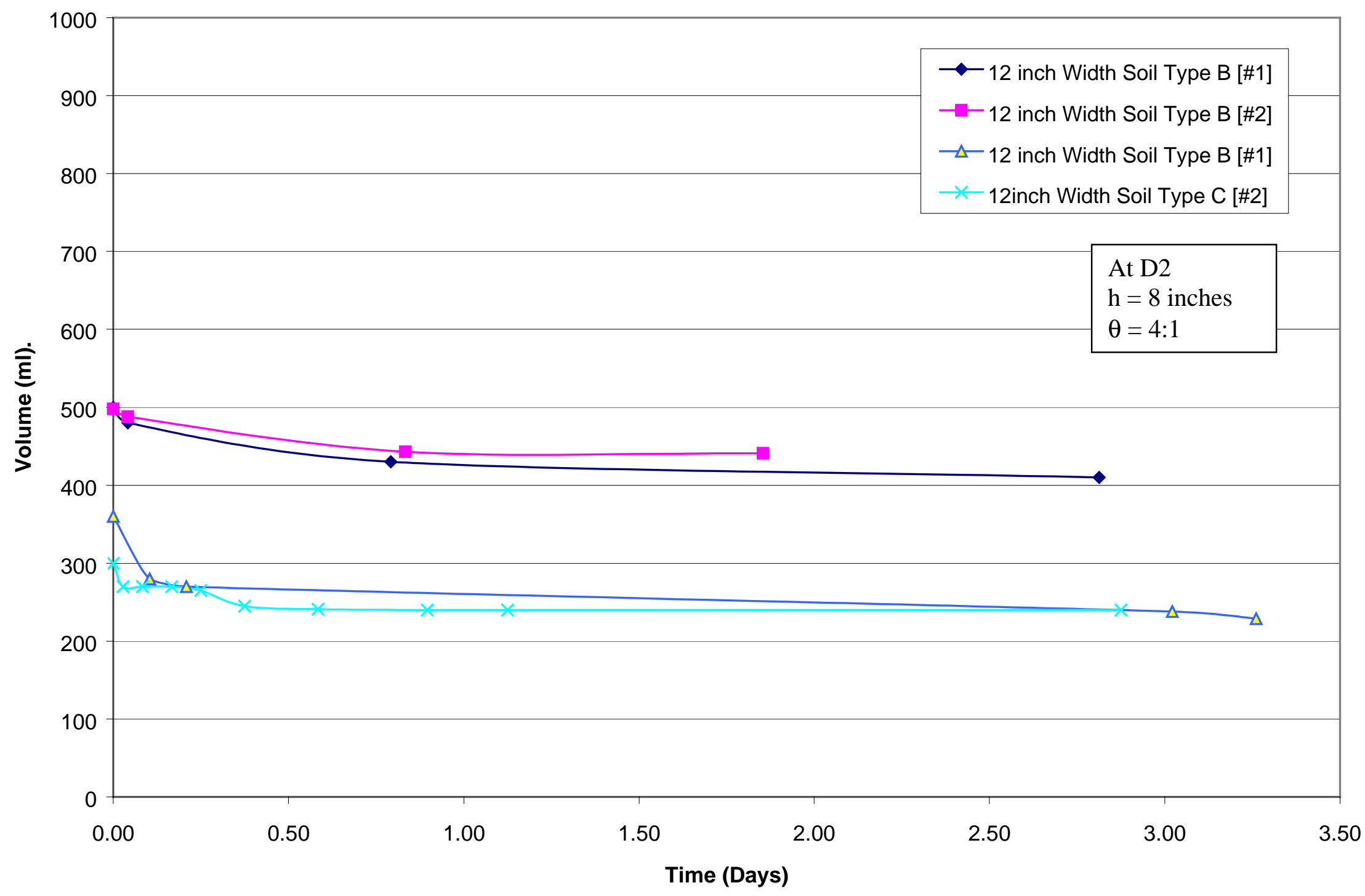

Figure 4.13: Influence of Soil Type under Transient Condition at D2 for 4:1 Slope Angle. 


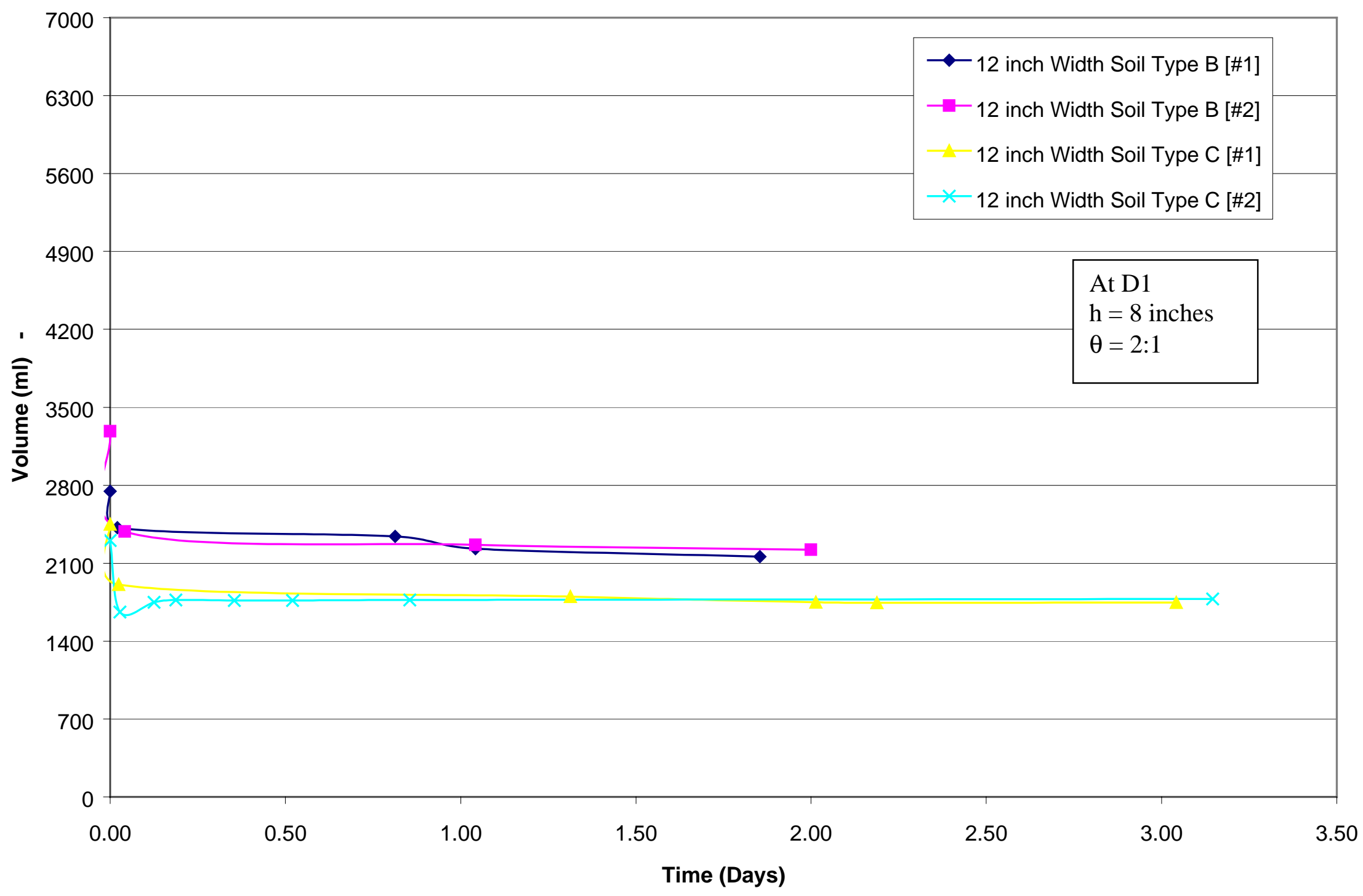

Figure 4.14: Influence of Soil Type under Transient Condition at D1 for 2:1 Slope Angle. 


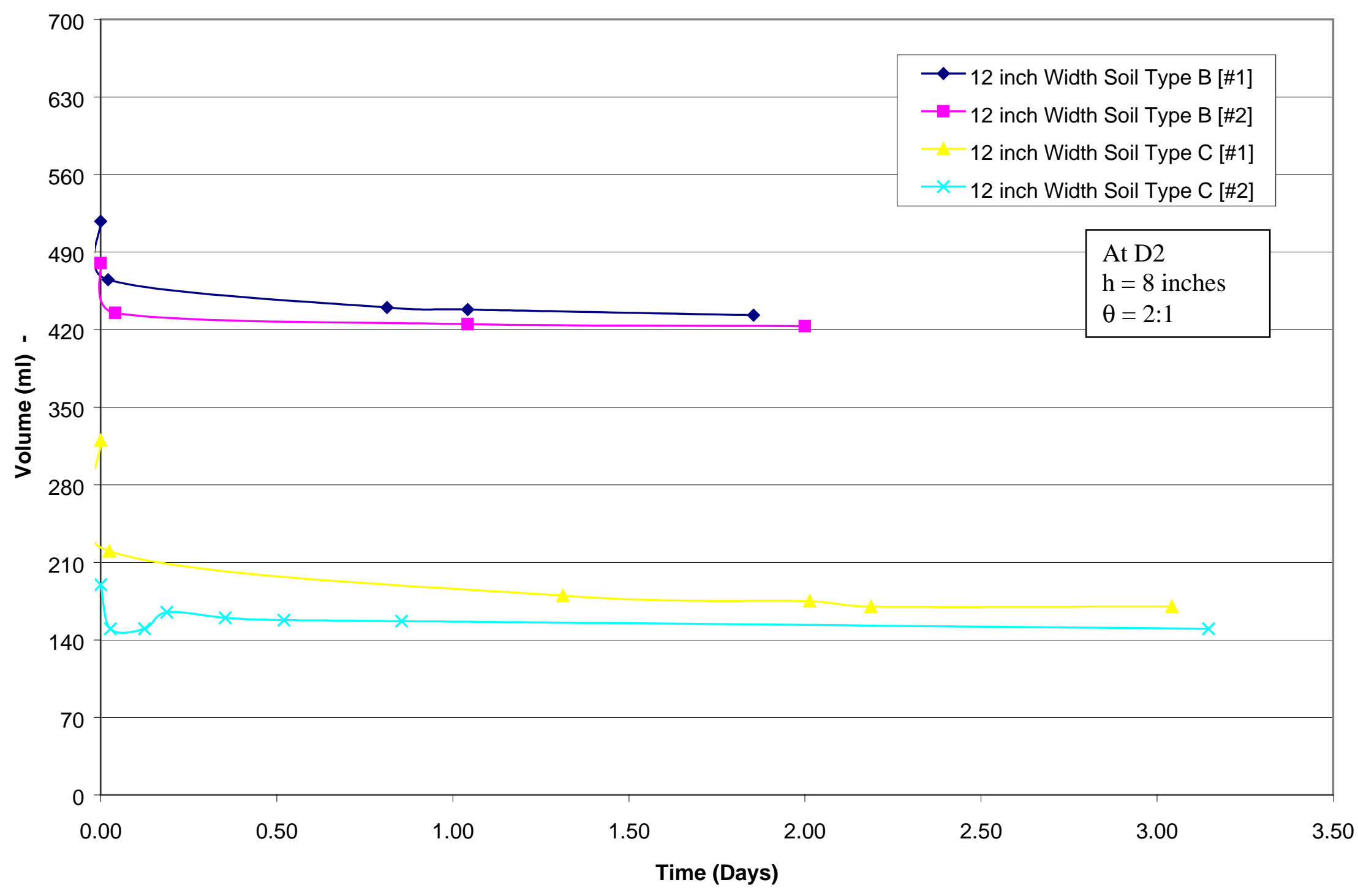

Figure 4.15: Influence of Soil Type under Transient Condition at D2 for 2:1 Slope Angle. 


\subsubsection{Steady State Condition}

The influence of soil type on the behavior of seepage under steady conditions is of great importance. As the hydraulic conductivity of a soil reduces, the resistance for longitudinal flow increases. Because of this resistance, the liquid flowing through the soil tries to find the shortest path. The water flows toward the drain because it poses the least resistance. For this reason, the removal rate dramatically increases in the first drain. Figures 4.16 to 4.27 show trend lines for soils types A and B for half trench spacing of 18 inches $(46 \mathrm{~cm}), 12$ inches $(30 \mathrm{~cm})$ and 6 inches $(15 \mathrm{~cm})$ for horizontal, 2:1, 3:1 and 4:1 inclination slopes. The saturation depth level was kept at $20 \mathrm{~cm}(8$ inches $)$ in all these experiments.

The total removal rate remains almost the same at ninety eight percent. However, there is a difference of almost twenty percent between the trends in the first drain. This difference slowly decreases as the distance along the drain increases. Appendix $\mathrm{H}$ contains experimental results for several other cases. Figure 4.13 to 4.27 and other figures in Appendix $\mathrm{H}$ show that soil samples with lower hydraulic conductivities have higher removal rate. The biggest difference can be seen in the first drain. This drain is the closest to the main water reservoir. At this point the fluid faces three possibilities: go through the soil toward the end drain, change direction toward the longitudinal drain or break through the top surface.

The first drain is more effective for soil type B than for soil type A. However, the rest of the drains become less effective when compared to soil A. In the case of soil B, the difference between drain one and two is only of about six percent, while for soil A the difference is about fifteen percent. 
Longitudinal drains are most effective with soils with low permeability. Once the drain is installed the possibility of landslides is reduced because the water level is reduced so the seepage force pushing the soil decreases. The influence of soil type on longitudinal drains is also related to all other factors. The spacing between longitudinal drains, the water level entering the soil and the inclination of the slope have an impact on the relationship between hydraulic conductivity and removal rate of water.

Another important factor is that at low hydraulic conductivity the volume of water flowing through the soil at any given time is smaller that that of a soil with greater permeability. Although the effectiveness of the longitudinal drain increases the amount of water collected decreases.

The overall influence of the soil type is very similar to the influence of the water level. The percentage of drainage increases, but the actual volumes of water decrease. 


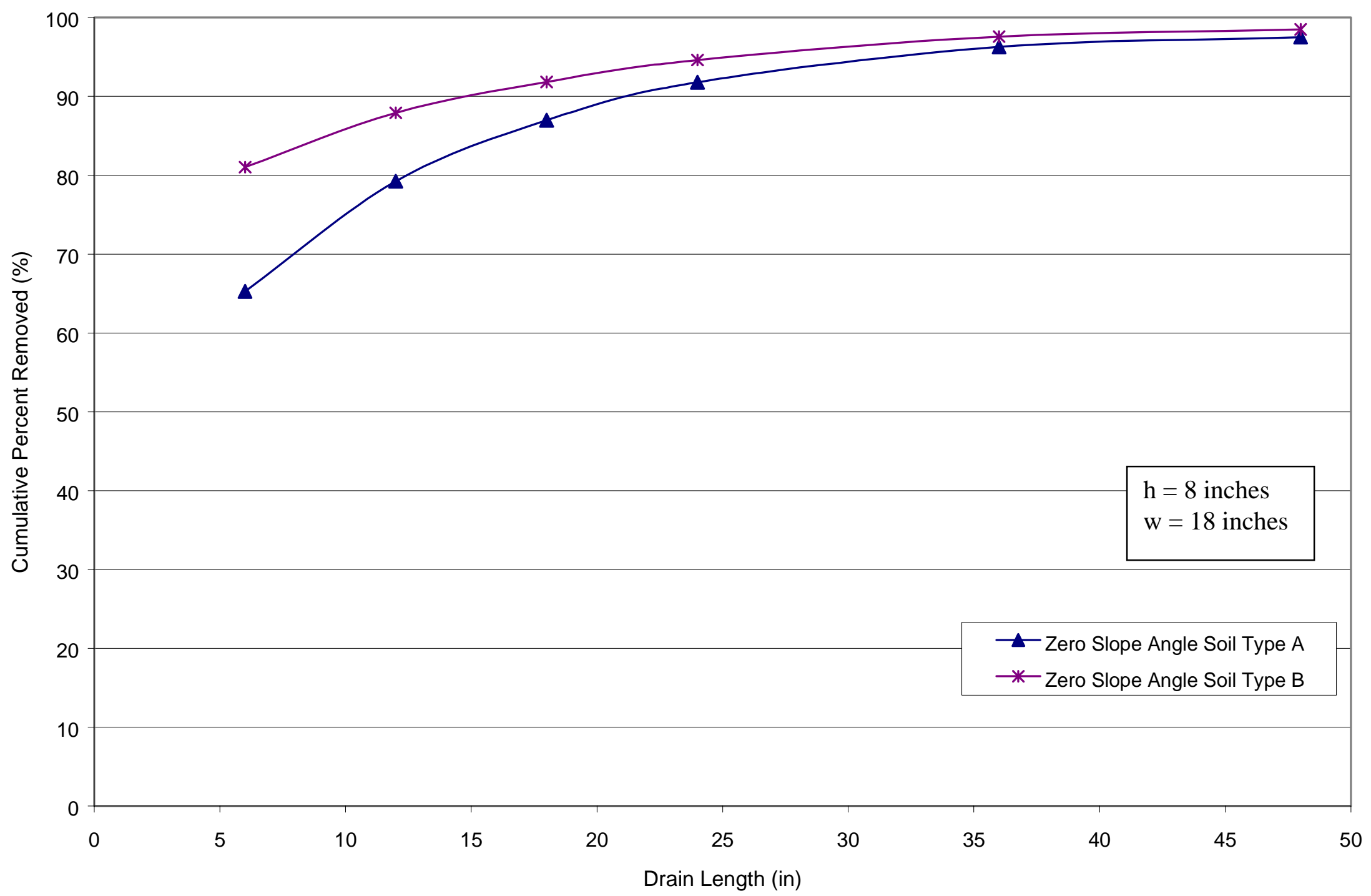

Figure 4.16: Influence of Soil Type for 8" Saturation Depth and 18" Half Trench Spacing. 


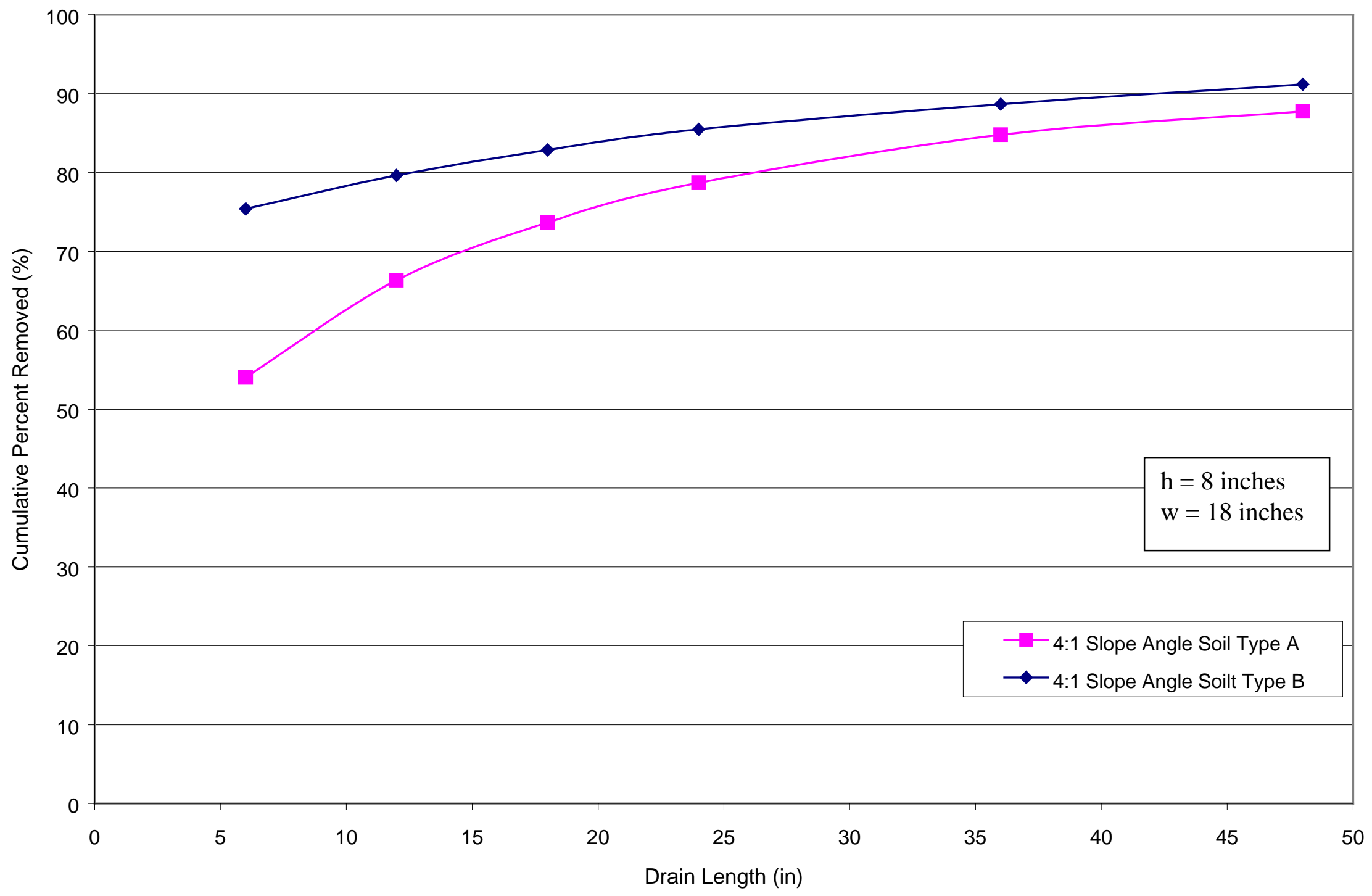

Figure 4.17: Influence of Soil Type for 8" Saturation Depth and 18" Half Trench Spacing. 


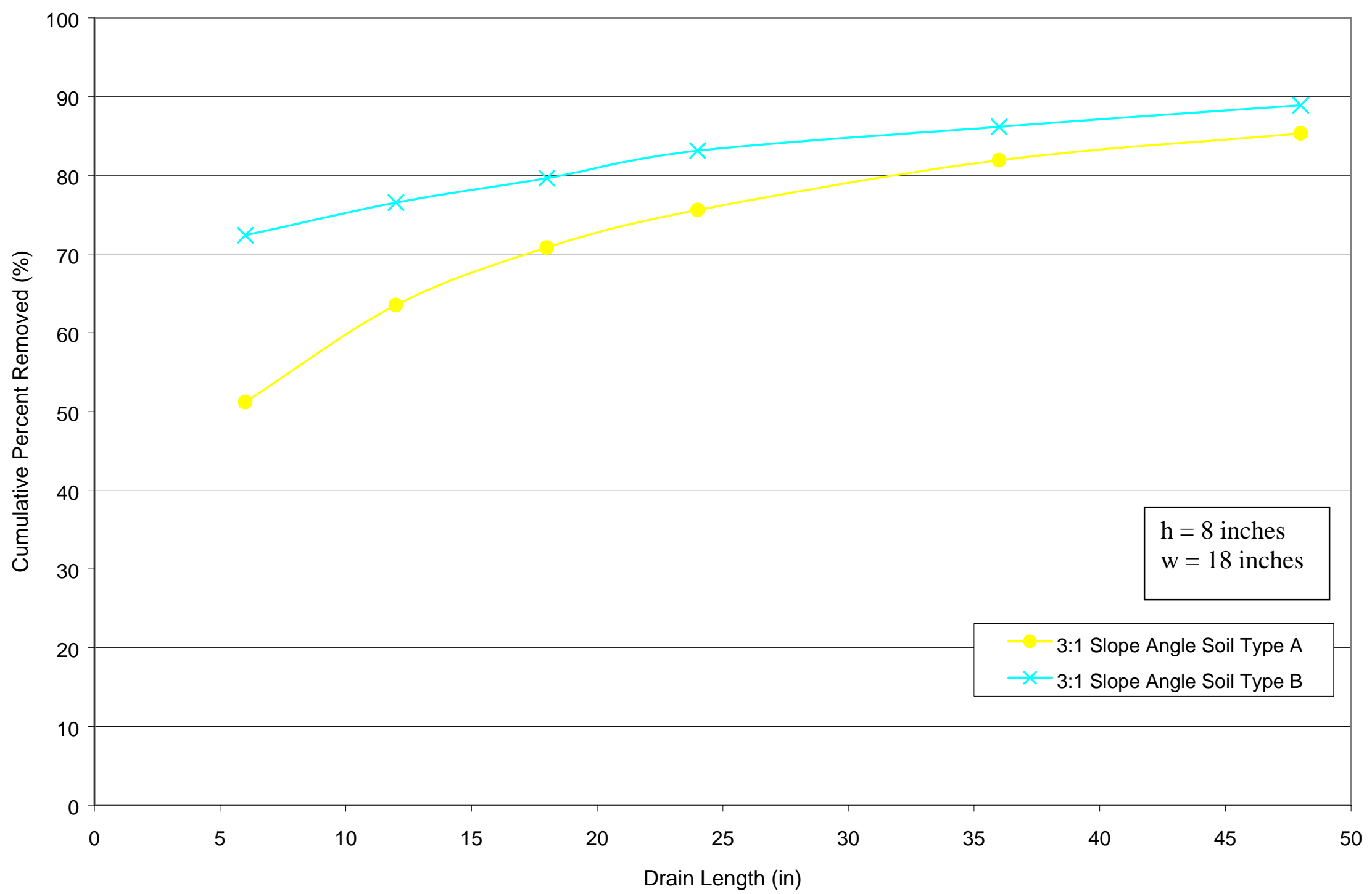

Figure 4.18: Influence of Soil Type for 8" Saturation Depth and 18" Half Trench Spacing. 


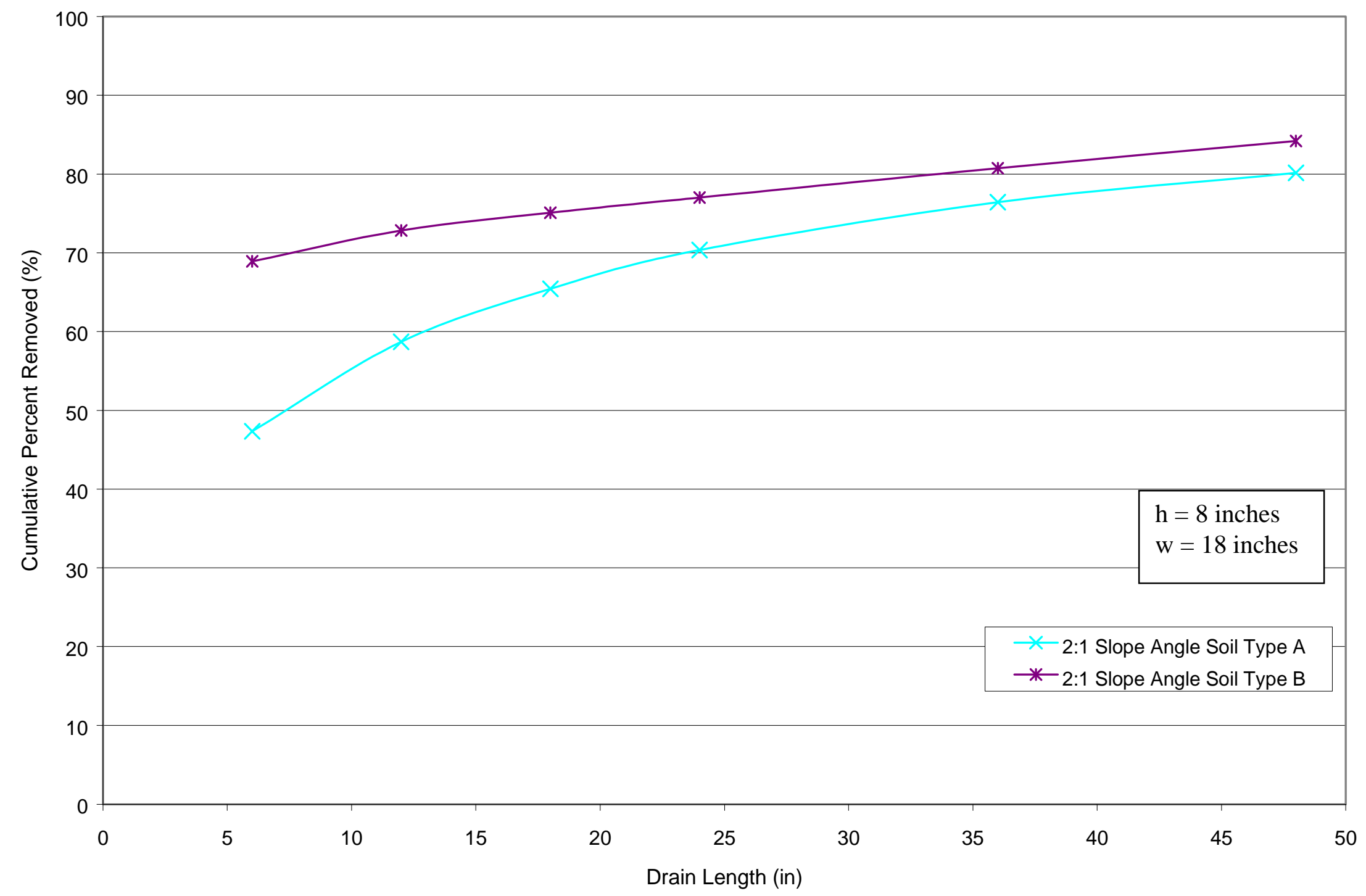

Figure 4.19: Influence of Soil Type for 8" Saturation Depth and 18" Half Trench Spacing. 


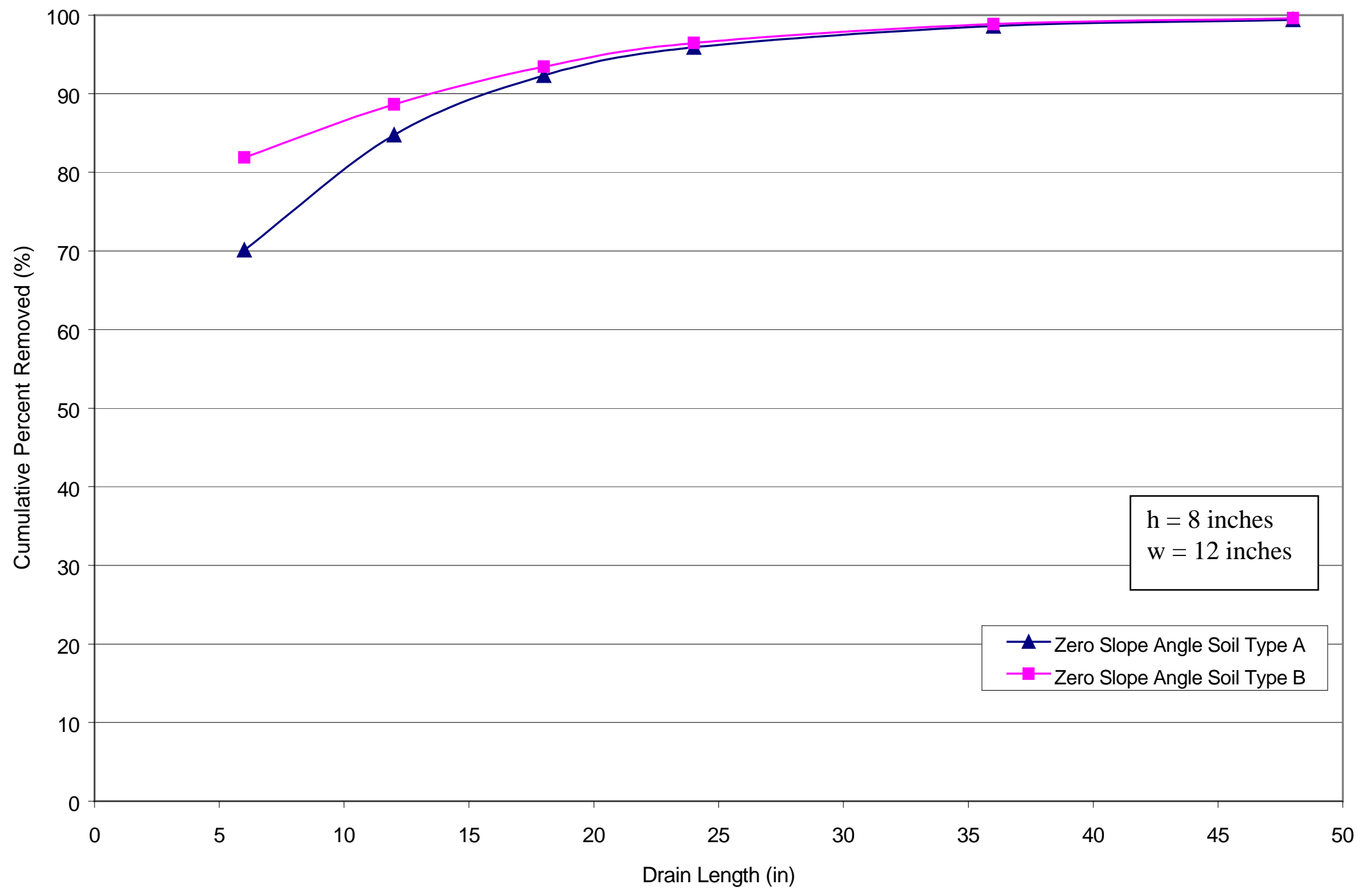

Figure 4.20: Influence of Soil Type for 8" Saturation Depth and 12" Half Trench Spacing. 


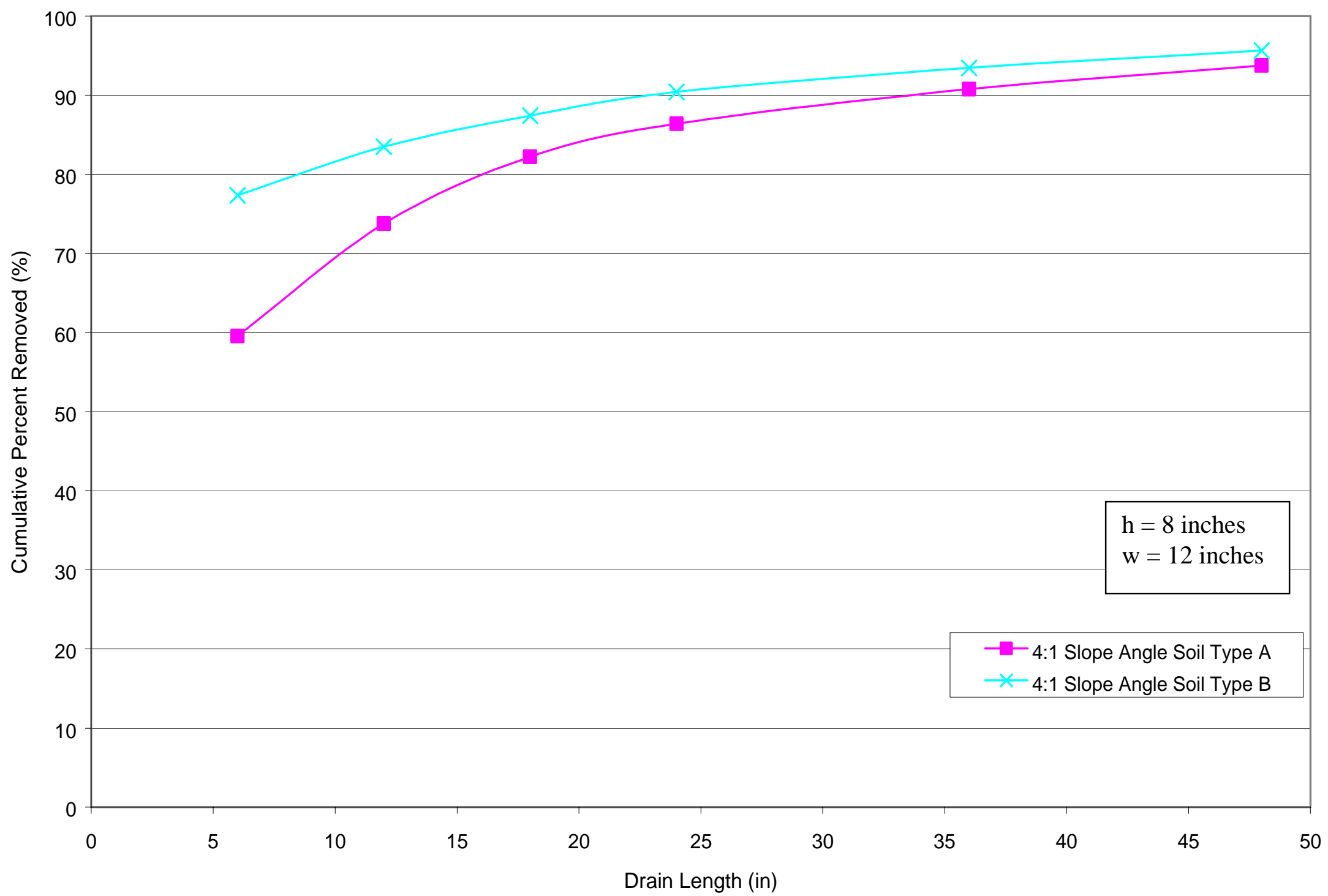

Figure 4.21: Influence of Soil Type for 8" Saturation Depth and 12" Half Trench Spacing. 


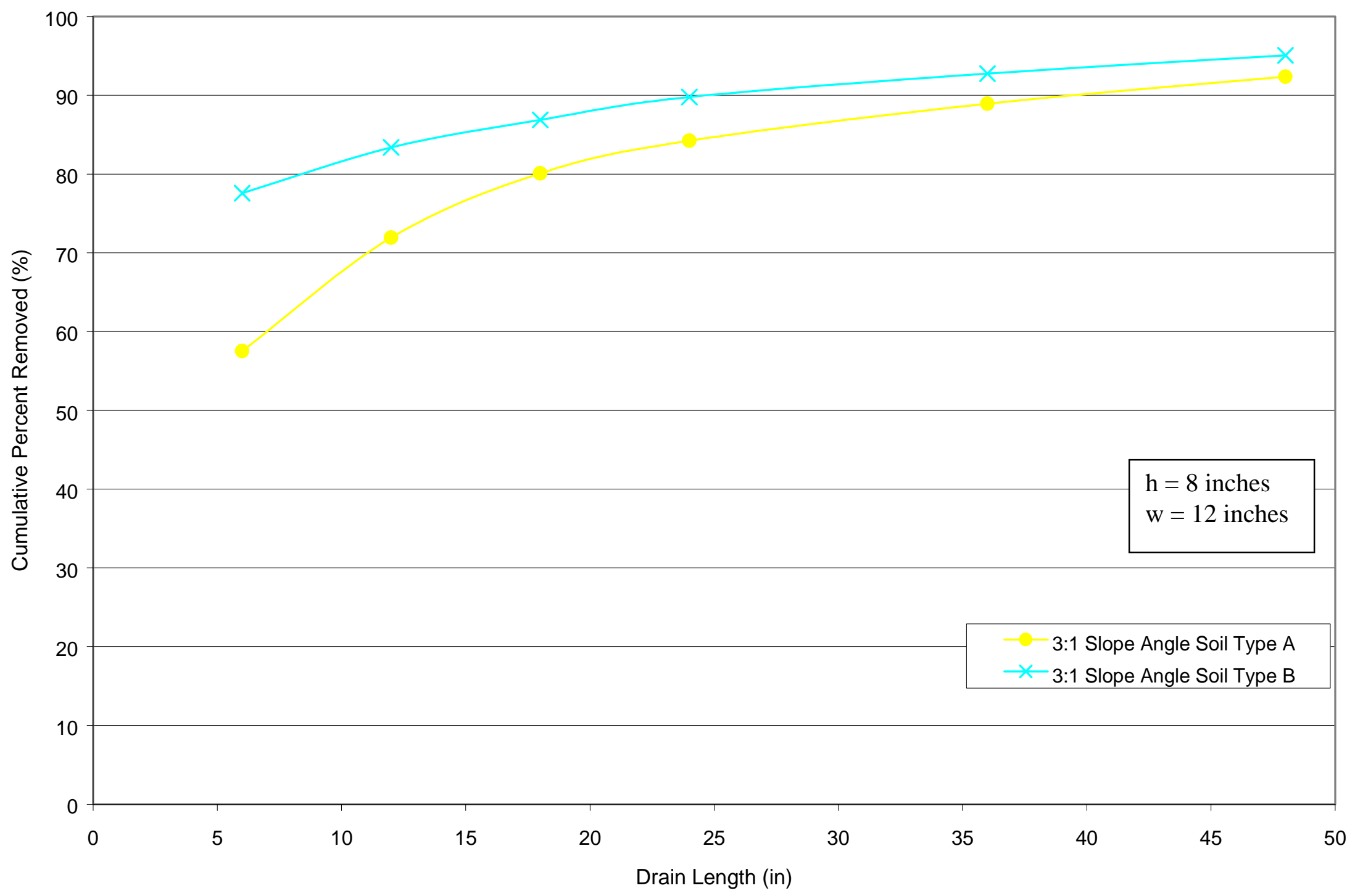

Figure 4.22: Influence of Soil Type for 8" Saturation Depth and 12" Half Trench Spacing. 


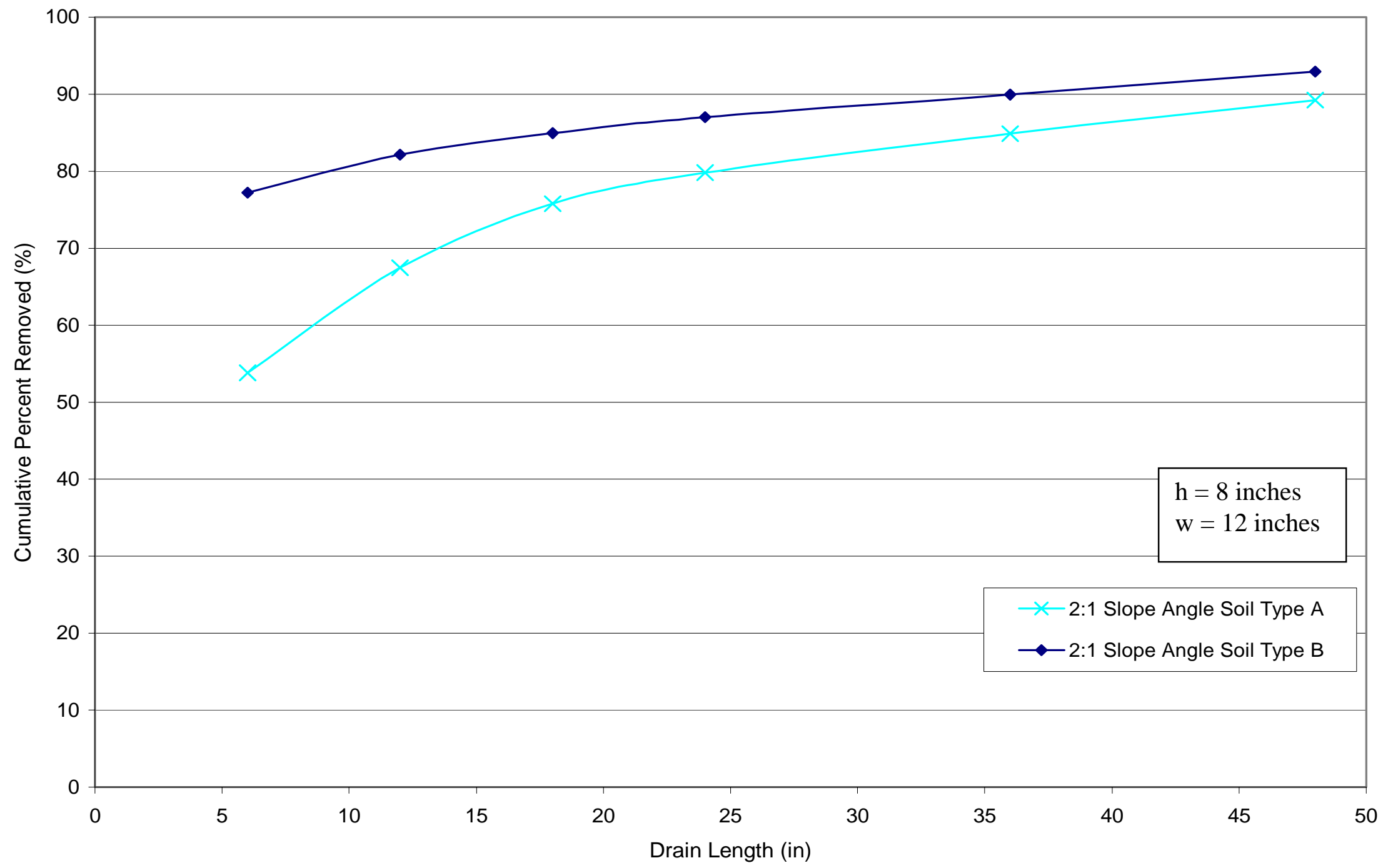

Figure 4.23: Influence of Soil Type for 8" Saturation Depth and 12" Half Trench Spacing. 


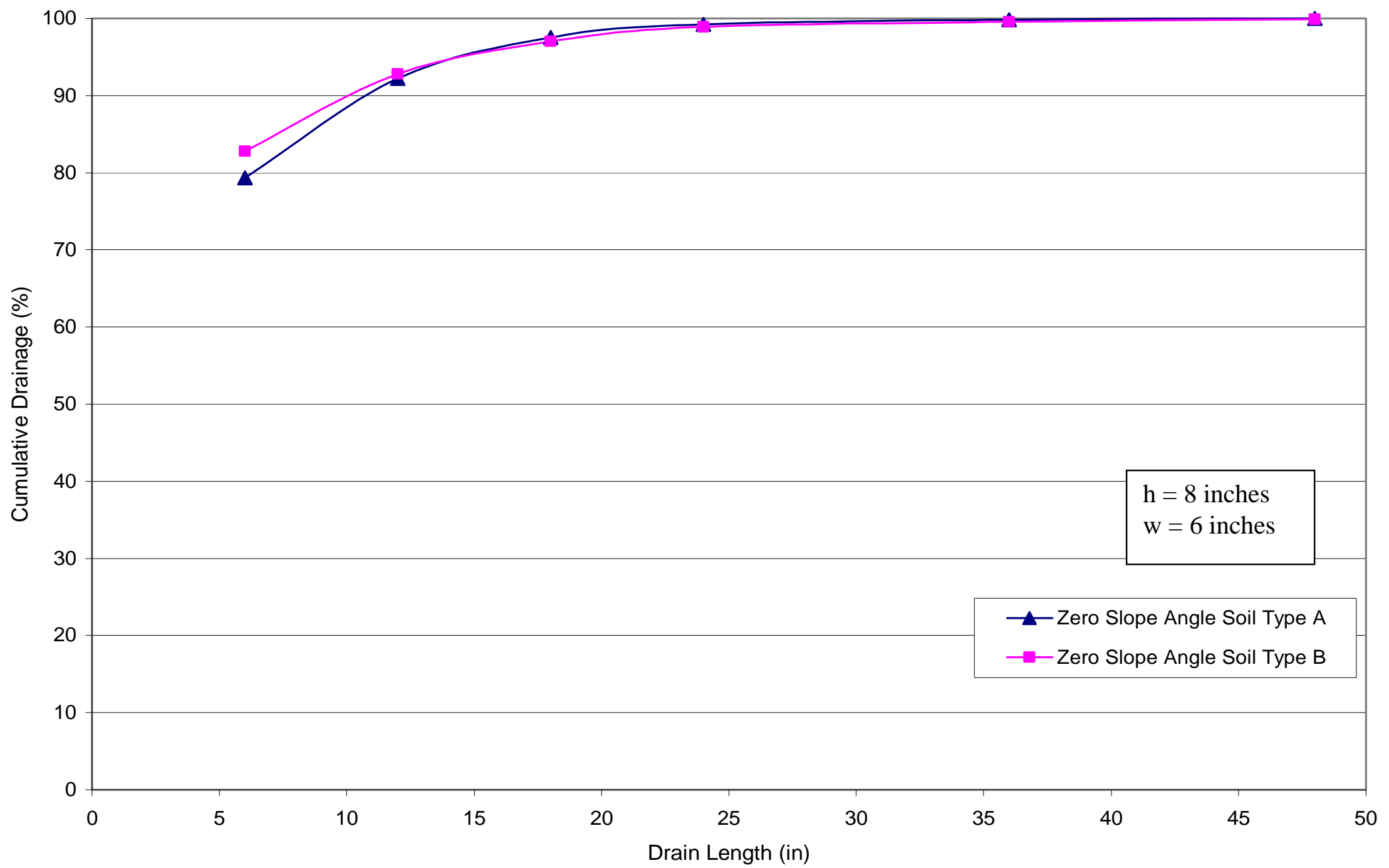

Figure 4.24: Influence of Soil Type for 8" Saturation Depth and 6" Half Trench Spacing. 


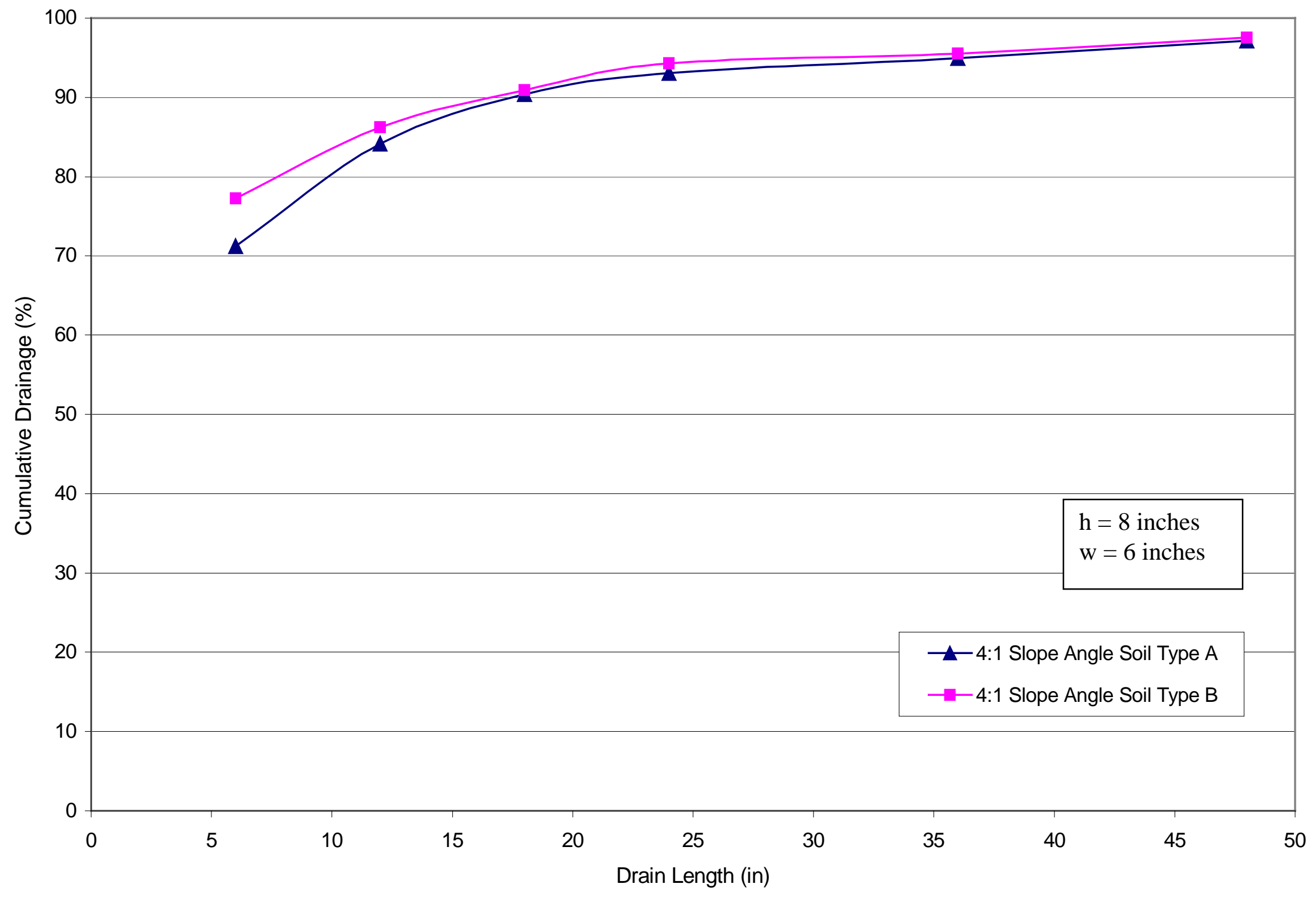

Figure 4.25: Influence of Soil Type for 8" Saturation Depth and 6" Half Trench Spacing. 


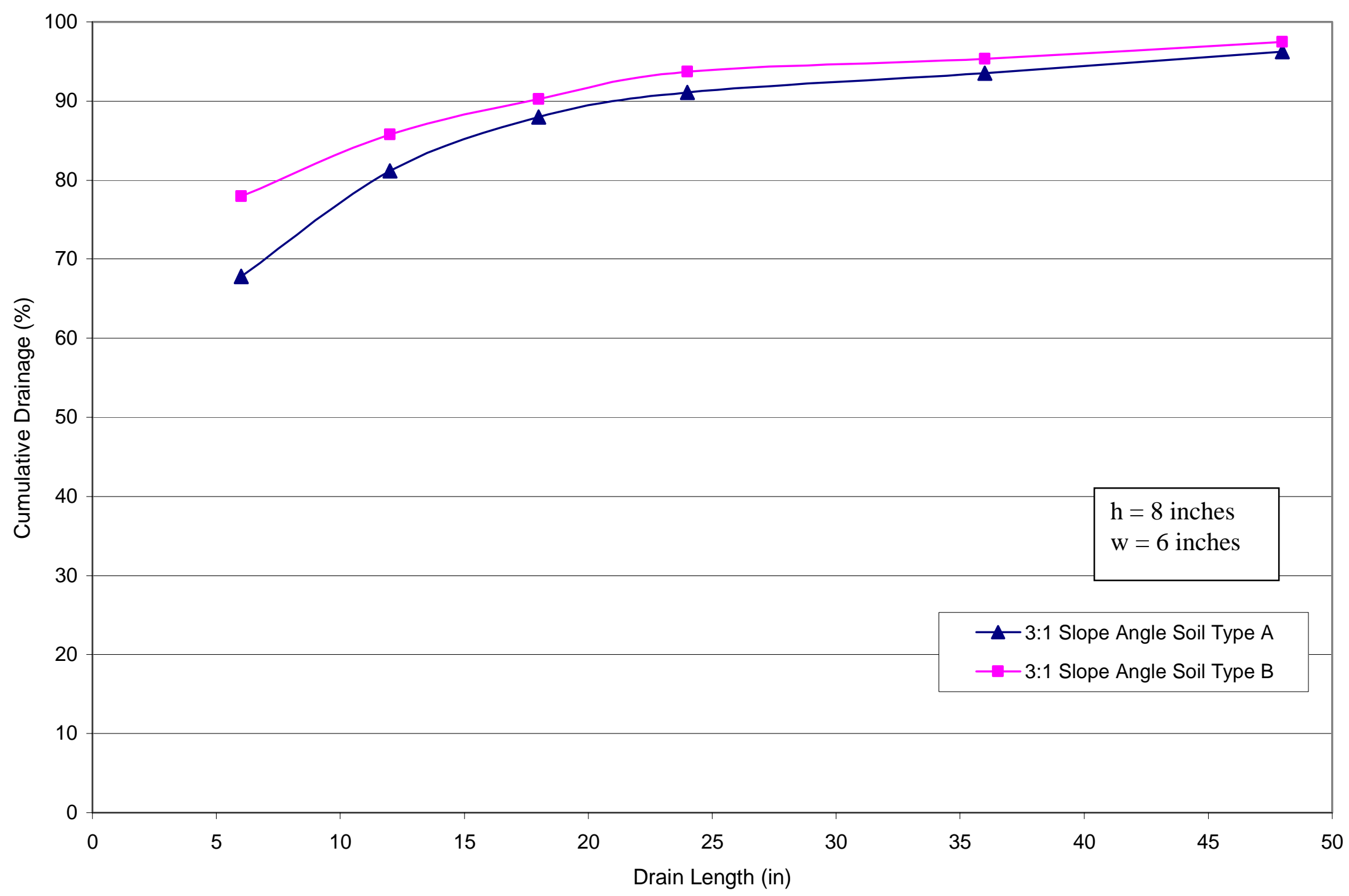

Figure 4.26: Influence of Soil Type for 8" Saturation Depth and 6" Half Trench Spacing. 


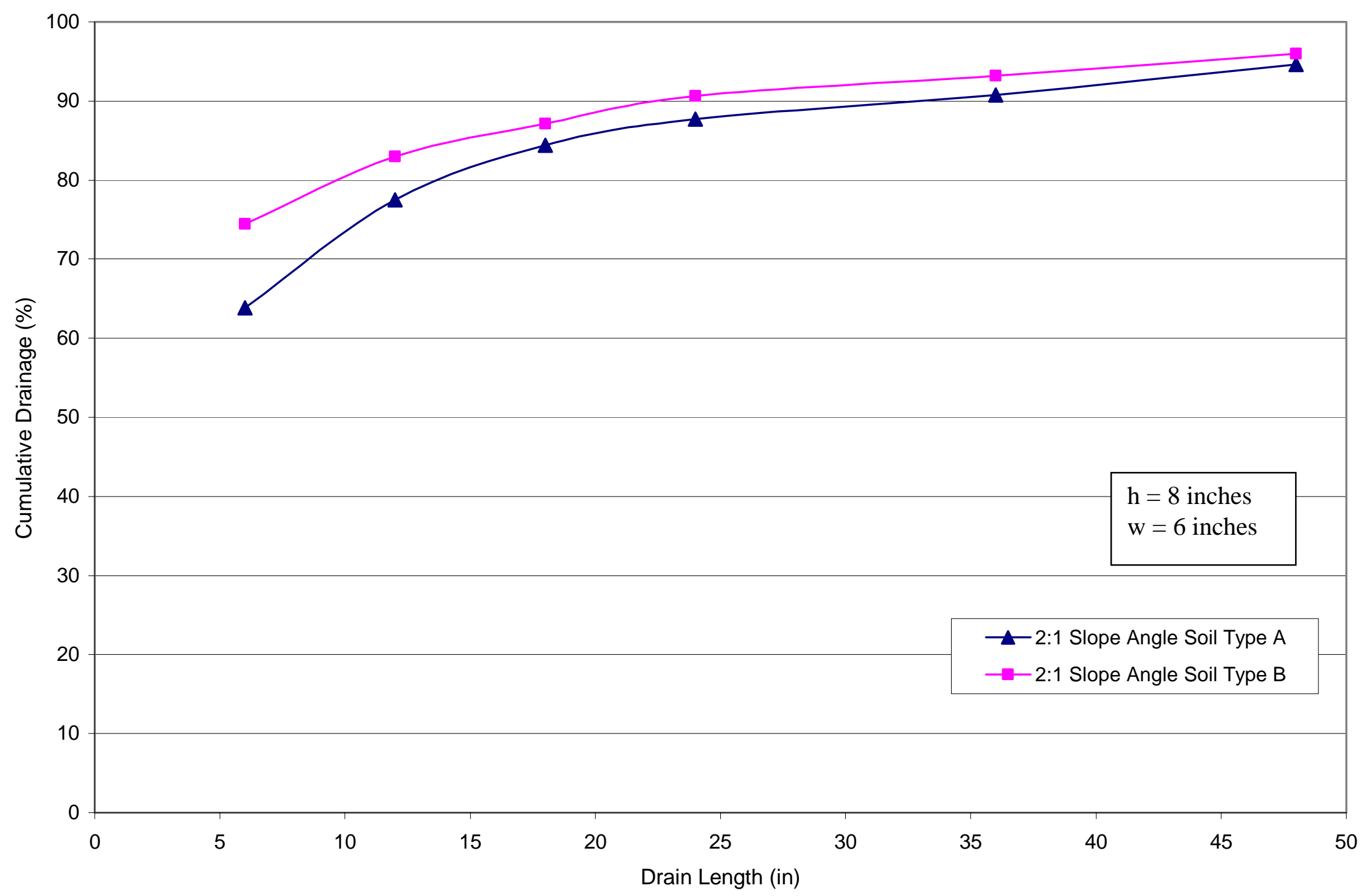

Figure 4.27: Influence of Soil Type for 8" Saturation Depth and 6" Half Trench Spacing. 


\subsection{VOLUMETRIC ANALYSIS OF TRANSIEN STATE}

In this section the amount of seepage water removed at each individual drain is studied. The behavior of flow into individual drains was observed over a period of time greater than two days. Figures in Appendix G show variation of drainage with time. In these figures, volumes instead of cumulative percentages are used to study the changes that occur during the transitional period. This transitional period ends when the flow stabilizes. Figure 4.28 shows the transition for all drains for the soil type B $\left(10^{-4} \mathrm{~cm} / \mathrm{s}\right.$ hydraulic conductivity) for a slope of 4:1, a water depth level of 8 inches $(20 \mathrm{~cm})$ and a half trench spacing of 18 inches $(46 \mathrm{~cm})$. This figure as well as the other figures in Appendix G show that the flow undergoes a dramatic change during the first few hours. After a period of one day the flow is almost stable.

All other factors affecting the cumulative percentages (inclination, soil type, and trench spacing) also affect the drainage volumes in individual drains. The time period for the transitional flow does not change. Depending on other factors the fluctuation of drainage volumes may be higher or lower, but they tend to happen at similar times. The stabilization period remains unchanged.

The most influential factor affecting the volumetric flow is the water level. The volume of water collected in each drain increases as the water level increases. When the trench spacing is reduced the volumes also reduce, but in a previous section it was shown that the effectiveness increased. The reason for this is simple. In the previous case, percentage of drainage was considered, taking into account the overall volume flowing through the soil. Although the effectiveness of the drain is better for smaller trench spacing the seepage volumes collected are smaller. 


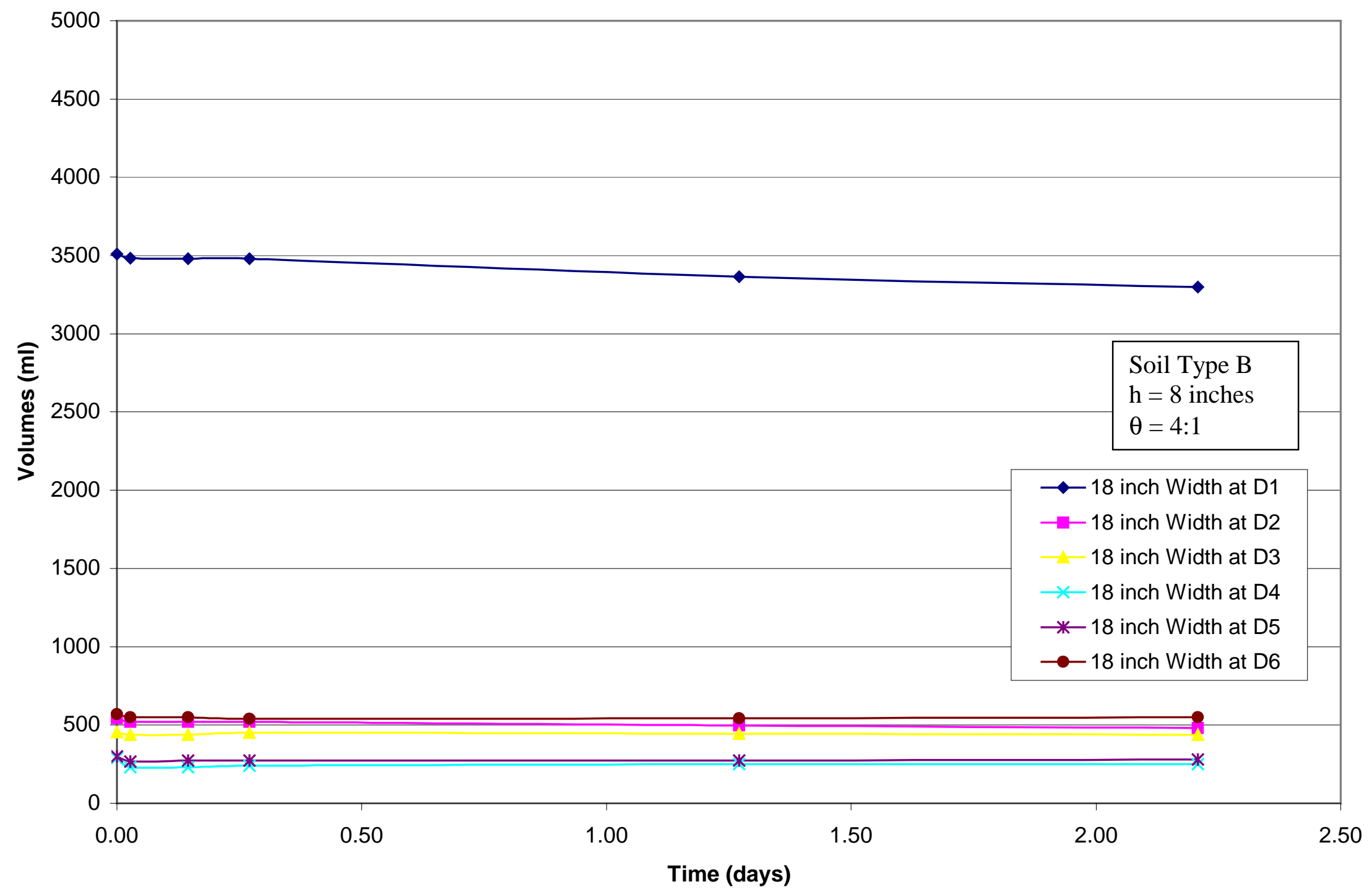

Figure 4.28: Volumetric Analysis of All Drains for 8" Saturation Depth and 4:1 Slope Angle. 


\subsection{PIEZOMETRIC DATA}

\subsubsection{Transient State Condition}

The piezometric head is influenced by the installation of longitudinal drains. Once the drainage of the soil sample begins the piezometric head decreases. Figures 4.29 through 4.34 show the transition pattern of the piezometric head for soil type B at the transverse section at $\mathrm{X}$ (12 inches from water tank). These trends show that the water profile drops down gradually with time. Soon after the drains are activated the water profile drops quickly. The drop in the water profile after one day becomes negligible. The water profile at time zero (before opening the drains) is almost a flat line. Soon after the drains are activated the water level drops but the changes become less noticeable.

Figures 4.29 and 4.30 show piezometric head for a soil specimen of 18 inches width at 4:1 slope angle and 2:1 slope angle, respectively. Figures 4.31 and 4.32 show piezometric head for a soil specimen of 12 inches width at 4:1 slope angle and 2:1 slope angle, respectively. Figures 4.33 and 4.34 show piezometric head for a soil specimen of 6 inches width at 4:1 slope angle and 2:1 slope angle, respectively. All these figures show the same trend. 


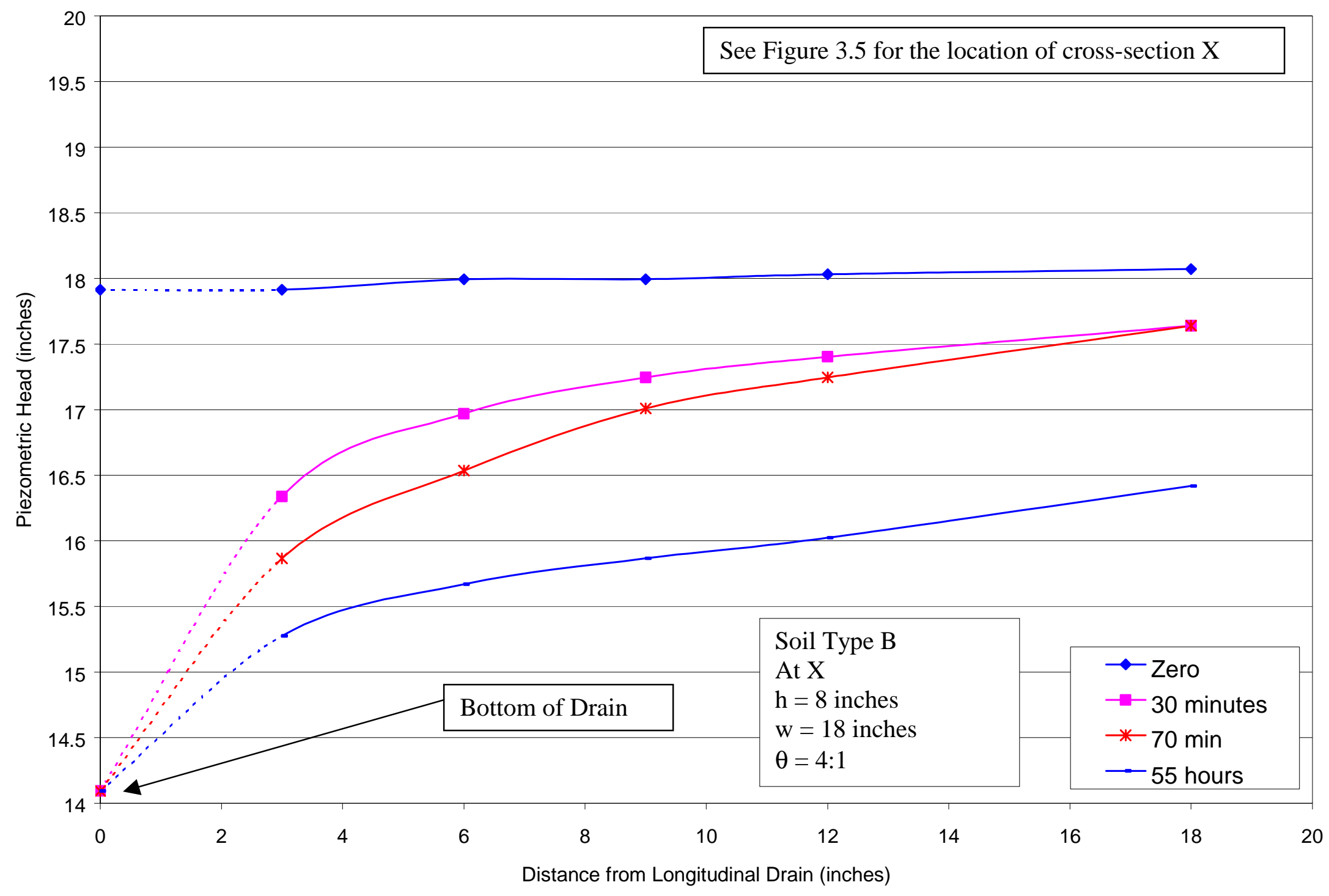

Figure 4.29: Variation of Piezometric Head at Cross-section $X$ for $w=18$ inches and 4:1 Slope Angle. 


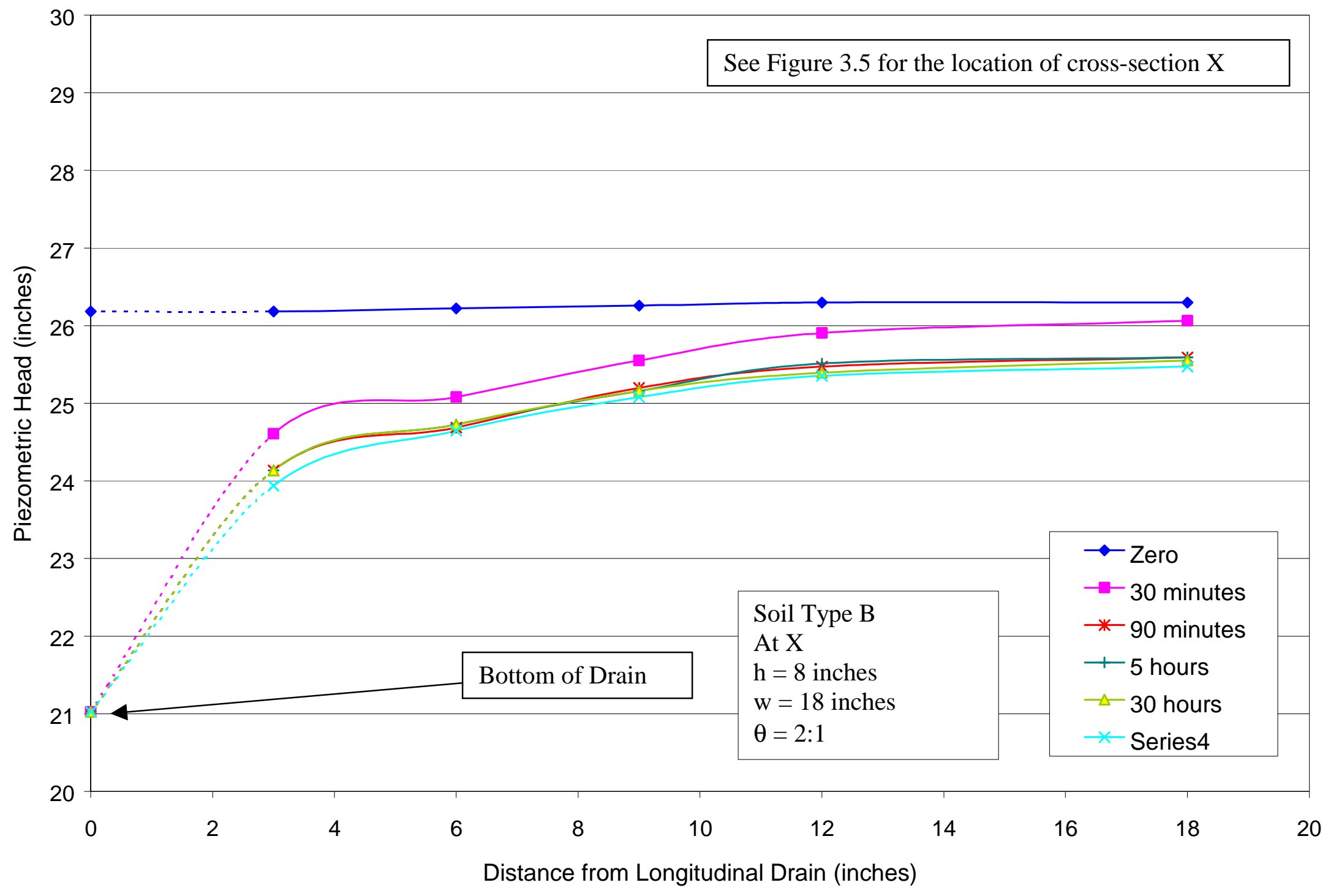

Figure 4.30: Variation of Piezometric Head at Cross-section X for $\mathrm{w}=18$ inches and 2:1 Slope Angle. 


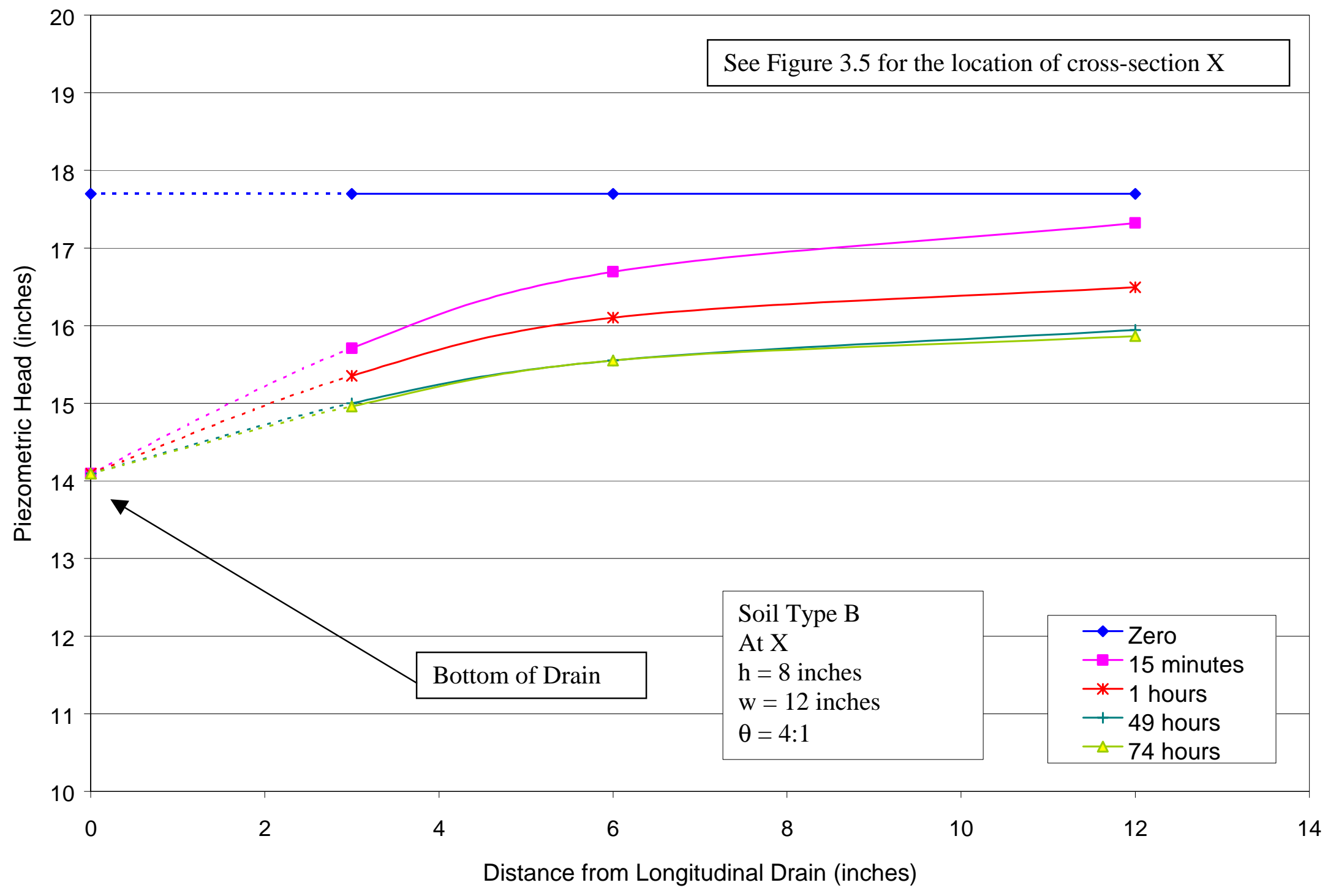

Figure 4.31: Variation of Piezometric Head at Cross-section X for $\mathrm{w}=12$ inches and 4:1 Slope Angle. 


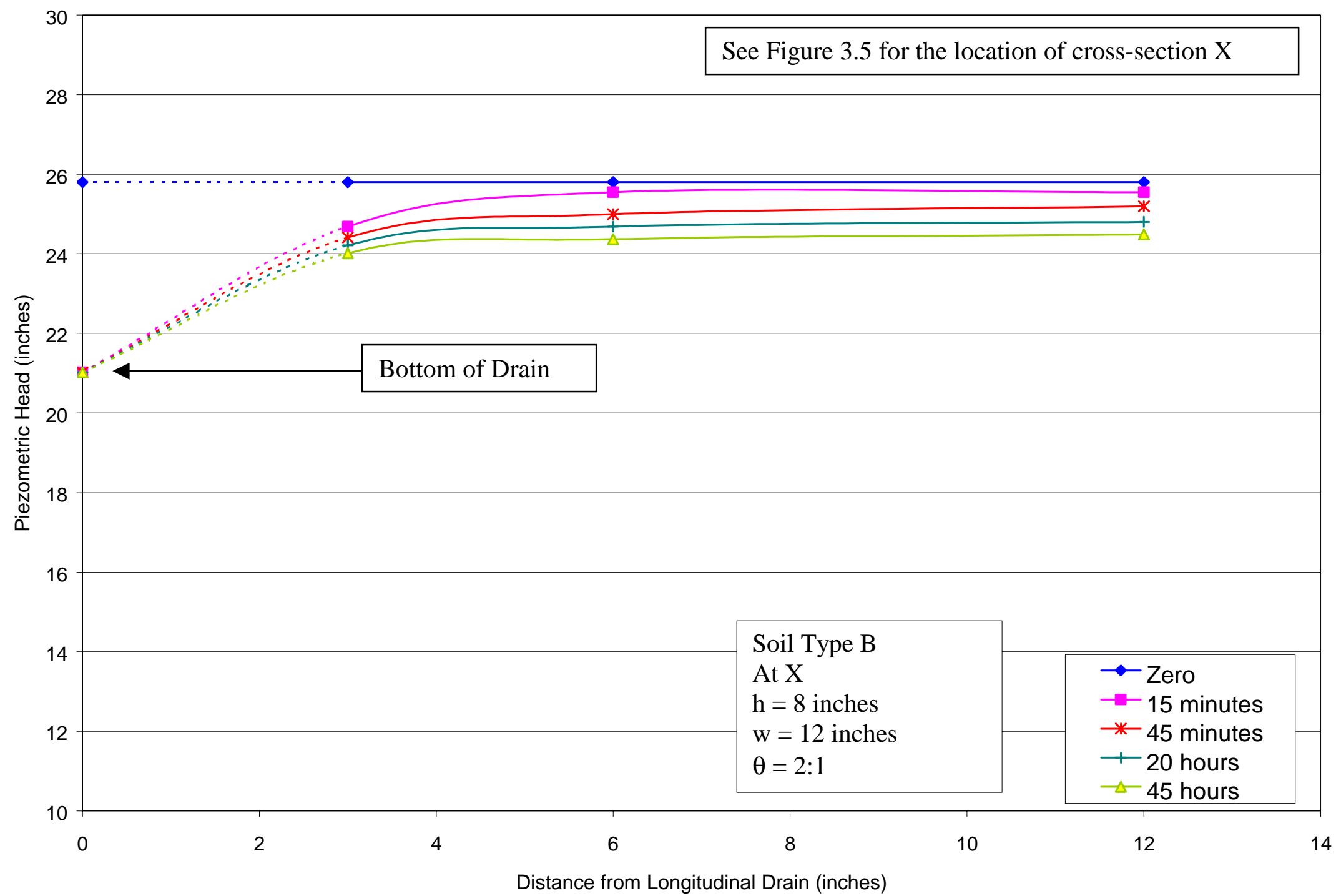

Figure 4.32: Variation of Piezometric Head at Cross-section X for $\mathrm{w}=12$ inches and 2:1 Slope Angle. 


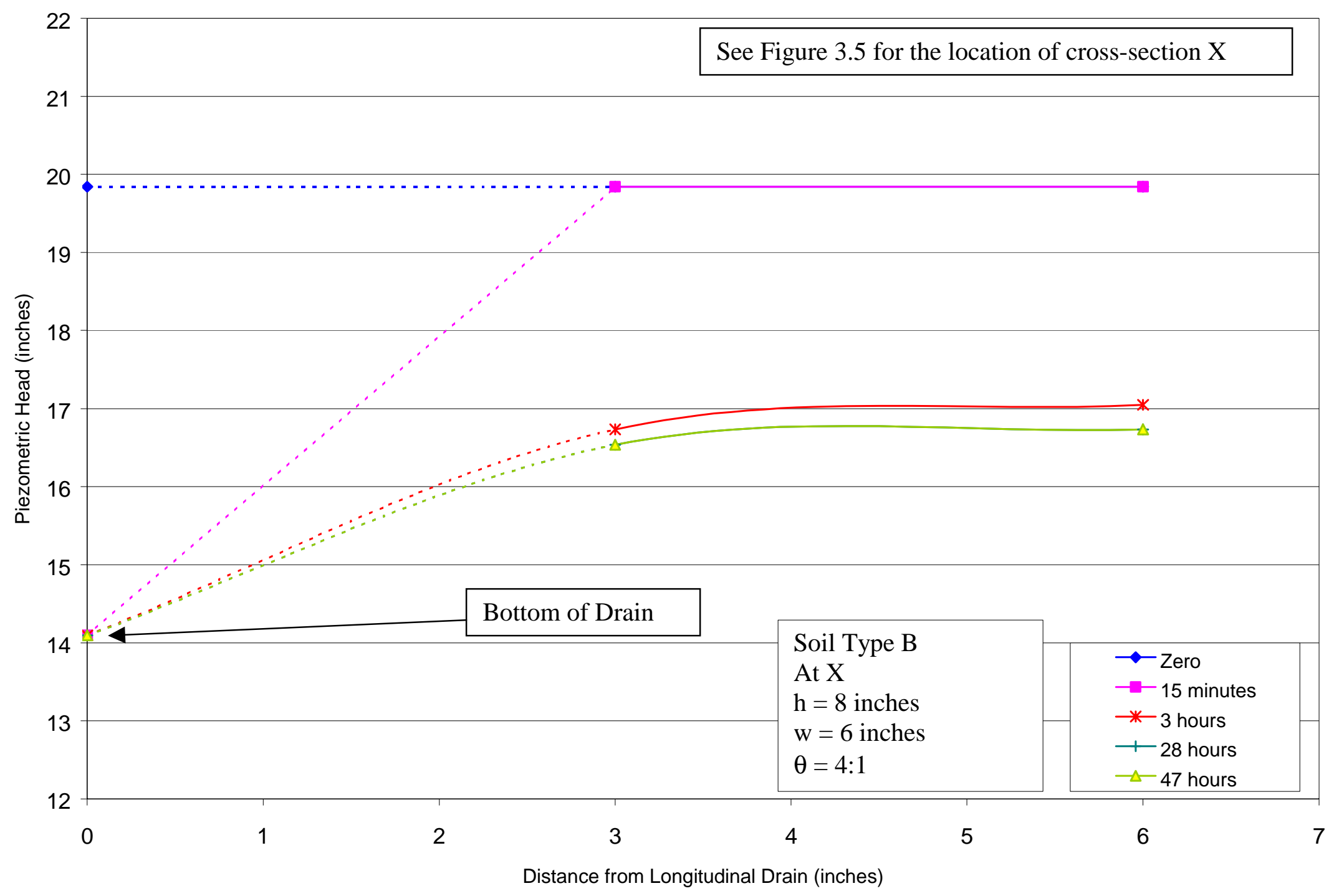

Figure 4.33: Variation of Piezometric Head at Cross-section X for $w=6$ inches and 4:1 Slope Angle. 


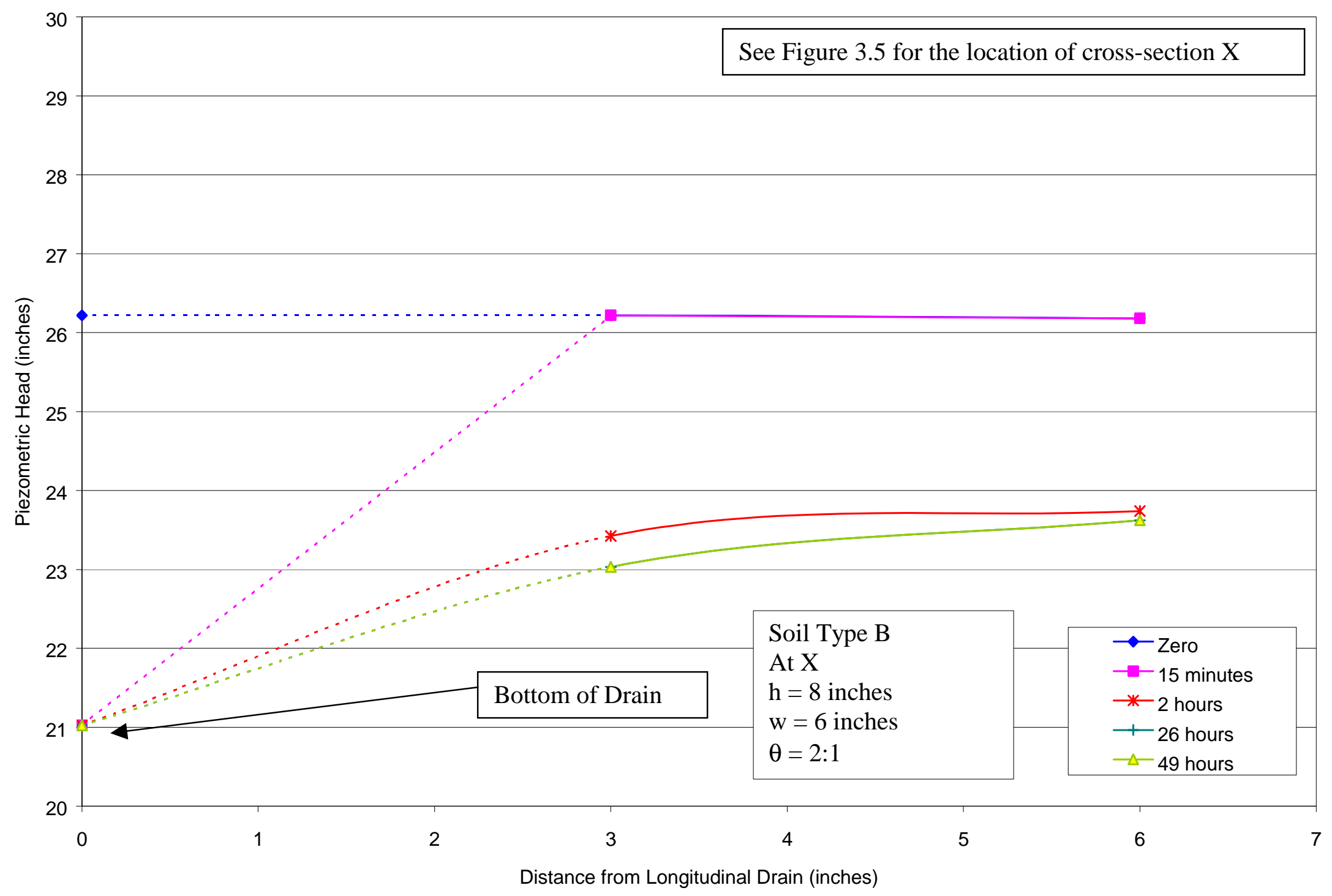

Figure 4.34: Variation of Piezometric Head at Cross-section X for $\mathrm{w}=6$ inches and 2:1 Slope Angle. 


\subsubsection{Steady State Condition}

The piezometric data provides a profile of the water flowing through the soil sample. The main line of piezometers runs along the line of symmetry, giving a longitudinal profile. The other two lines provide a transverse profile at different locations ( $\mathrm{X}$ and $\mathrm{Y}$ in Figure 3.5). With the data from the piezometers, it is possible to see the shape of the water table in the soil. When the longitudinal drains are closed, the longitudinal water head decreases from the water tank to the end drain. The transverse profiles remain constant. The transverse profiles show a straight line across the soil zone. This pattern changes when the drains are opened. After the flow in the drains stabilizes, the transverse profile is no longer a flat surface. The water head decreases from the centerline to the drain. This decrease is shown in Figure 4.29, 4.30 and 4.31 (centerline, first transverse $(\mathrm{X})$ and second transverse $(\mathrm{Y})$ ). These figures are for soil type B with half trench spacing of 18 inches $(46 \mathrm{~cm})$, water depth of 8 inches $(20 \mathrm{~cm})$, and a slope of 4:1. All other figures for different slope angles and water depths can be found in Appendix I. These figures show similar trends.

For small trench spacing the water is somewhat confined. For this reason the decreasing profiles tend to be smooth, while in the case of large trench spacing the profile changes. Trench spacing has a big influence on the piezometric heads. 


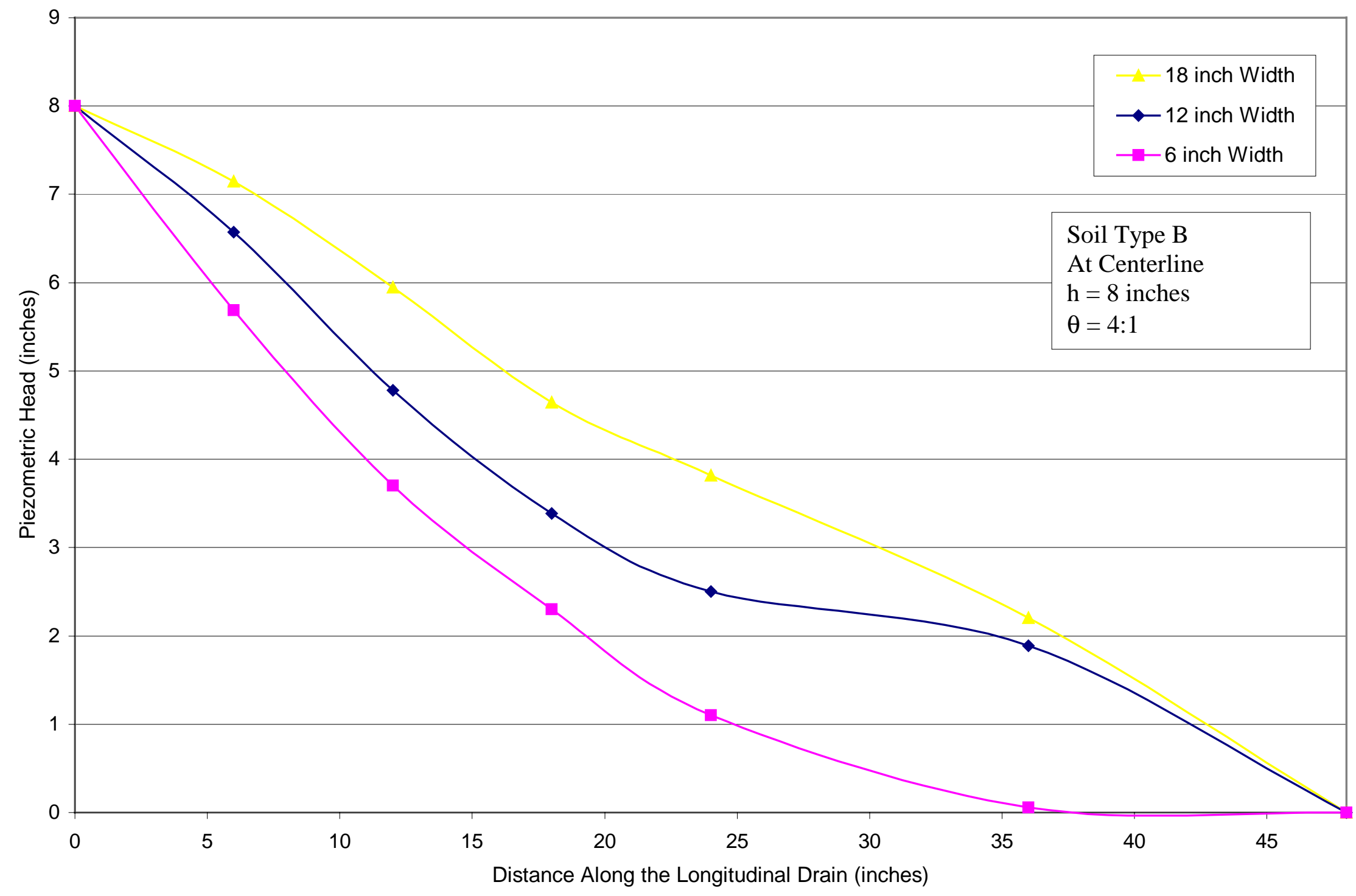

Figure 4.35: Influence of Trench Spacing on Piezometric Head at the Centerline for 8" Saturation Depth and 4:1 Slope Angle. 


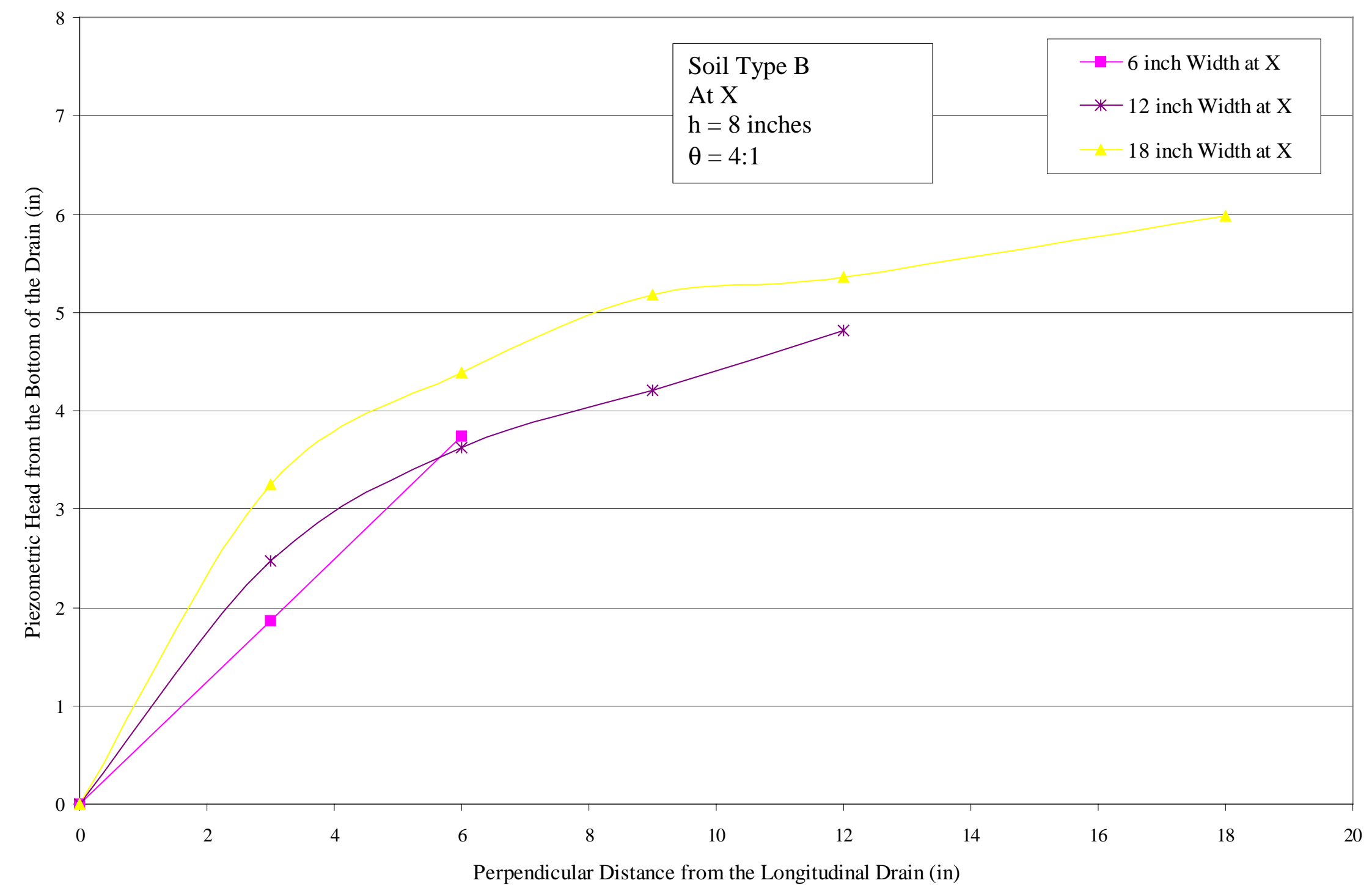

Figure 4.36: Piezometric Head at 12" from Tank for 8" Saturation Depth and 4:1 Slope Angle. 


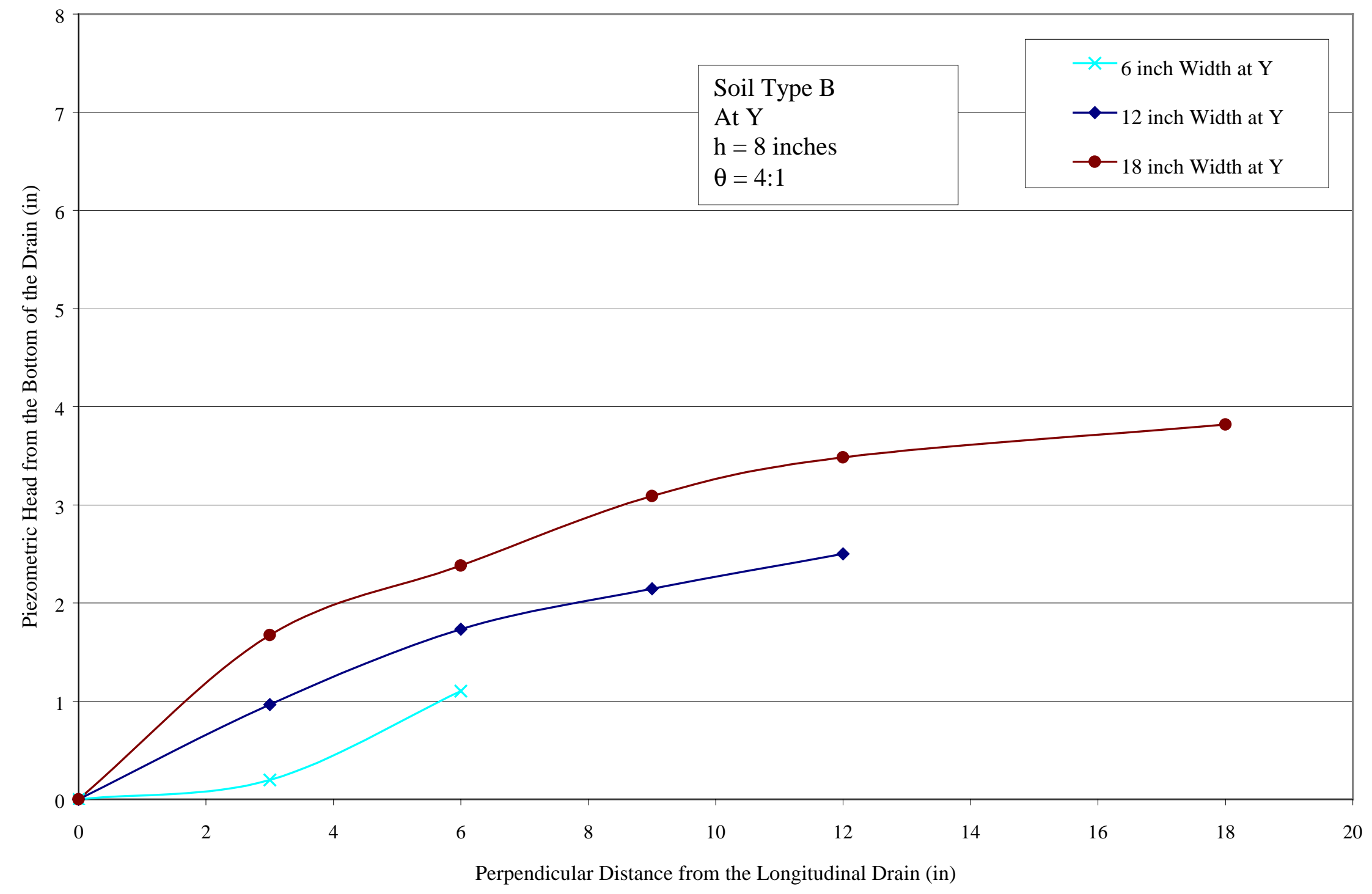

Figure 4.37: Piezometric Head at 24" from Tank for 8" Saturation Depth and 4:1 Slope Angle. 


\section{CHAPTER 5}

\section{CONCLUSIONS AND RECOMMENDATIONS}

\subsection{CONCLUSIONS}

After the completion of more than thirty experiments and an analysis of data the following conclusions can be made.

- The effectiveness of longitudinal drains is inversely proportional to the spacing between trenches.

- The slope inclination angle reduces the overall effectiveness of the longitudinal drain. This may create stability problems.

- The effectiveness of longitudinal drains is proportional to the water depth.

- The first three sections of the longitudinal drain are the most critical ones. The first drain is the most important of these.

- The hydraulic conductivity of the soil is directly proportional to the effectiveness of the longitudinal drains.

- Longitudinal drains can effectively reduce the seepage flow in soils.

- Fluctuations in flow after installation of longitudinal drains in laboratory experiments recedes after one day.

Longitudinal drains are a non-expensive way to solve a major problem causing landslides. It is shown that if adequately installed a longitudinal drain could reduce the seepage by ninety percent. The longitudinal drain becomes fully functional within one day under laboratory conditions. The transient condition appears to be very small. In view of the limited data collected at the beginning of the transient condition, part of the transient condition may have been missed in the experiments. 


\subsection{RECOMMENDATIONS}

In future experiments, more data should be collected within the first few hours of the transient condition. It was shown in this study that the firt three drains are the most criticall ones. Future study could focus on these drains and possible changes in their size. The effectiveness of having shorter drains should be investigated. A larger model could be constructed to study the effect of scale. More data should be collected for different types of soils.

A computer modeling study should be undertaken to predict the behavior of longitudinal drains under both the laboratory and field conditions. 


\section{REFERENCES}

1. Cedergren, Harry R. (1977) "Seepage, Drainage, and Flow Nets." Wiley, New York..

2. Cruden, D.M. (1991) “A Simple Definition of a Landslide.” Bulletin of the International Association of Engineering Geology, Vol 43, 27-29.

3. Dai, F.C., Lee C.F., Ngai Y.Y. (2001) "Landslide risk assessment and management: an overview." Engineering Geology, Vol 64, 65-87.

4. $\quad$ Das, B.M. (1985) "Foundation Engineering.” PWS Publishing Company, fourth edition, Boston.

5. Das, B.M. (1985) "Principles of Geotechnical Engineering." PWS Publishing Company, fourth edition, Boston.

6. Kent, P.E. (1966) "The Transport mechanism in catastrophic rock falls." J. Geology, Vol 74, 79-83.

7. Legros, F. (2001) “The mobility of long-runout landslides." Engineering Geology, Vol 63, 301-331. 
8. Li, T., Wang, S. (1992) "Landslide Hazard and their Mitigation in China." Science Press, Beijing, 84.

9. Schuster, R.L., Fleming, R.W. (1986) "Economic losses and fatalities due to landslides." Bulletin of the Association of Engineering Geologists, Vol 23(1), 1128.

10. Stanic, B. (1984) "Influence of Drainage Trenches on Slope Stability." Journal of Geotechnical Engineering, ASCE, Vol 110(11), 1624-1636.

11. Wang F.G., Sassa K., Wang G. (2001) "Mechanism of a long-runout landslide triggered by August 1998 heavy rainfall in Fukushima prefecture, Japan.” Engineering Geology, Vol 63, 169-185. 


\section{APPENDIX A}

Grain Size and Hydraulic Conductivity

For

Soil Type B (15\% Clay content) 


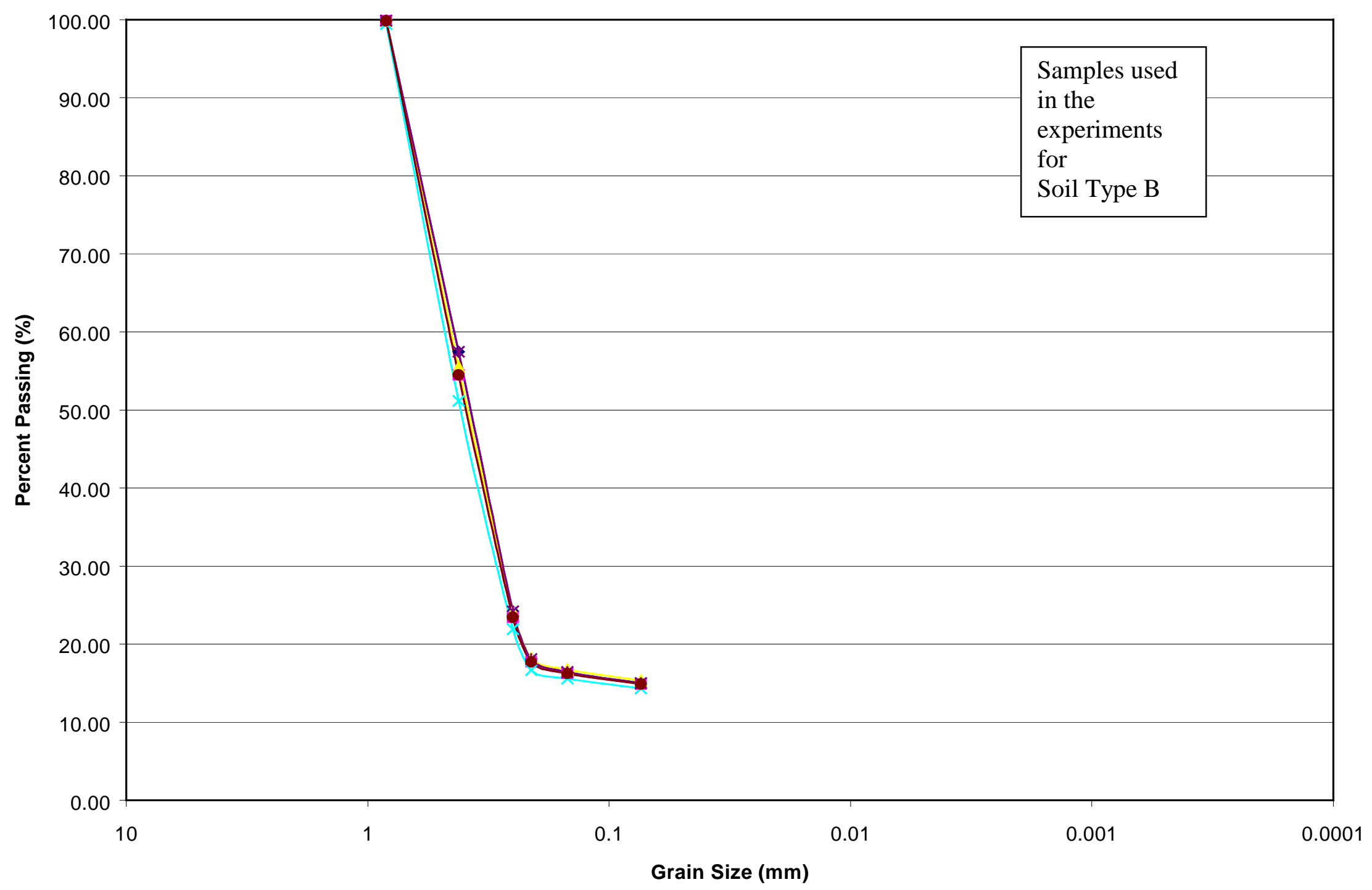

Figure A.1: Grain Seize for Soil Type B Samples. 


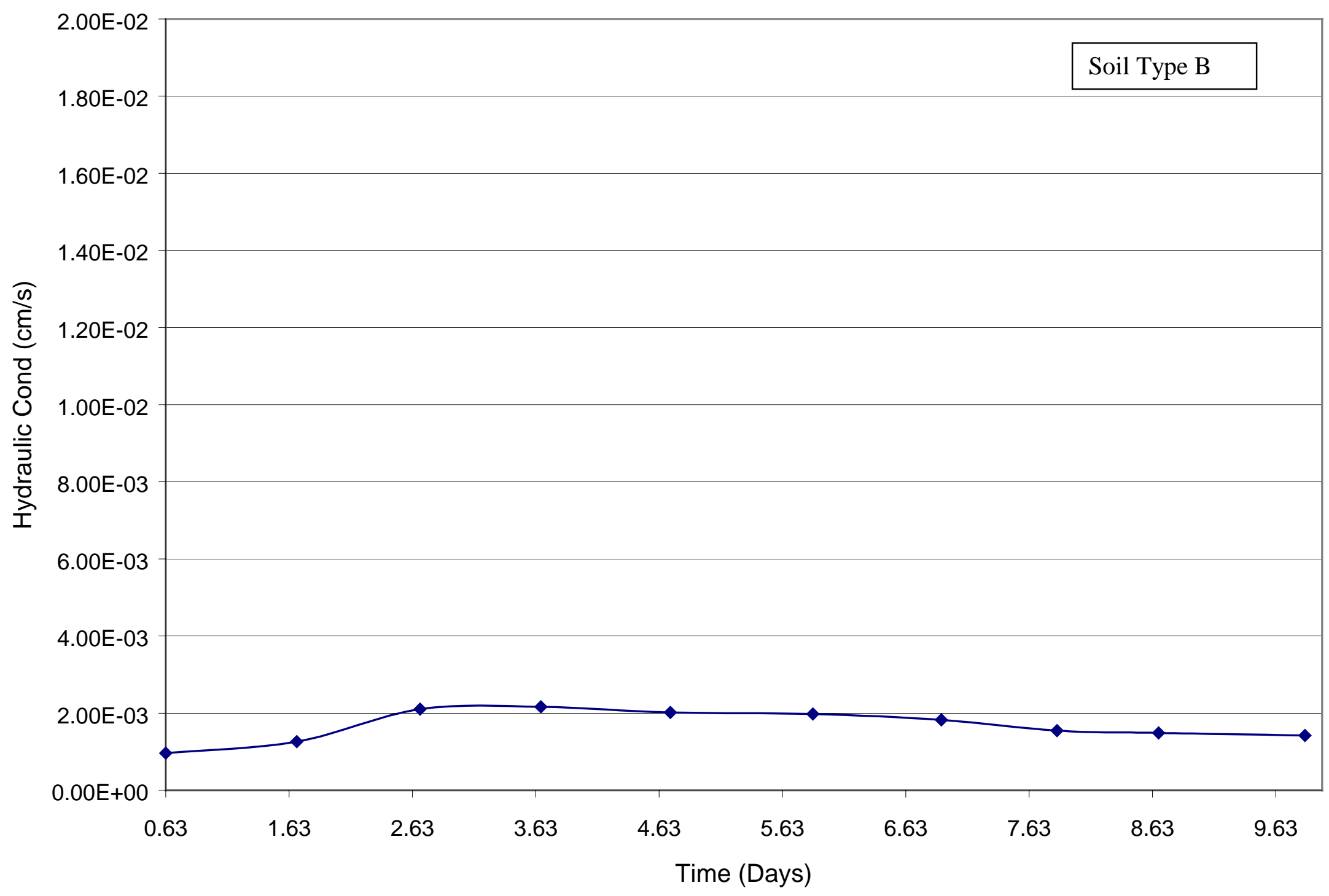

Figure A.2: Hydraulic Conductivity for Soil Type B (set-up \# 13). 


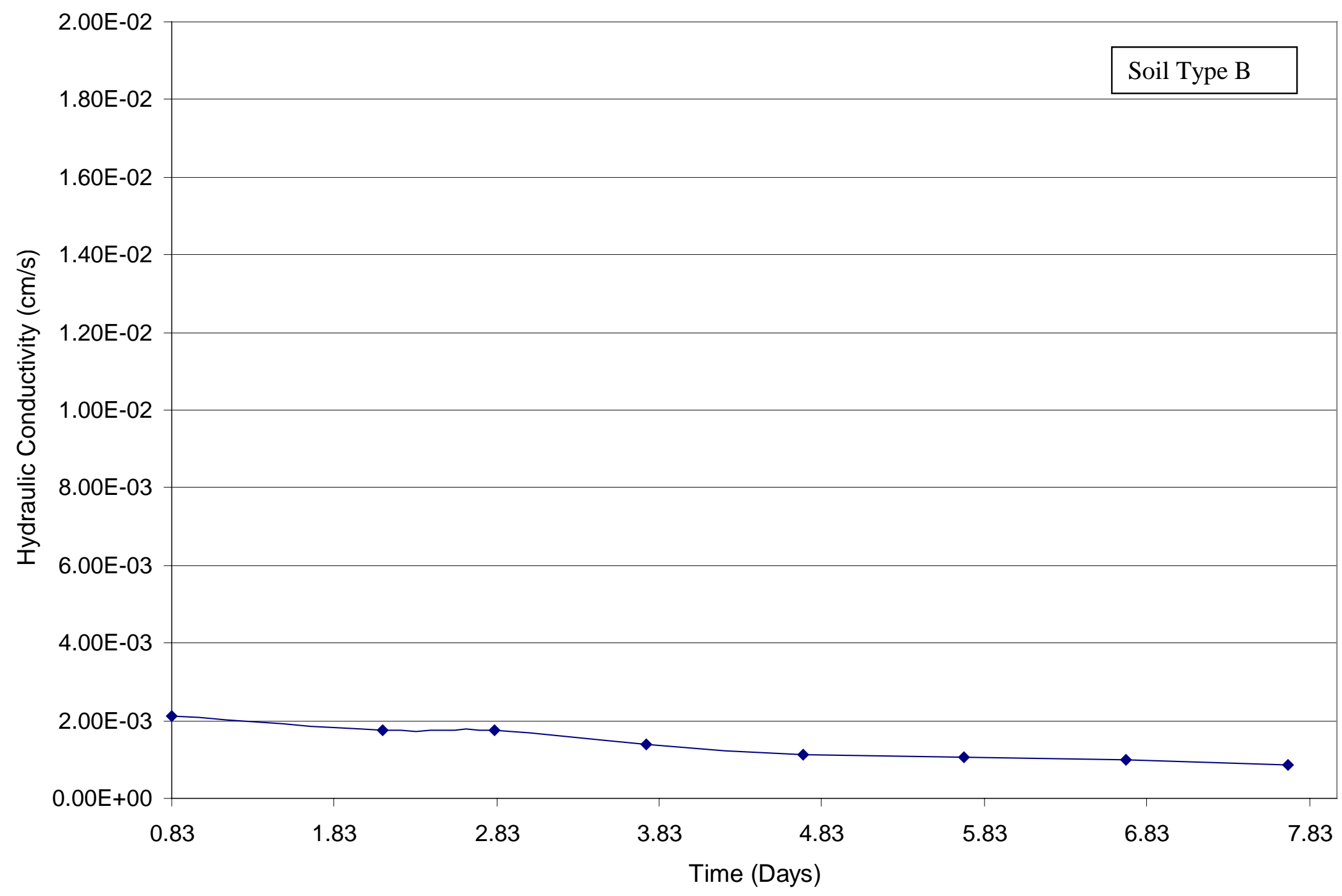

Figure A.3: Hydraulic Conductivity for Soil Type B (set-up \# 14). 


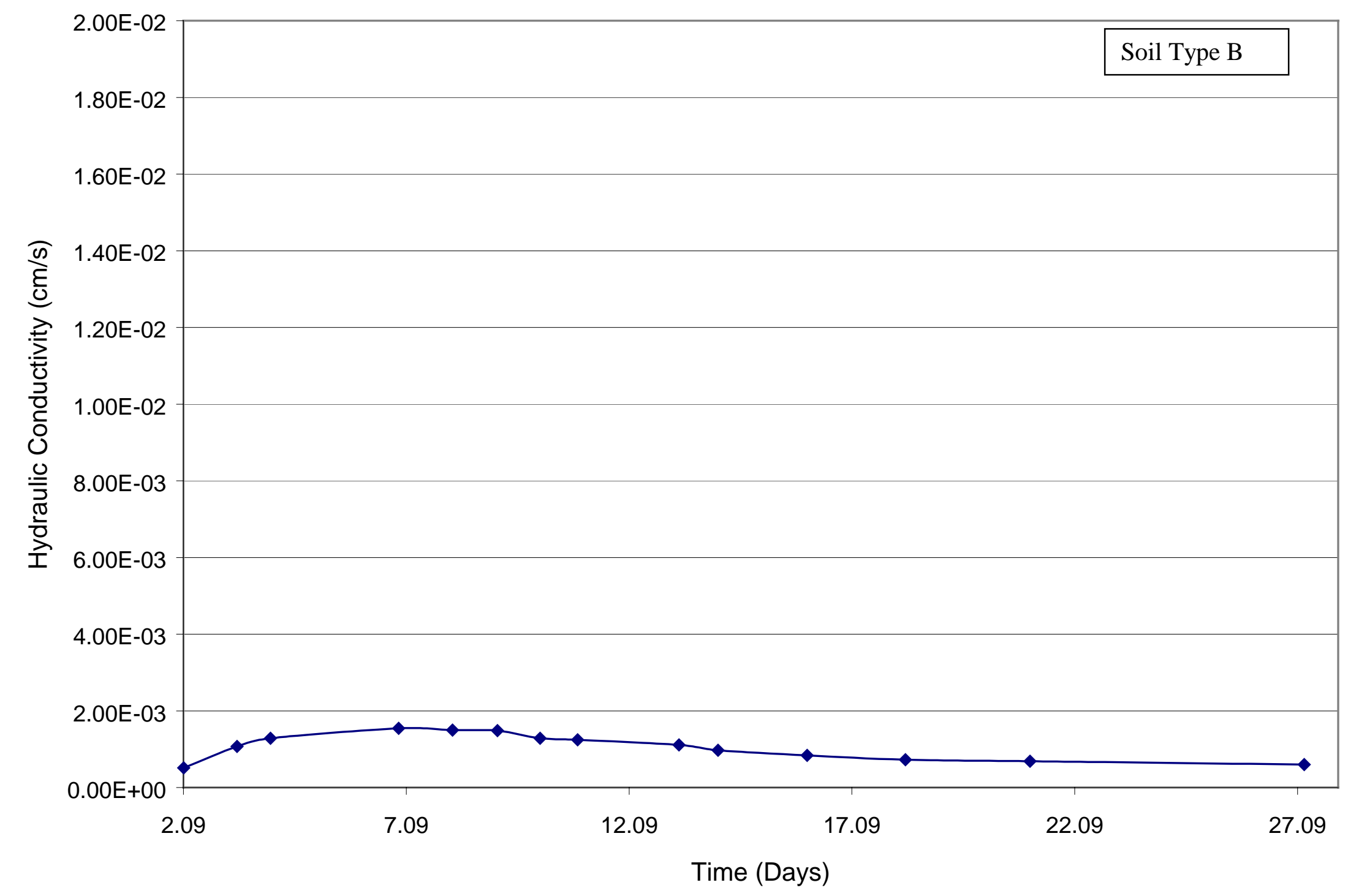

Figure A.4: Hydraulic Conductivity for Soil Type B (set-up \# 15). 


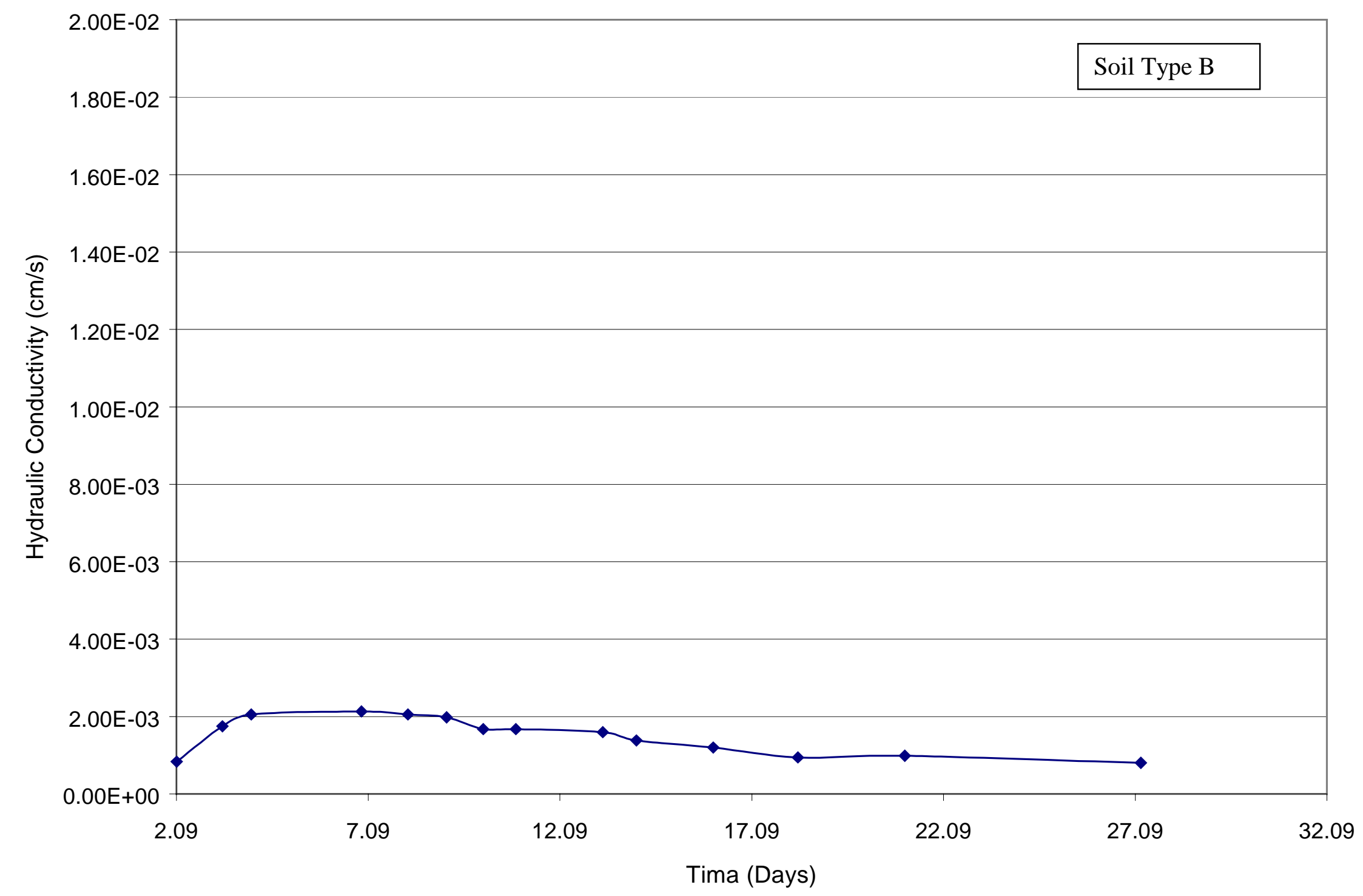

Figure A.5: Hydraulic Conductivity for Soil Type B (set-up \# 16). 


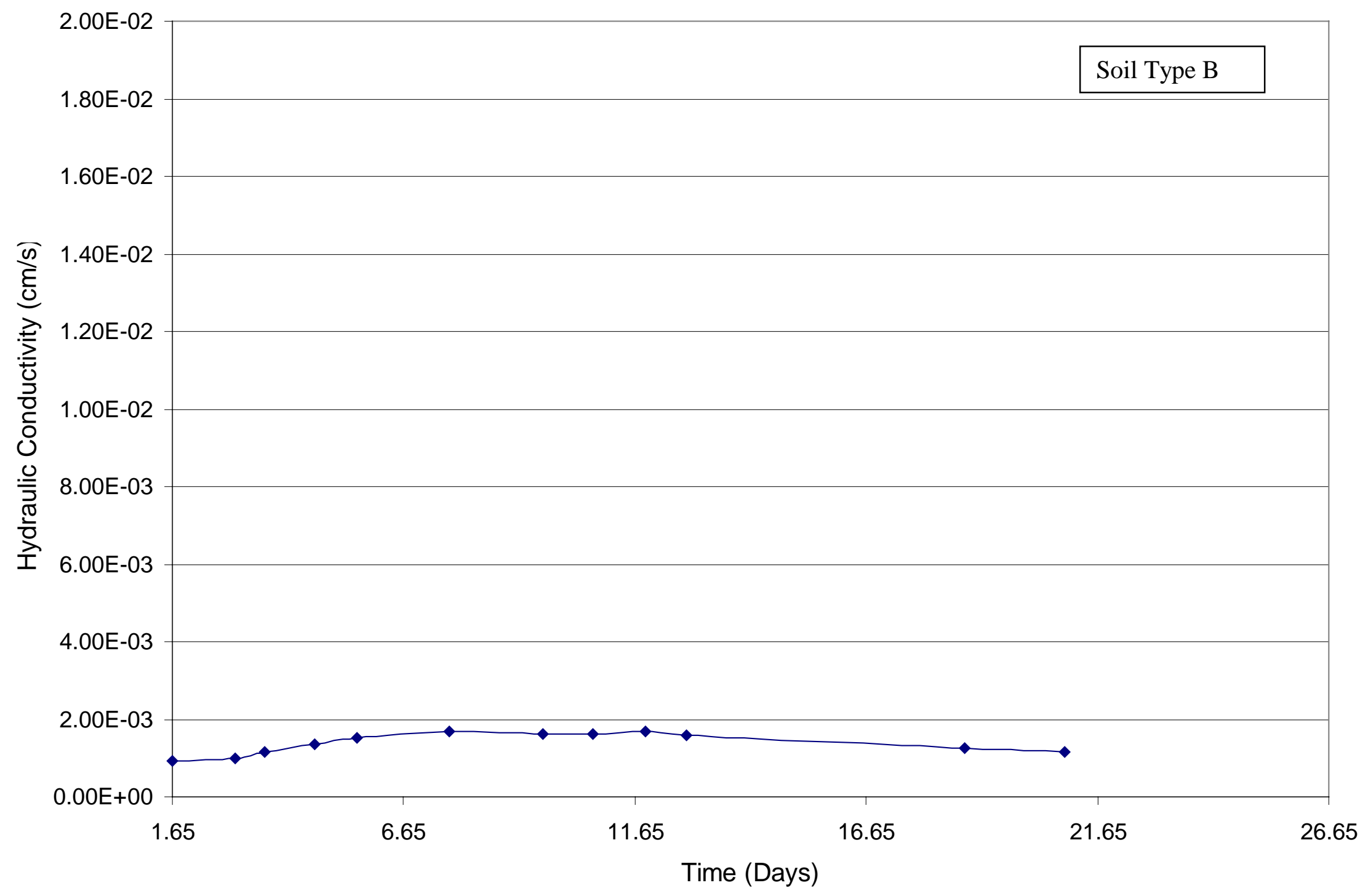

Figure A.6: Hydraulic Conductivity for Soil Type B (set-up \# 17). 


\title{
APPENDIX B
}

\author{
Transient Condition
}

For Soil Type B (15\% Clay Content)

For Different Trench Spacing and Slope Angles 


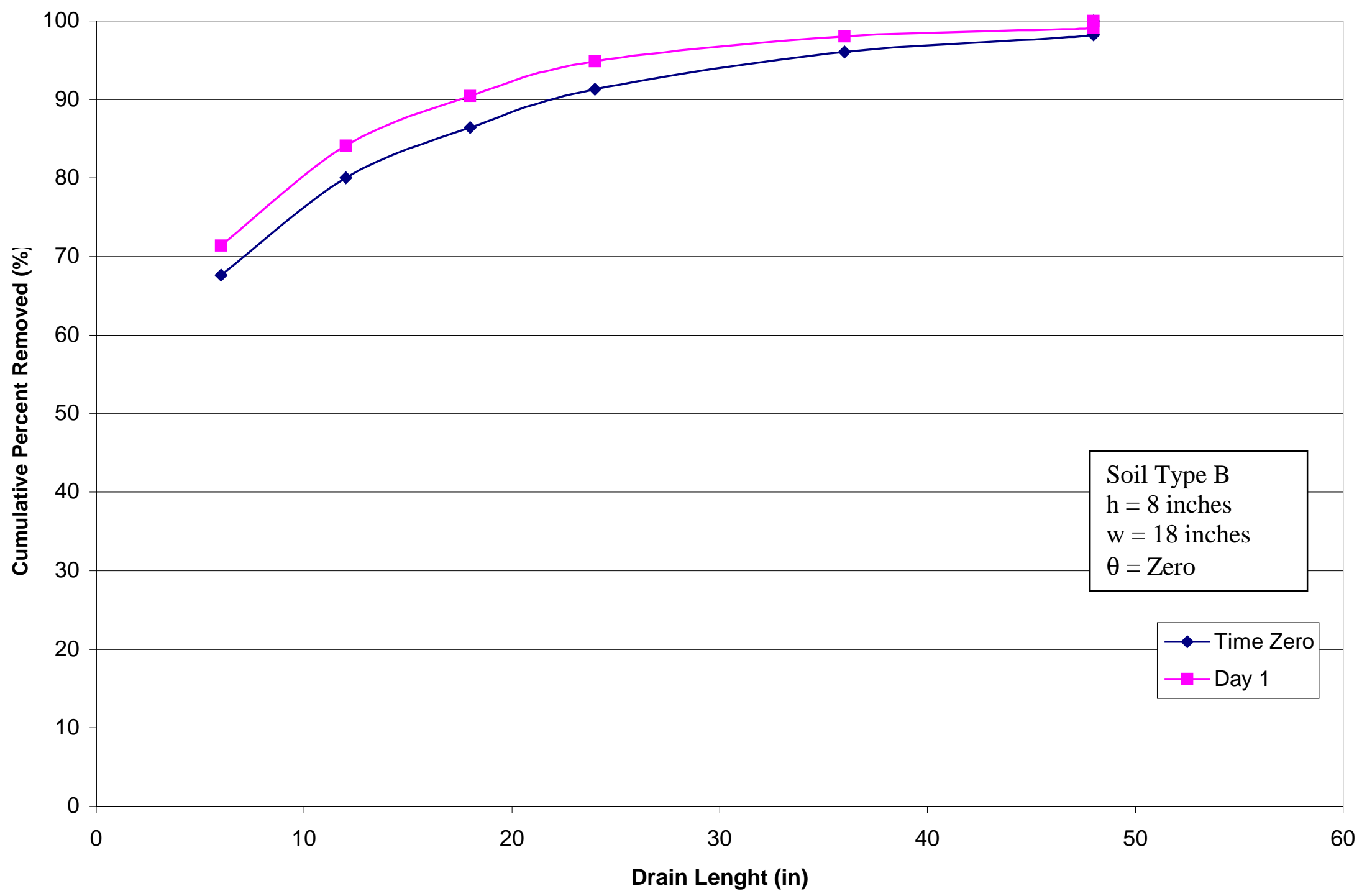

Figure B.1: Transient Condition for Soil Type B ( $w=18$ inches, Zero Slope Angle). 


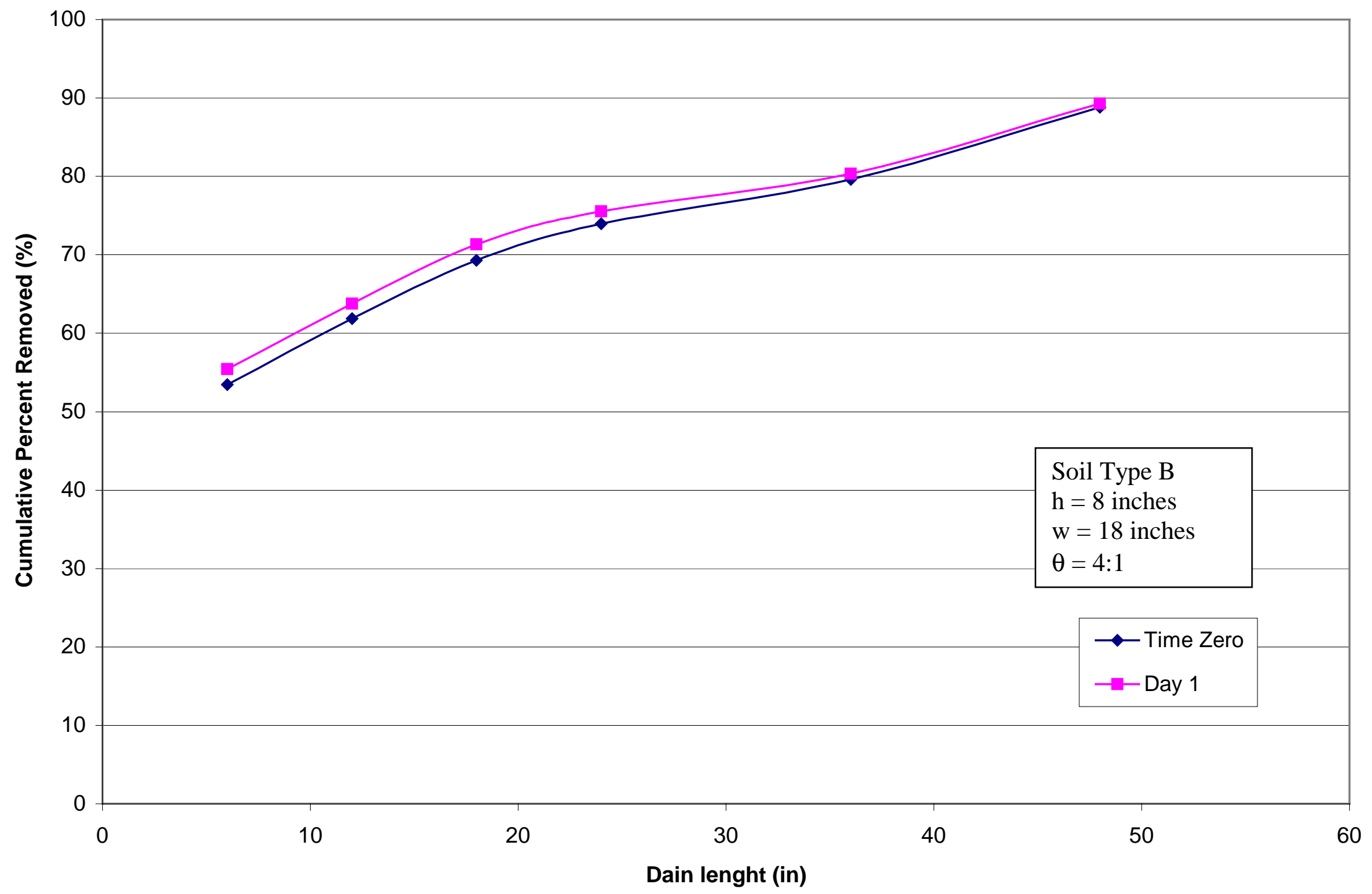

Figure B.2: Transient Condition for Soil Type B ( $w=18$ inches, 4:1 Slope Angle). 


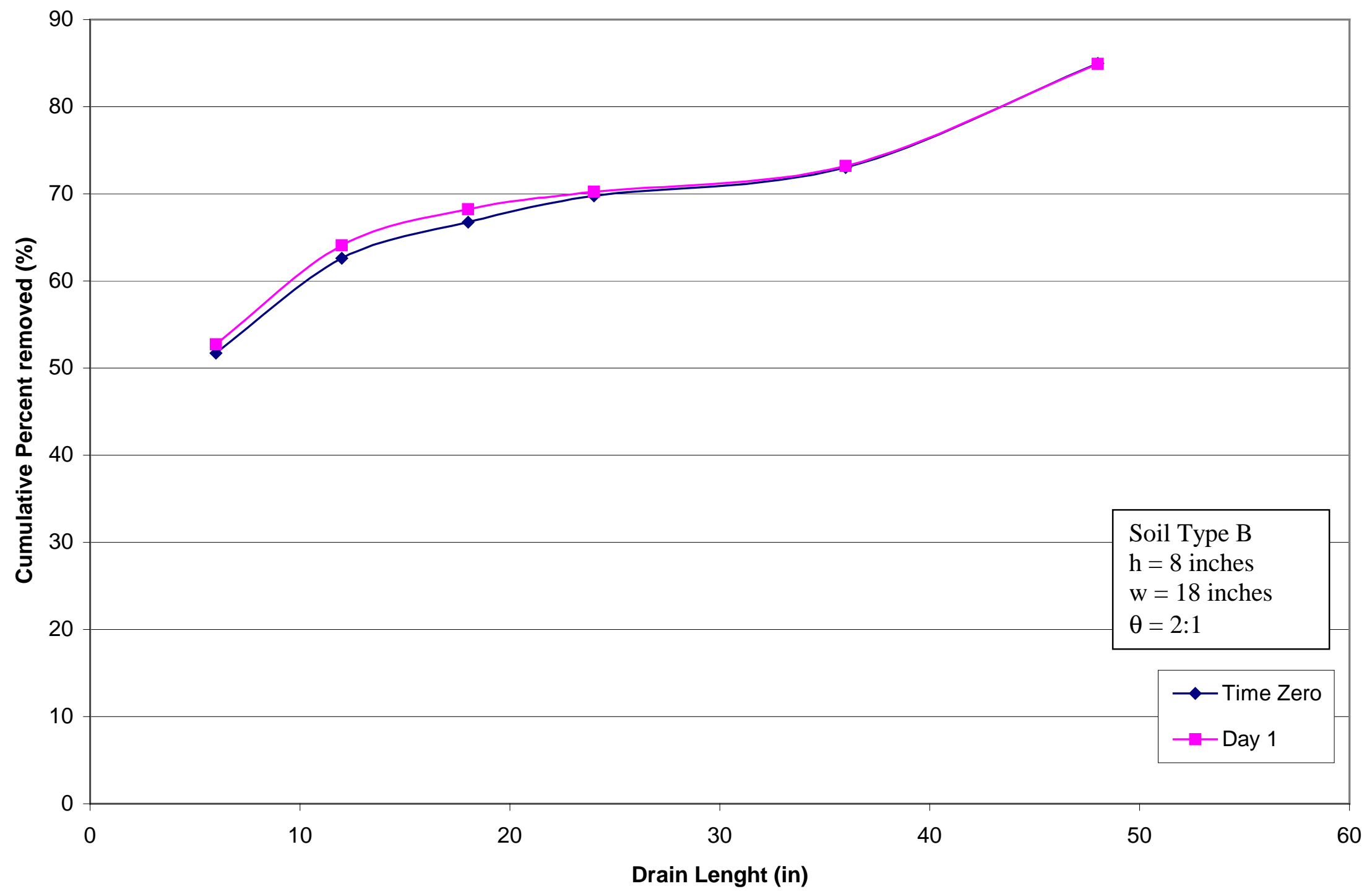

Figure B.3: Transient Condition for Soil Type B ( $w=18$ inches, 2:1 Slope Angle). 


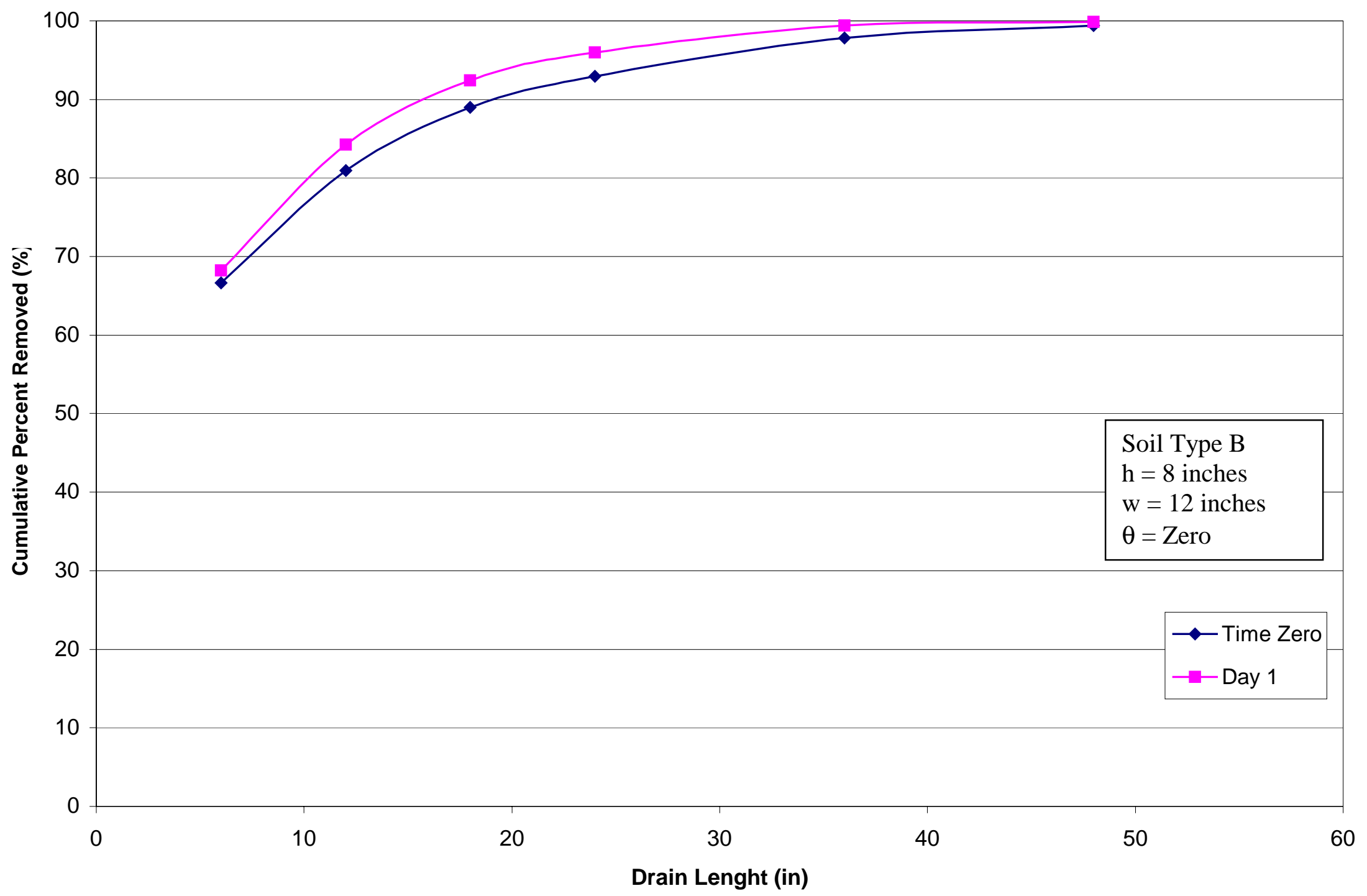

Figure B.4: Transient Condition for Soil Type B ( $w=12$ inches, Zero Slope Angle). 


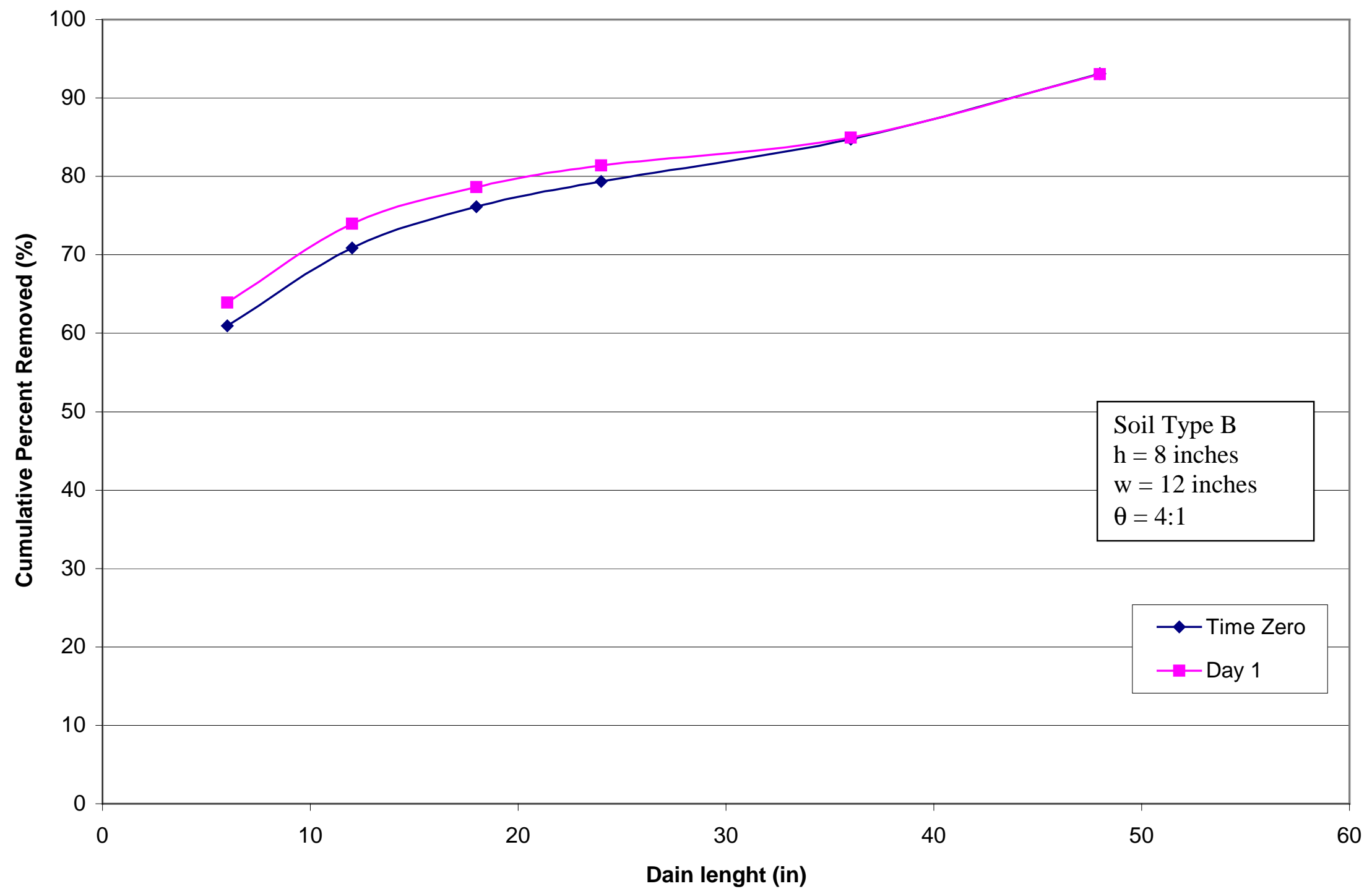

Figure B.5: Transient Condition for Soil Type B ( $w=12$ inches, 4:1 Slope Angle). 


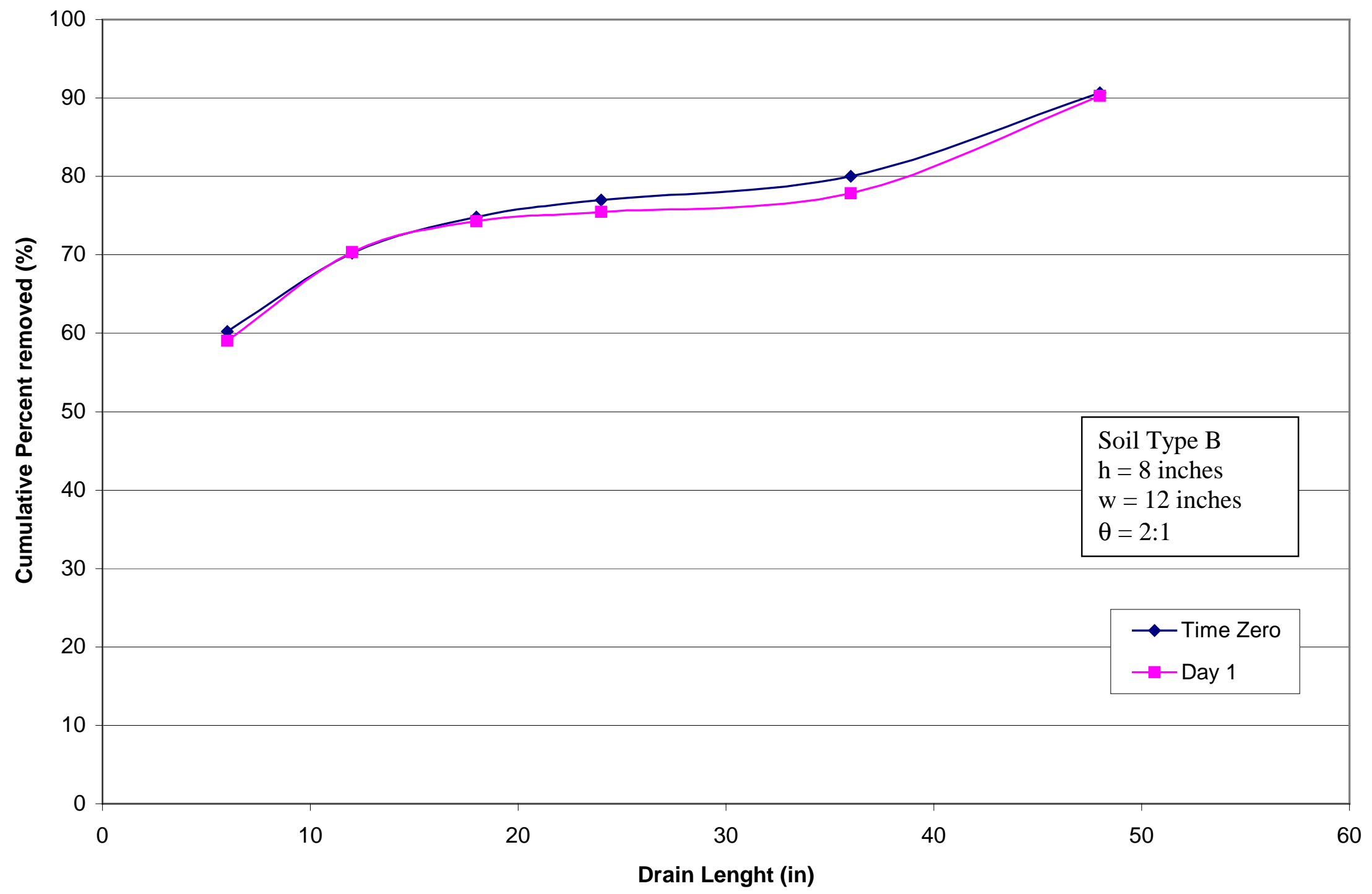

Figure B.6: Transient Condition for Soil Type B ( $w=12$ inches, 2:1 Slope Angle). 


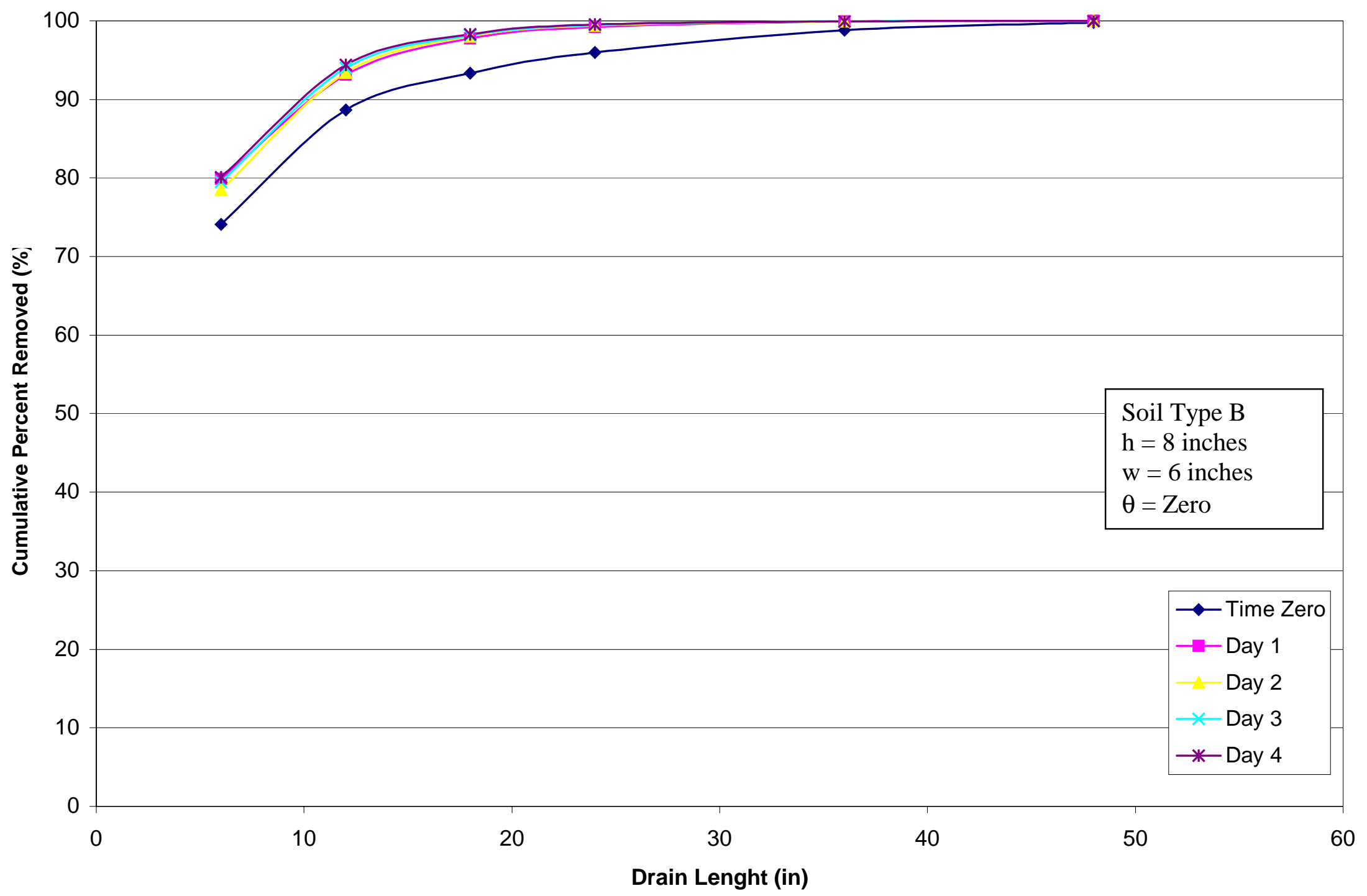

Figure B.7: Transient Condition for Soil Type B ( $w=6$ inches, Zero Slope Angle). 


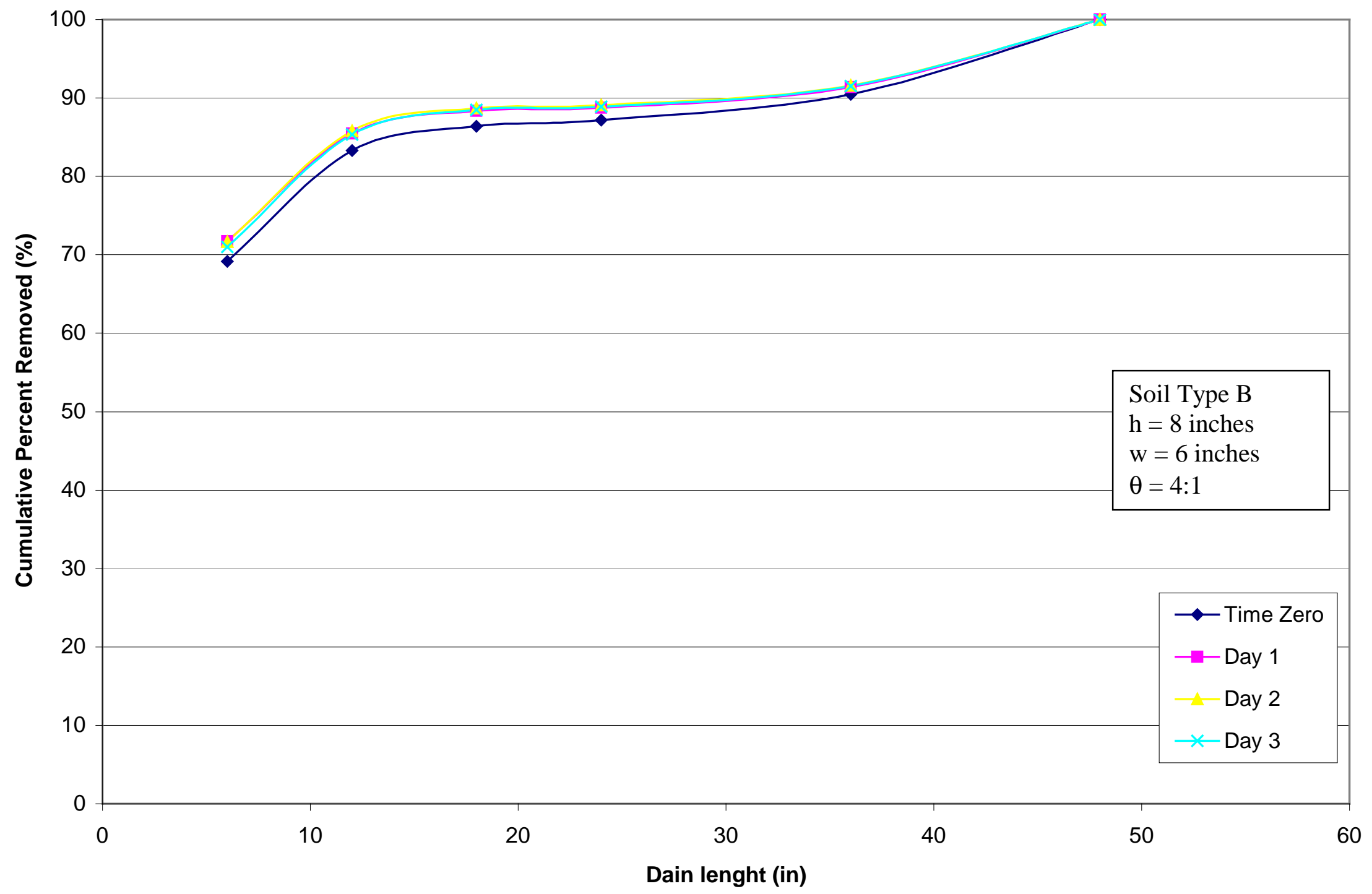

Figure B.8: Transient Condition for Soil Type B ( $w=6$ inches, 4:1 Slope Angle). 


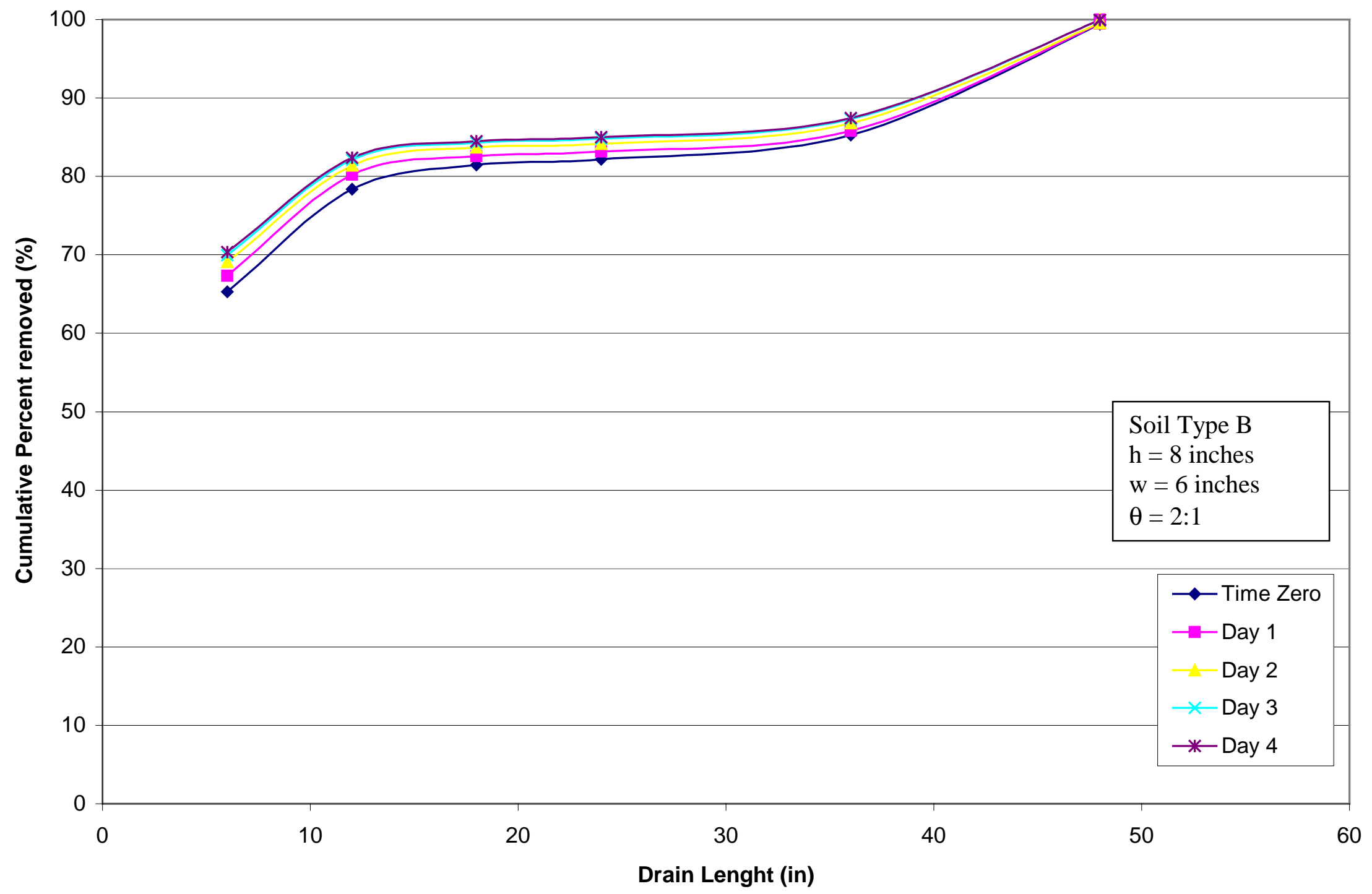

Figure B.9: Transient Condition for Soil Type B ( $w=6$ inches, 2:1 Slope Angle). 


\section{APPENDIX C}

Seepage Removal

for Soil Type B (15\% Clay Content)

for Different Half Trench Spacing and Slope Angles. 


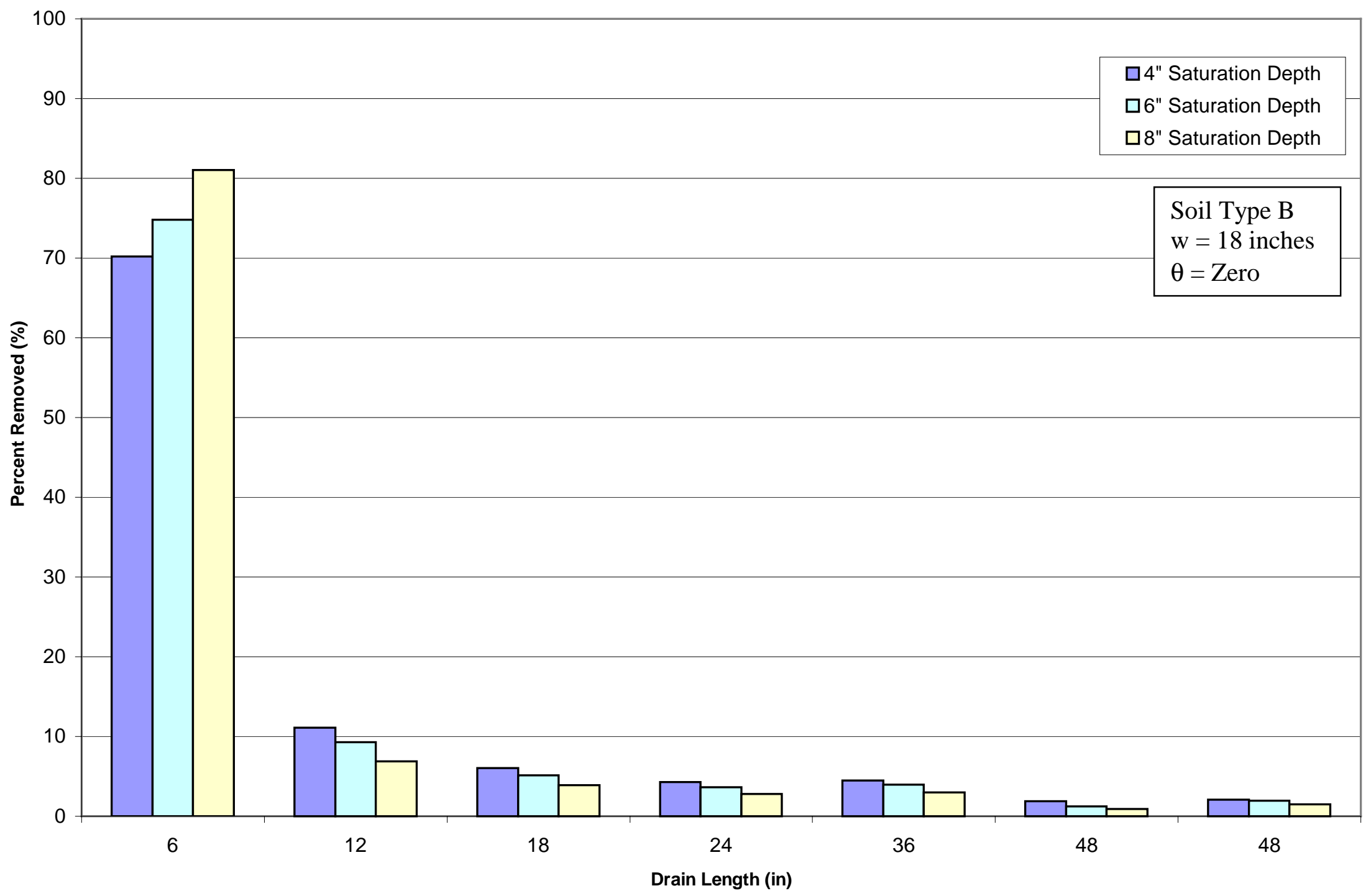

Figure C.1: Percent Seepage for Soil Type B ( $w=18$ inches, Zero Slope Angle). 


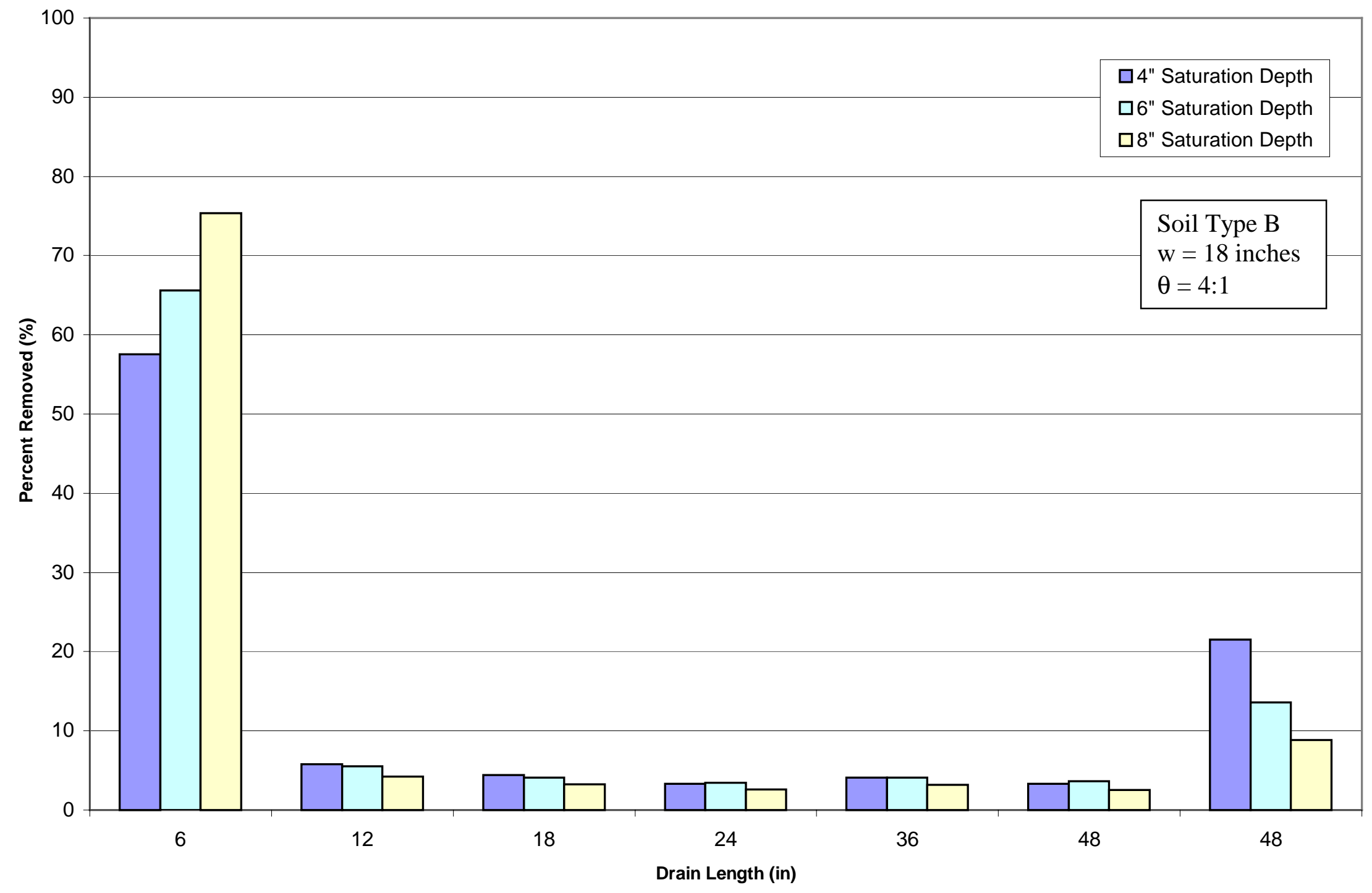

Figure C.2: Percent Seepage for Soil Type B ( $w=18$ inches, 4:1 Slope Angle). 


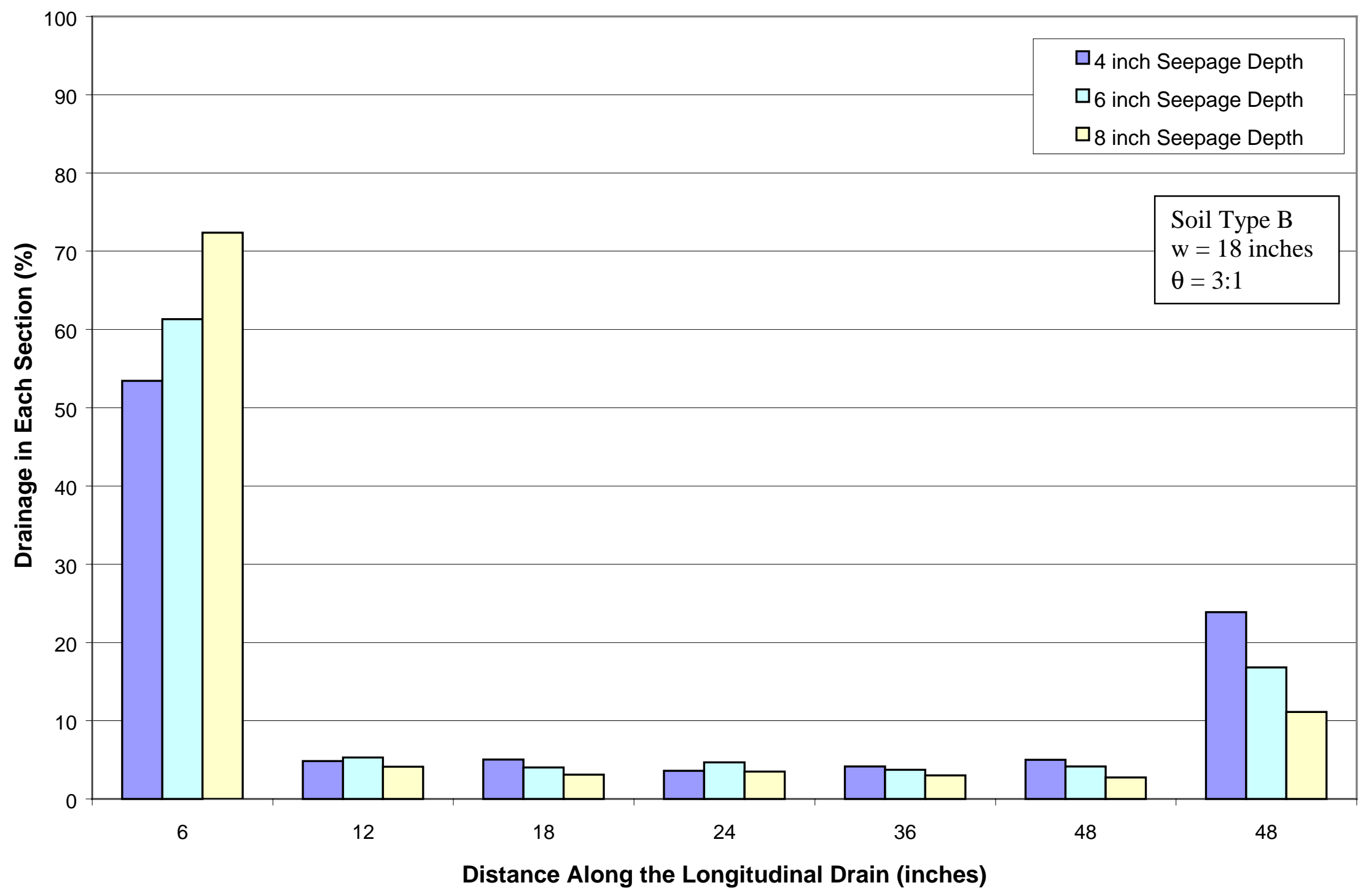

Figure C.3: Percent Seepage for Soil Type B ( $w=18$ inches, 3:1 Slope Angle). 


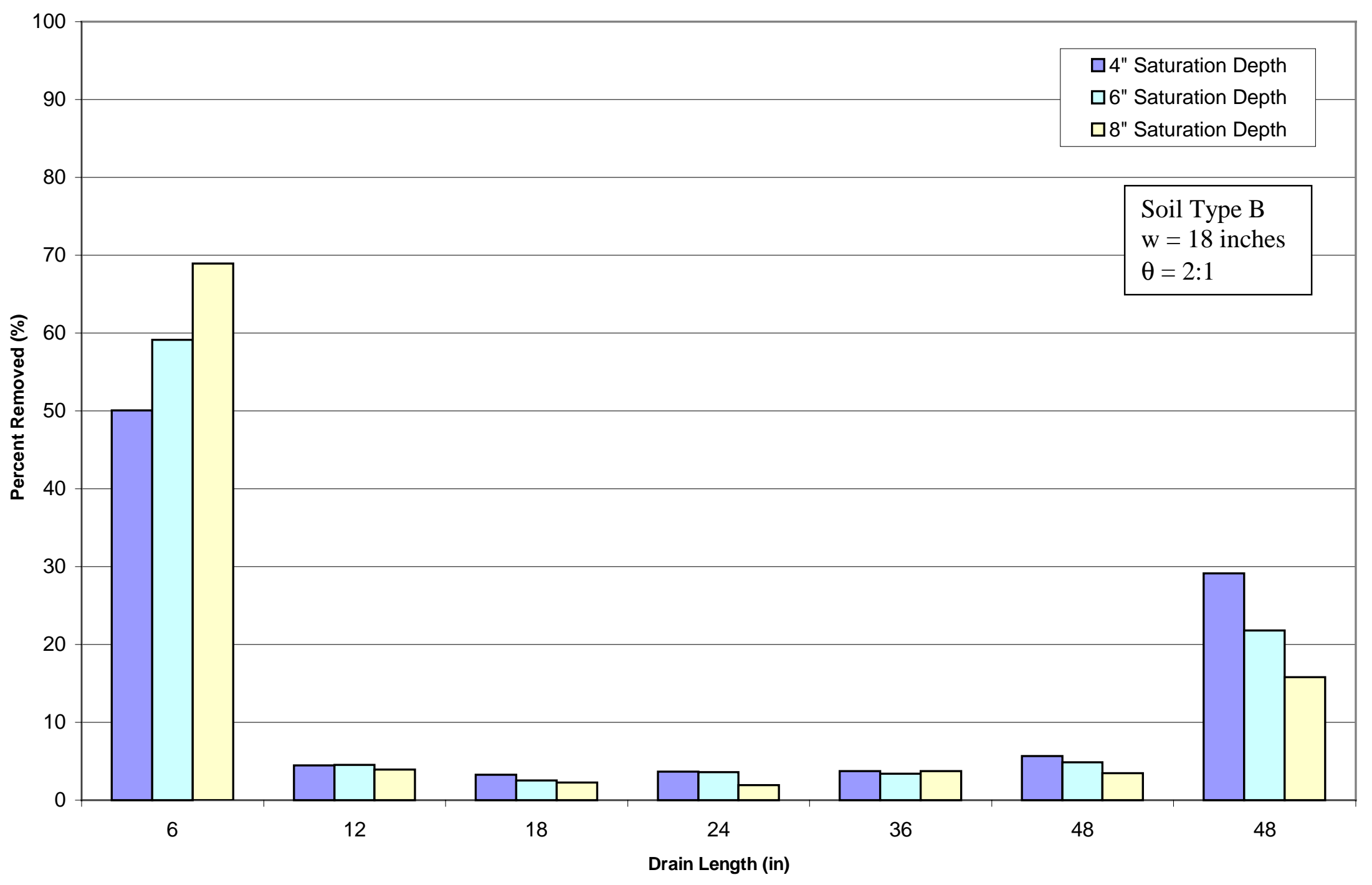

Figure C.4: Percent Seepage for Soil Type B ( $w=18$ inches, 2:1 Slope Angle). 


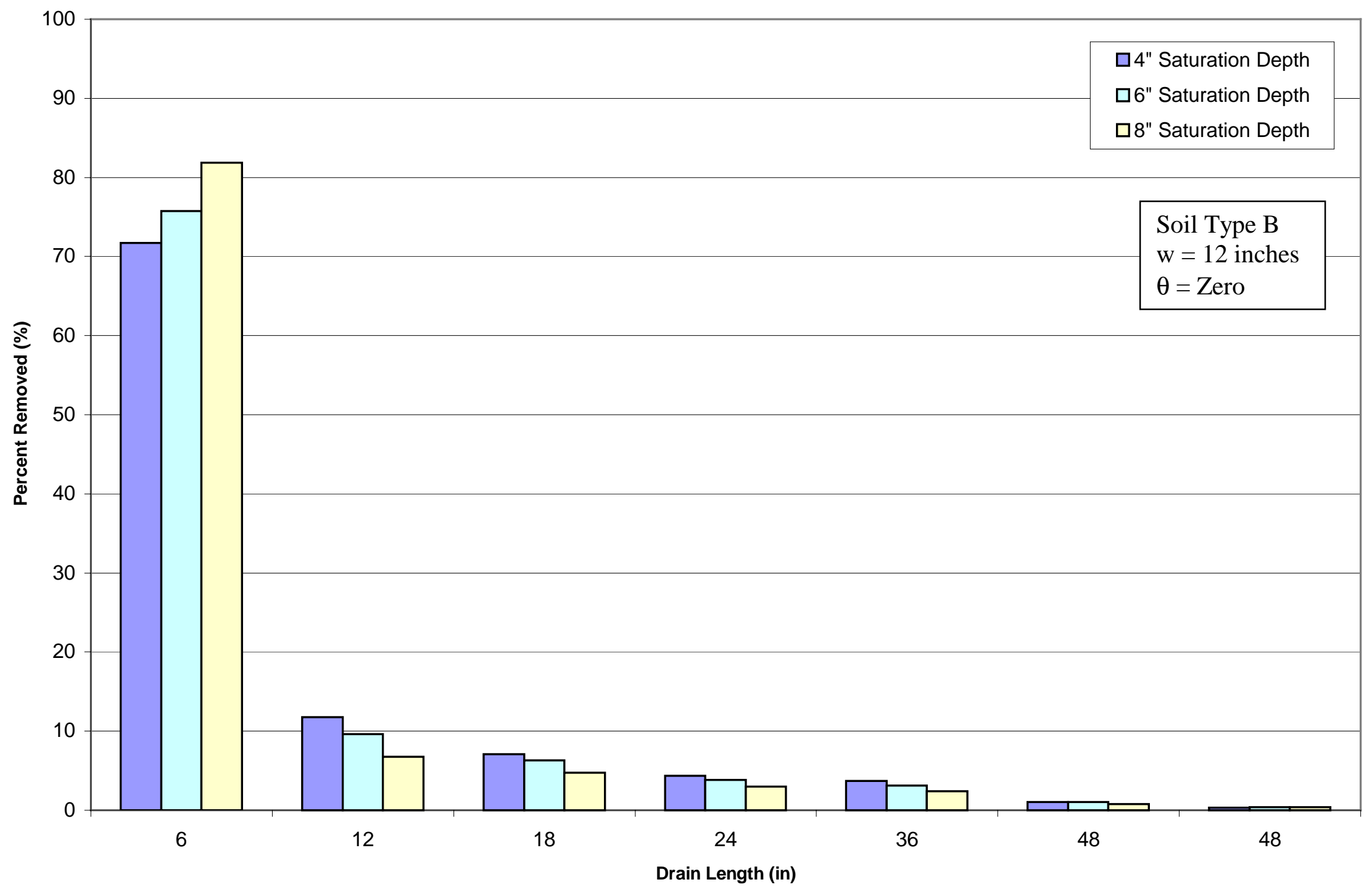

Figure C.5: Percent Seepage for Soil Type B ( $w=12$ inches, Zero Slope Angle). 


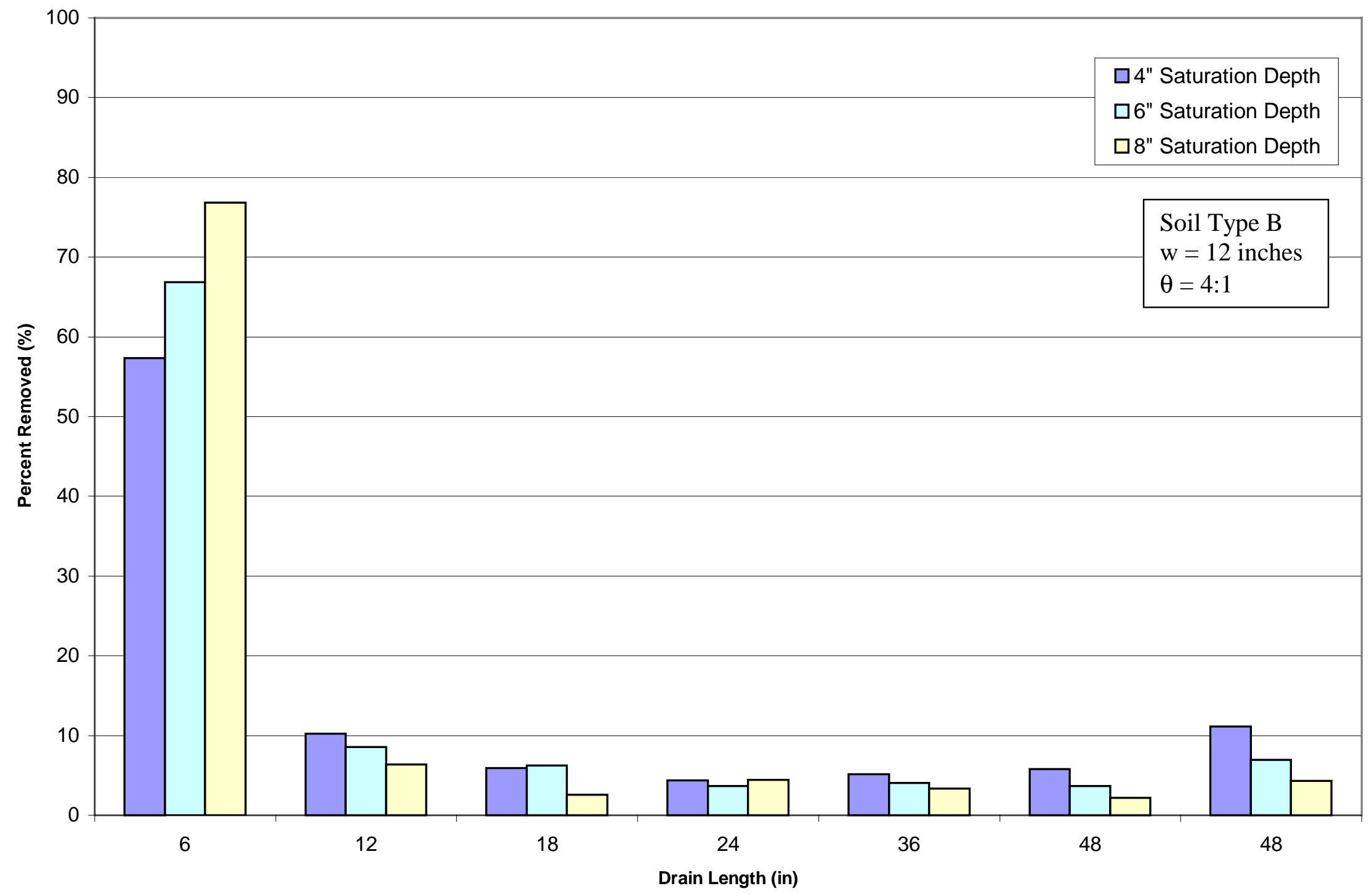

Figure C.6: Percent Seepage for Soil Type B ( $w=12$ inches, 4:1 Slope Angle). 


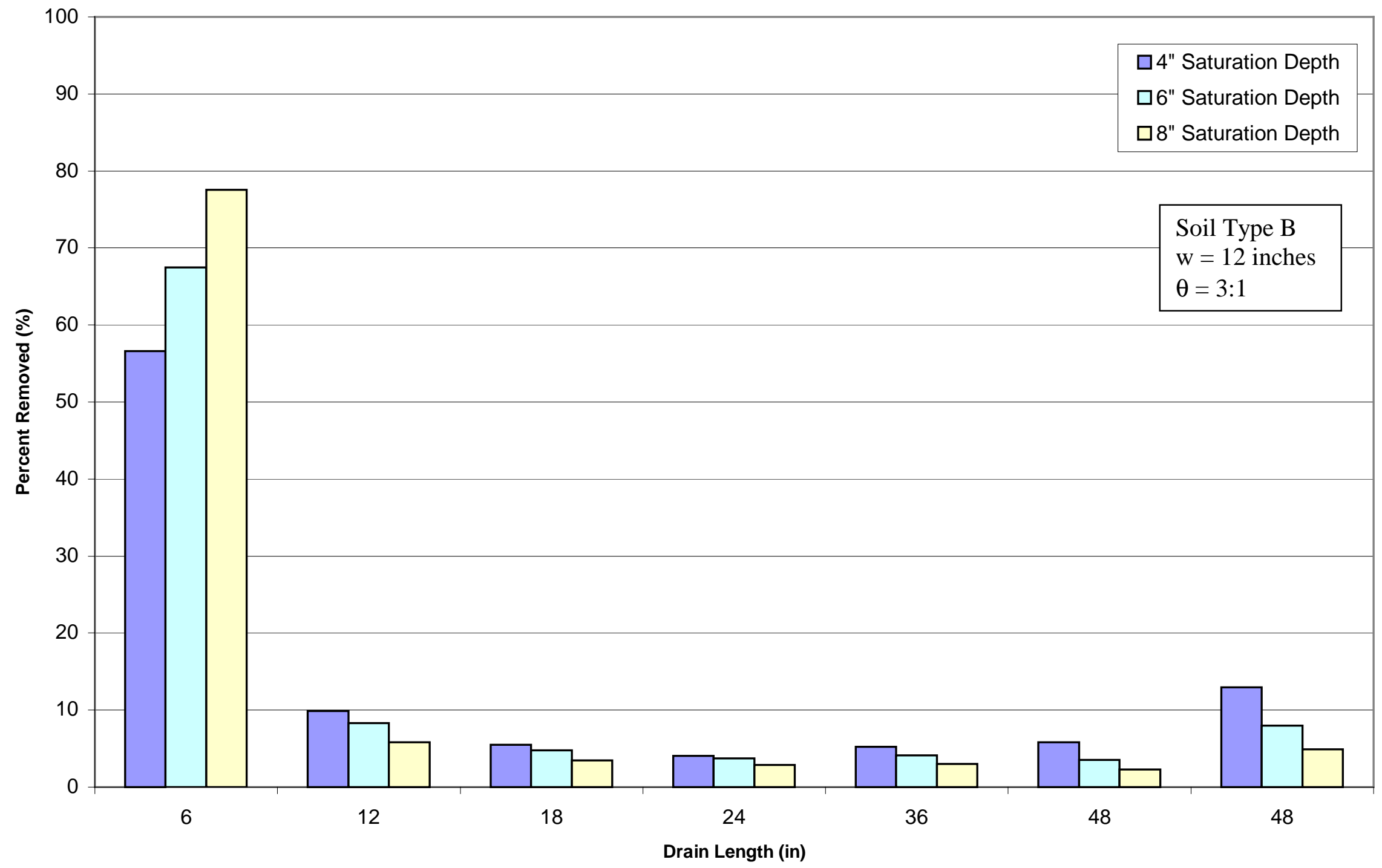

Figure C.7: Percent Seepage for Soil Type B ( $w=12$ inches, 3:1 Slope Angle). 


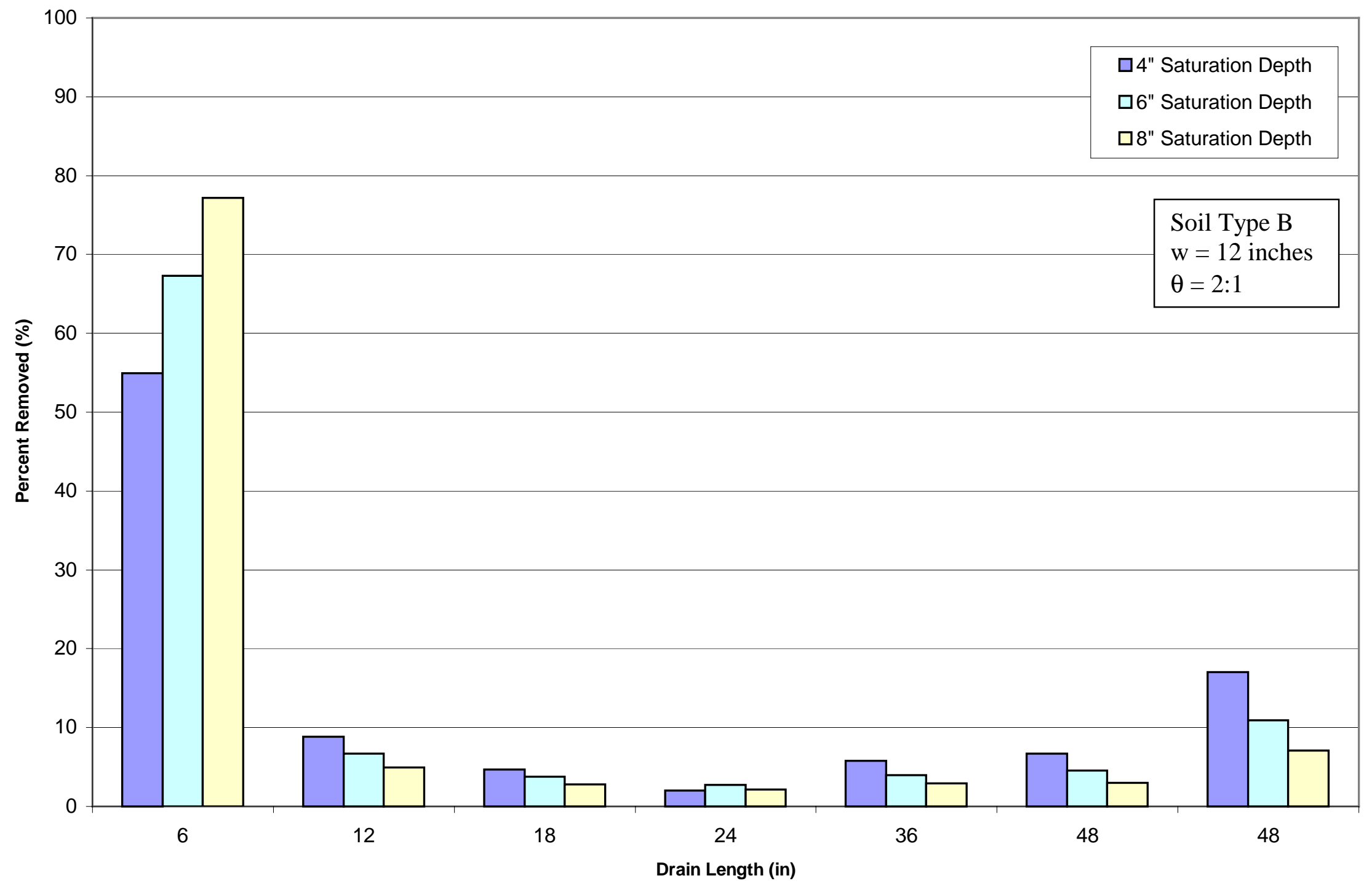

Figure C.8: Percent Seepage for Soil Type B ( $w=12$ inches, 2:1 Slope Angle). 


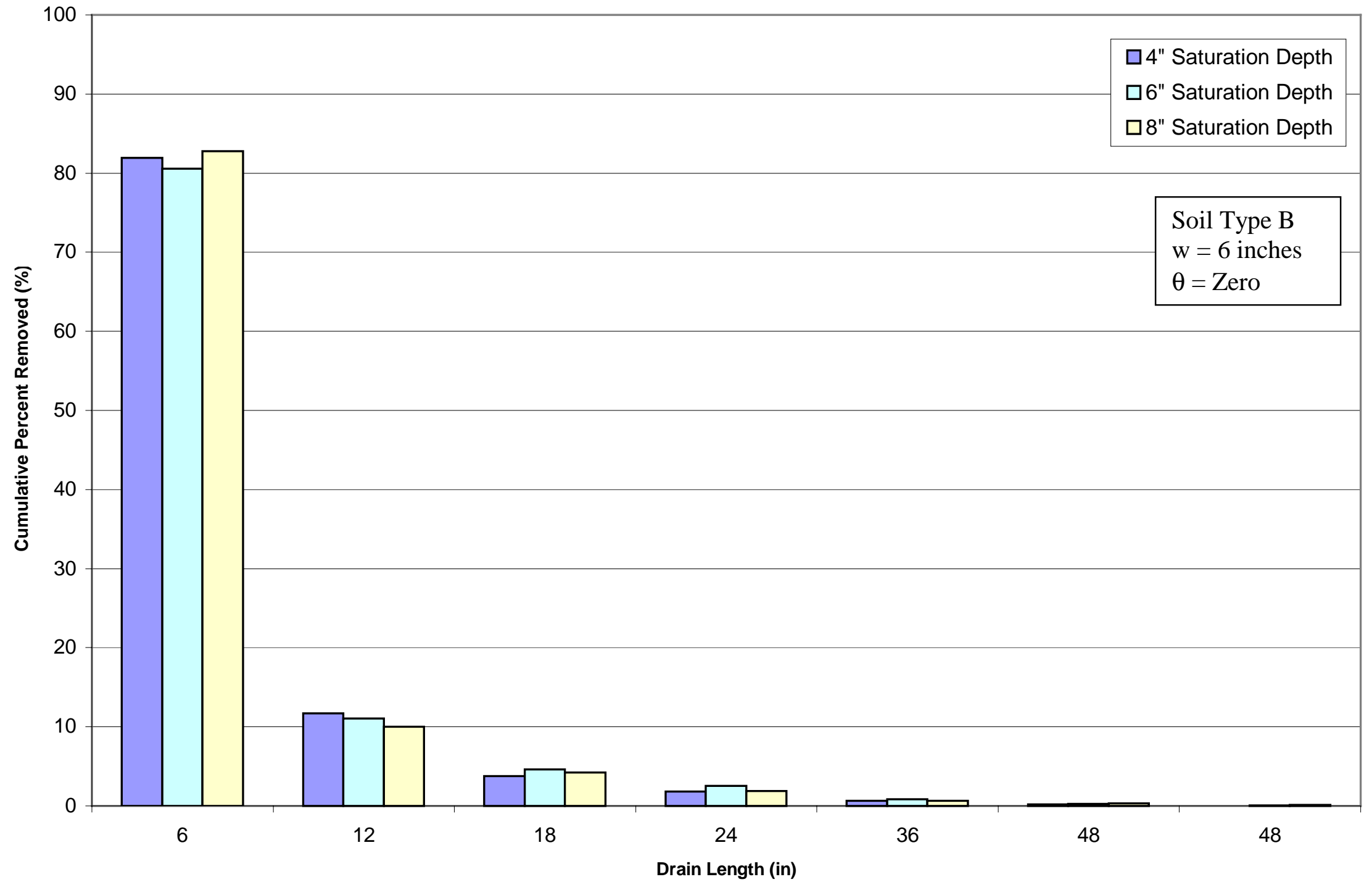

Figure C.9: Percent Seepage for Soil Type B ( $w=6$ inches, Zero Slope Angle). 


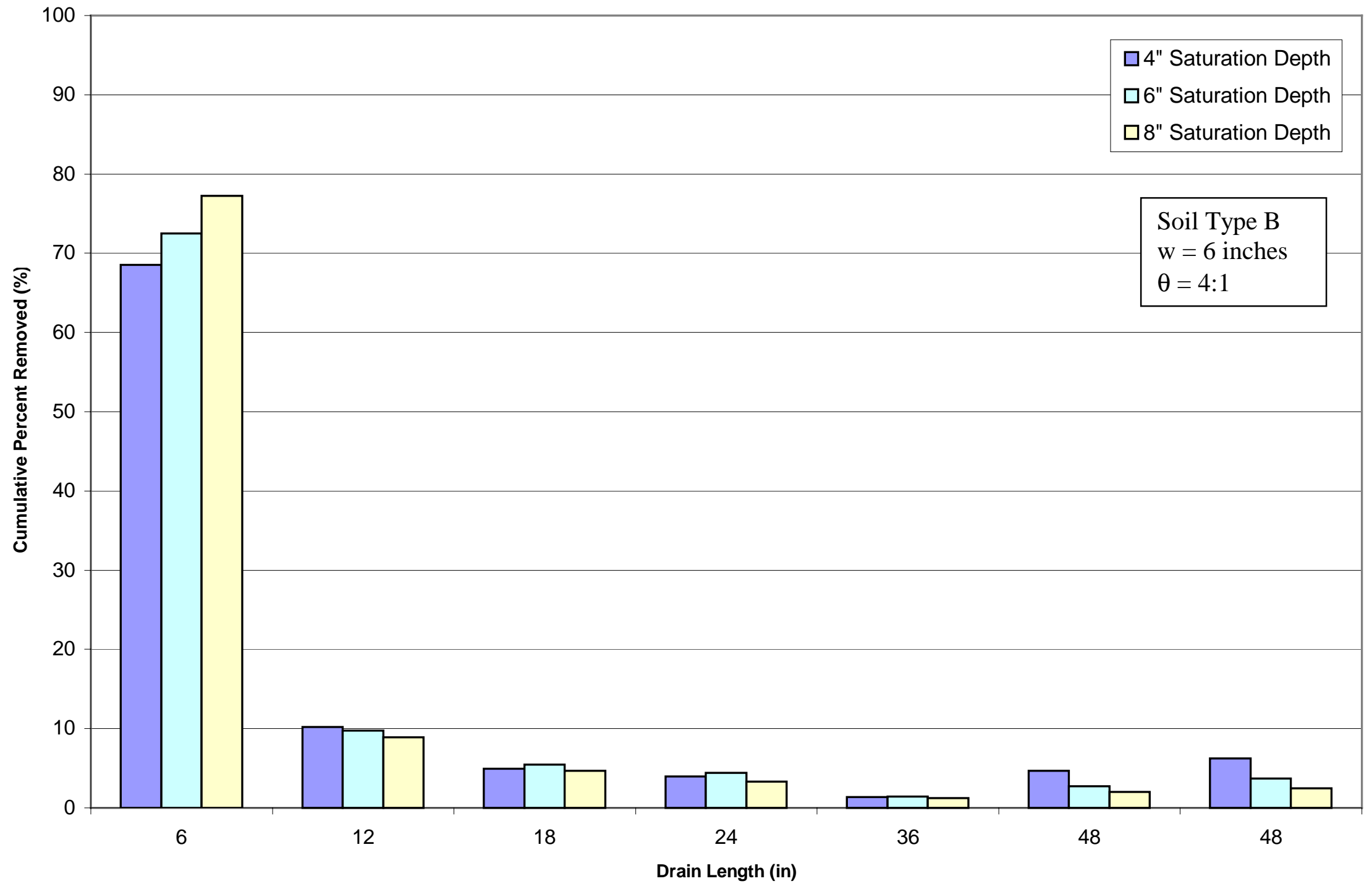

Figure C.10: Percent Seepage for Soil Type B ( $w=6$ inches, 4:1 Slope Angle). 


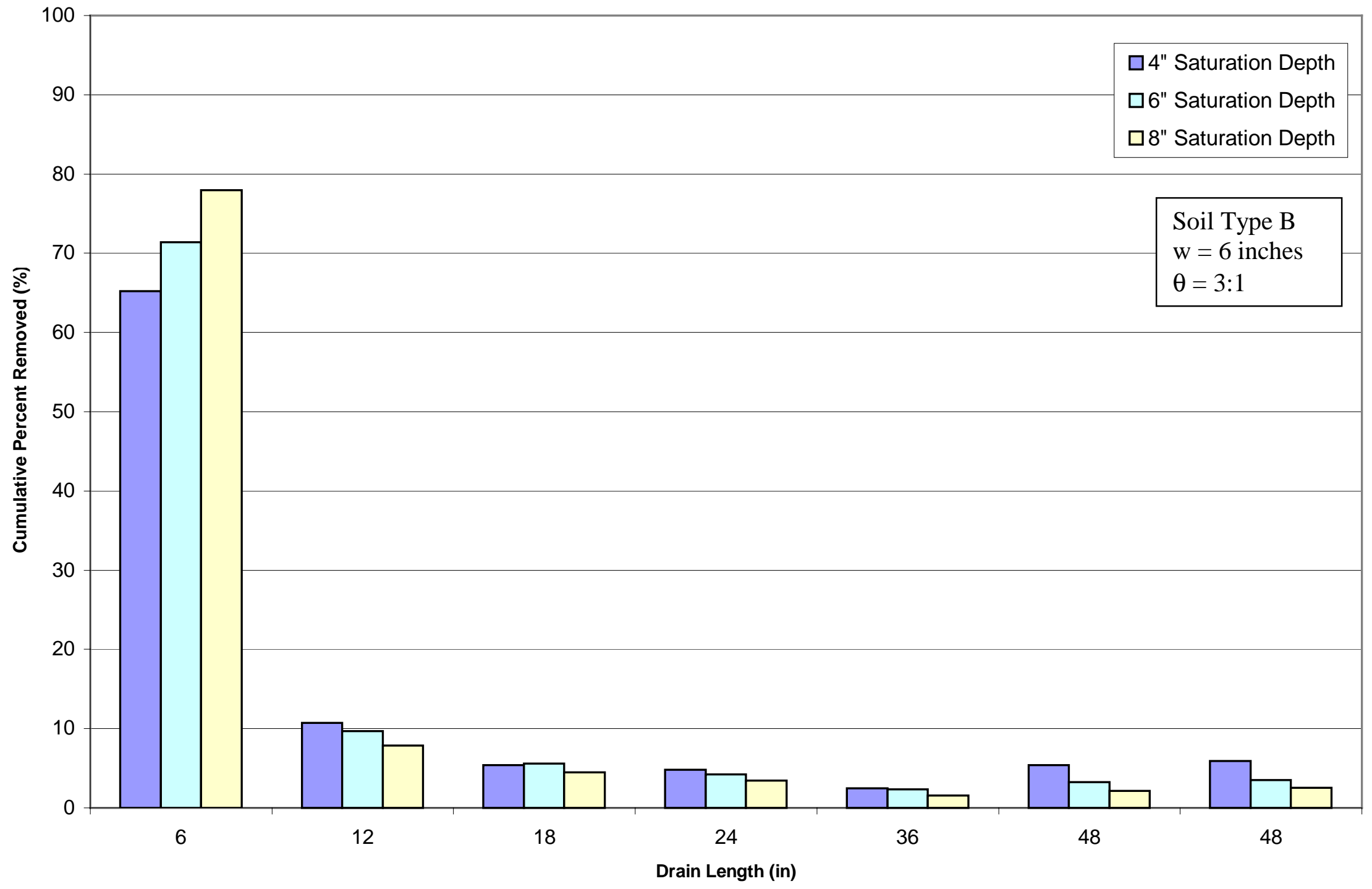

Figure C.11: Percent Seepage for Soil Type B ( $w=6$ inches, 3:1 Slope Angle). 


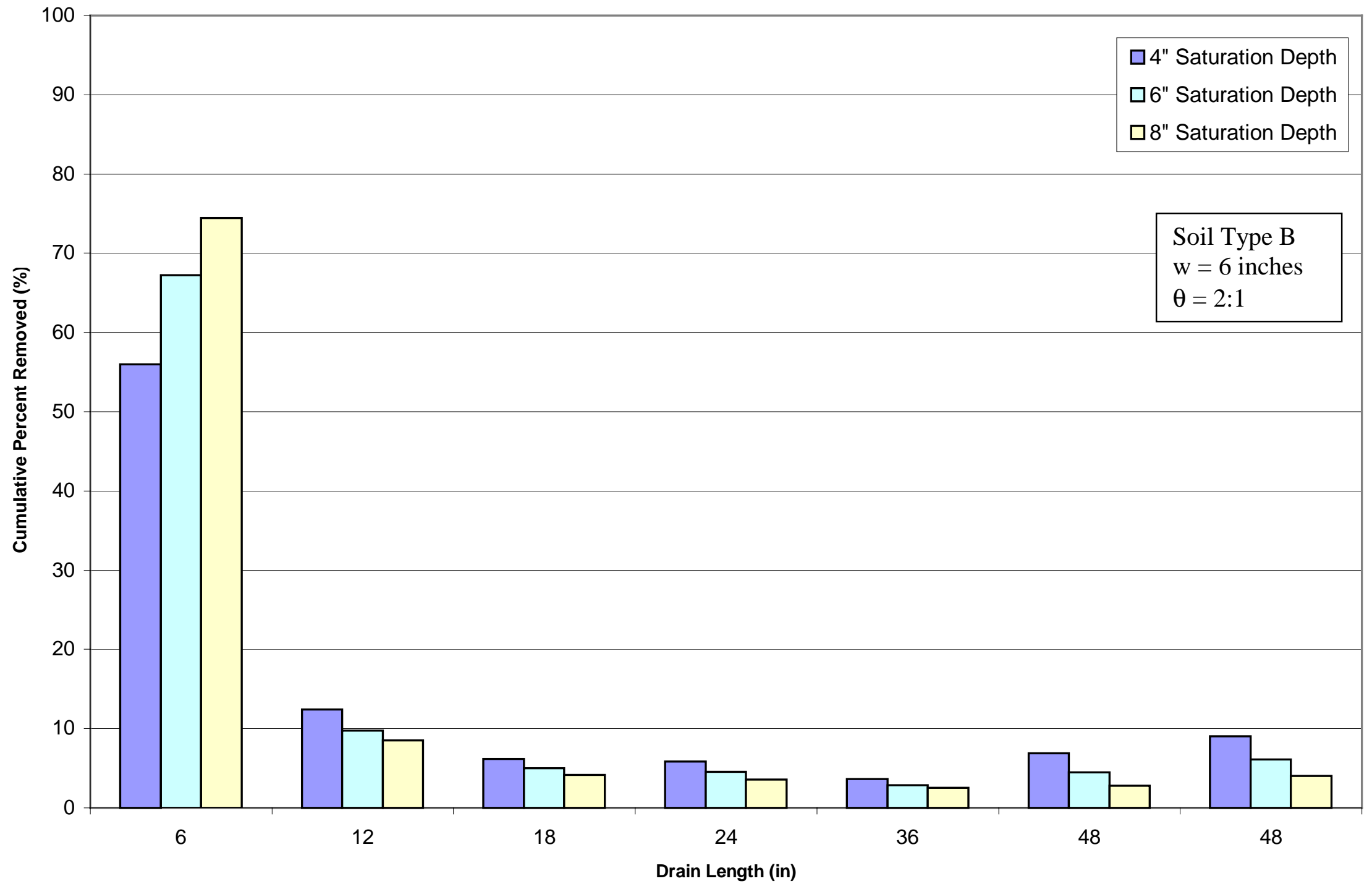

Figure C.12: Percent Seepage for Soil Type B ( $w=6$ inches, 2:1 Slope Angle). 


\begin{abstract}
APPENDIX D
Influence of Slope Angle

for Soil Type B (15\% Clay Content)

for Different Saturation Depth and Half Trench Spacing
\end{abstract}




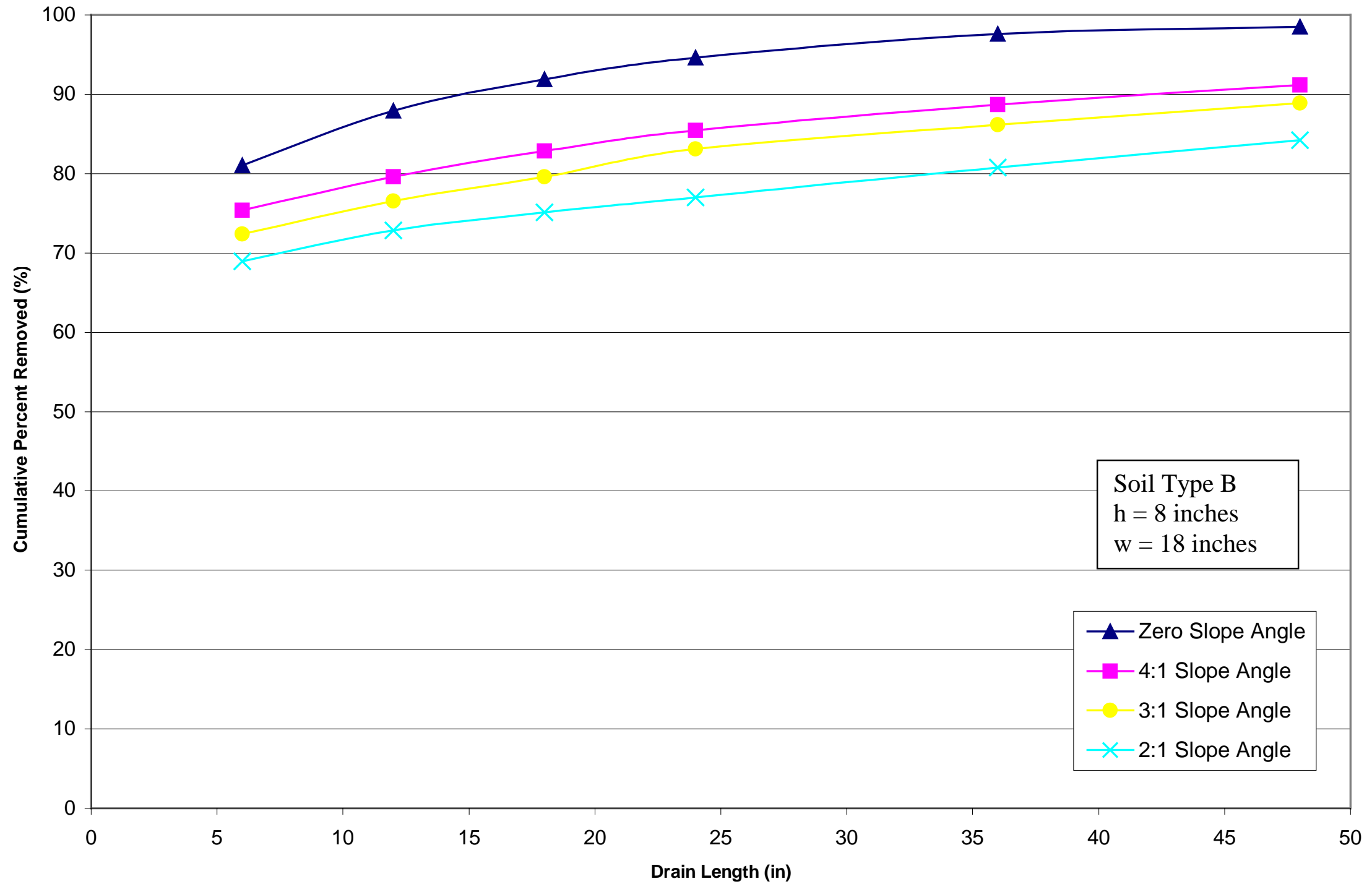

Figure D.1: Influence of Slope Angle for Soil Type B ( $h=8$ inches, $w=18$ inches). 


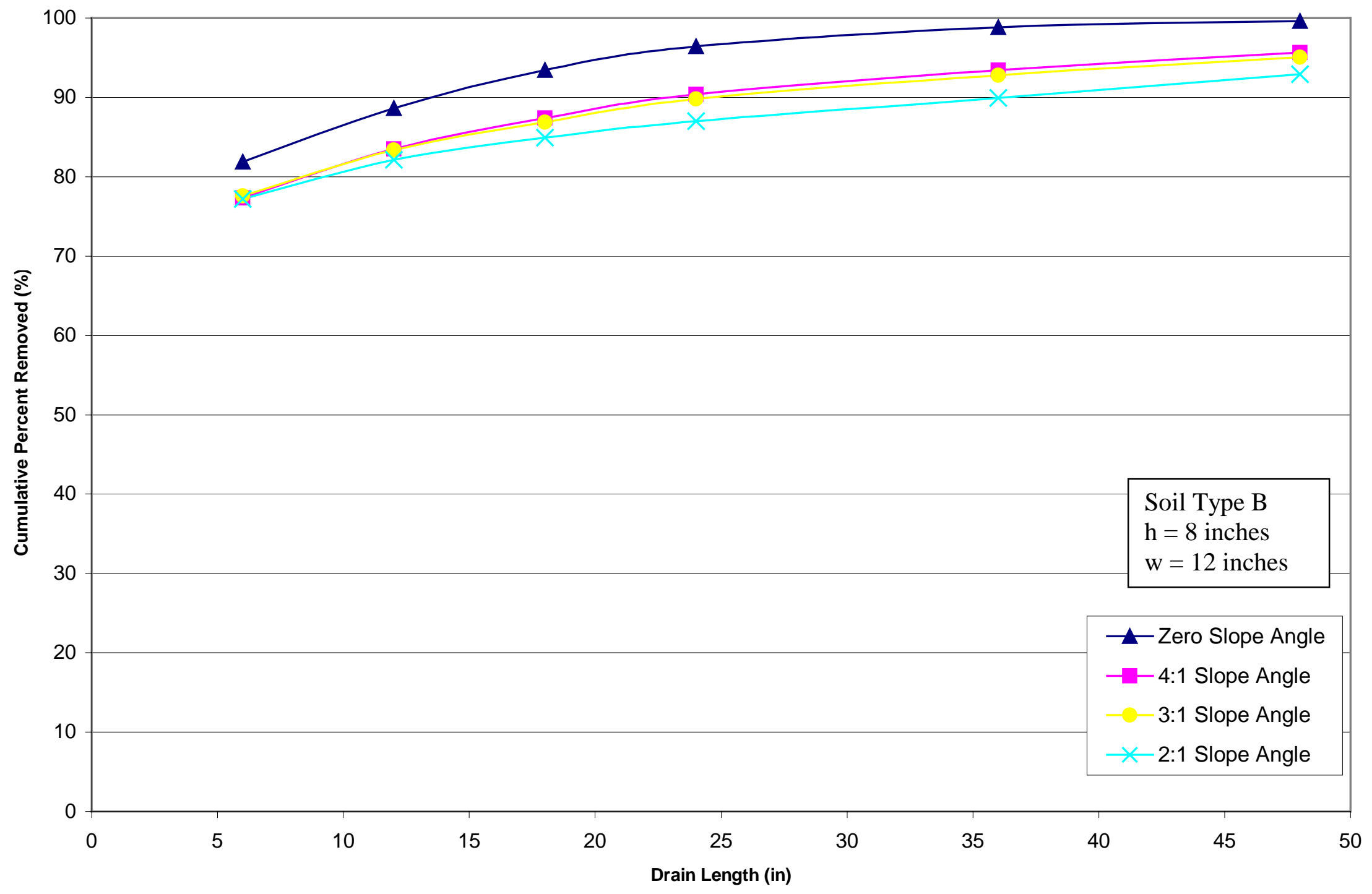

Figure D.2: Influence of Slope Angle for Soil Type B ( $h=8$ inches, $w=12$ inches). 


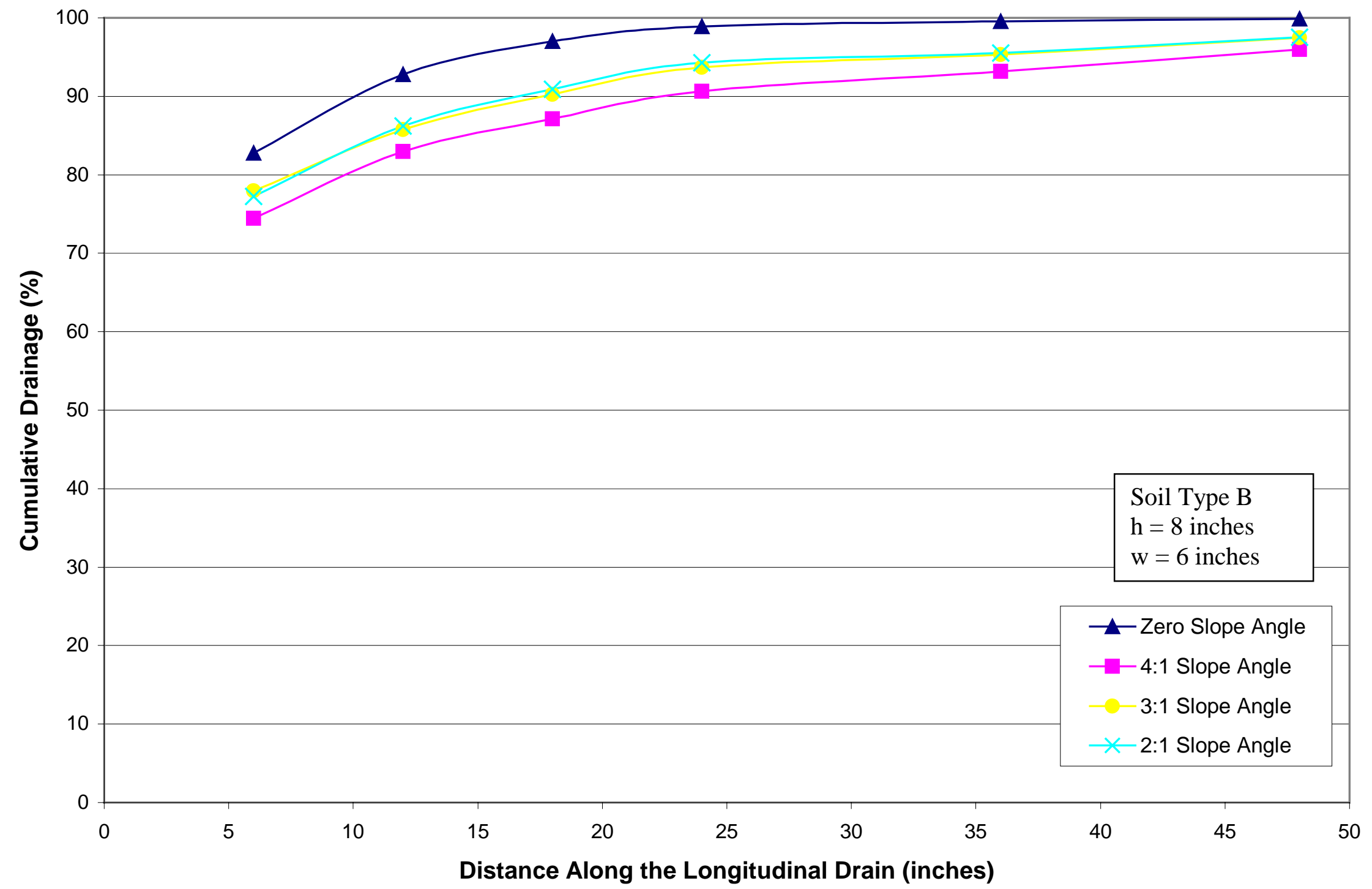

Figure D.3: Influence of Slope Angle for Soil Type B ( $h=8$ inches, $w=6$ inches). 


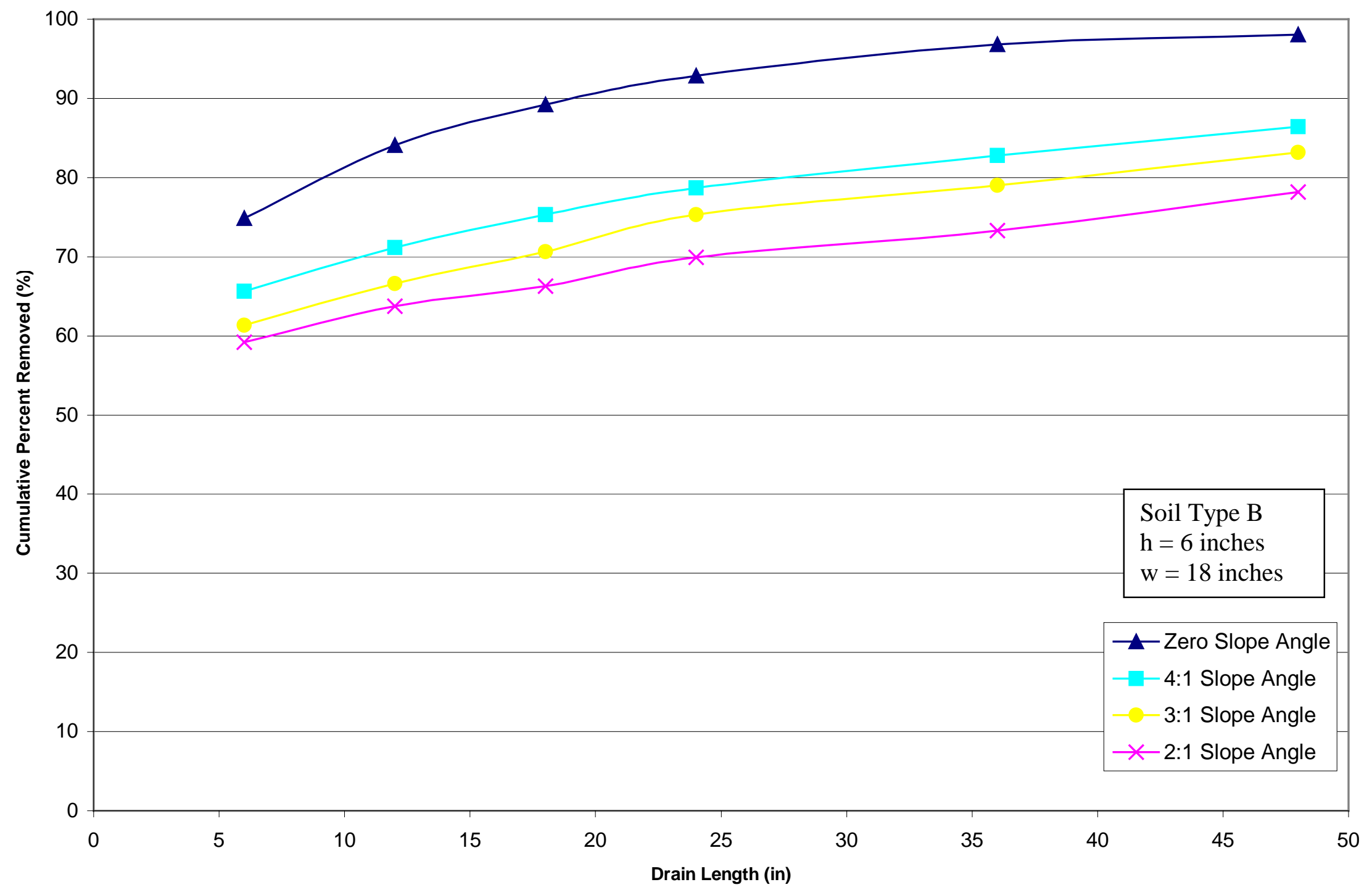

Figure D.4: Influence of Slope Angle for Soil Type B ( $h=6$ inches, $w=18$ inches). 


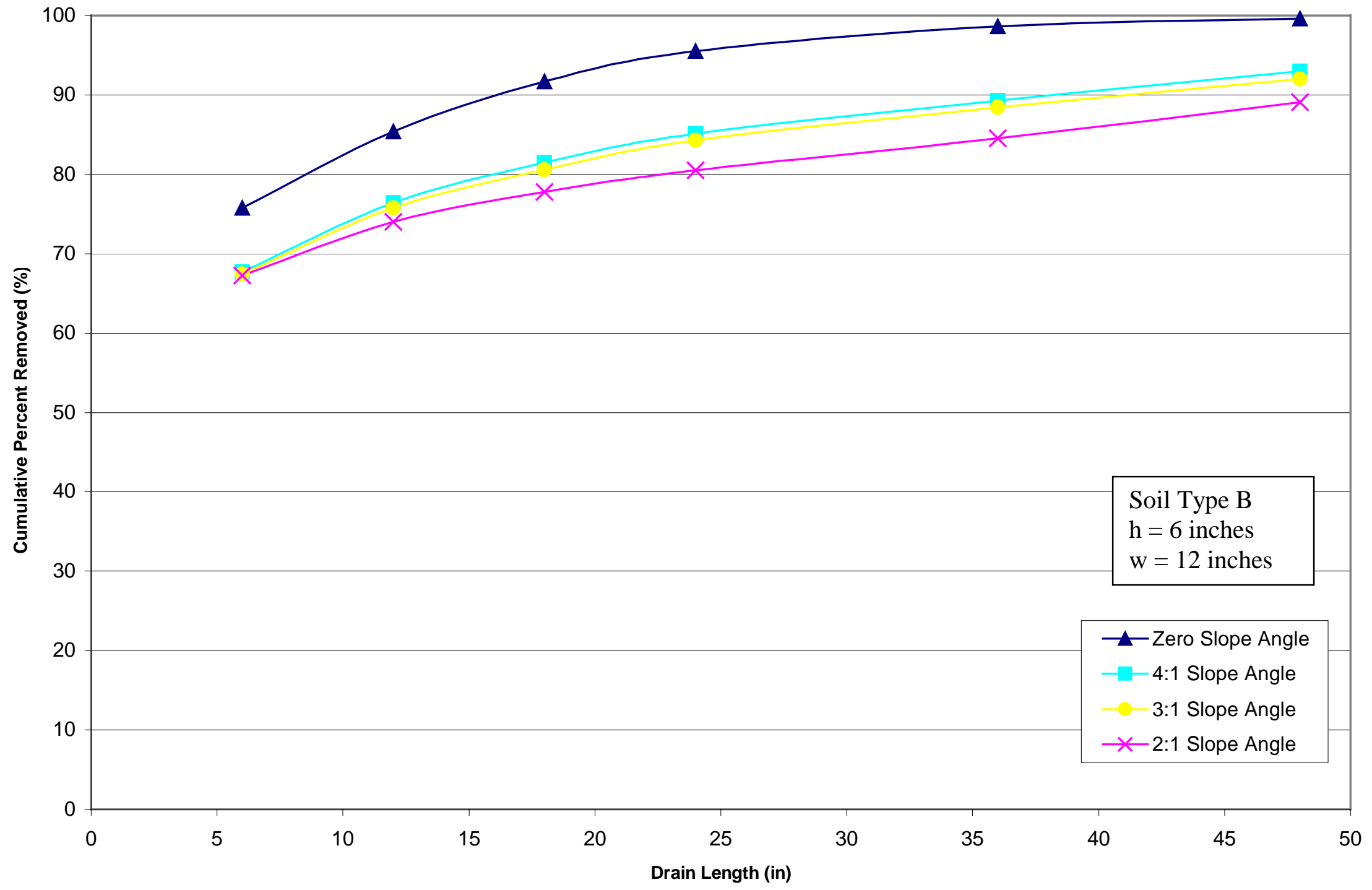

Figure D.5: Influence of Slope Angle for Soil Type B ( $h=6$ inches, $w=12$ inches). 


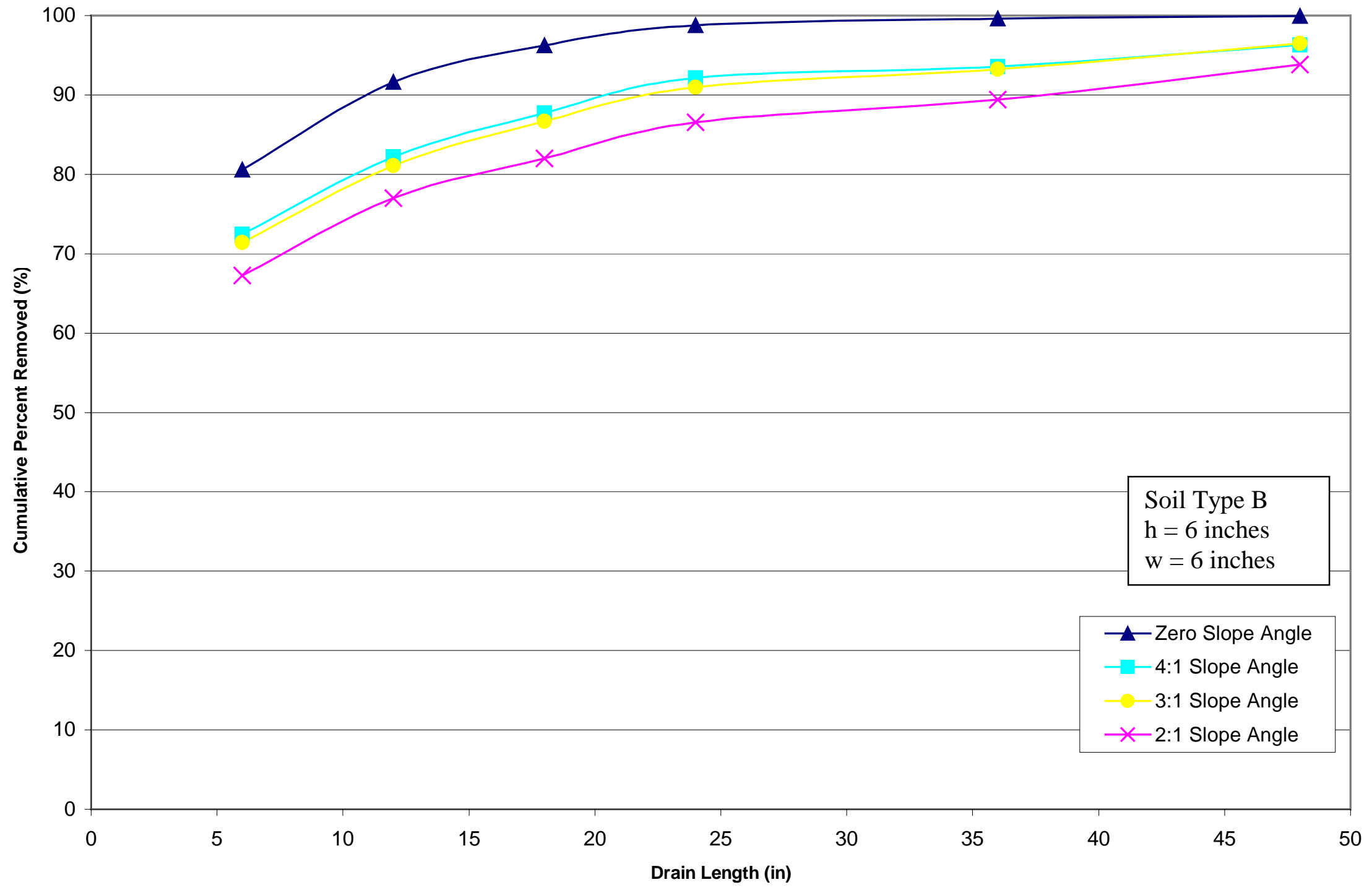

Figure D.6: Influence of Slope Angle for Soil Type B ( $h=6$ inches, $w=6$ inches). 


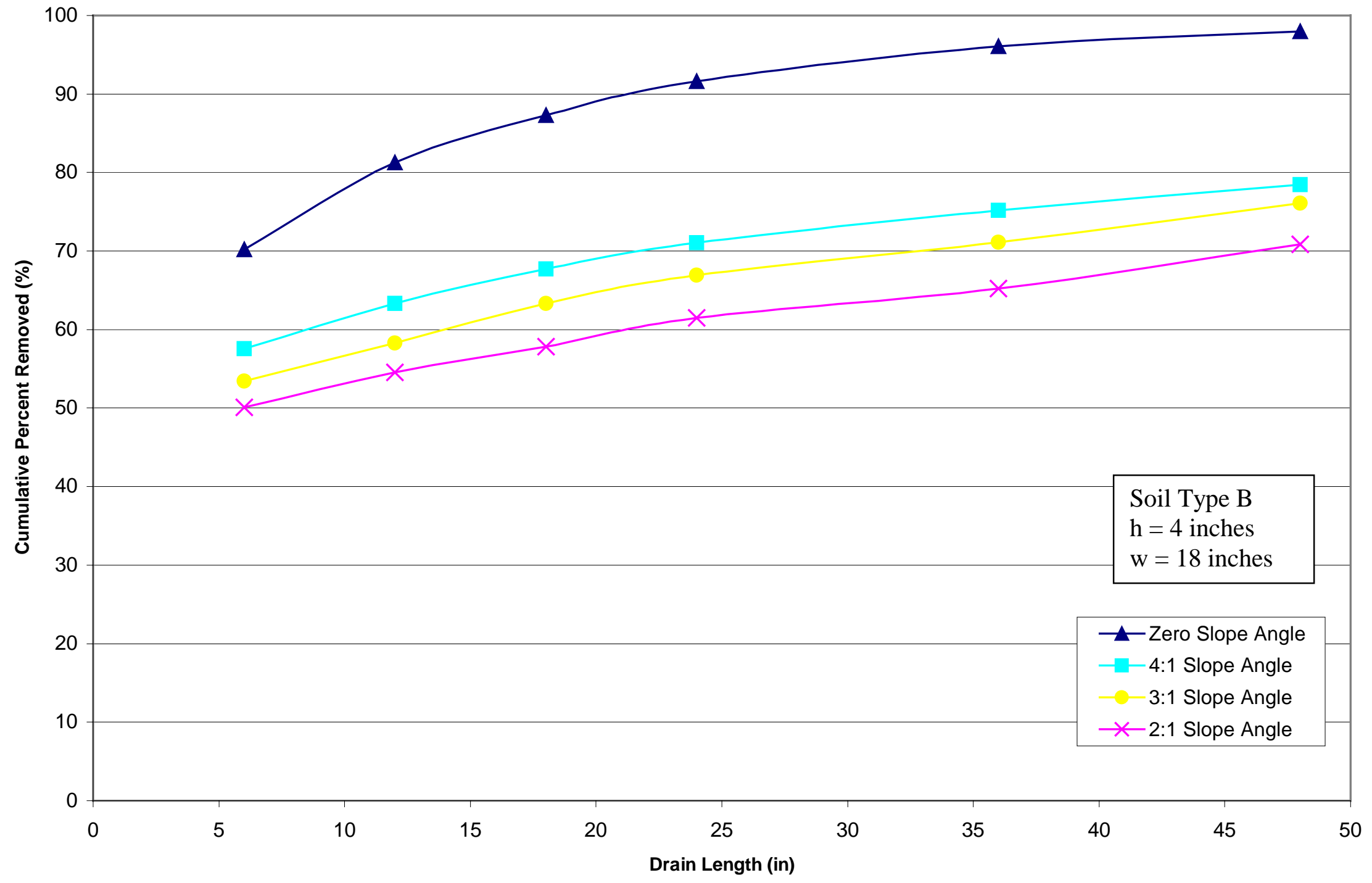

Figure D.7: Influence of Slope Angle for Soil Type B ( $h=4$ inches, $w=18$ inches). 


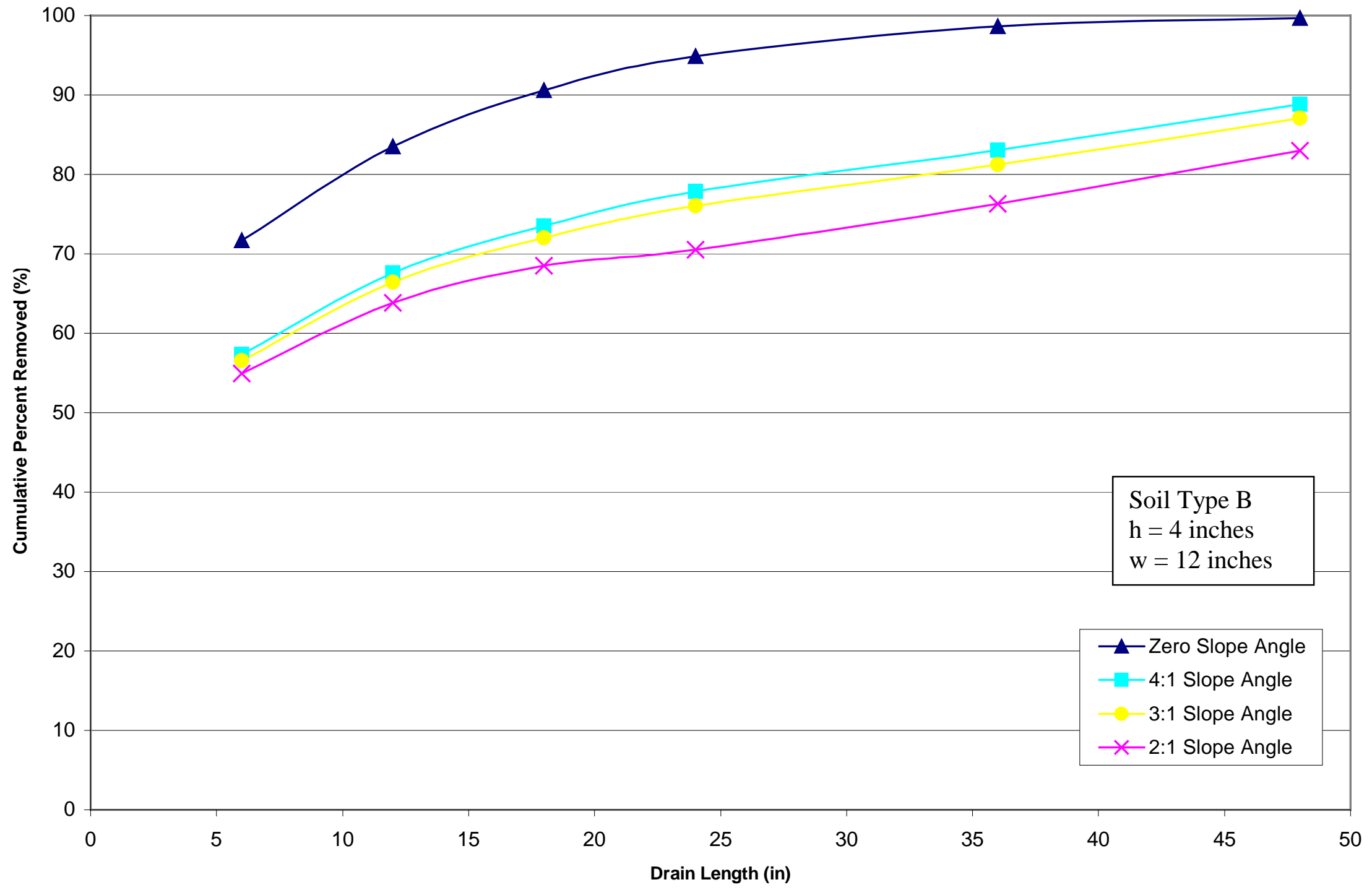

Figure D.8: Influence of Slope Angle for Soil Type B ( $h=4$ inches, $w=12$ inches). 


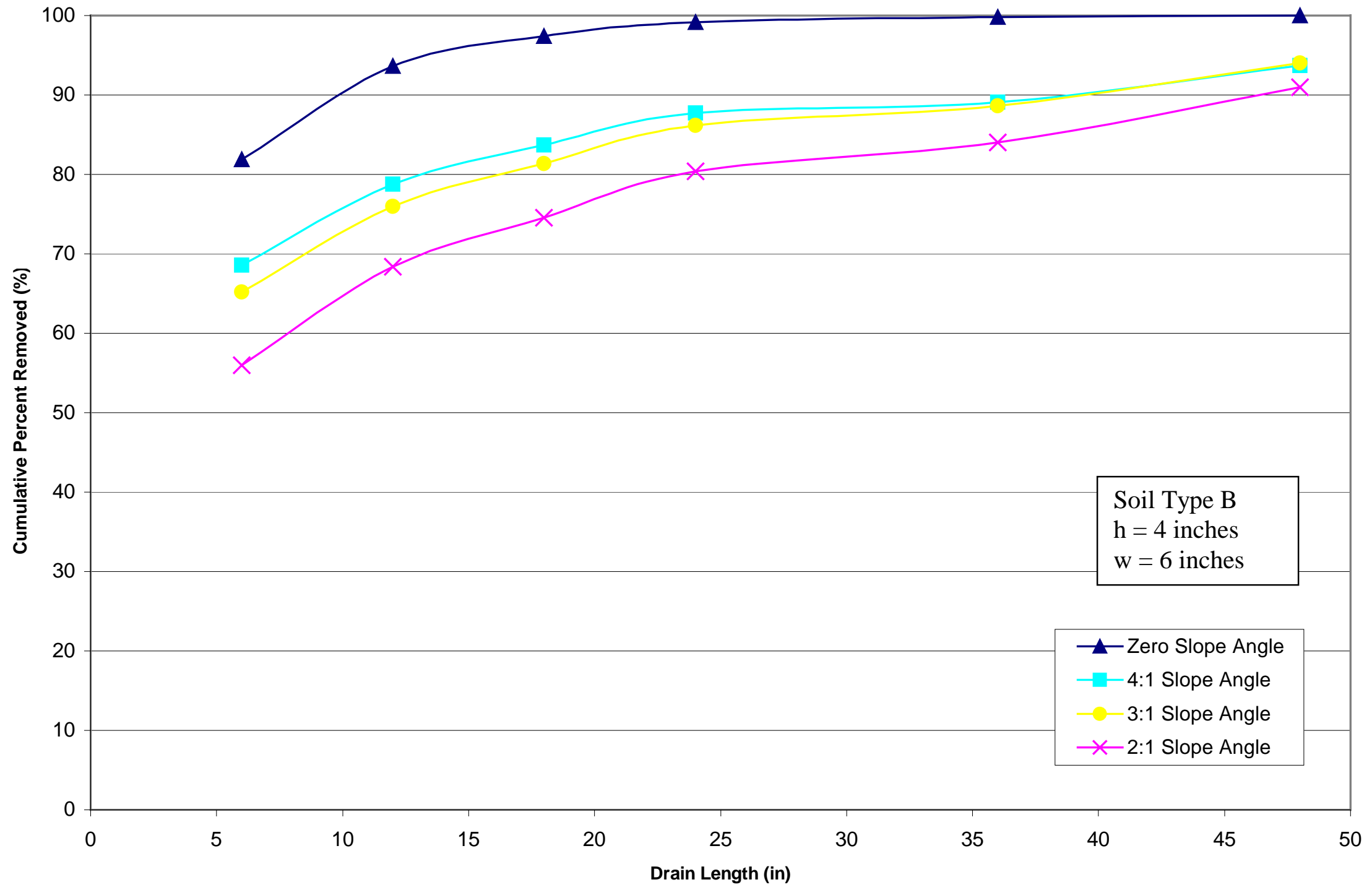

Figure D.9: Influence of Slope Angle for Soil Type B $(h=4$ inches, $w=6$ inches). 


\begin{abstract}
APPENDIX E
Influence of Trench Spacing

for Soil Type B (15\% Clay Content)

for Different Saturation Depth and Slope Angles.
\end{abstract}




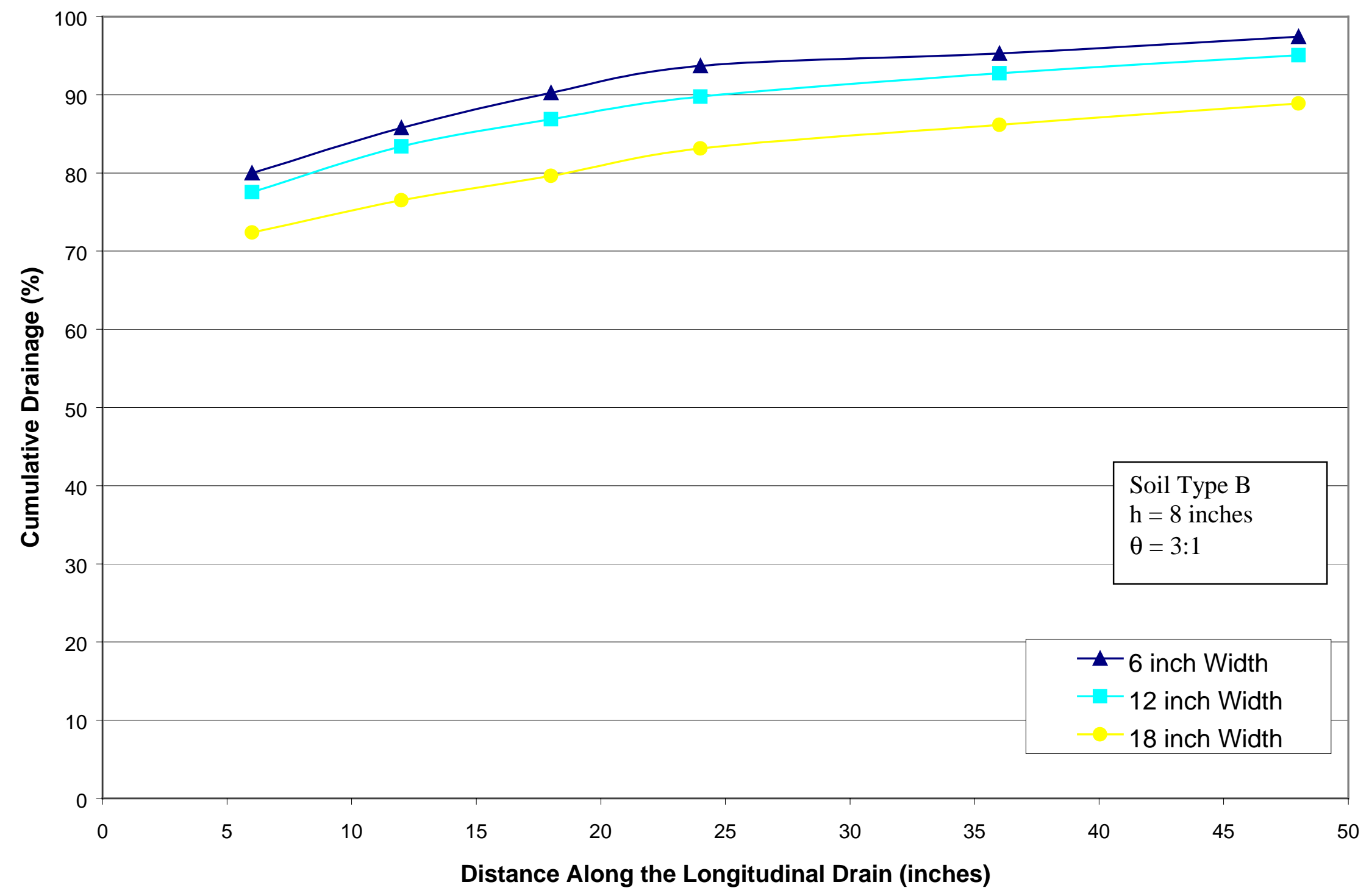

Figure E.1: Influence of Trench Spacing for soil Type B ( $h=8$ inches, 3:1 Slope Angle). 


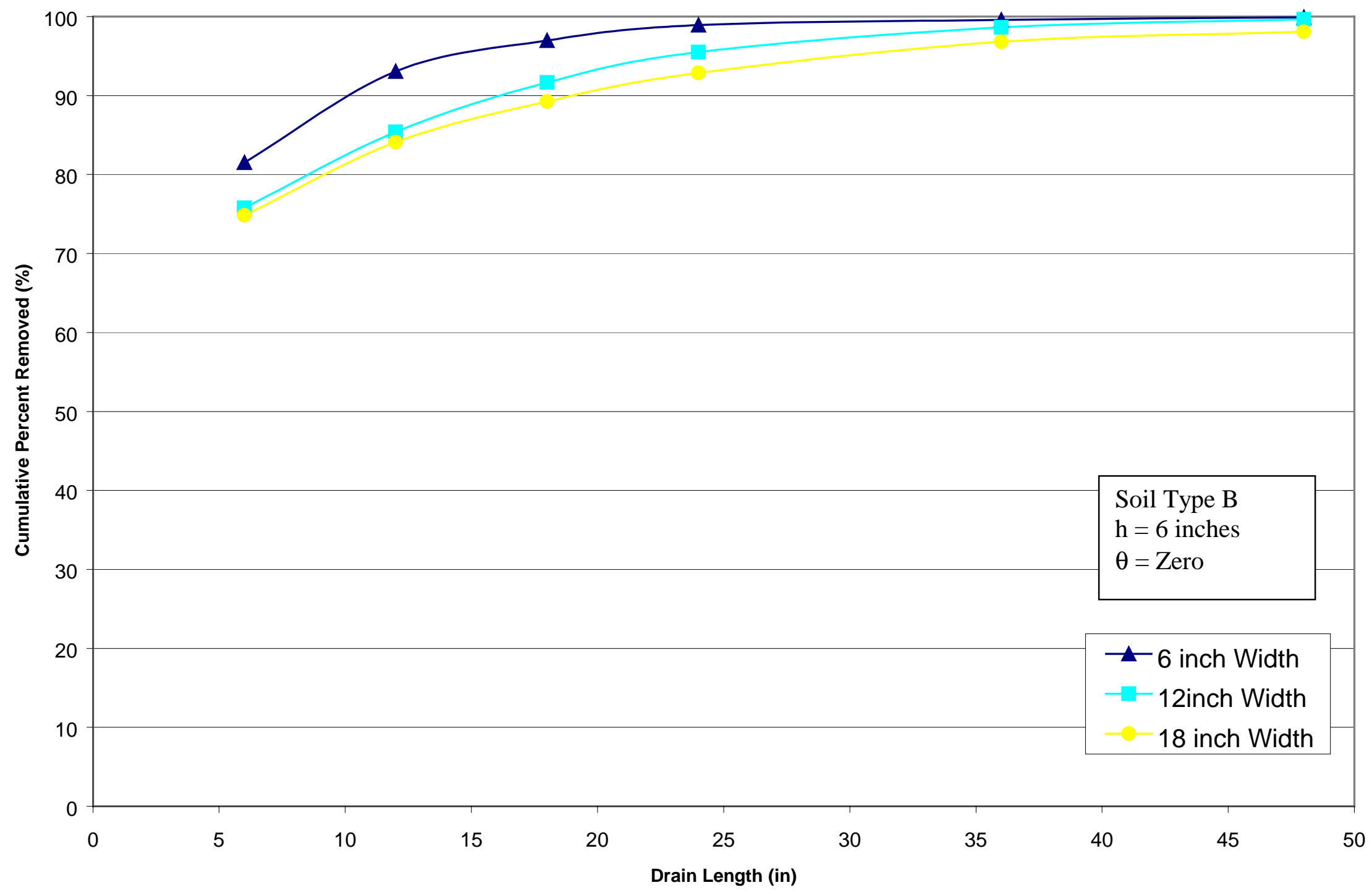

Figure E.2: Influence of Trench Spacing for soil Type B ( $h=6$ inches, Zero Slope Angle). 


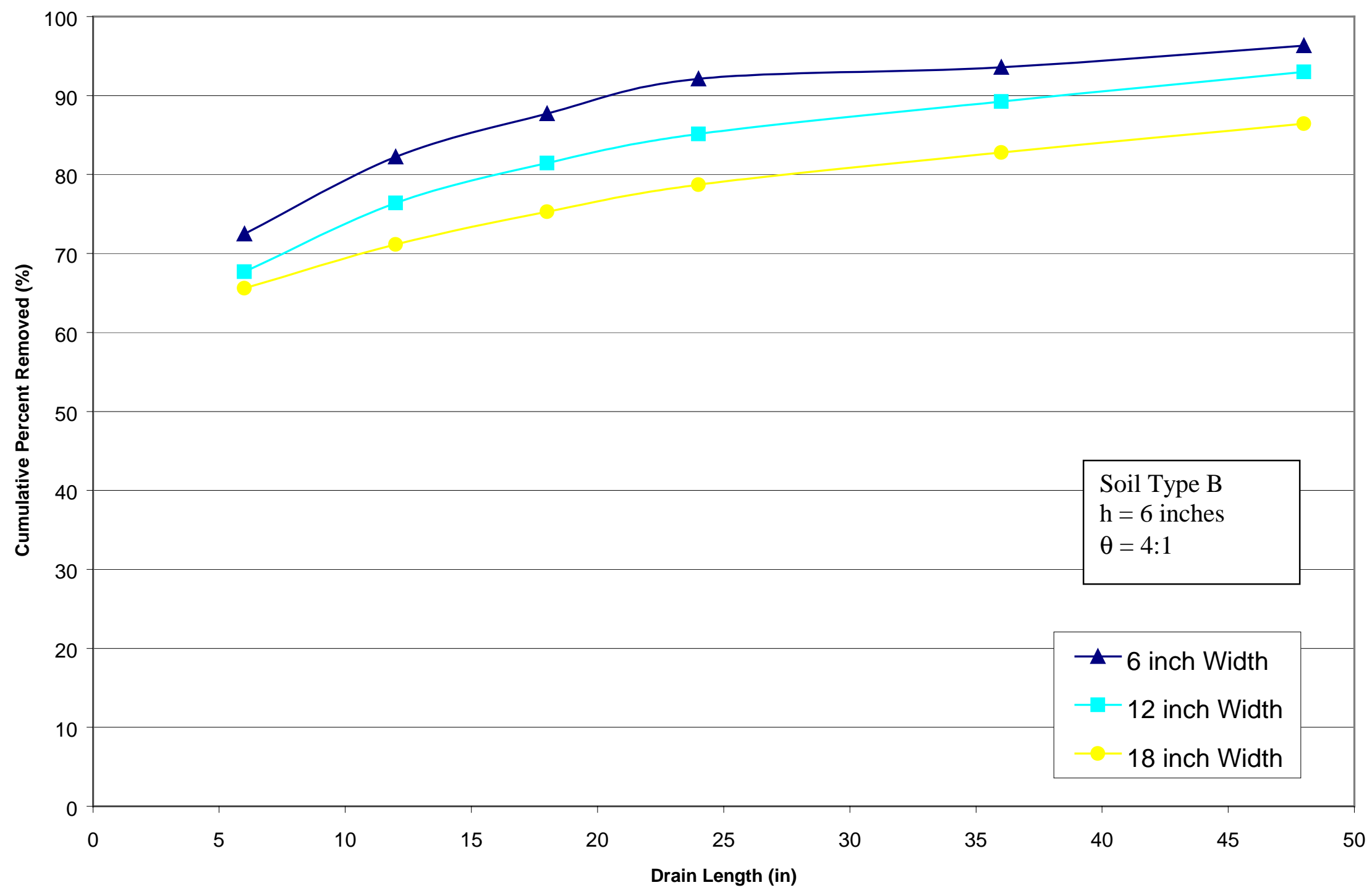

Figure E.3: Influence of Trench Spacing for soil Type B ( $h=6$ inches, 4:1 Slope Angle). 


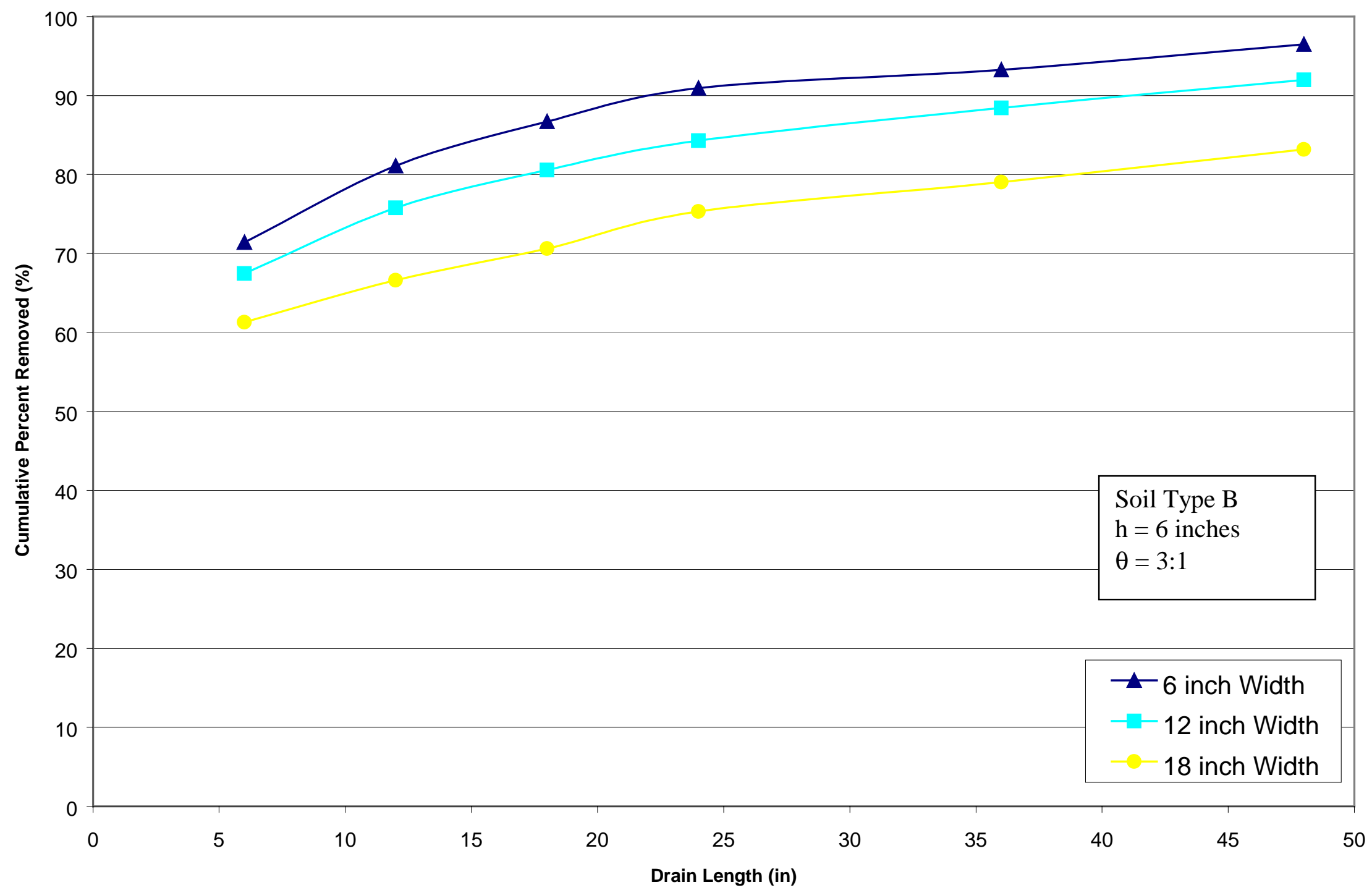

Figure E.4: Influence of Trench Spacing for soil Type B ( $h=6$ inches, 3:1 Slope Angle). 


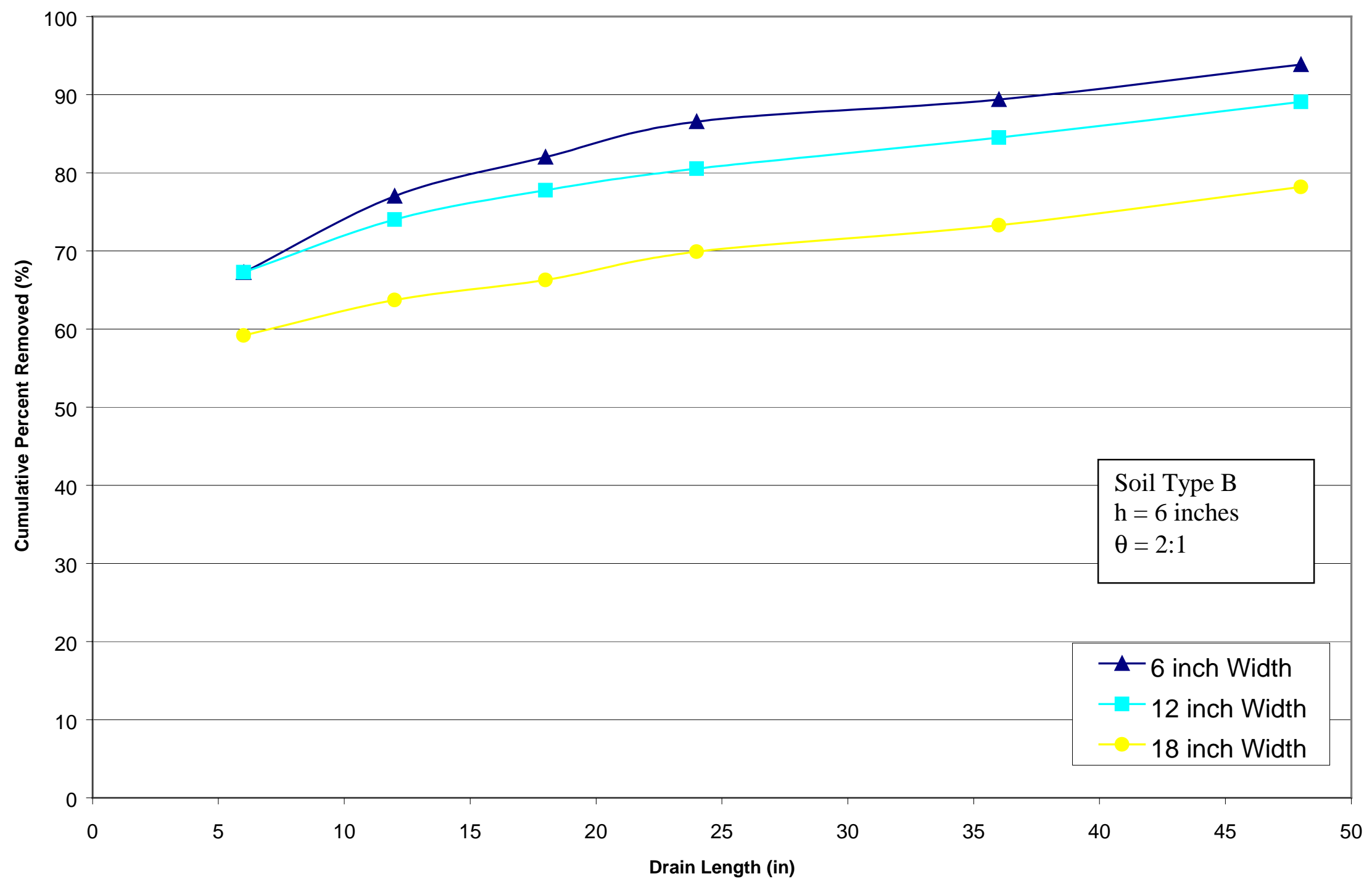

Figure E.5: Influence of Trench Spacing for soil Type B ( $h=6$ inches, 2:1 Slope Angle). 


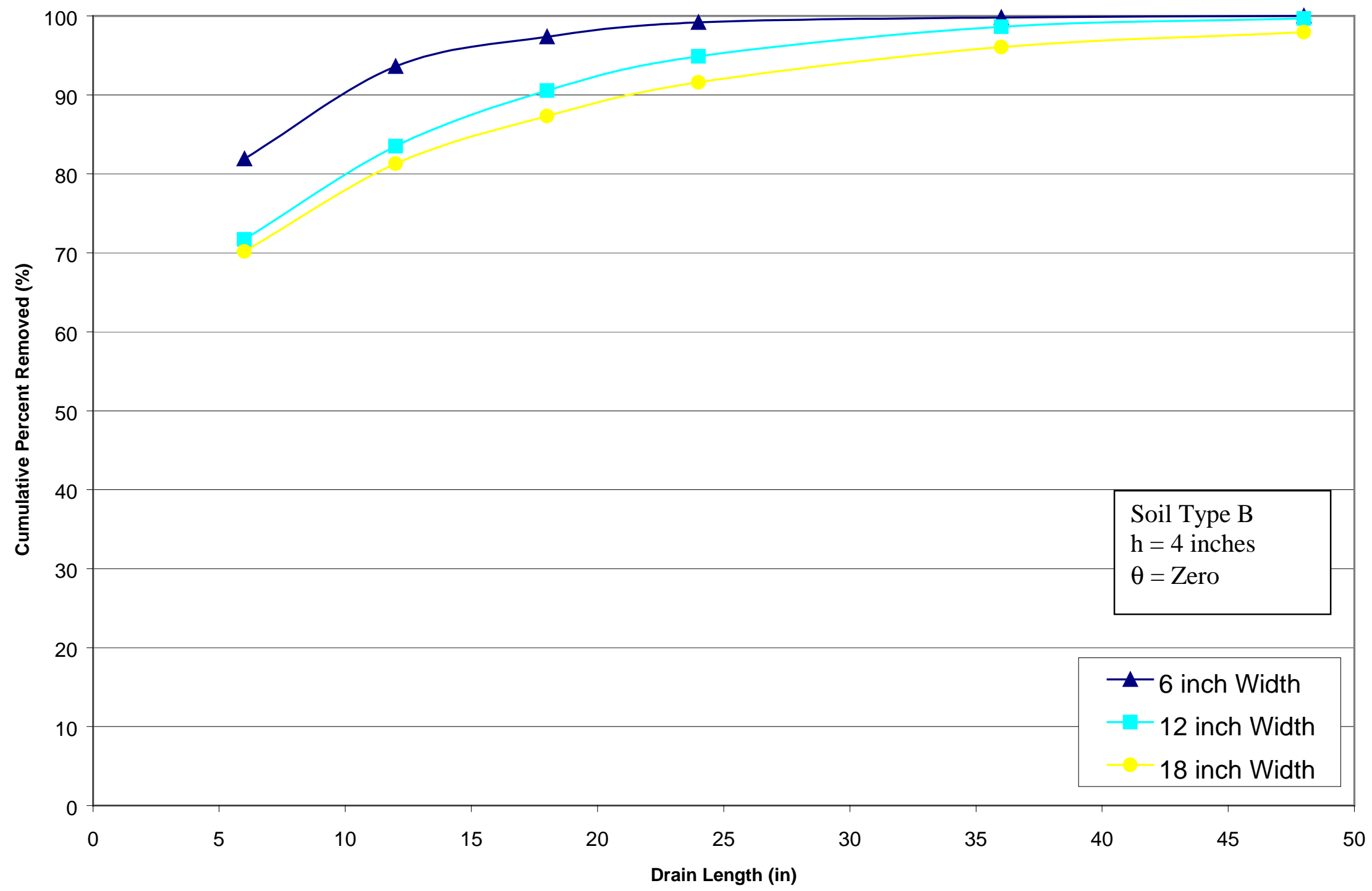

Figure E.6: Influence of Trench Spacing for soil Type B ( $h=4$ inches, Zero Slope Angle). 


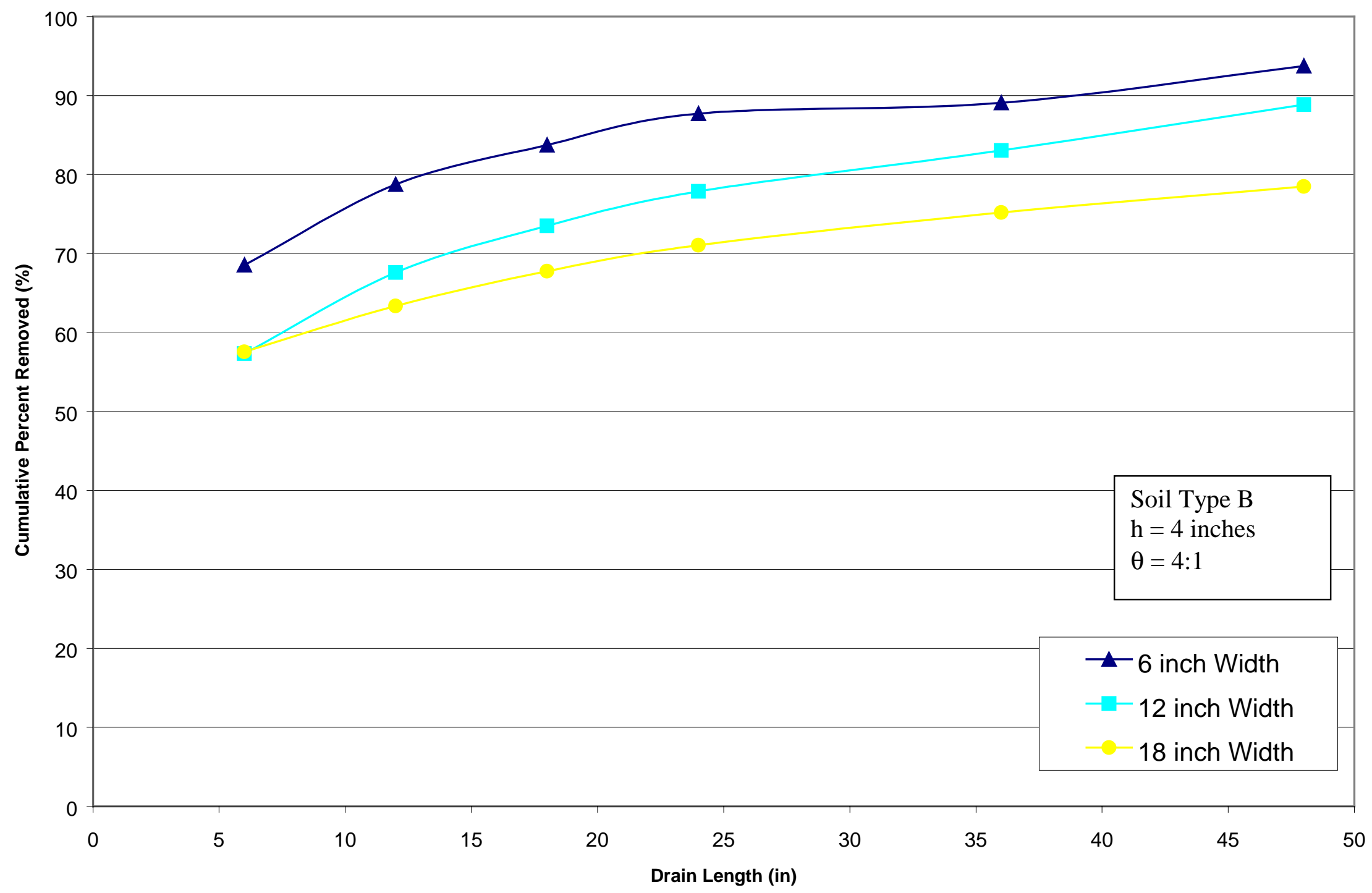

Figure E.7: Influence of Trench Spacing for soil Type B ( $h=4$ inches, 4:1 Slope Angle). 


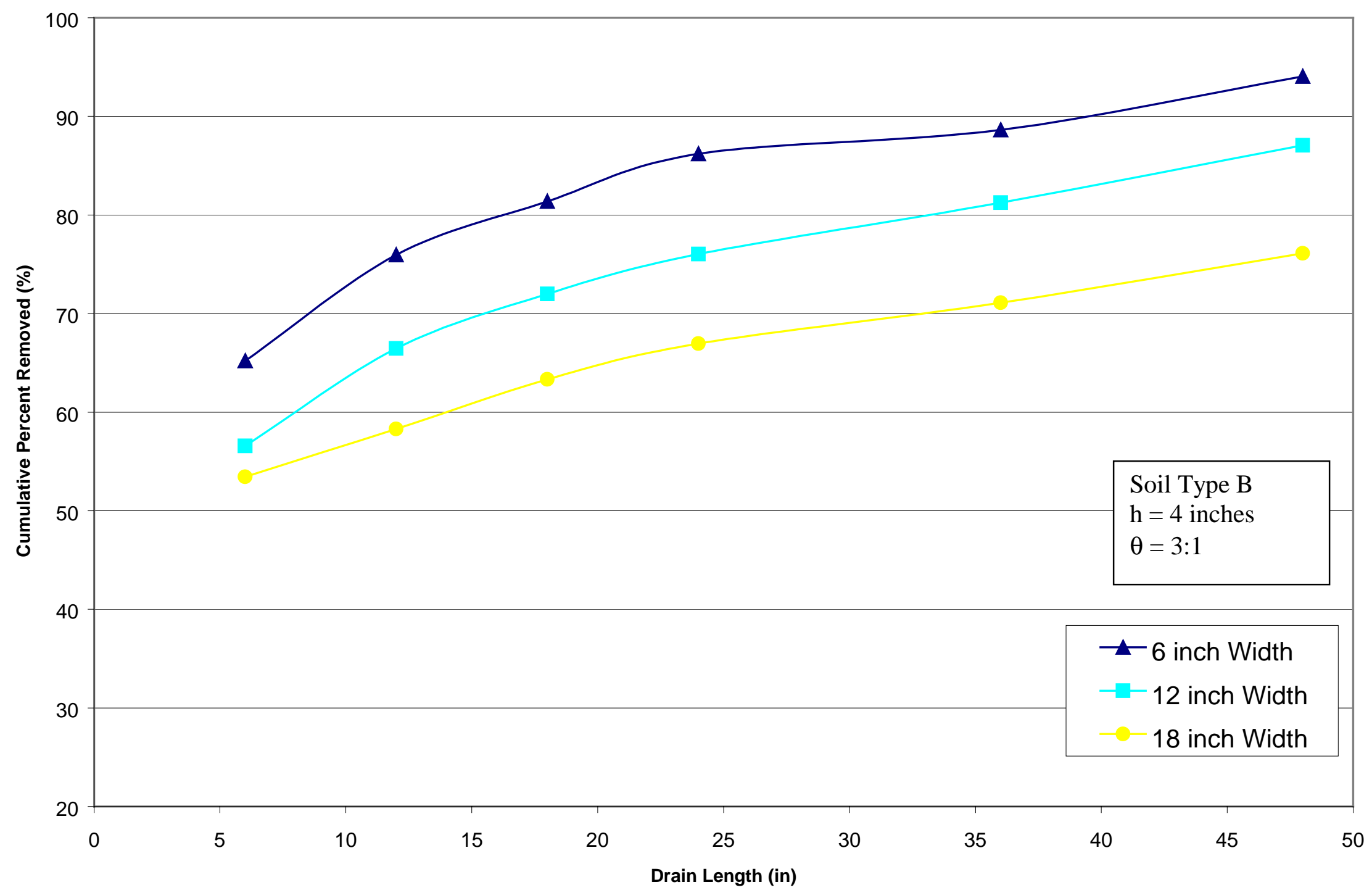

Figure E.8: Influence of Trench Spacing for soil Type B ( $h=4$ inches, 3:1 Slope Angle). 


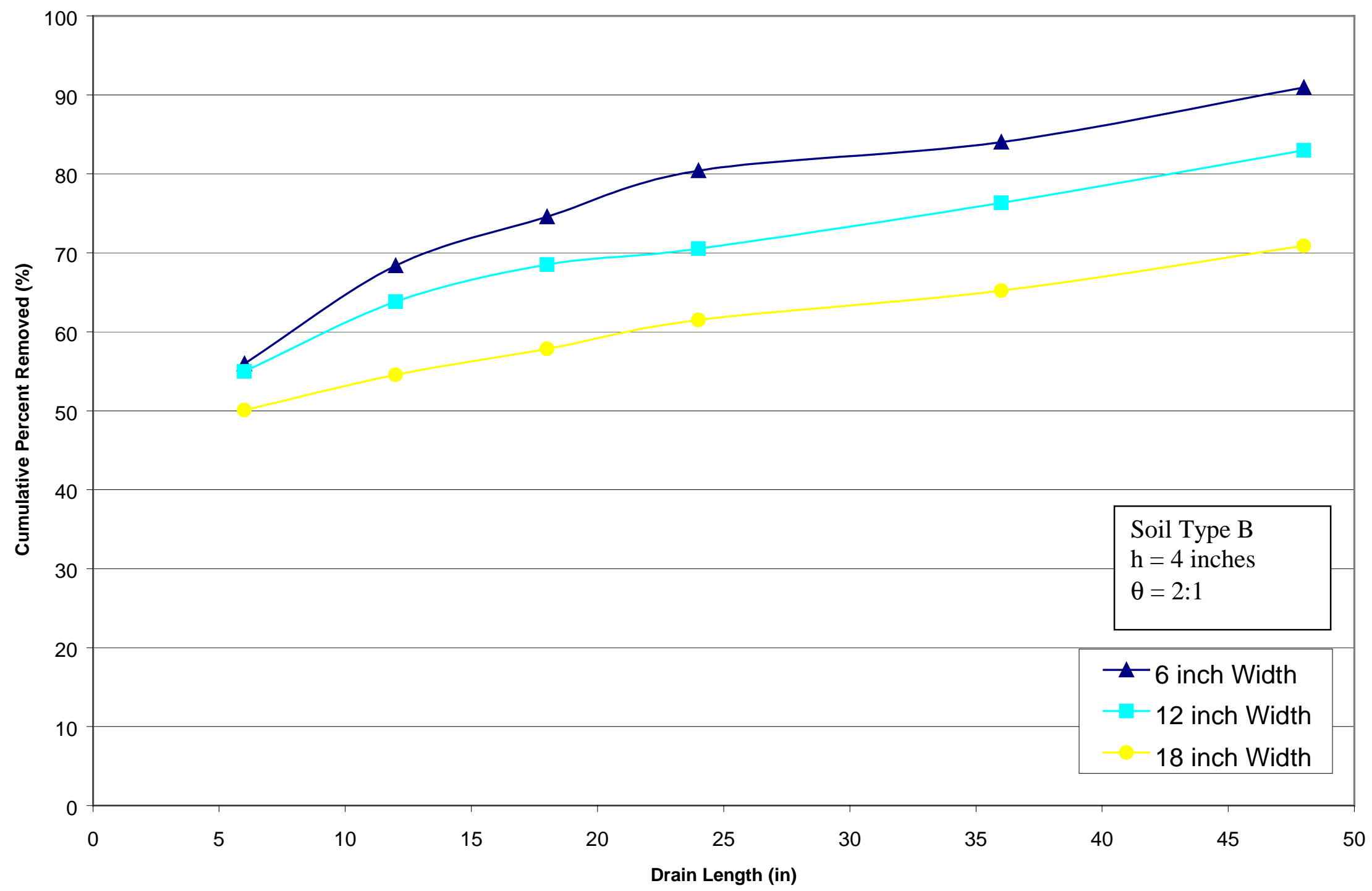

Figure E.9: Influence of Trench Spacing for soil Type B ( $h=4$ inches, 2:1 Slope Angle). 


\section{APPENDIX F}

Influence of Saturation Depth

for Soil Type B (15\% Clay Content)

for different Trench Spacing and Slope Angles. 


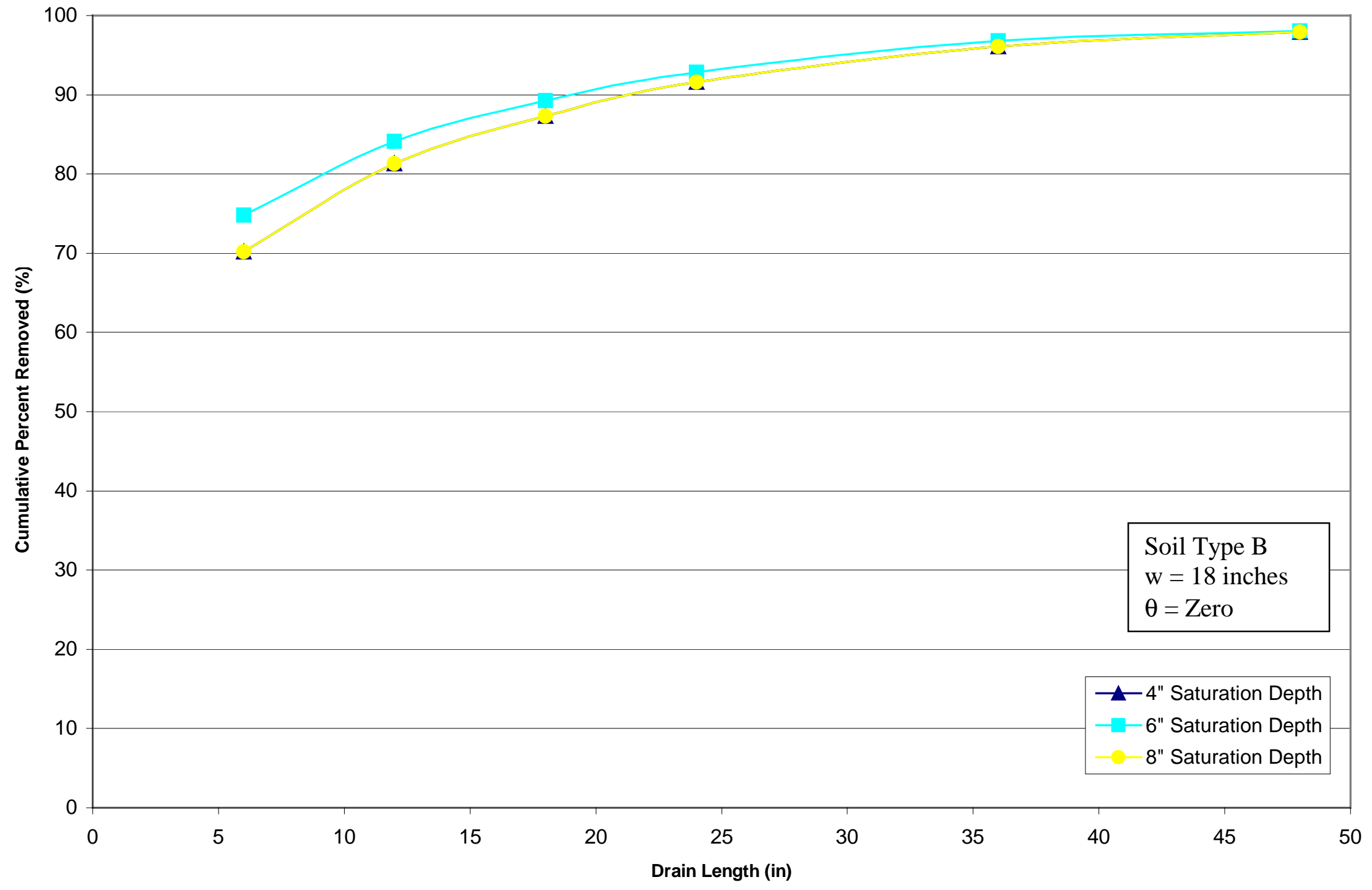

Figure F.1: Influence of Saturation Depth for soil Type B ( $w=18$ inches, Zero Slope Angle). 


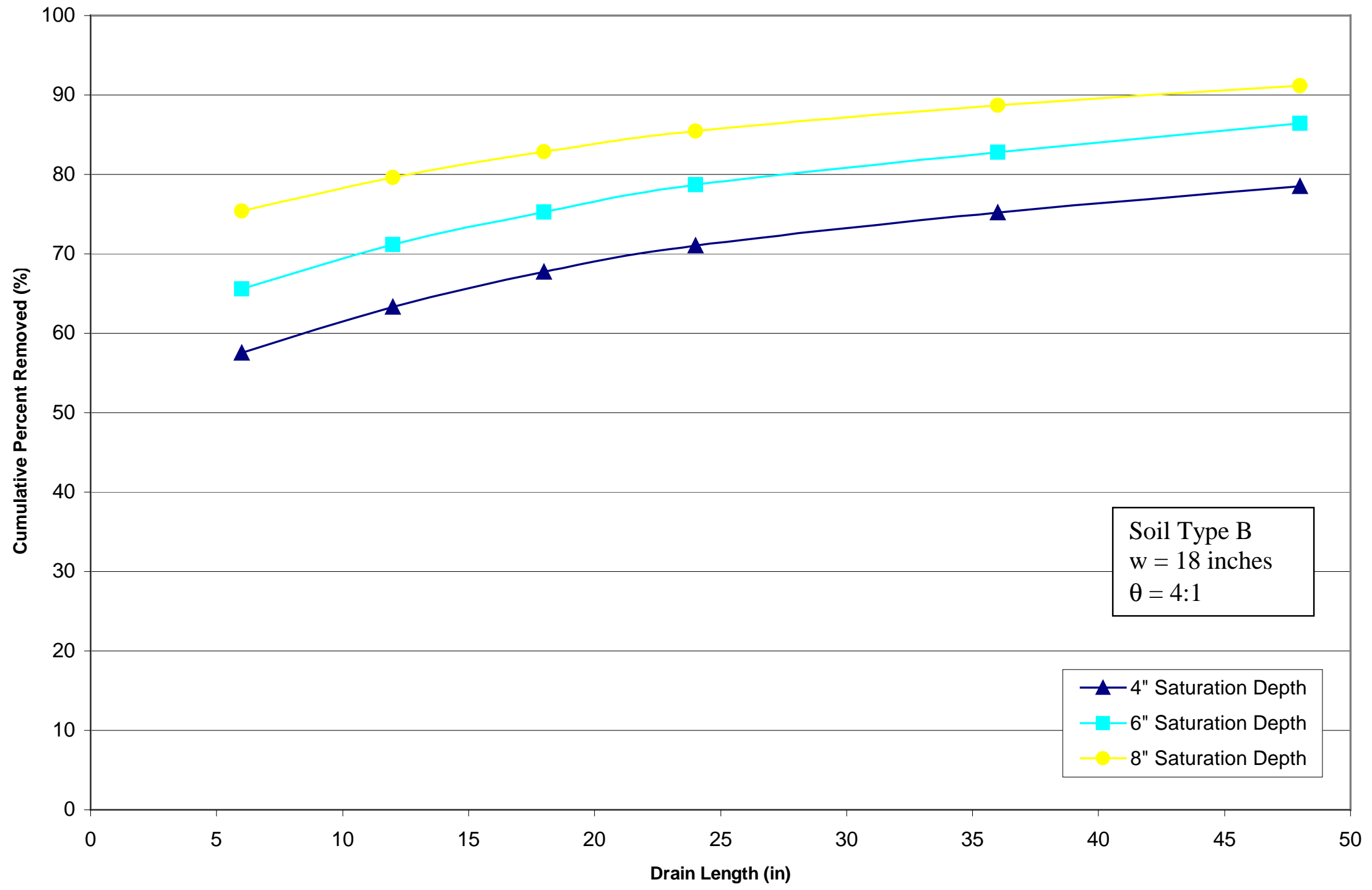

Figure F.2: Influence of Saturation Depth for soil Type B ( $w=18$ inches, 4:1 Slope Angle). 


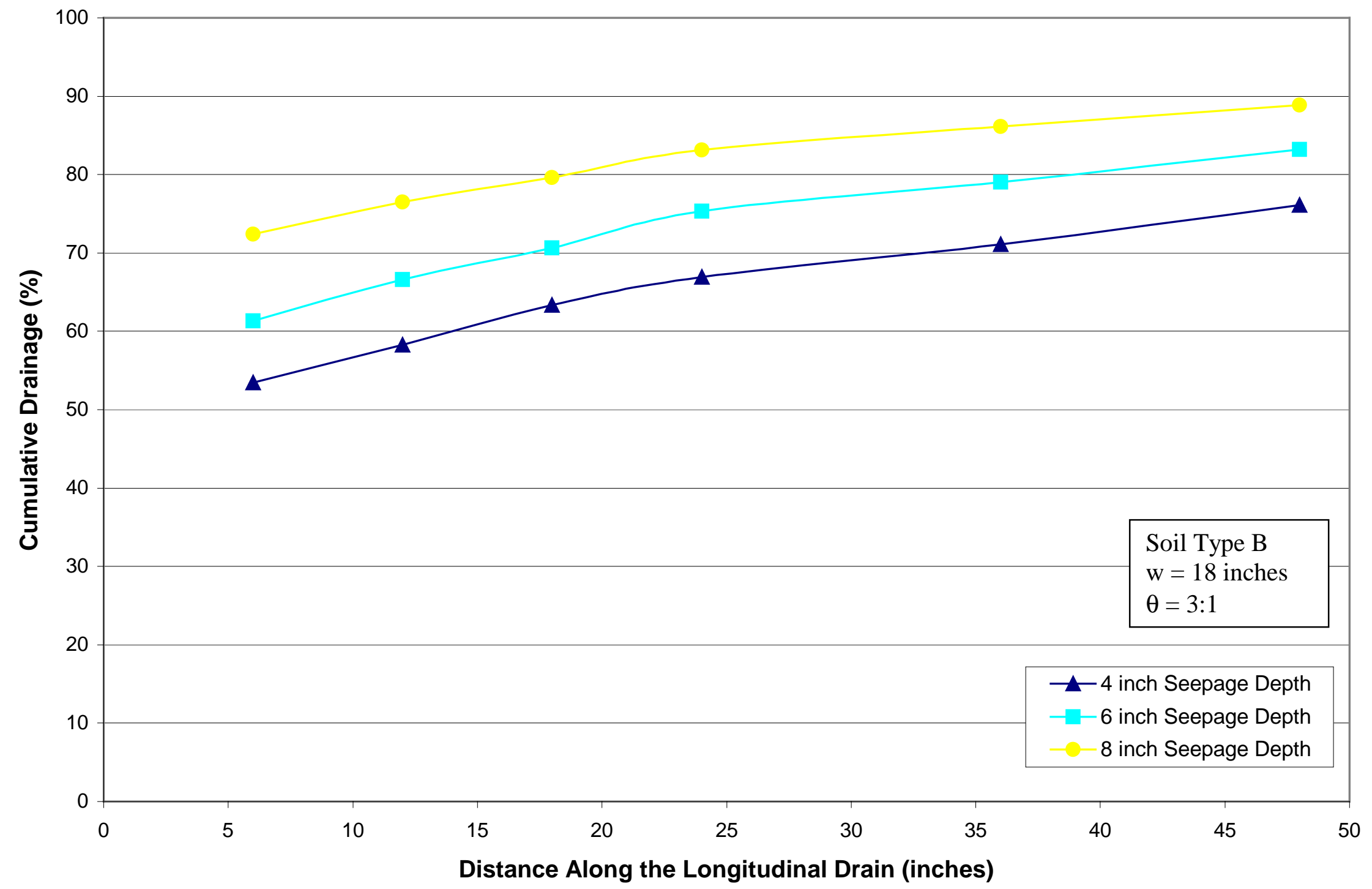

Figure F.3: Influence of Saturation Depth for soil Type B ( $w=18$ inches, 3:1 Slope Angle). 


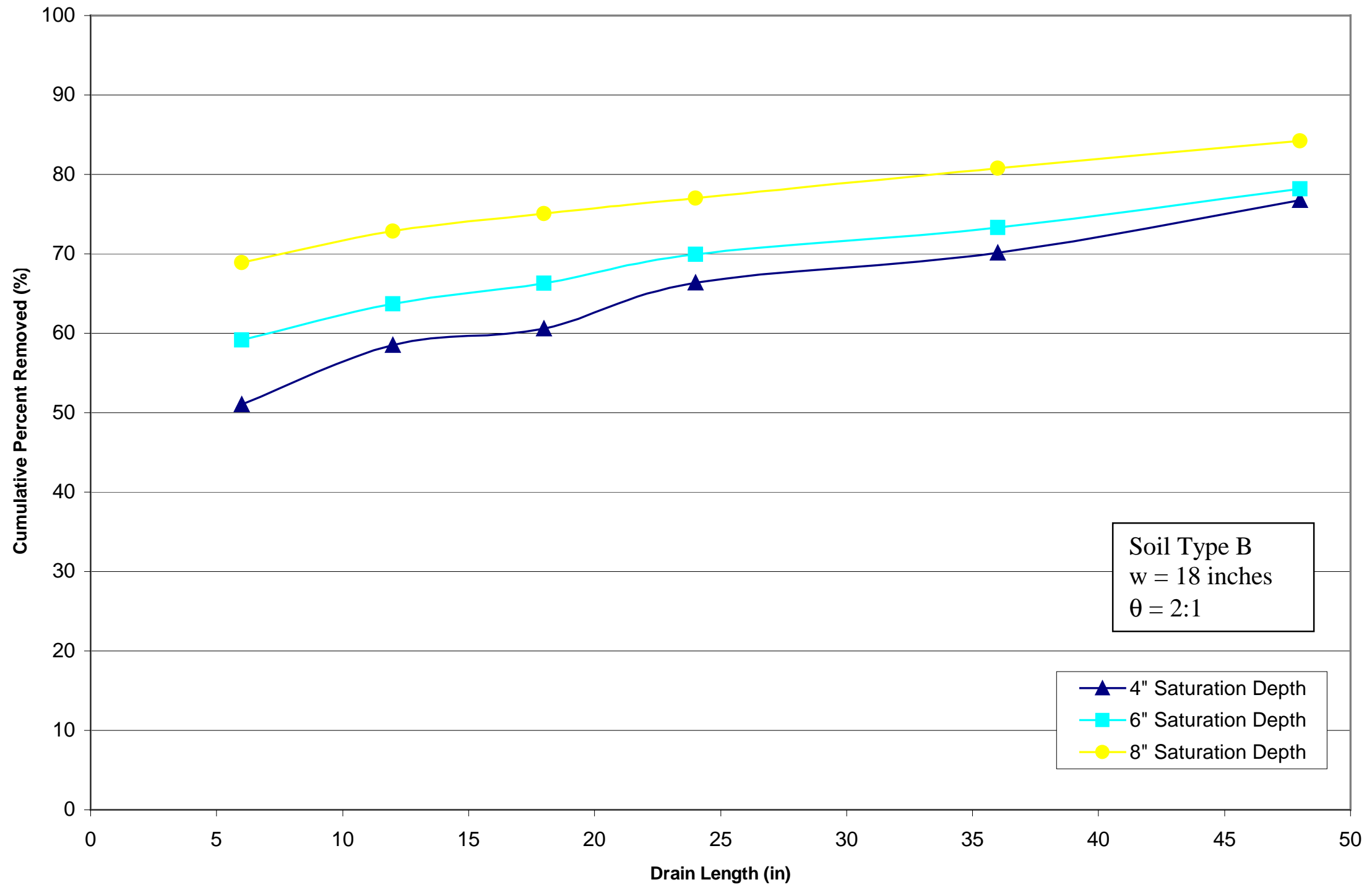

Figure F.4: Influence of Saturation Depth for soil Type B ( $w=18$ inches, 2:1 Slope Angle). 


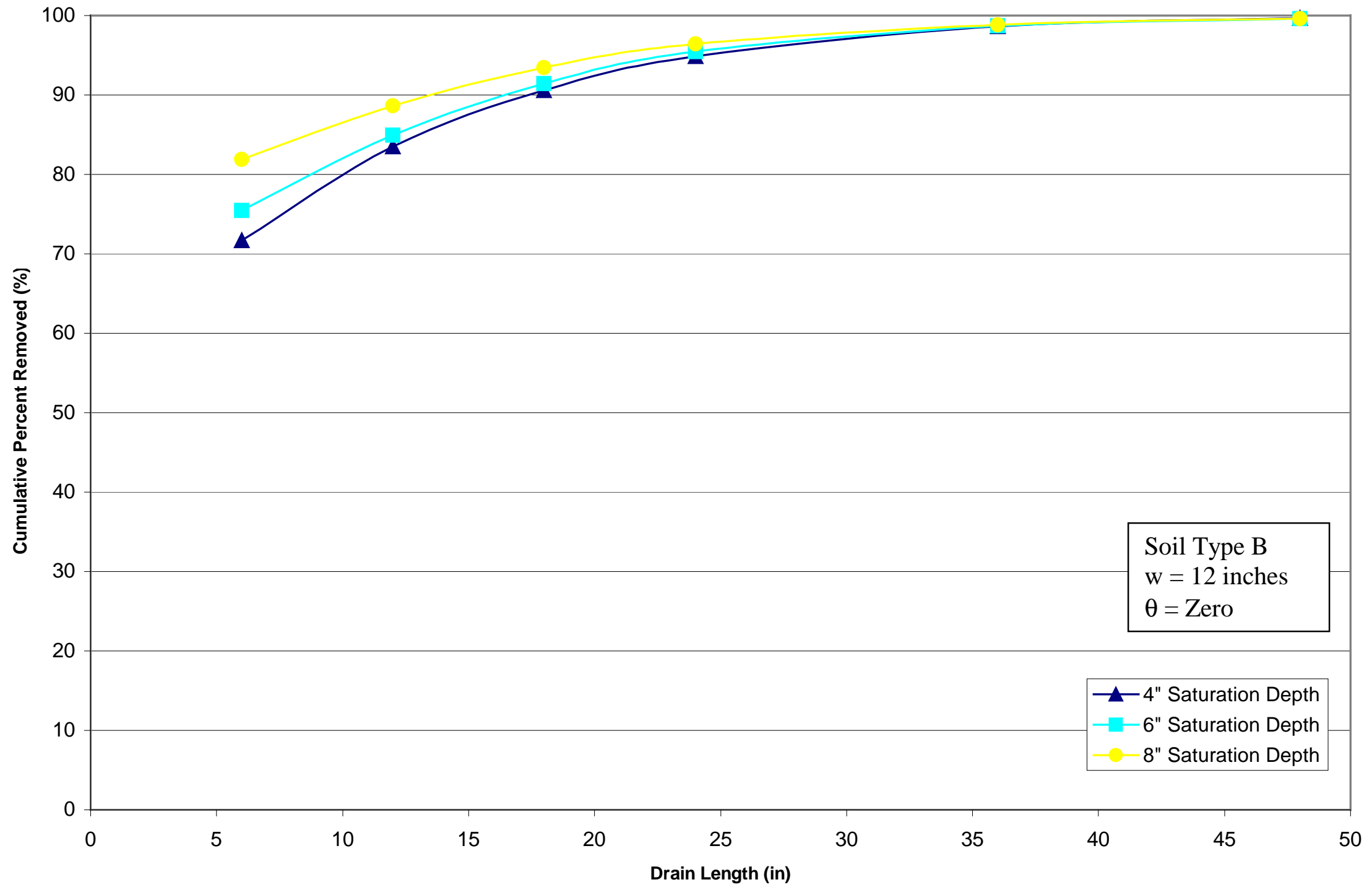

Figure F.5: Influence of Saturation Depth for soil Type B ( $w=12$ inches, Zero Slope Angle). 


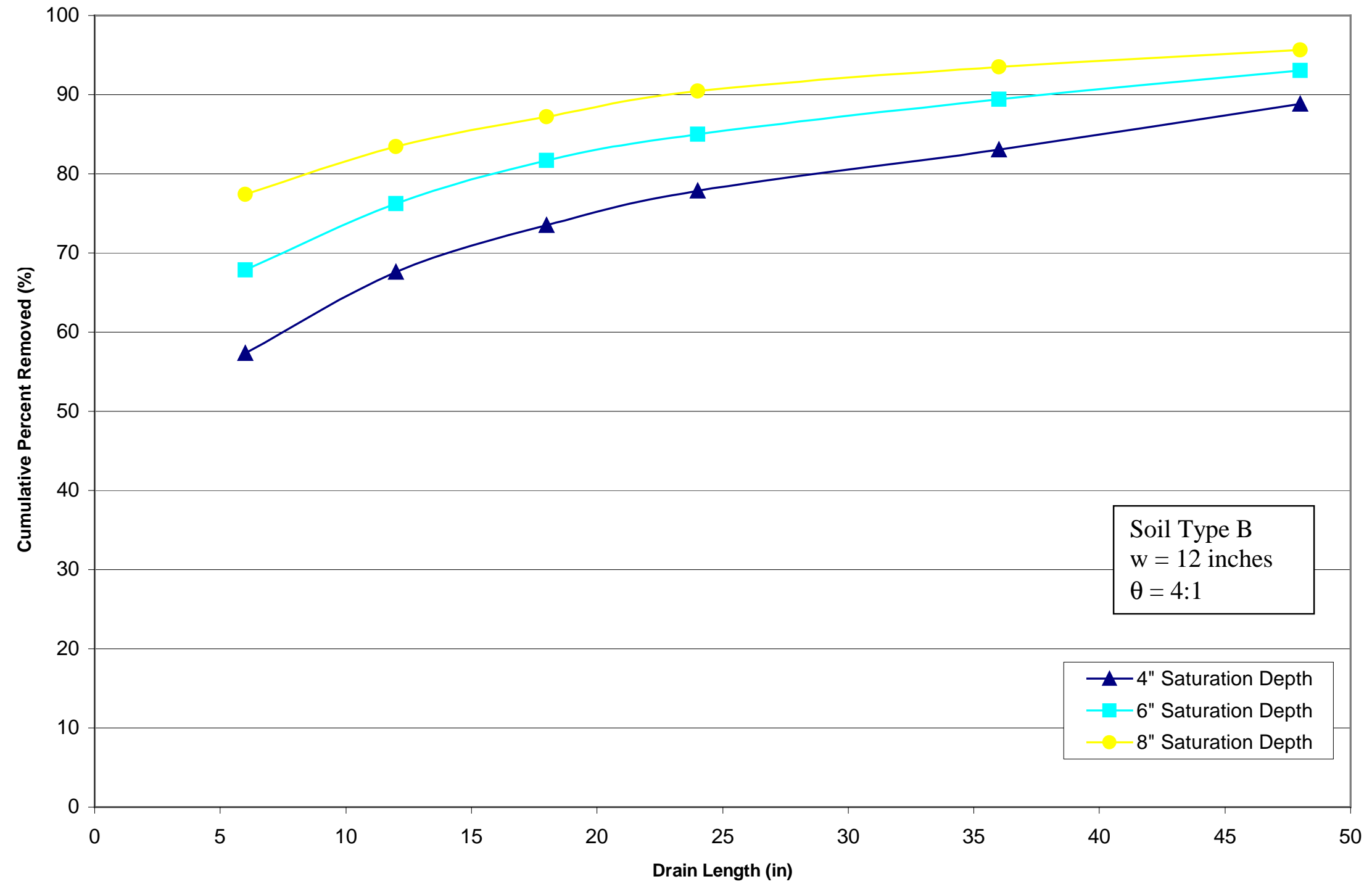

Figure F.6: Influence of Saturation Depth for soil Type B ( $w=12$ inches, 4:1 Slope Angle). 


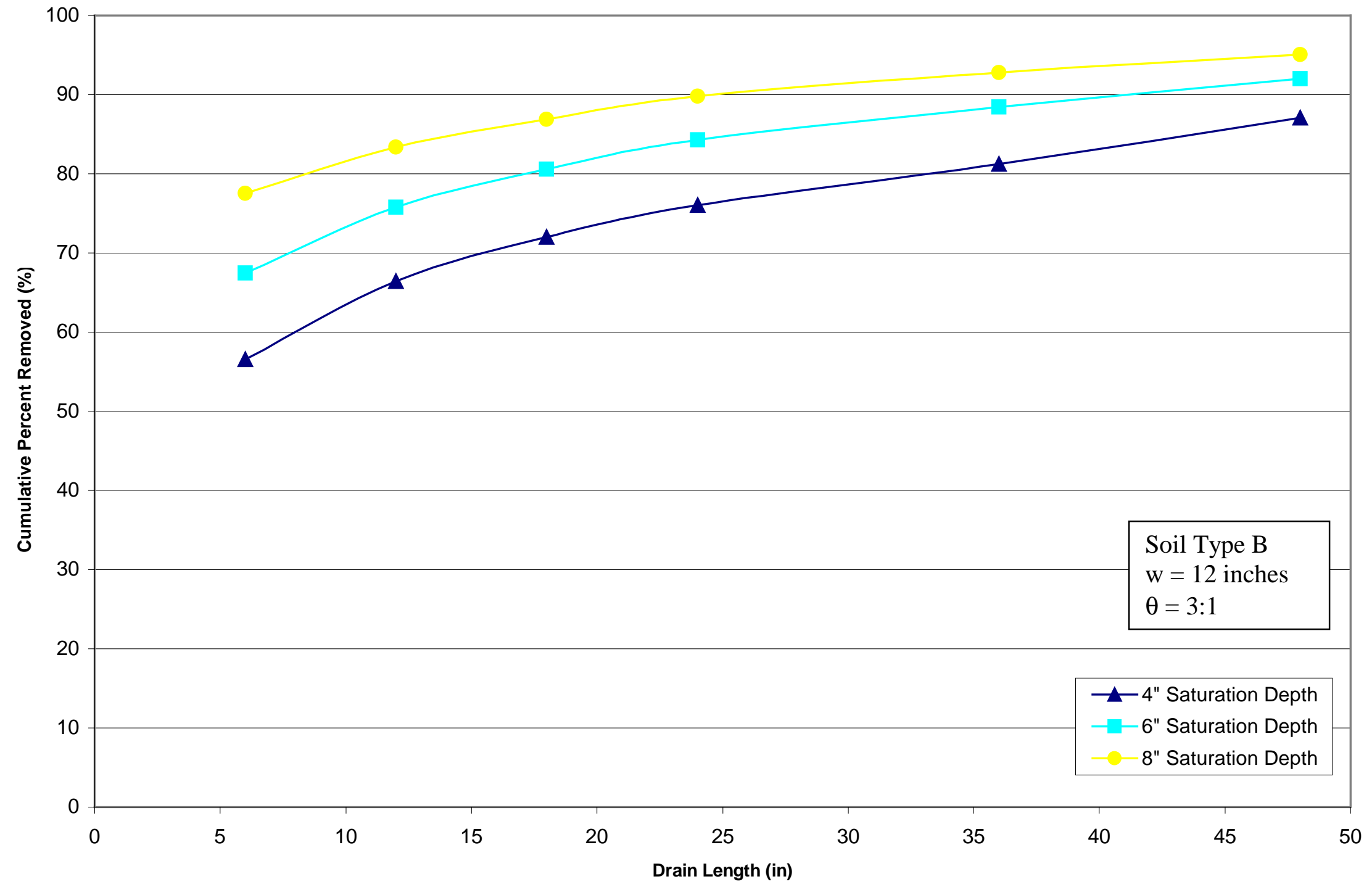

Figure F.7: Influence of Saturation Depth for soil Type B ( $w=12$ inches, 3:1 Slope Angle). 


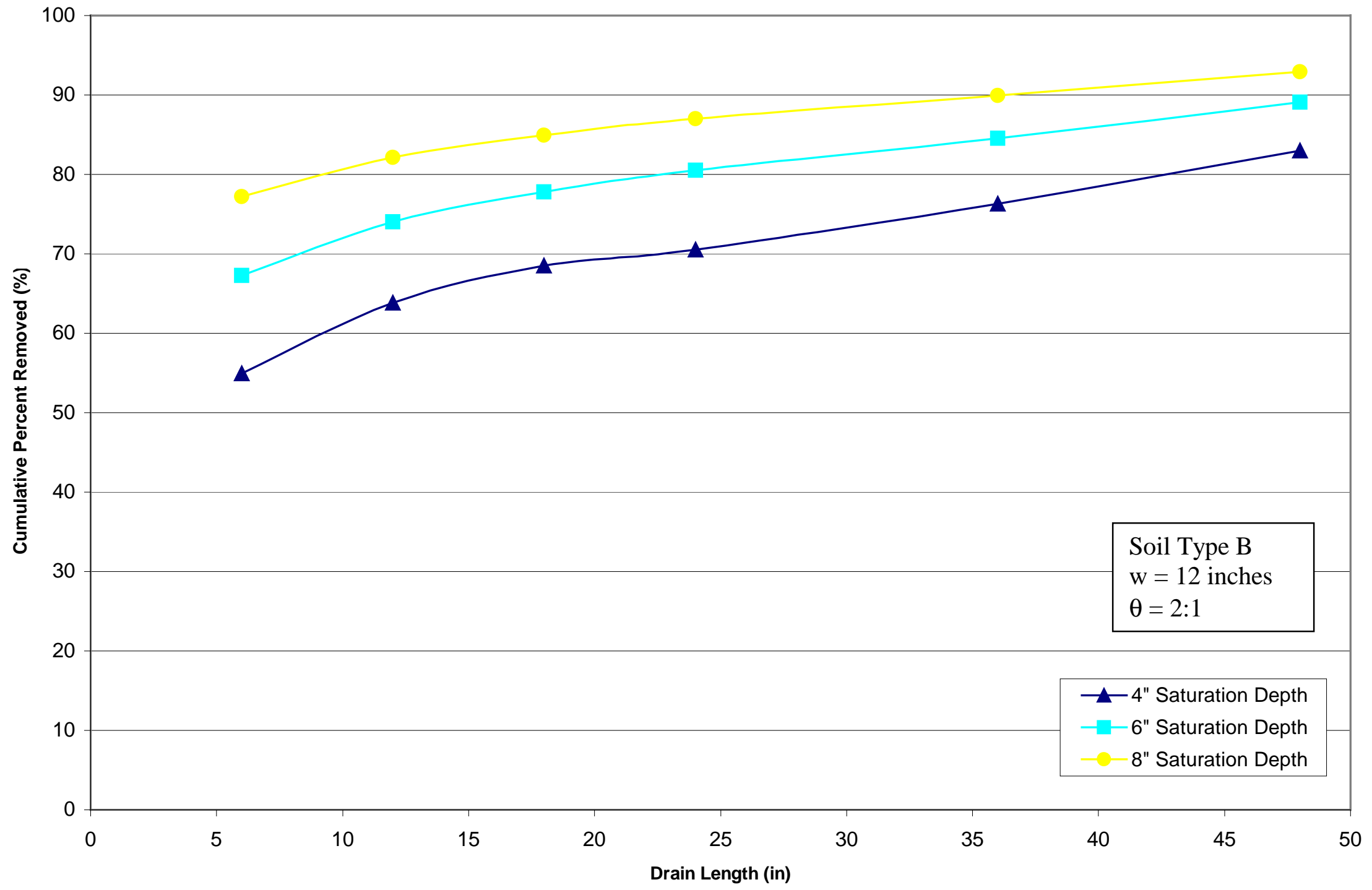

Figure F.8: Influence of Saturation Depth for soil Type B ( $w=12$ inches, 2:1 Slope Angle). 


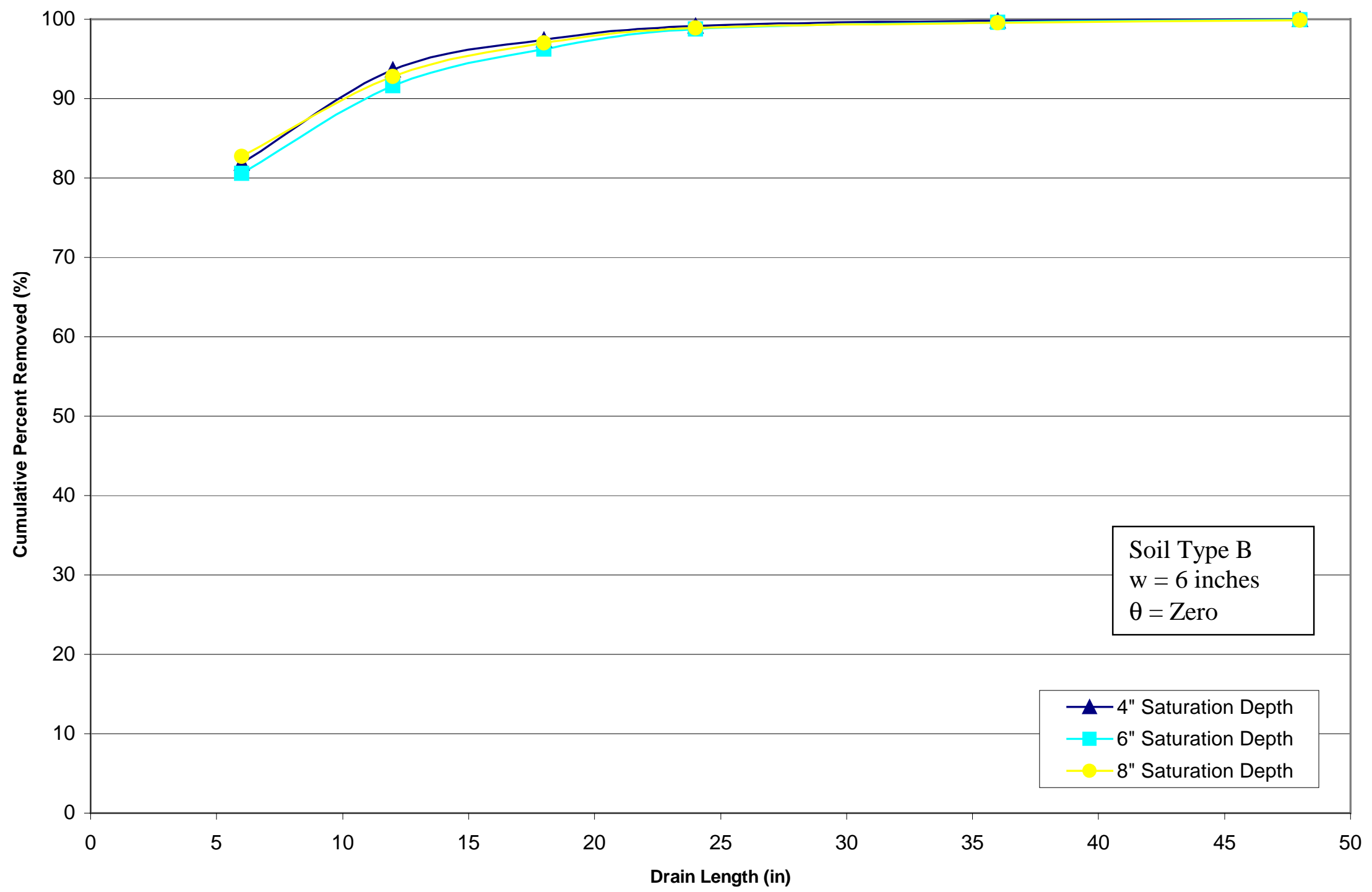

Figure F.9: Influence of Saturation Depth for soil Type B ( $w=6$ inches, Zero Slope Angle). 


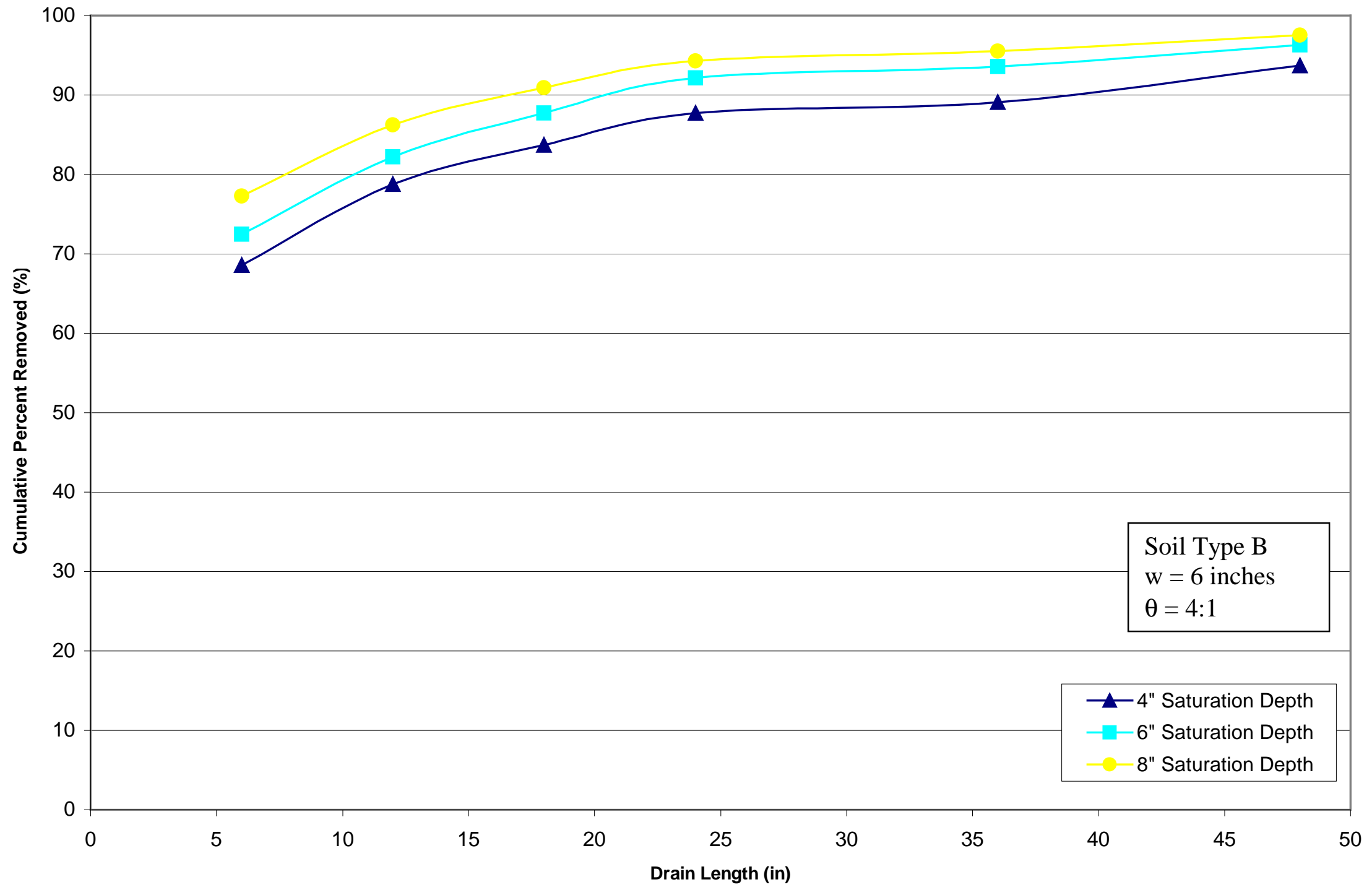

Figure F.10: Influence of Saturation Depth for soil Type B ( $w=6$ inches, 4:1 Slope Angle). 


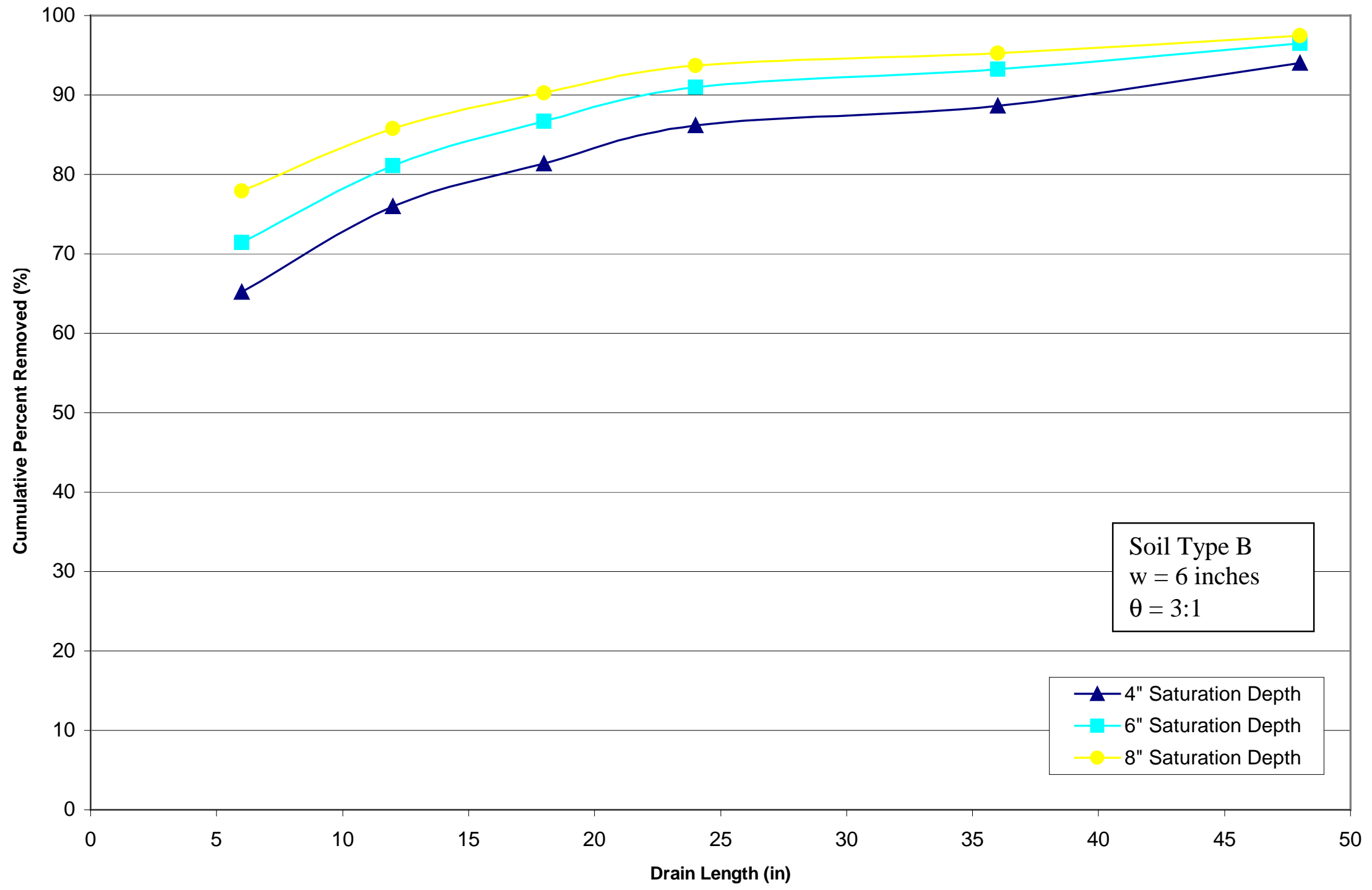

Figure F.11: Influence of Saturation Depth for soil Type B ( $w=6$ inches, 3:1 Slope Angle). 


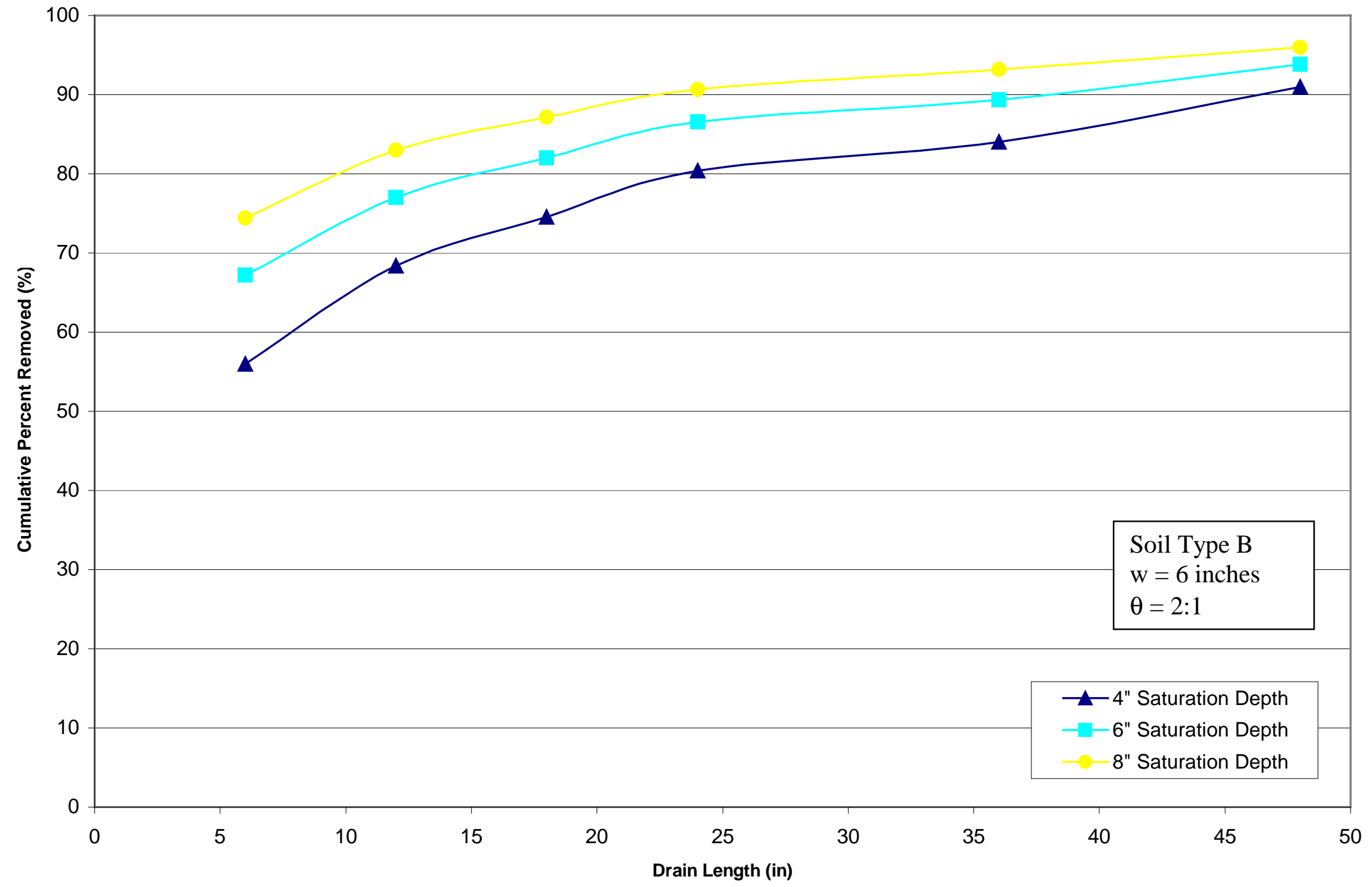

Figure F.12: Influence of Saturation Depth for soil Type B ( $w=6$ inches, 2:1 Slope Angle). 


\begin{abstract}
APPENDIX G
Influence of Soil Type on Transient Condition

for 12" Half Trench Spacing at Each Drain

for Different Slope Angles.
\end{abstract}

Soils B and C (15\% Clay Content and 25\% Clay Content) 


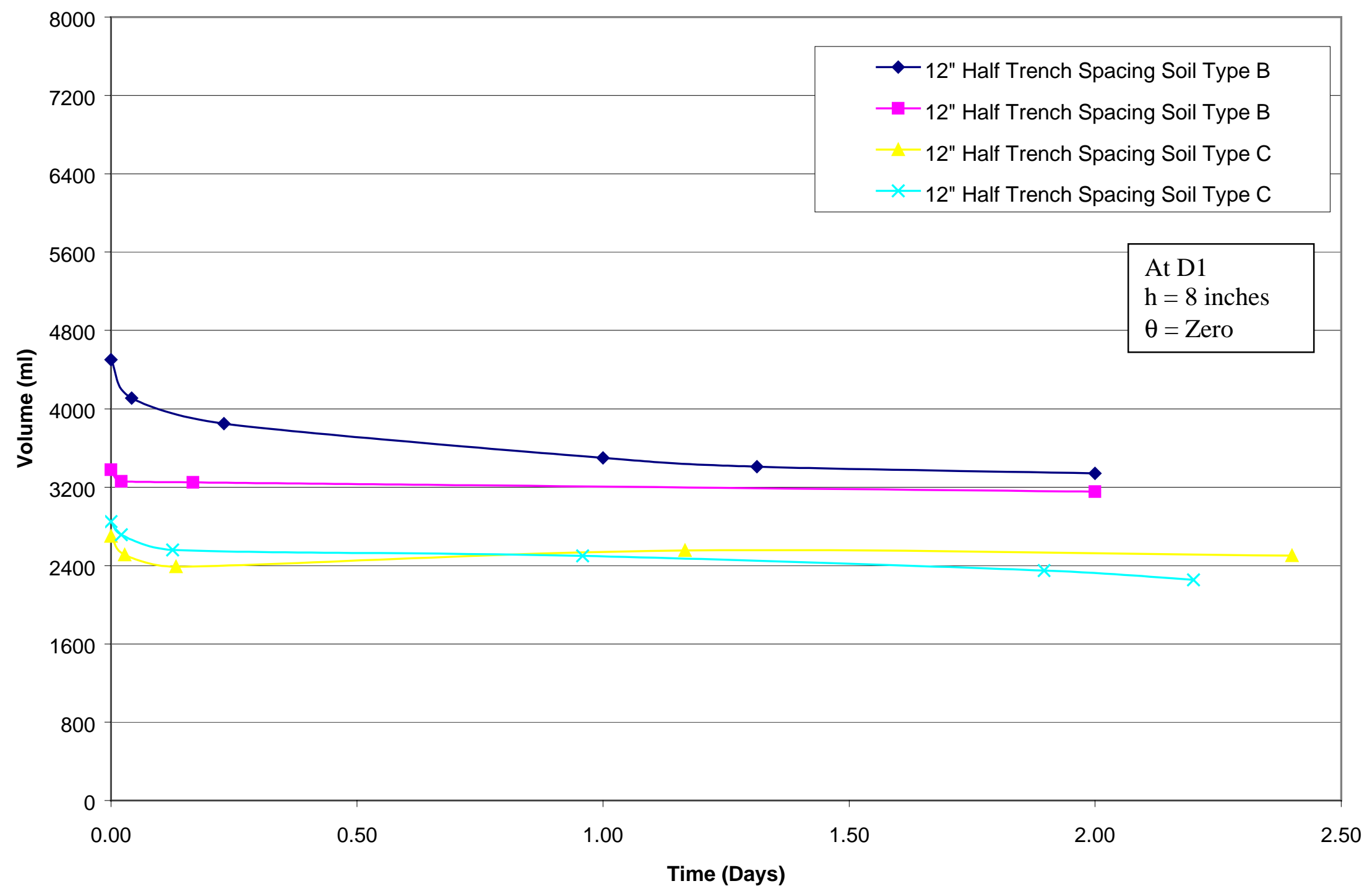

Figure G.1: Influence of Soil Type Transient Condition at D1 ( $w=12$ inches, Zero Slope Angle). 


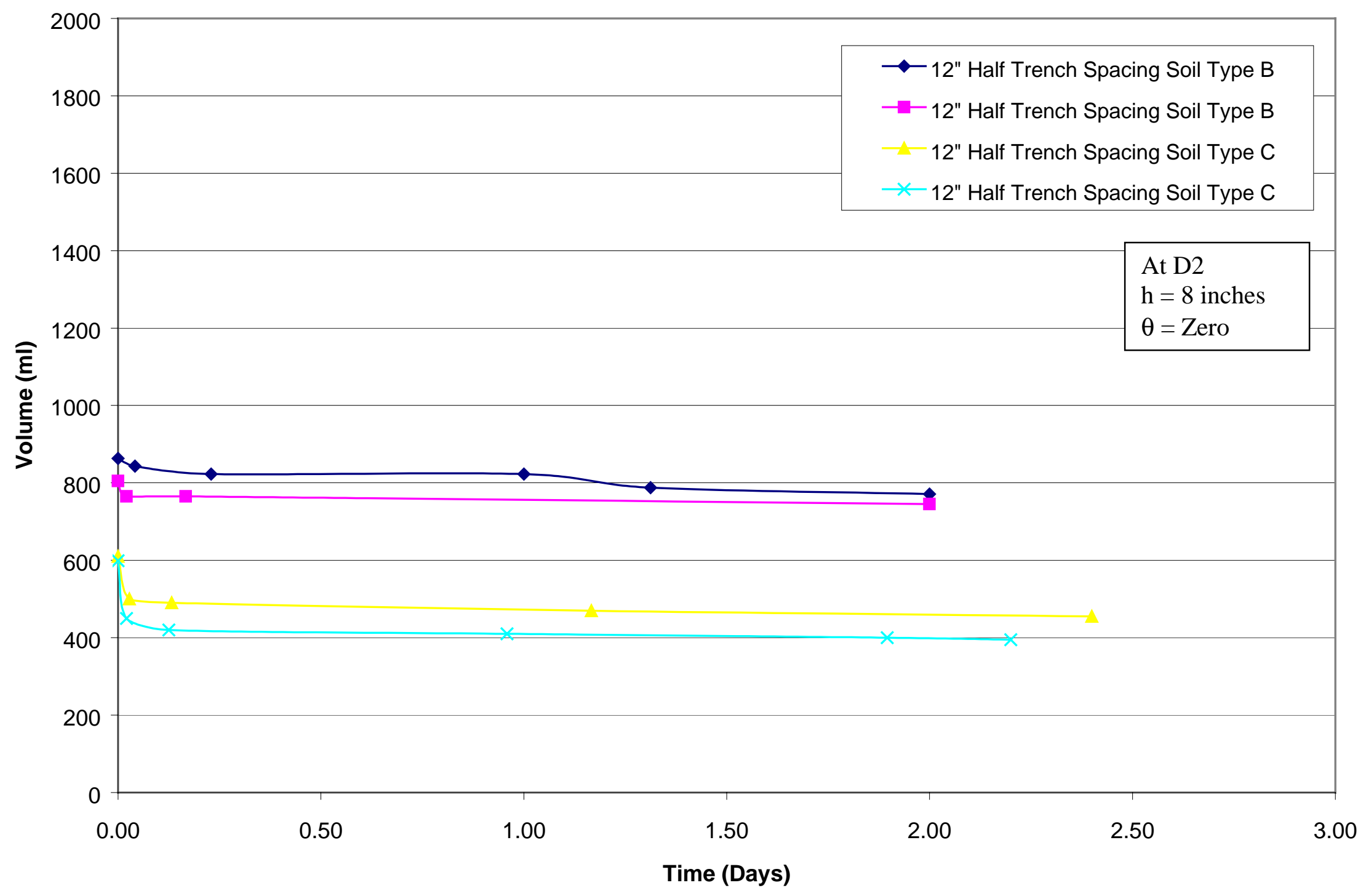

Figure G.2: Influence of Soil Type Transient Condition at D2 ( $w=12$ inches, Zero Slope Angle). 


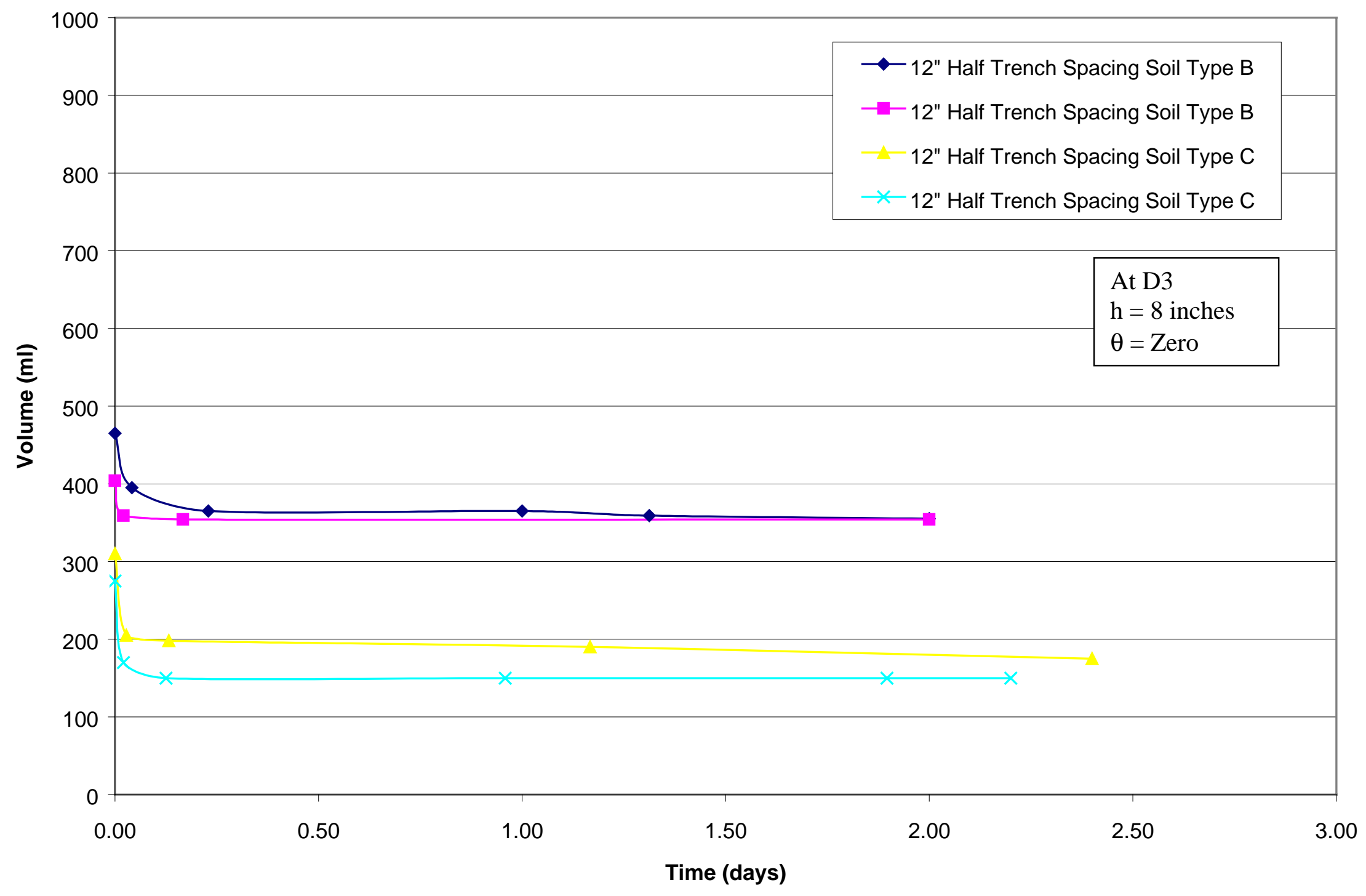

Figure G.3: Influence of Soil Type Transient Condition at D3 ( $w=12$ inches, Zero Slope Angle). 


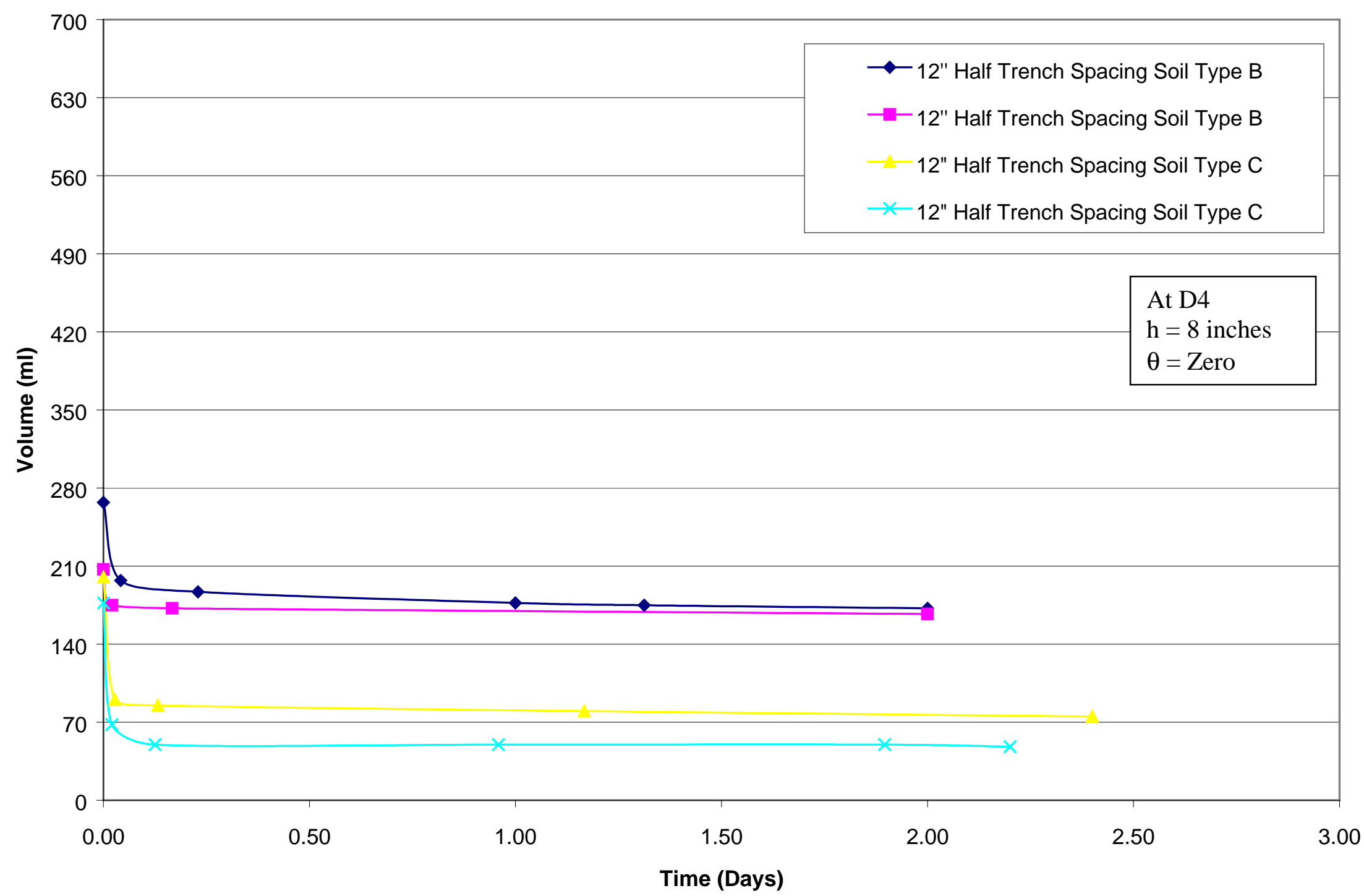

Figure G.4: Influence of Soil Type Transient Condition at D4 ( $w=12$ inches, Zero Slope Angle). 


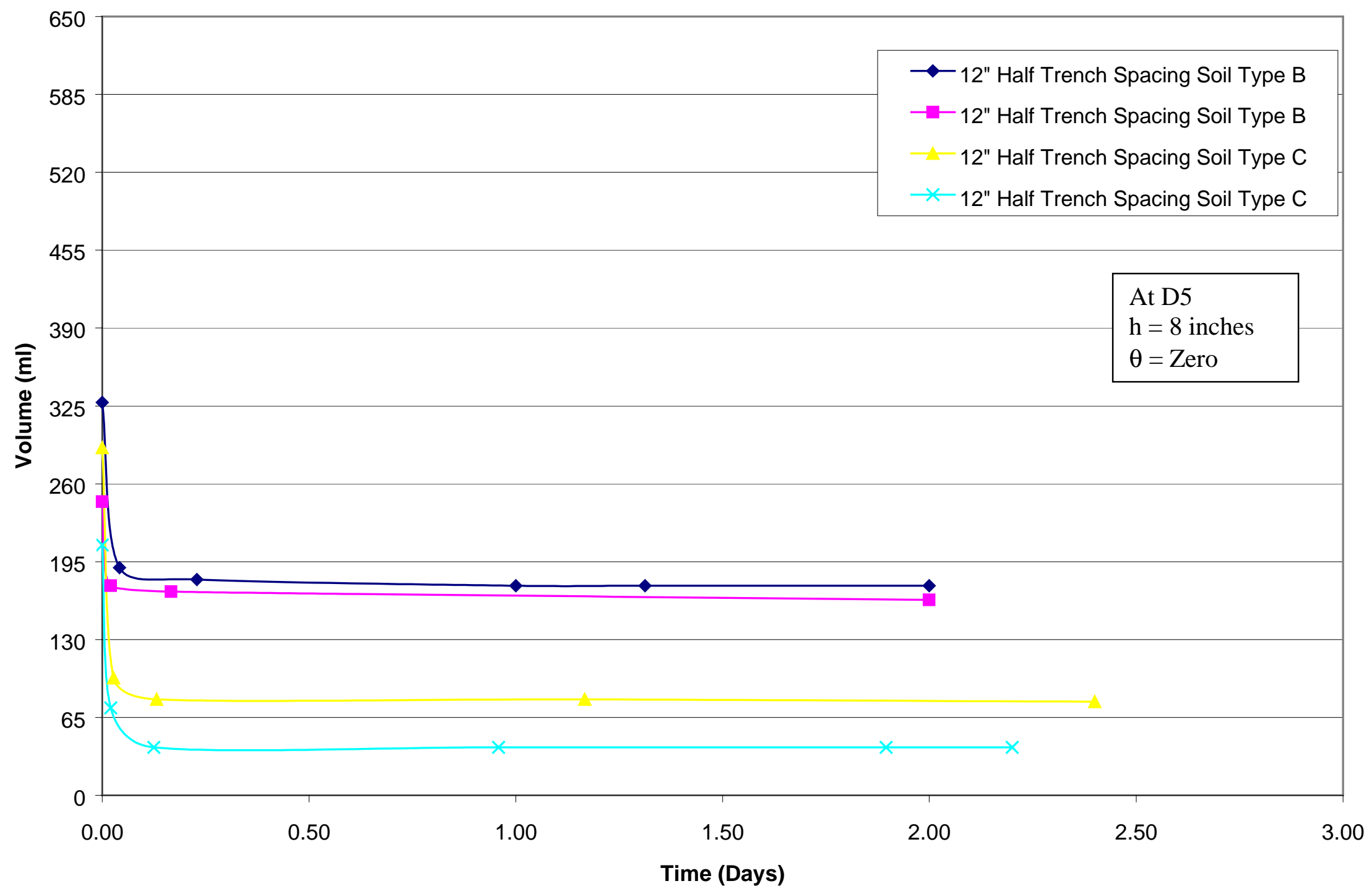

Figure G.5: Influence of Soil Type Transient Condition at D5 ( $\mathrm{w}=12$ inches, Zero Slope Angle). 


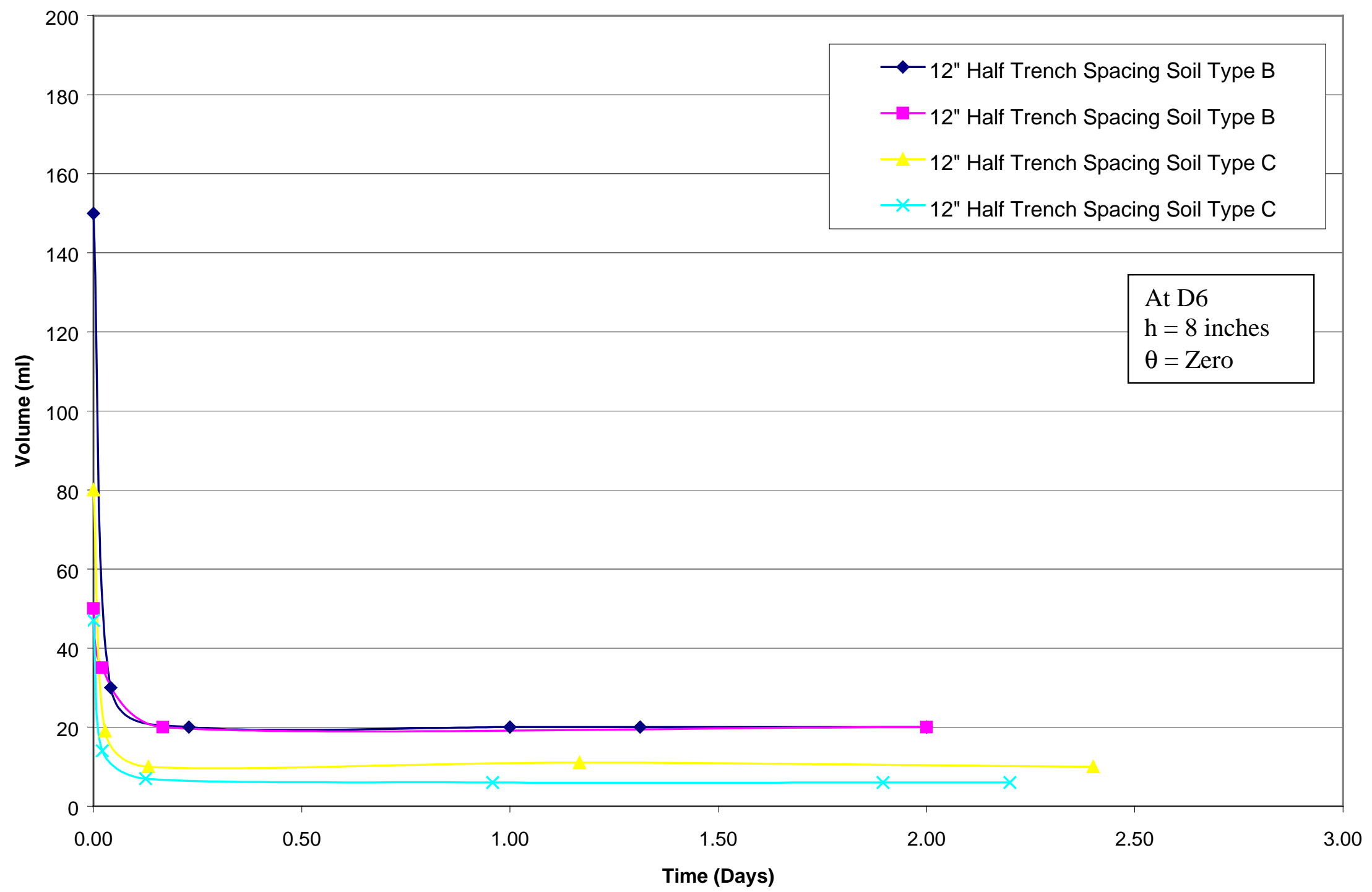

Figure G.6: Influence of Soil Type Transient Condition at D6 ( $\mathrm{w}=12$ inches, Zero Slope Angle). 


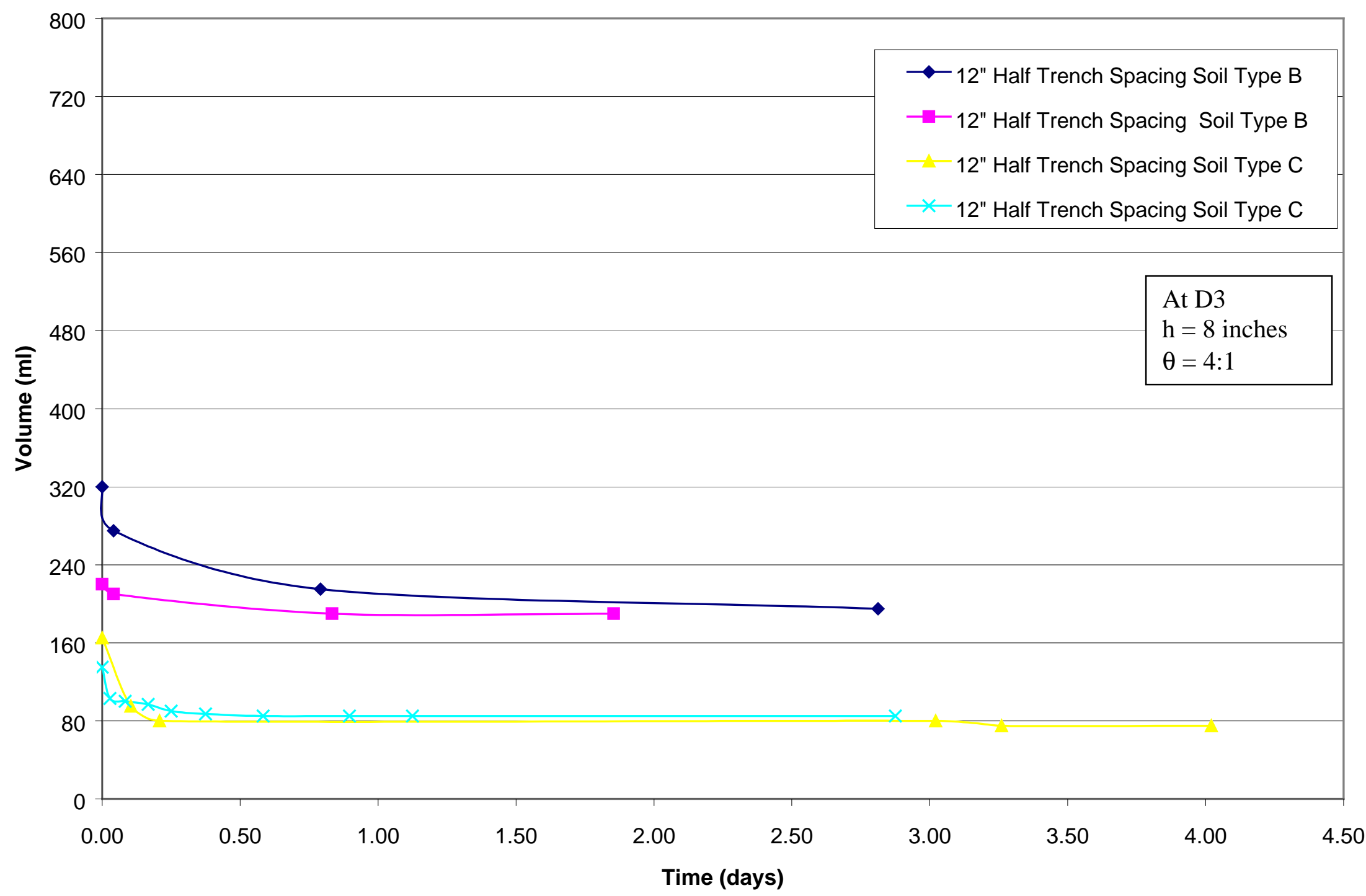

Figure G.7: Influence of Soil Type Transient Condition at D3 ( $w=12$ inches, 4:1 Slope Angle). 


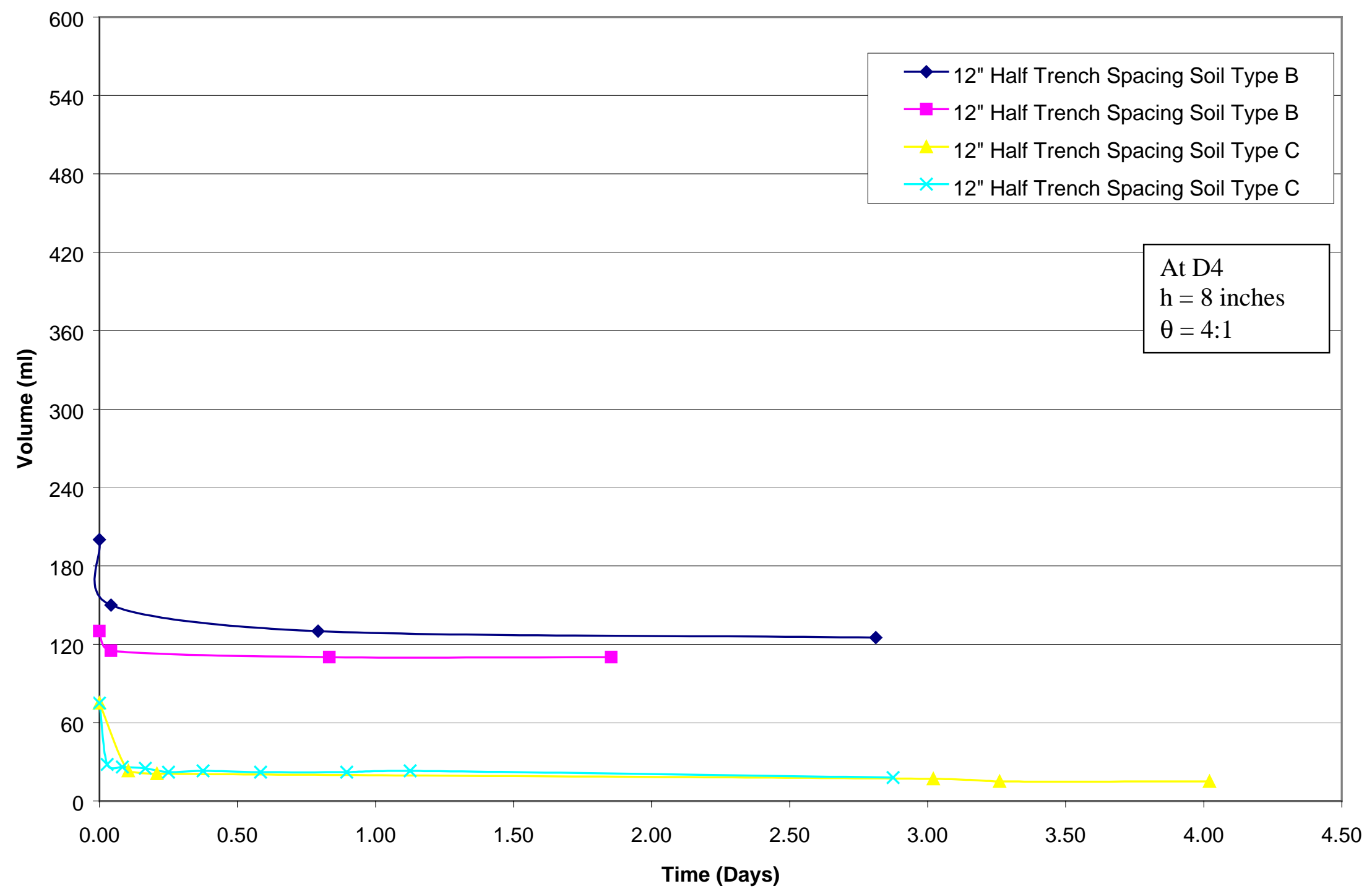

Figure G.8: Influence of Soil Type Transient Condition at D4 ( $w=12$ inches, 4:1 Slope Angle). 


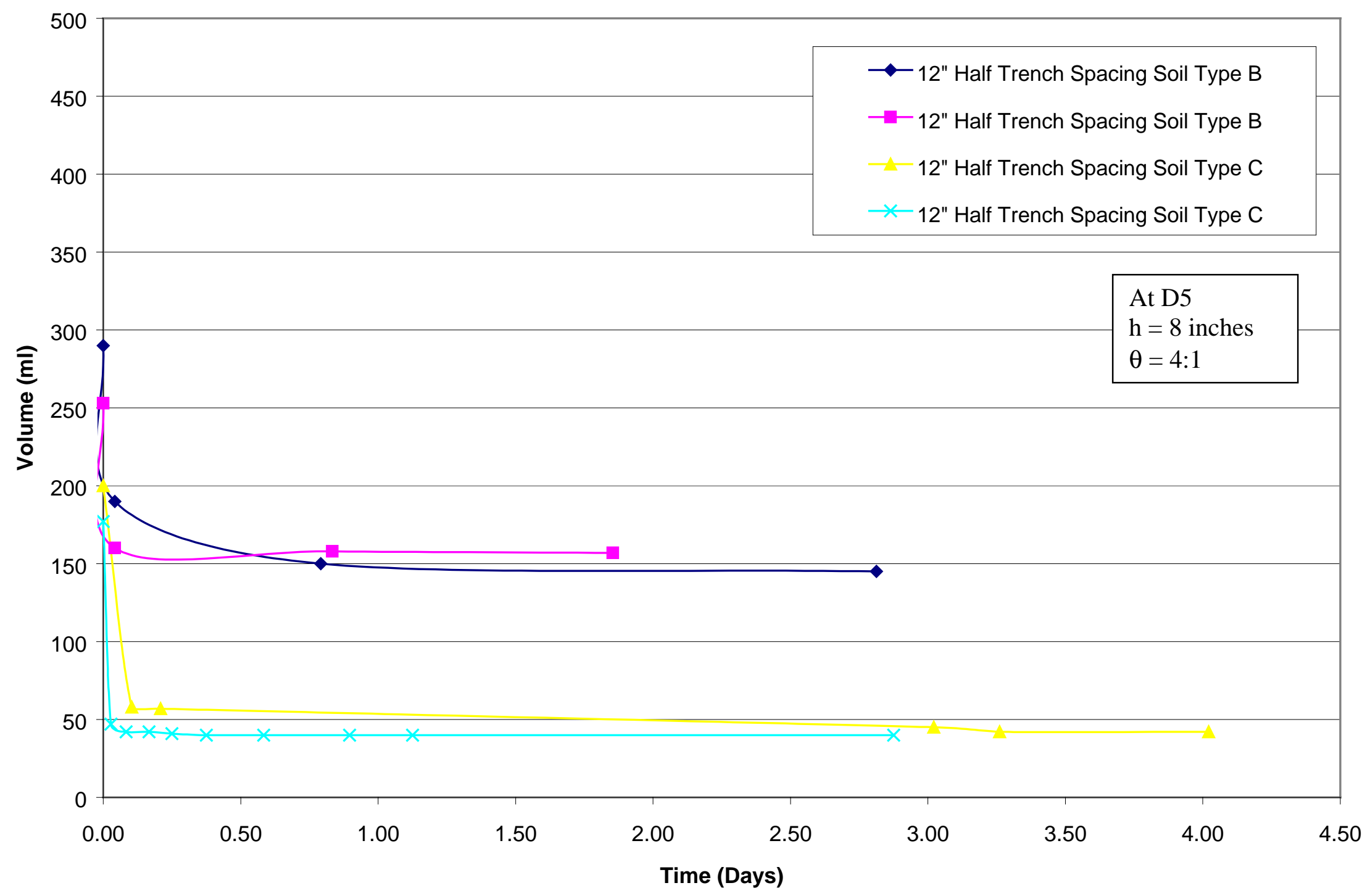

Figure G.9: Influence of Soil Type Transient Condition at D5 ( $w=12$ inches, 4:1 Slope Angle). 


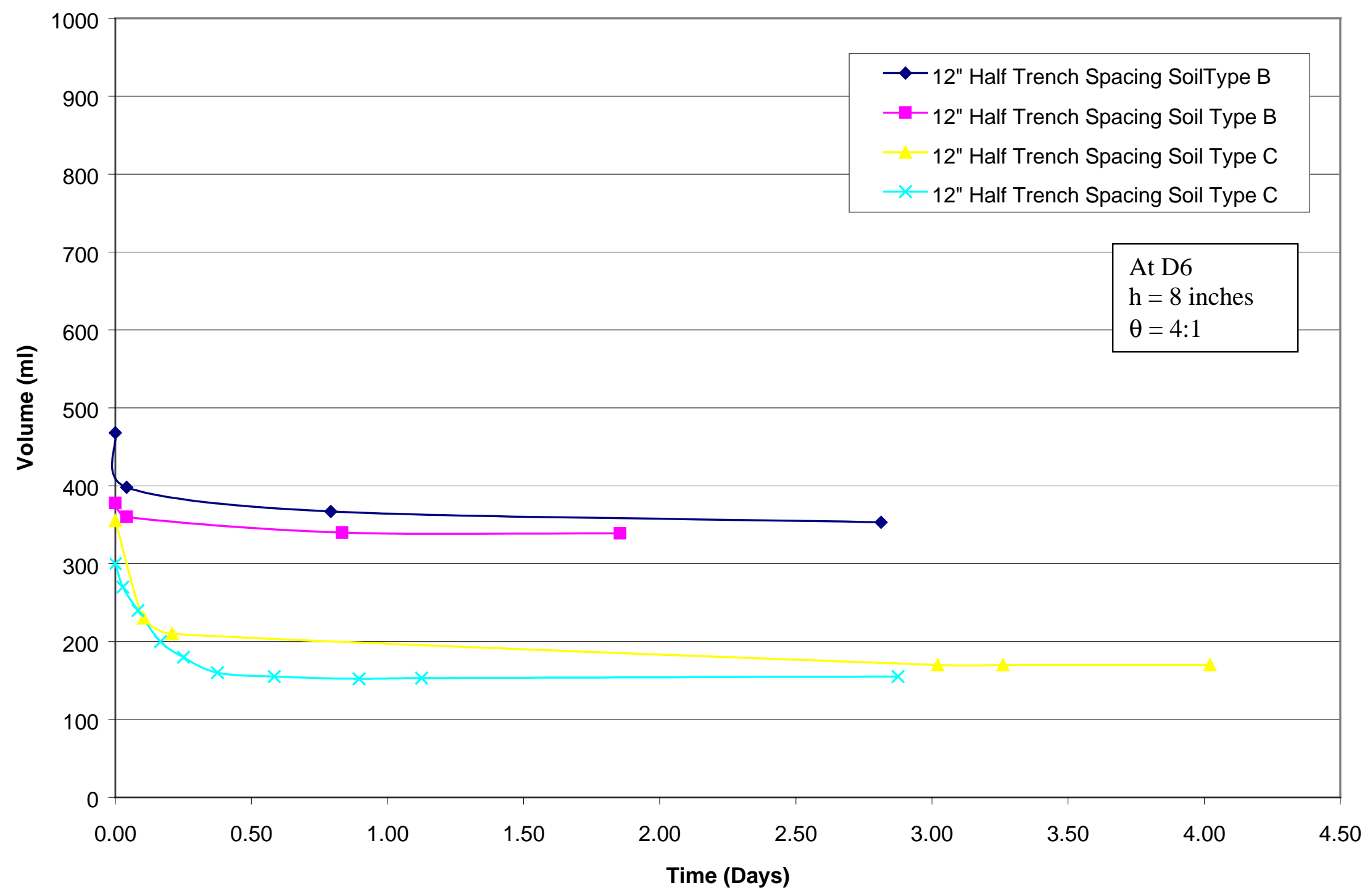

Figure G.10: Influence of Soil Type Transient Condition at D6 ( $w=12$ inches, 4:1 Slope Angle). 


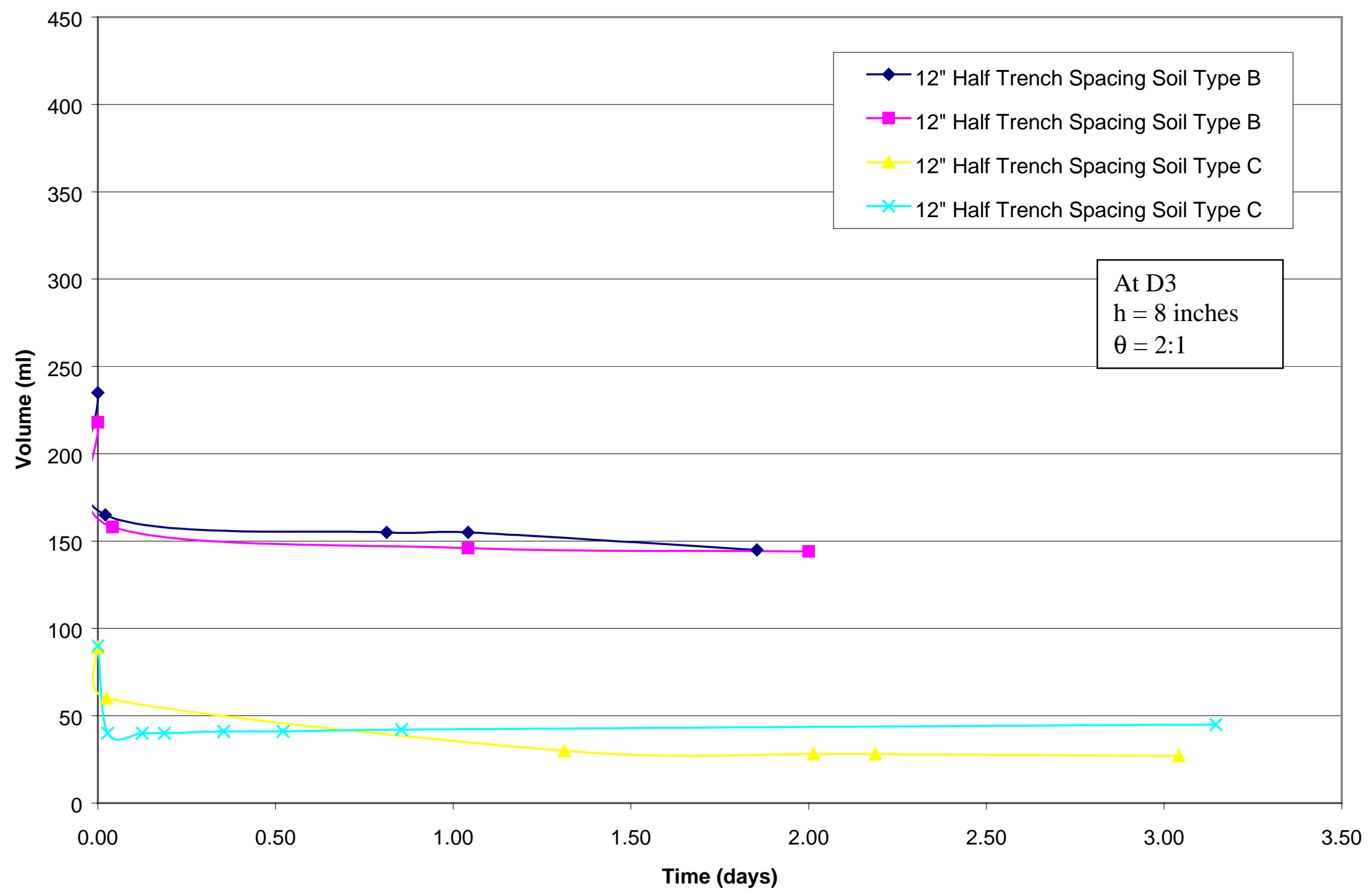

Figure G.11: Influence of Soil Type Transient Condition at D3 ( $w=12$ inches, 2:1 Slope Angle). 


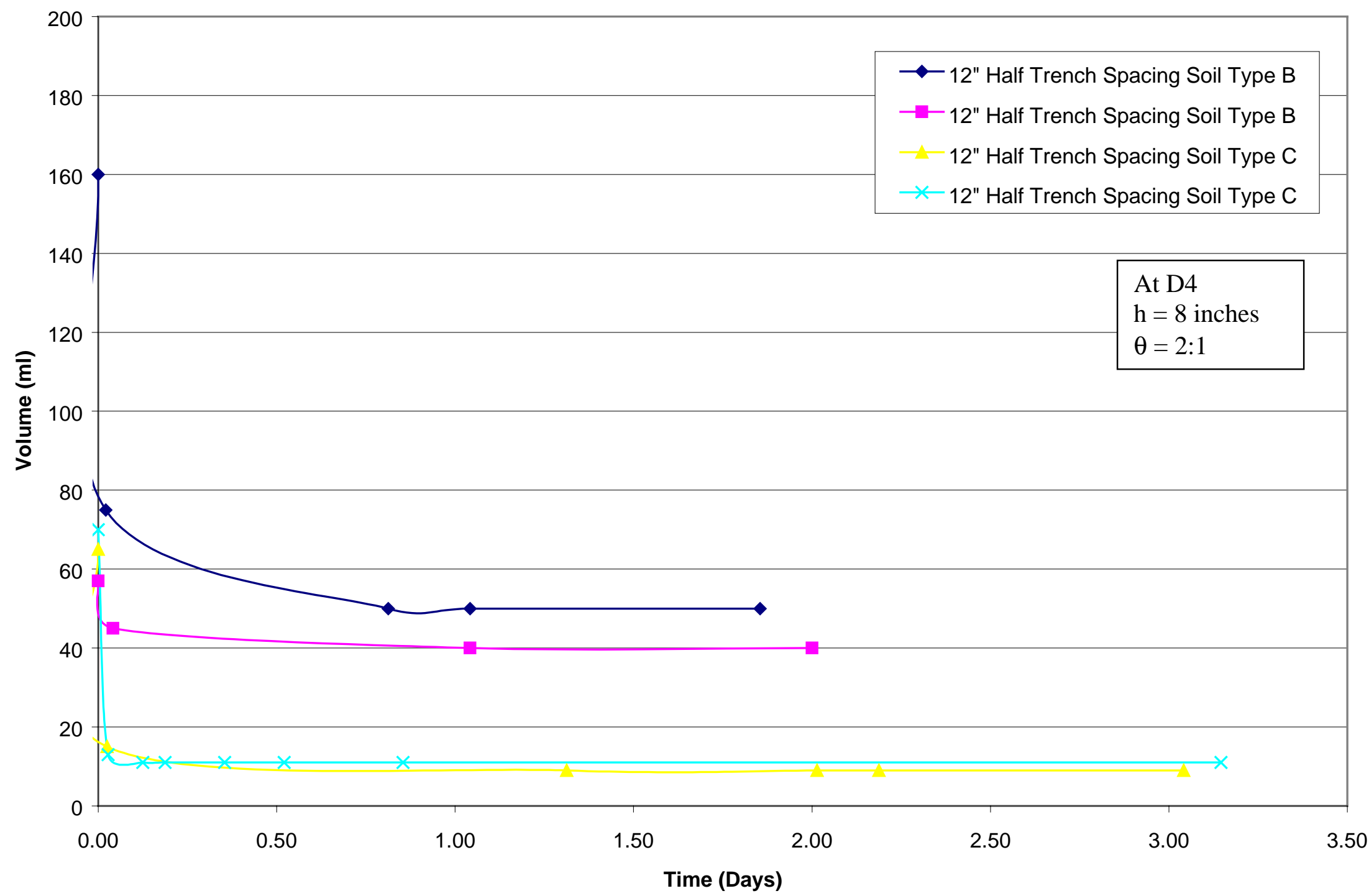

Figure G.12: Influence of Soil Type Transient Condition at D4 ( $w=12$ inches, 2:1 Slope Angle). 


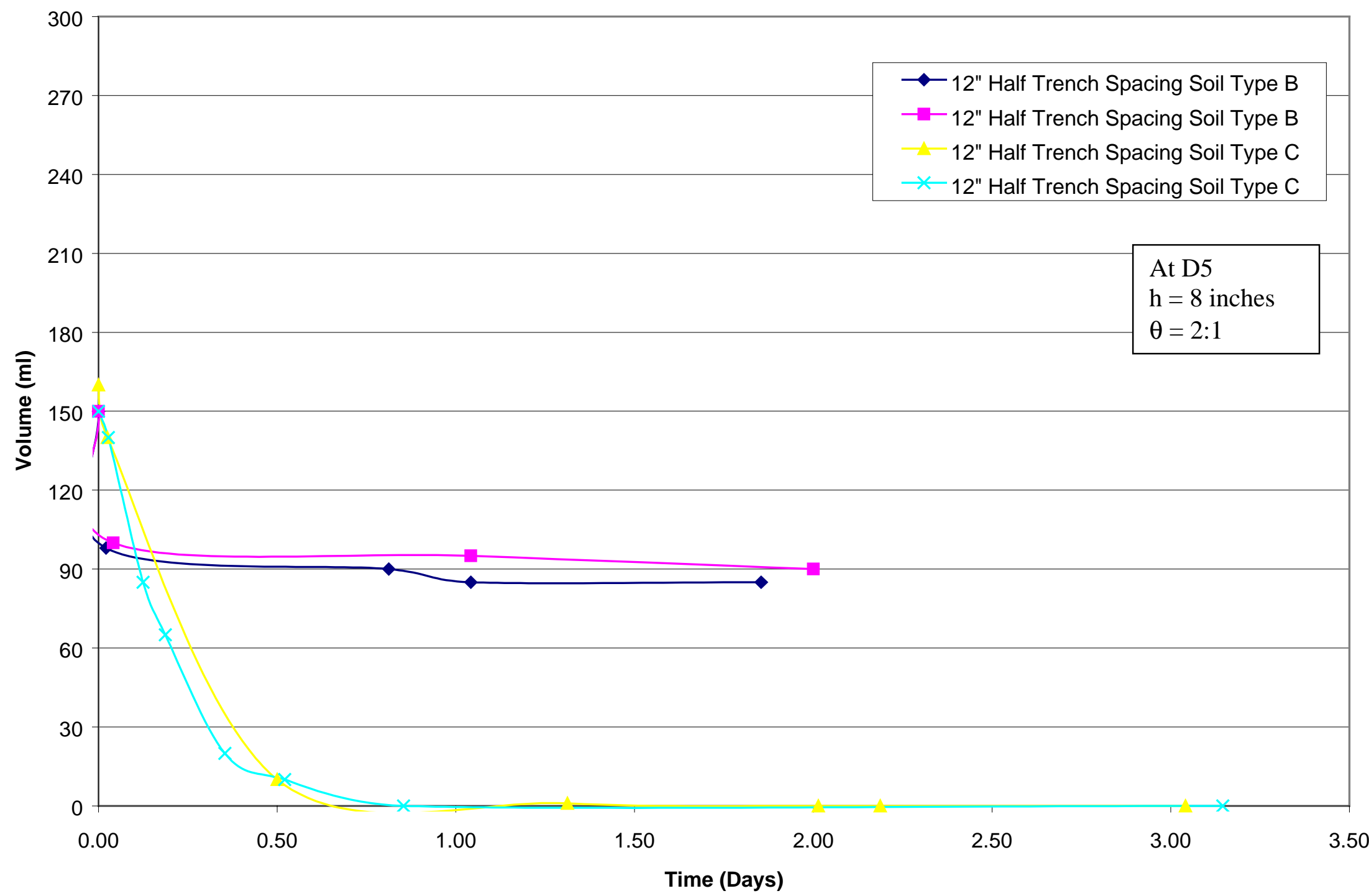

Figure G.13: Influence of Soil Type Transient Condition at D5 ( $w=12$ inches, 2:1 Slope Angle). 


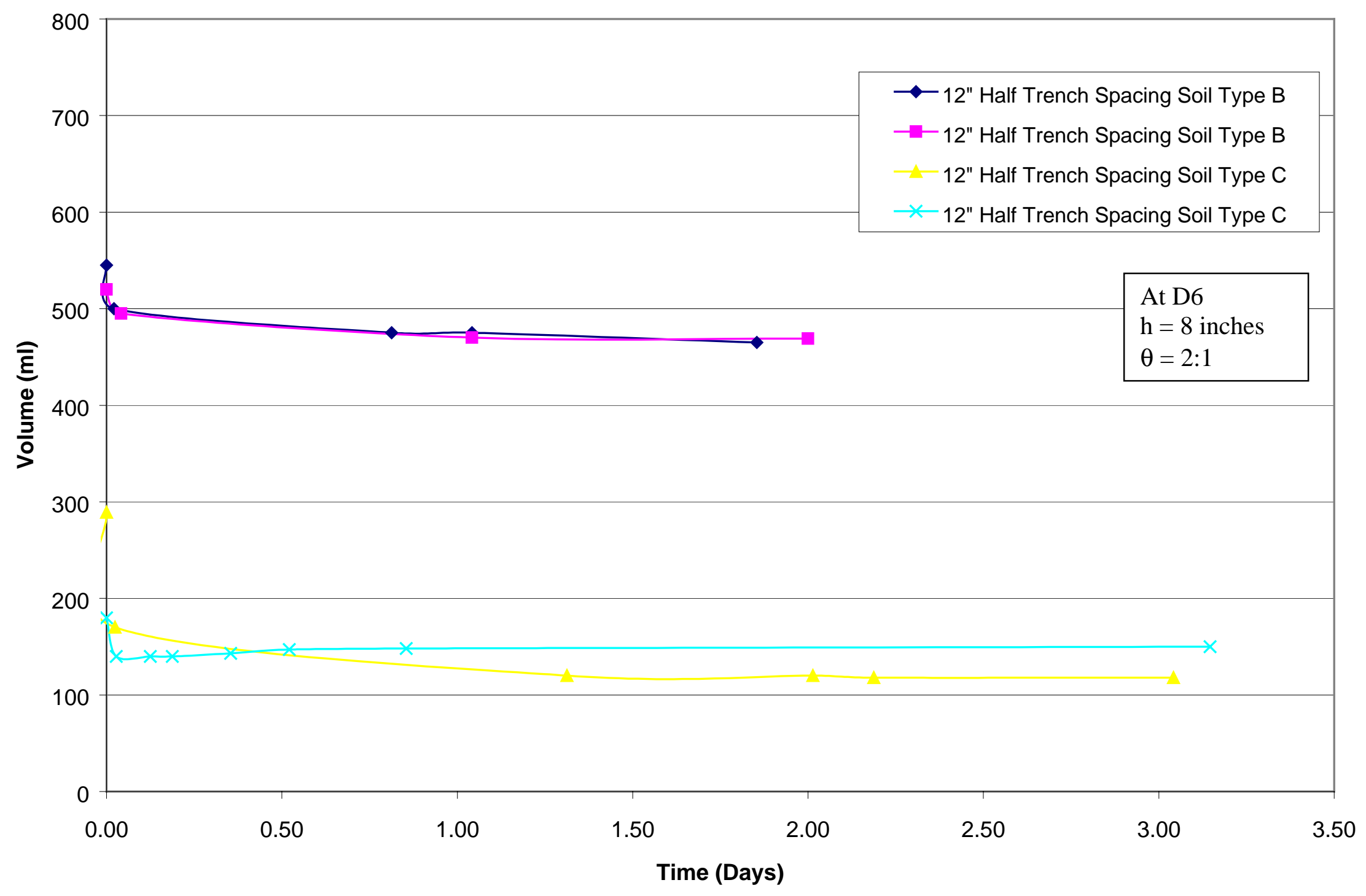

Figure G.14: Influence of Soil Type Transient Condition at D6 ( $w=12$ inches, 2:1 Slope Angle). 


\begin{abstract}
APPENDIX H
Influence of Soil Type on Steady State

for Different
\end{abstract}

Saturation Depths and Half Trench Spacing

Soil Types A and B (5\% Clay Content and 15\% Clay Content) 


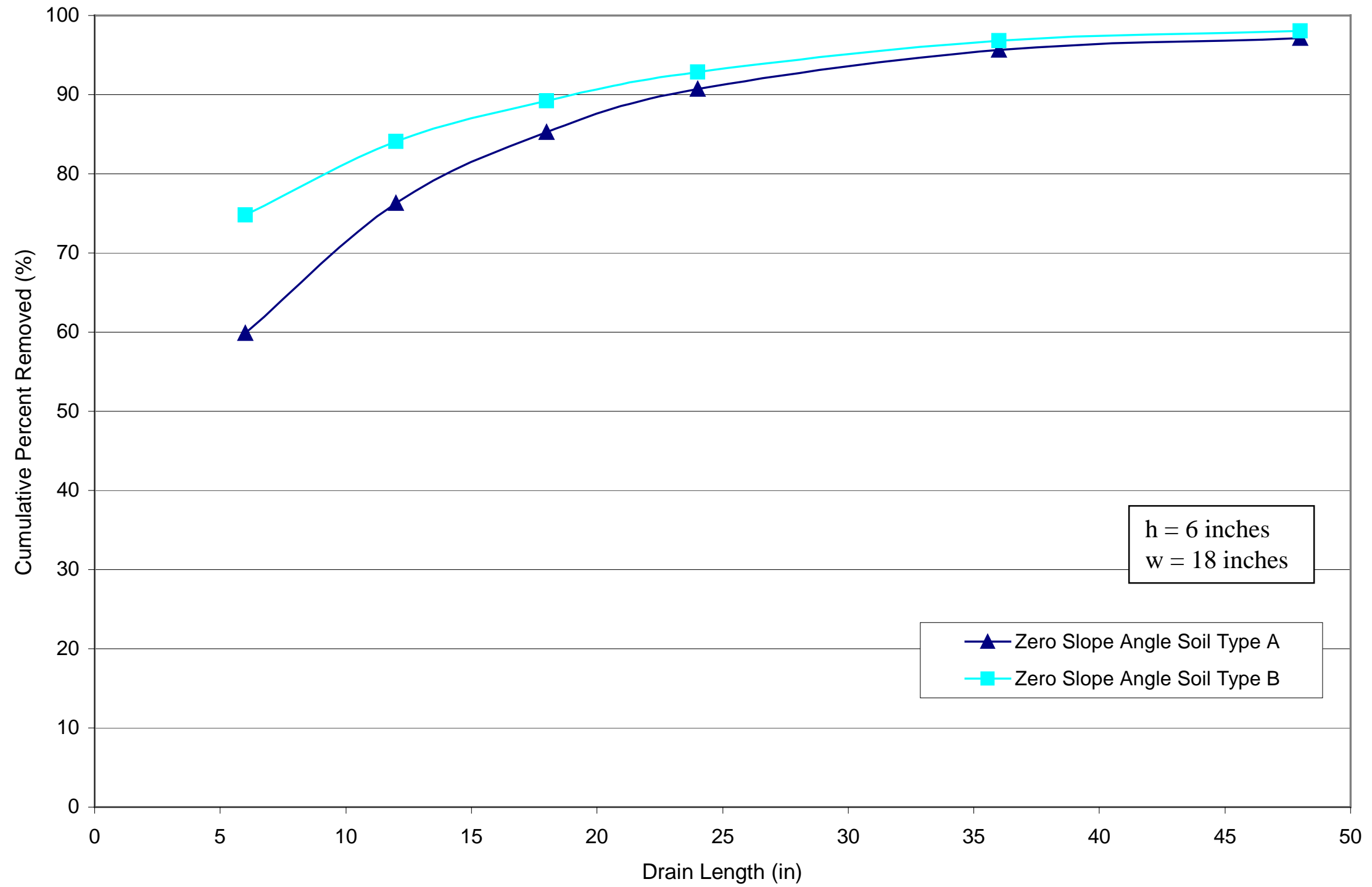

Figure H.1: Influence of Soil Type ( $h=6$ inches, $w=18$ inches). 


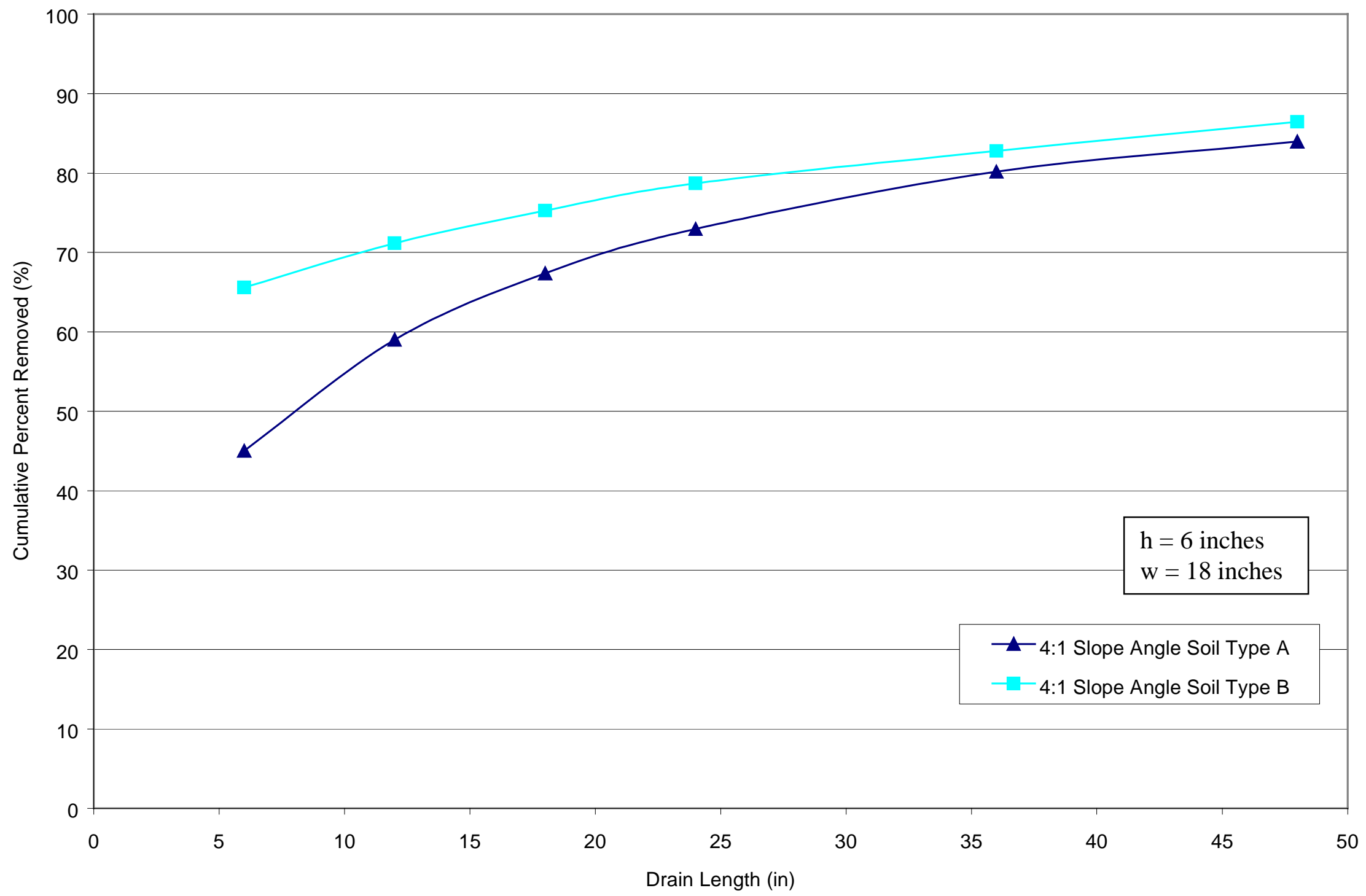

Figure H.2: Influence of Soil Type ( $\mathrm{h}=6$ inches, $\mathrm{w}=18$ inches). 


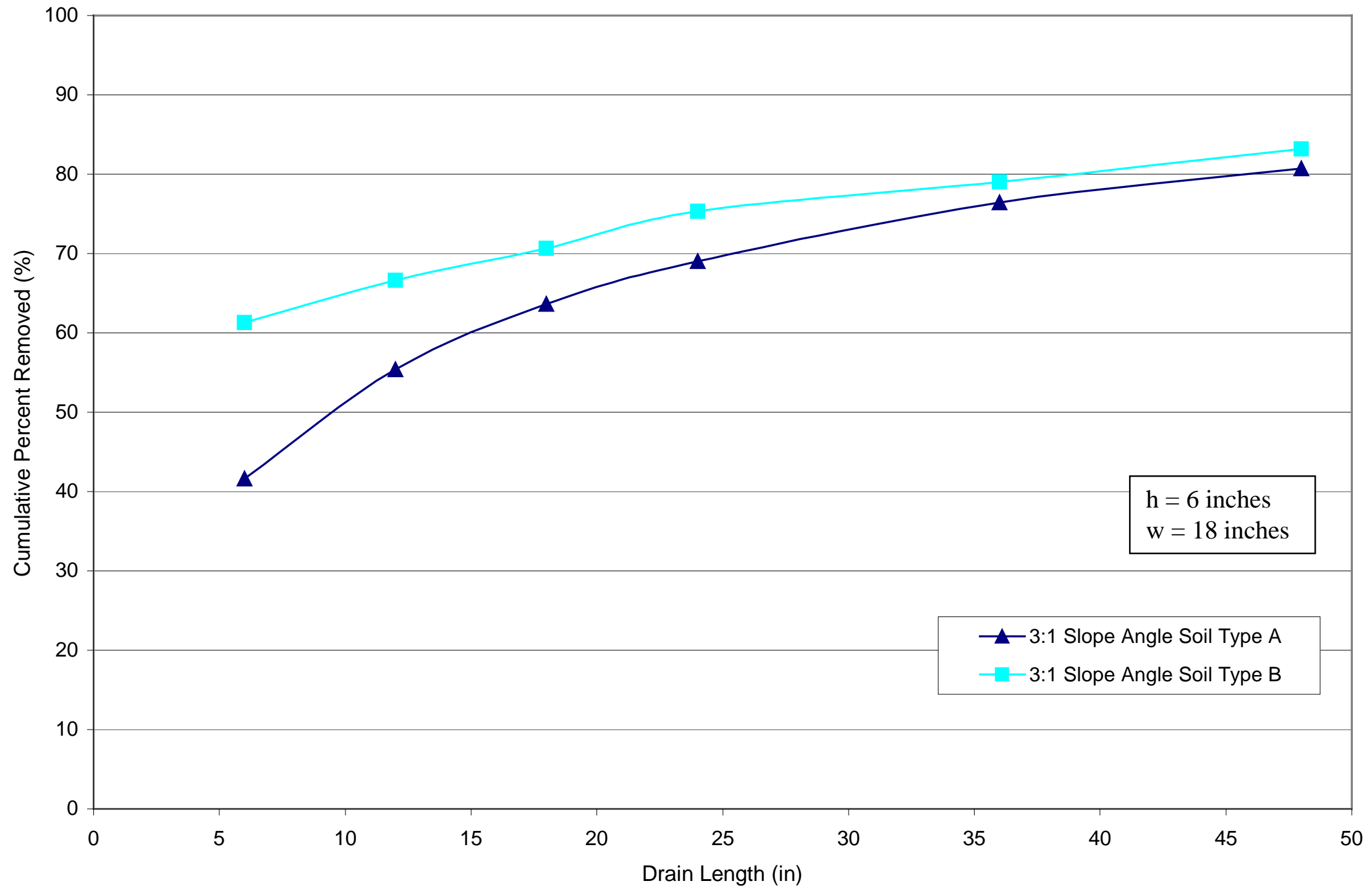

Figure H.3: Influence of Soil Type ( $h=6$ inches, $w=18$ inches). 


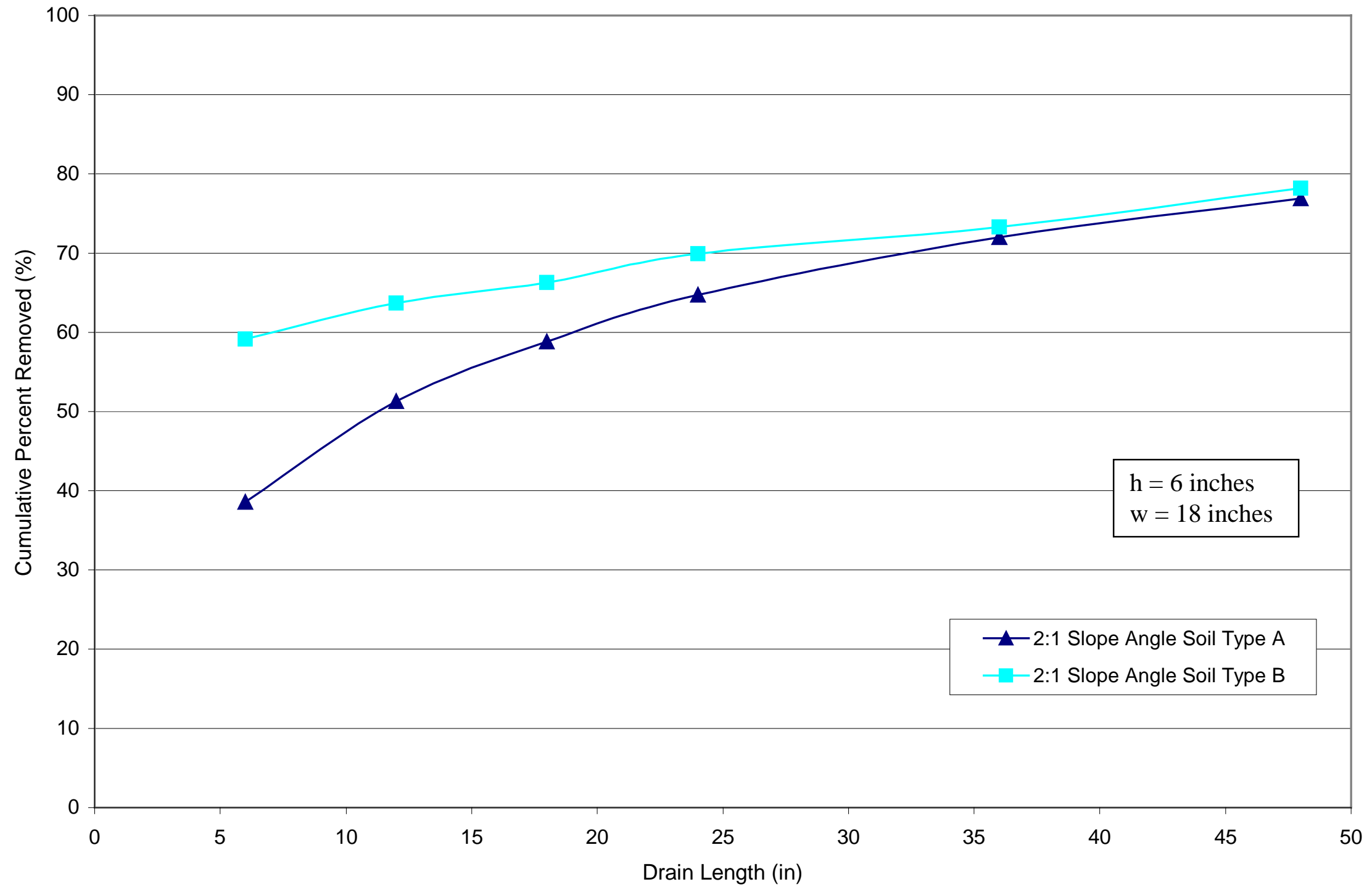

Figure H.4: Influence of Soil Type ( $\mathrm{h}=6$ inches, $\mathrm{w}=18$ inches). 


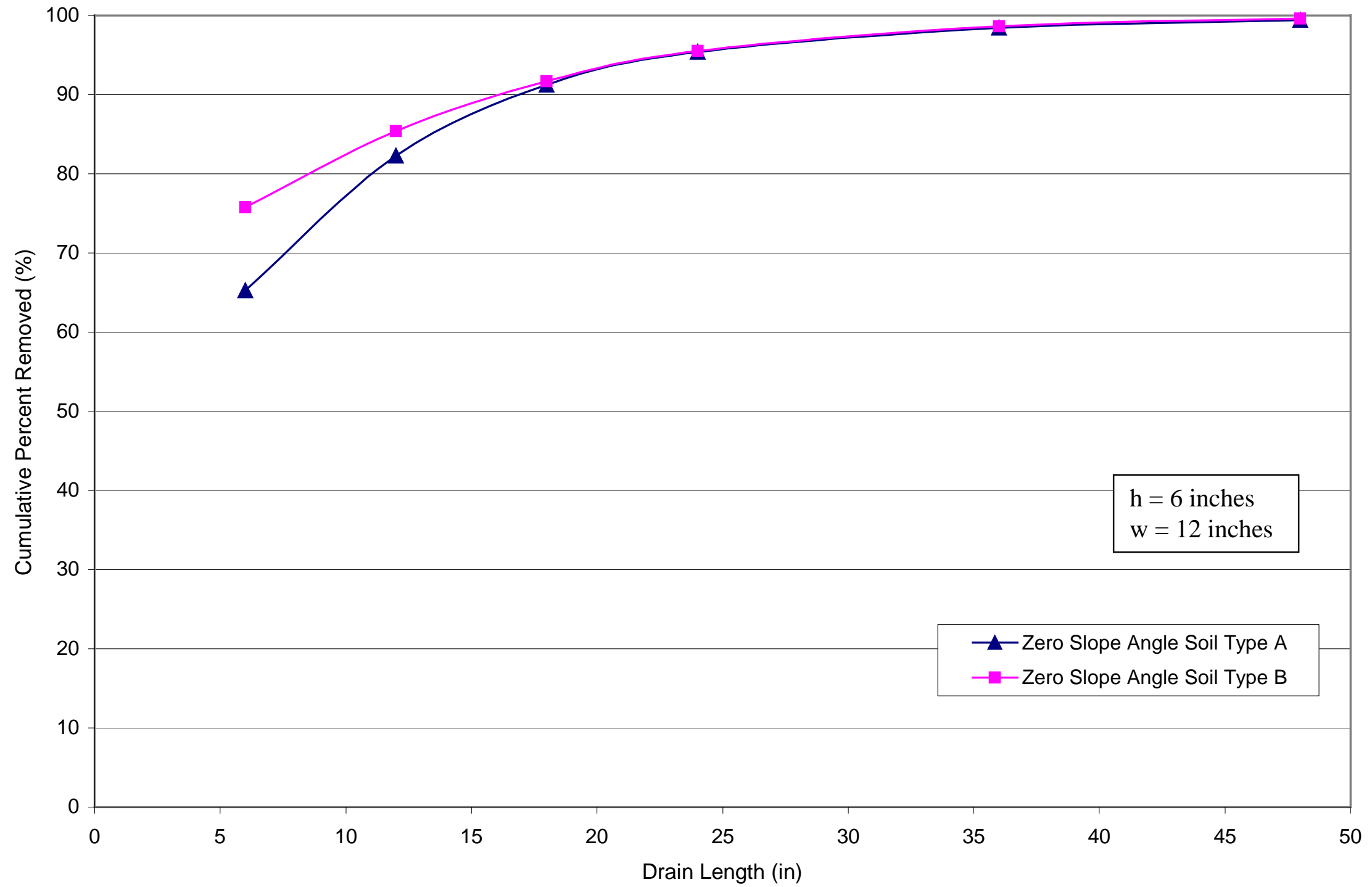

Figure H.5: Influence of Soil Type ( $h=6$ inches, $w=12$ inches). 


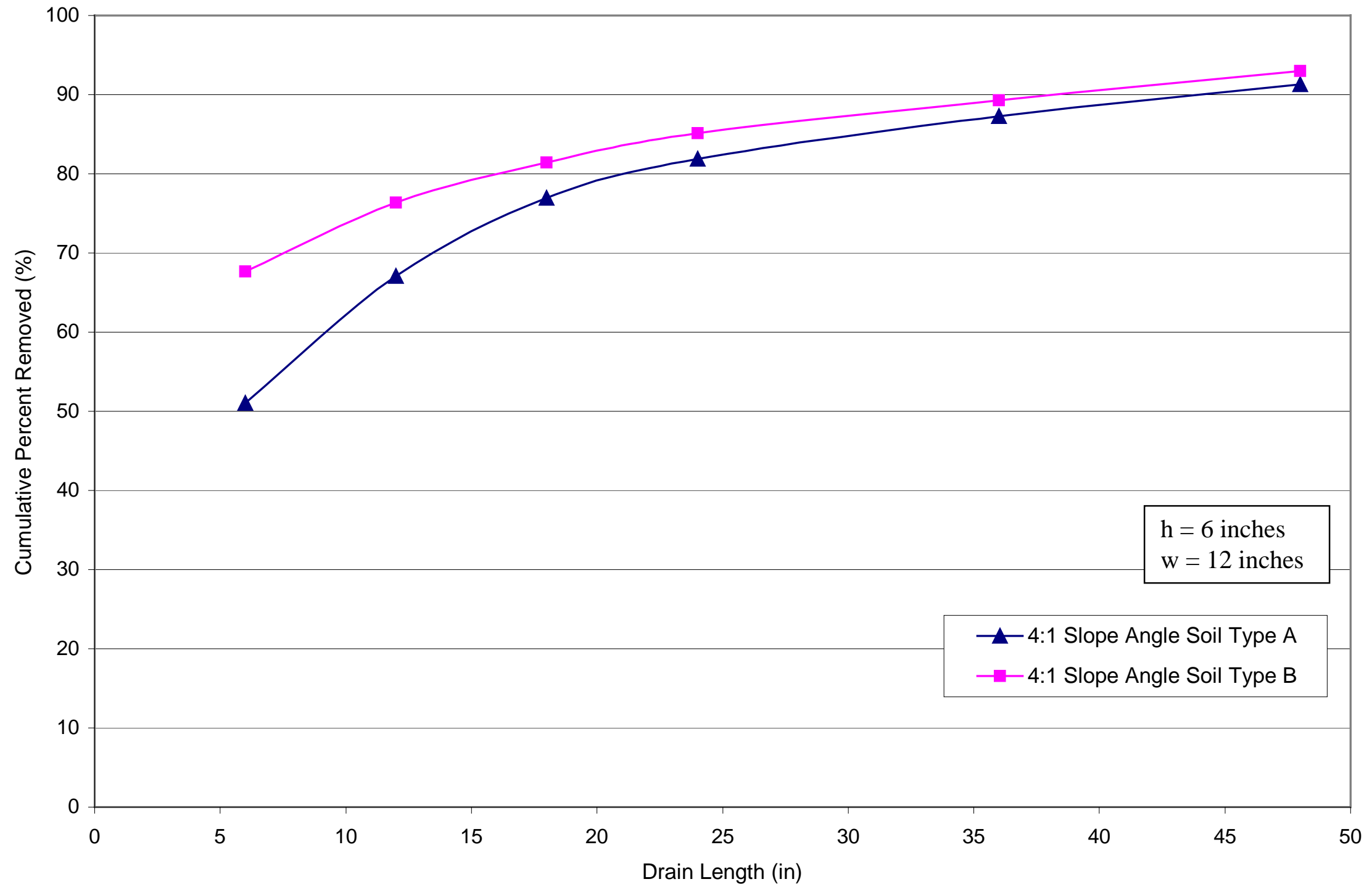

Figure H.6: Influence of Soil Type ( $h=6$ inches, $w=12$ inches). 


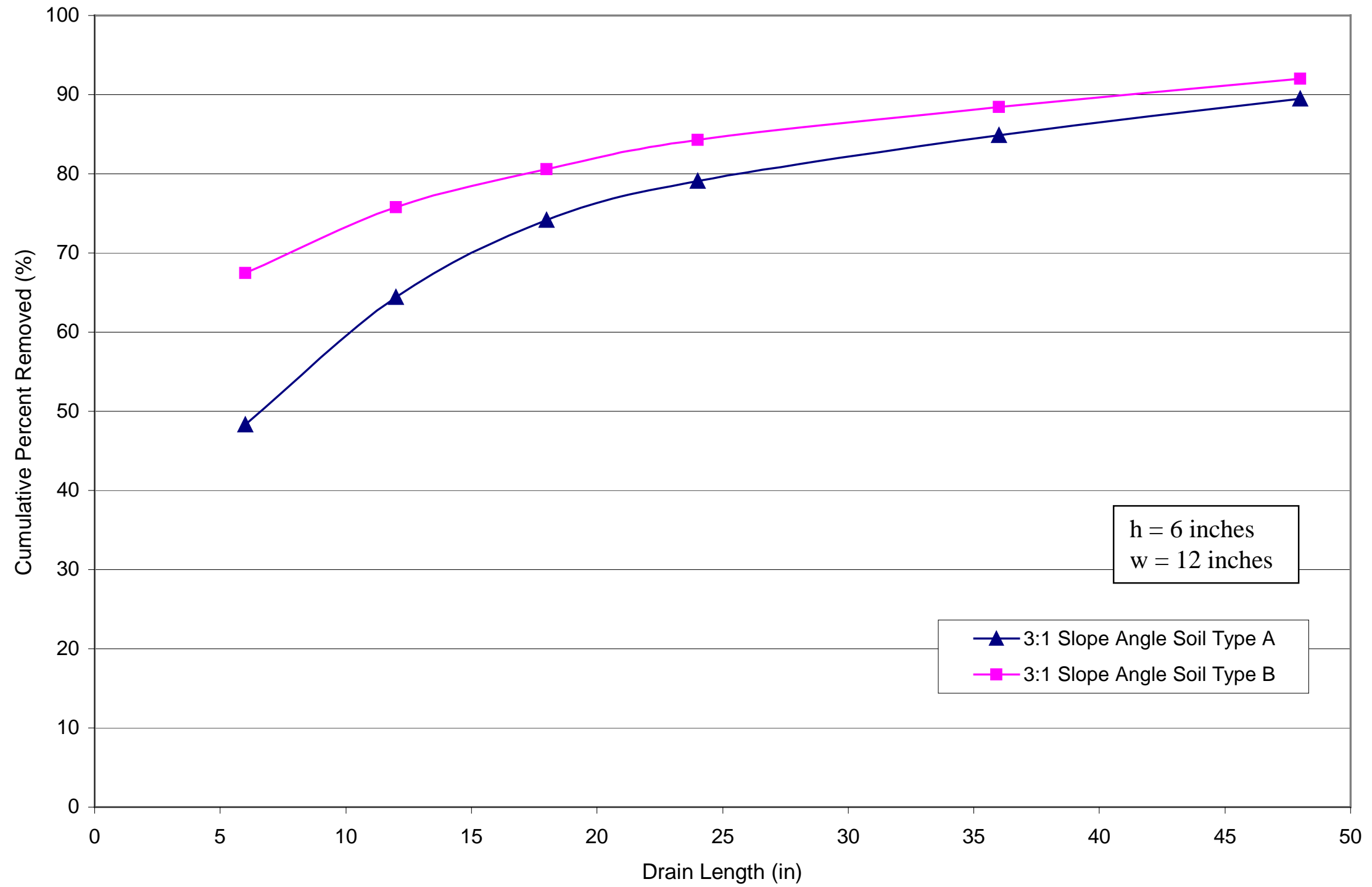

Figure H.7: Influence of Soil Type ( $h=6$ inches, $w=12$ inches). 


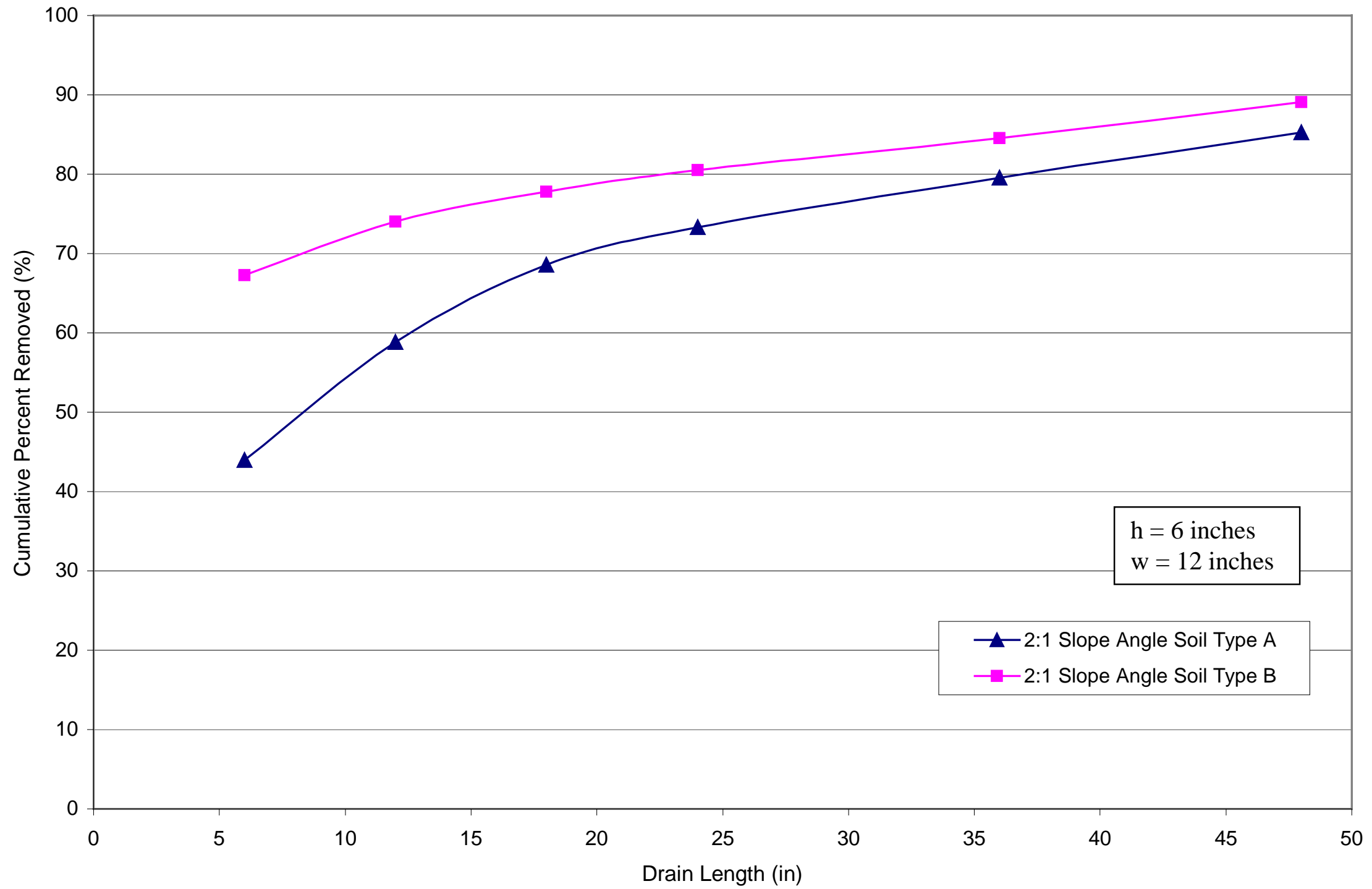

Figure H.8: Influence of Soil Type ( $h=6$ inches, $w=12$ inches). 


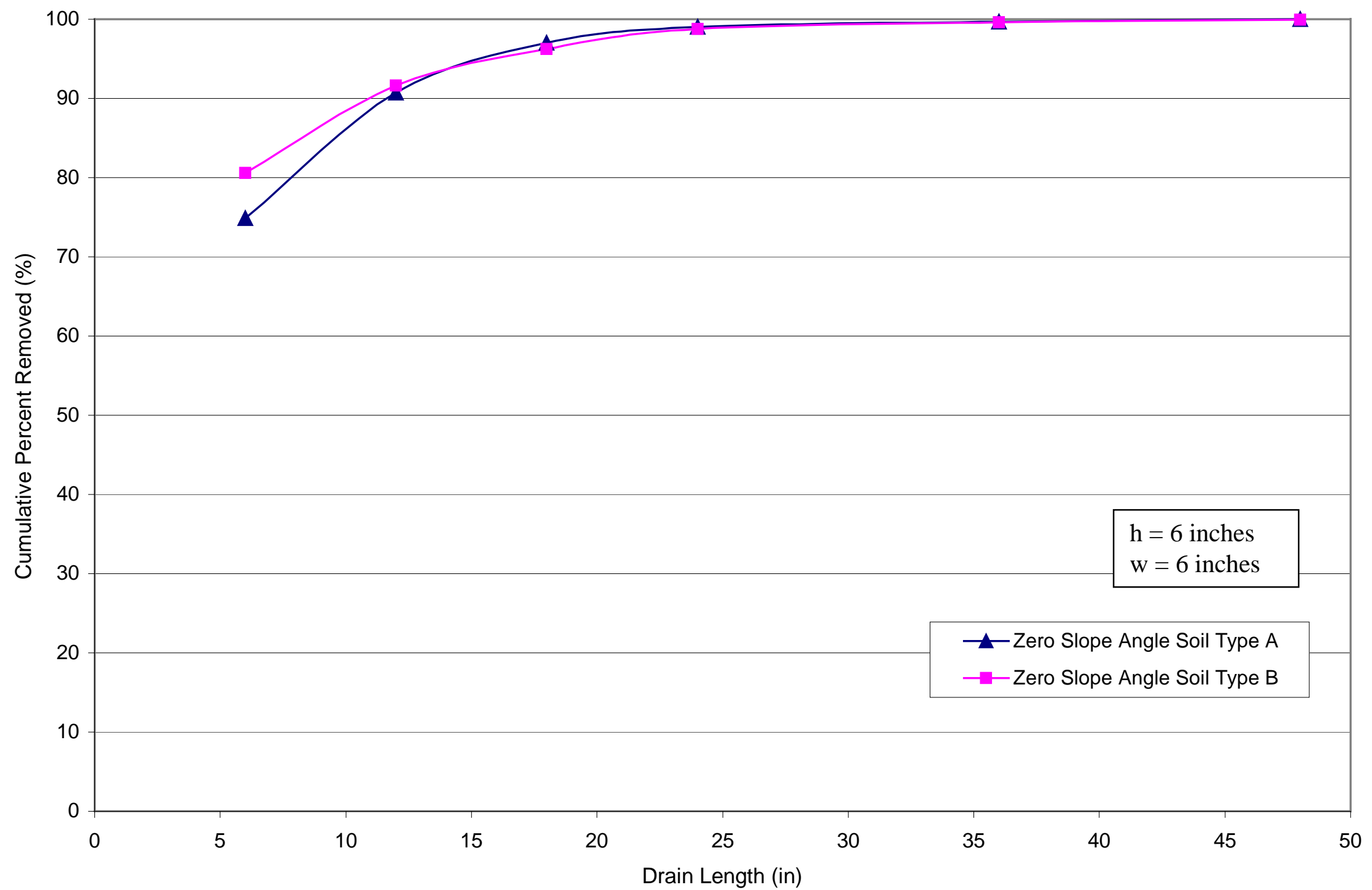

Figure H.9: Influence of Soil Type ( $h=6$ inches, $w=6$ inches). 


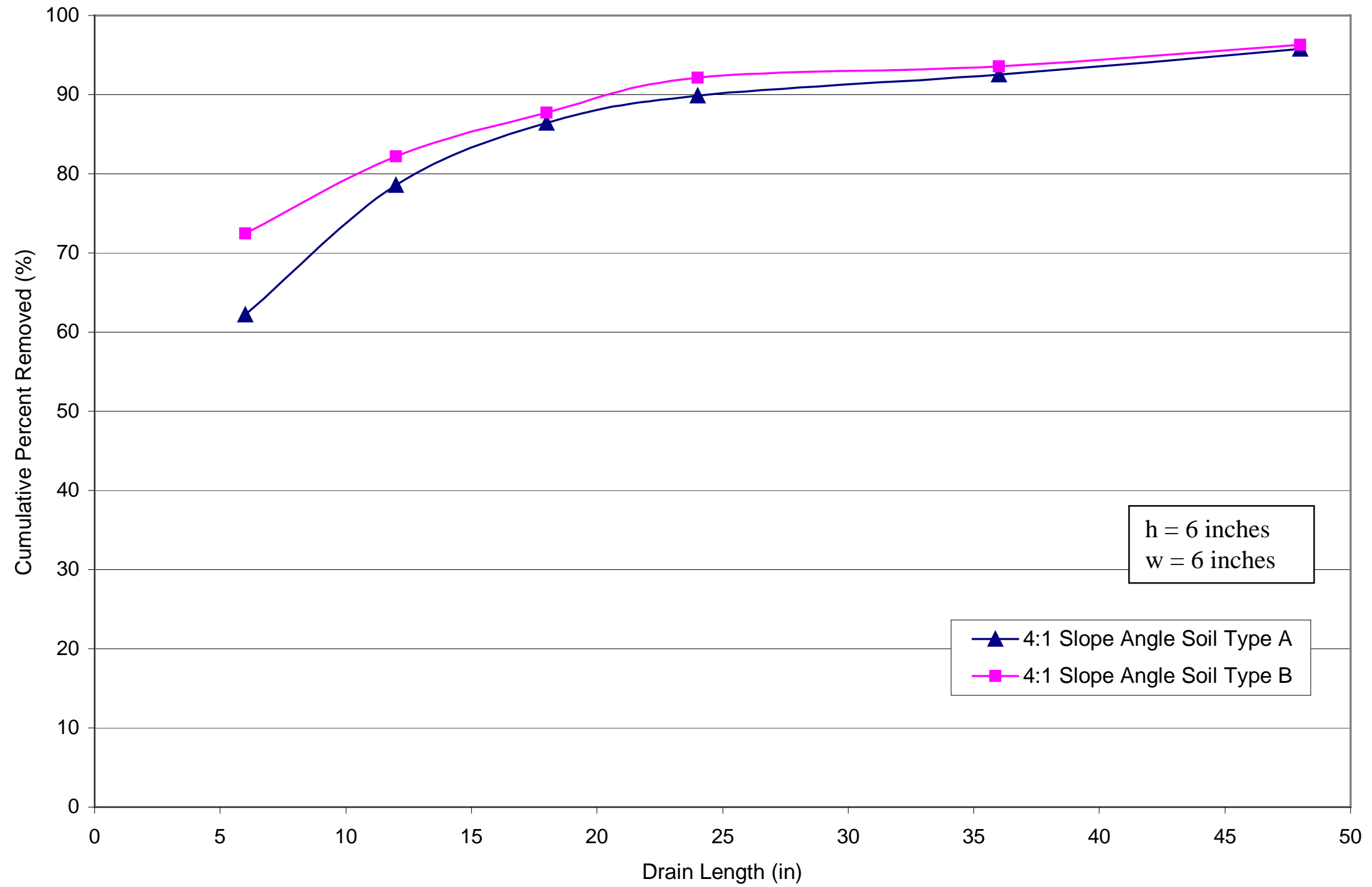

Figure H.10: Influence of Soil Type ( $h=6$ inches, $w=6$ inches). 


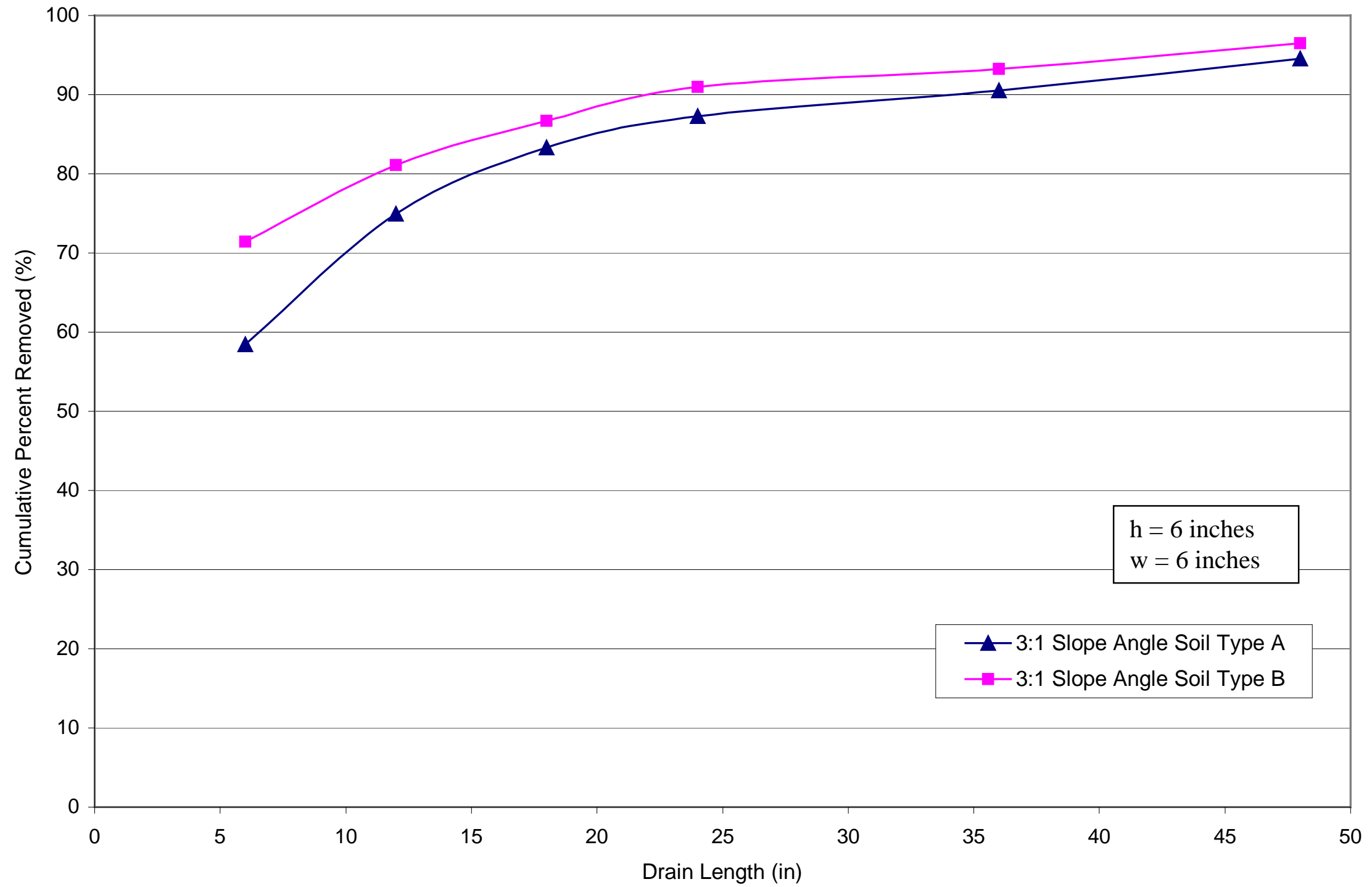

Figure H.11: Influence of Soil Type ( $h=6$ inches, $w=6$ inches). 


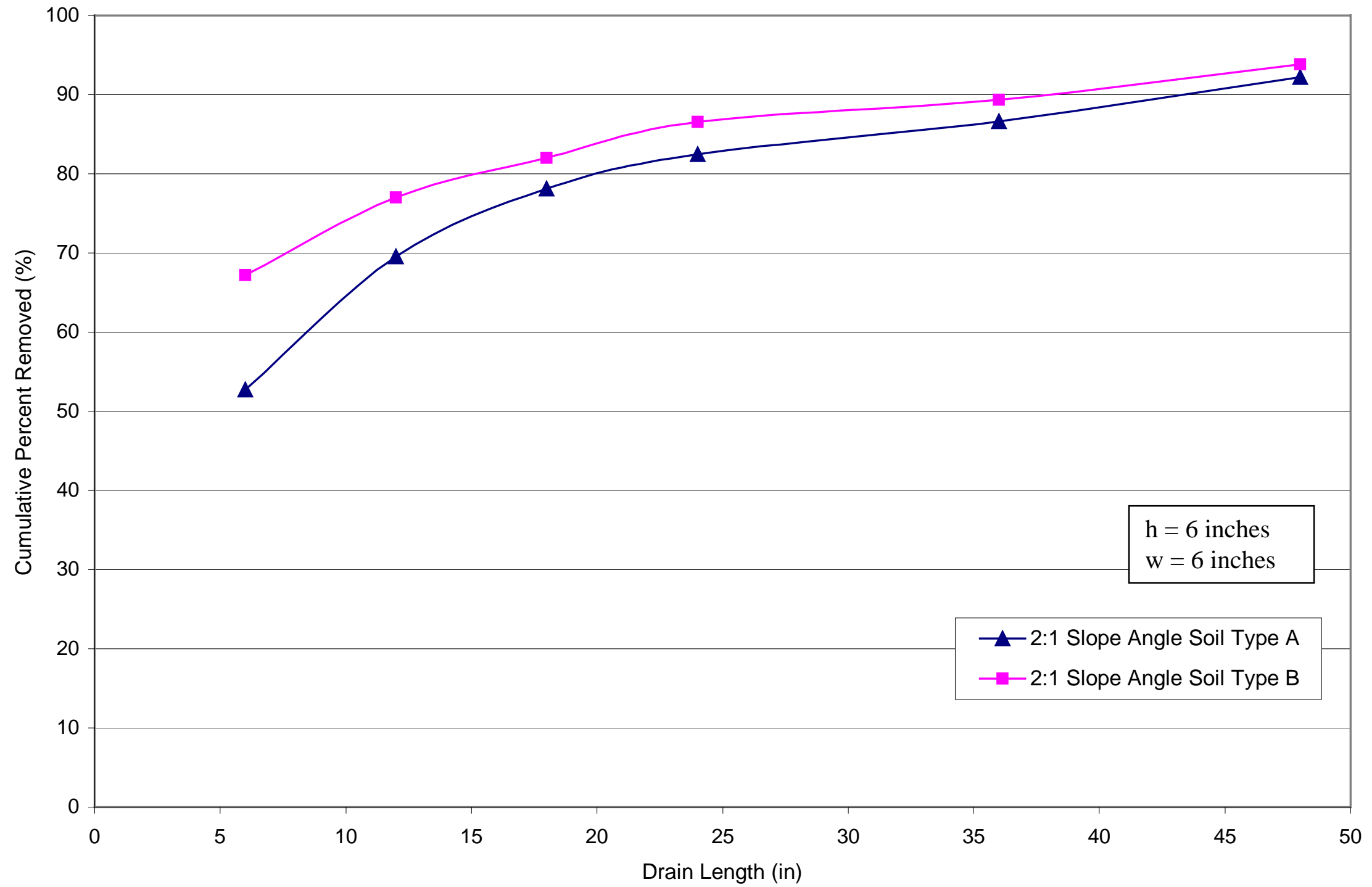

Figure H.12: Influence of Soil Type ( $h=6$ inches, $w=6$ inches). 


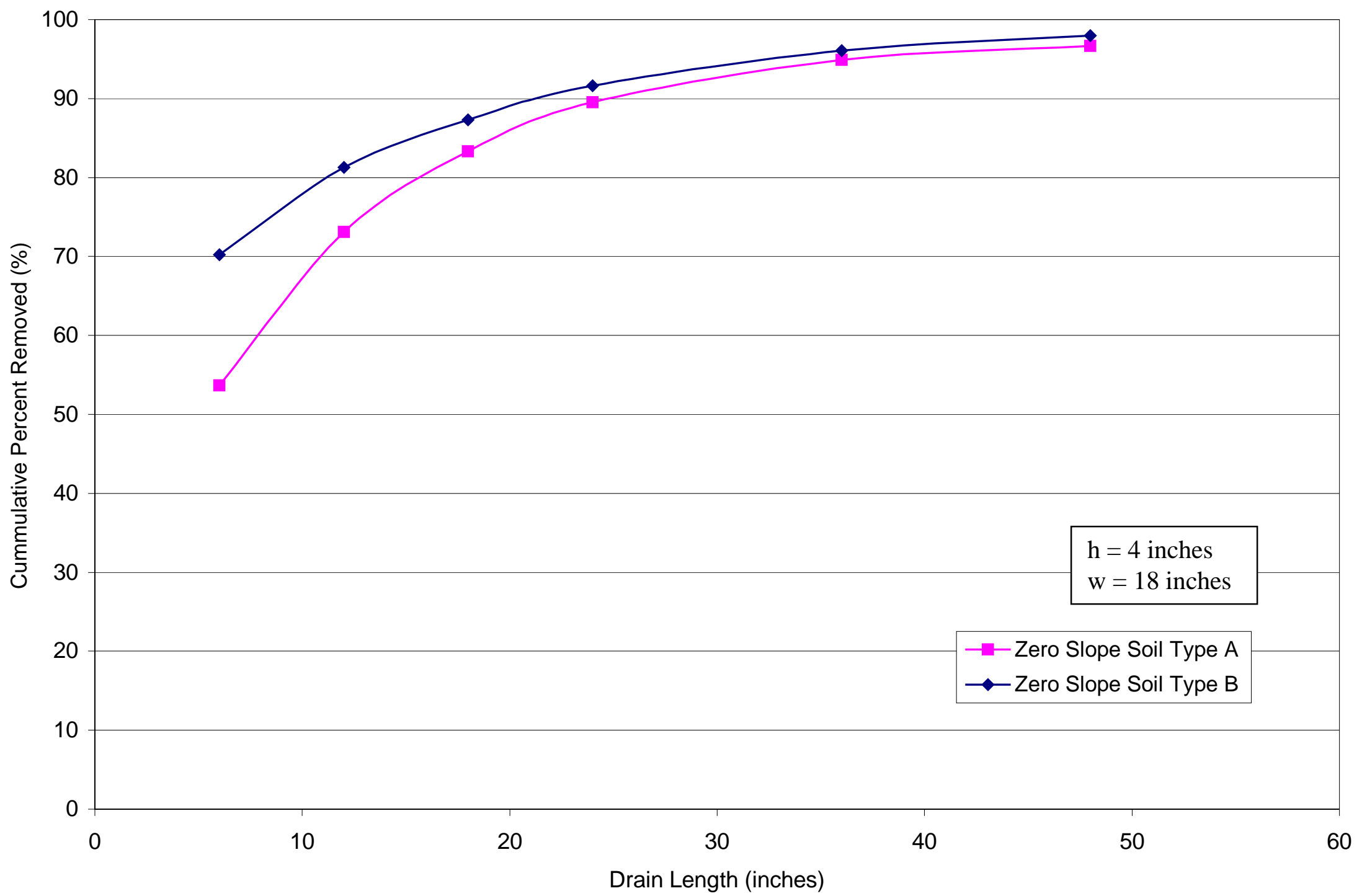

Figure H.13: Influence of Soil Type ( $h=4$ inches, $w=18$ inches). 


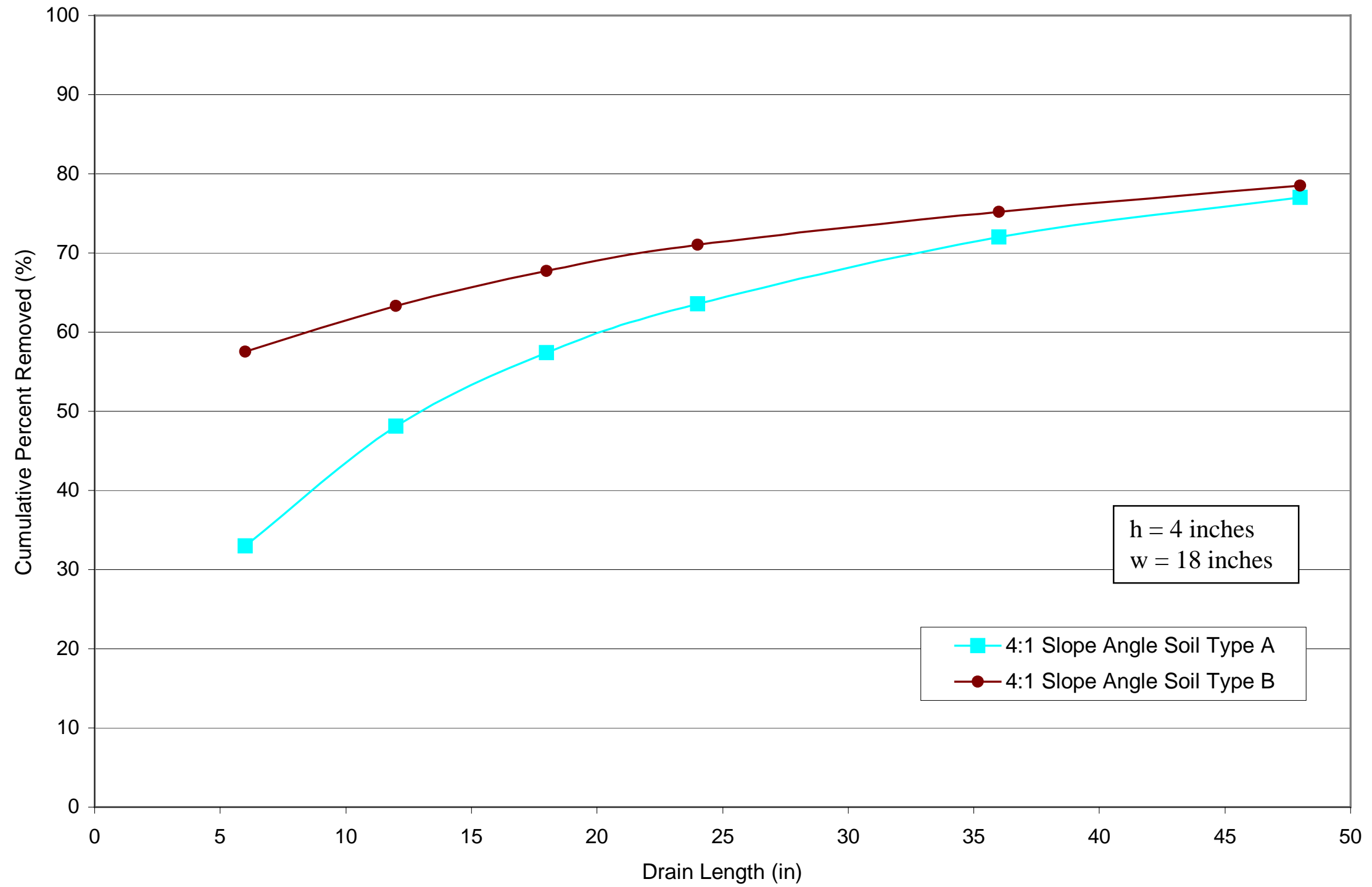

Figure H.14: Influence of Soil Type ( $h=4$ inches, $w=18$ inches). 


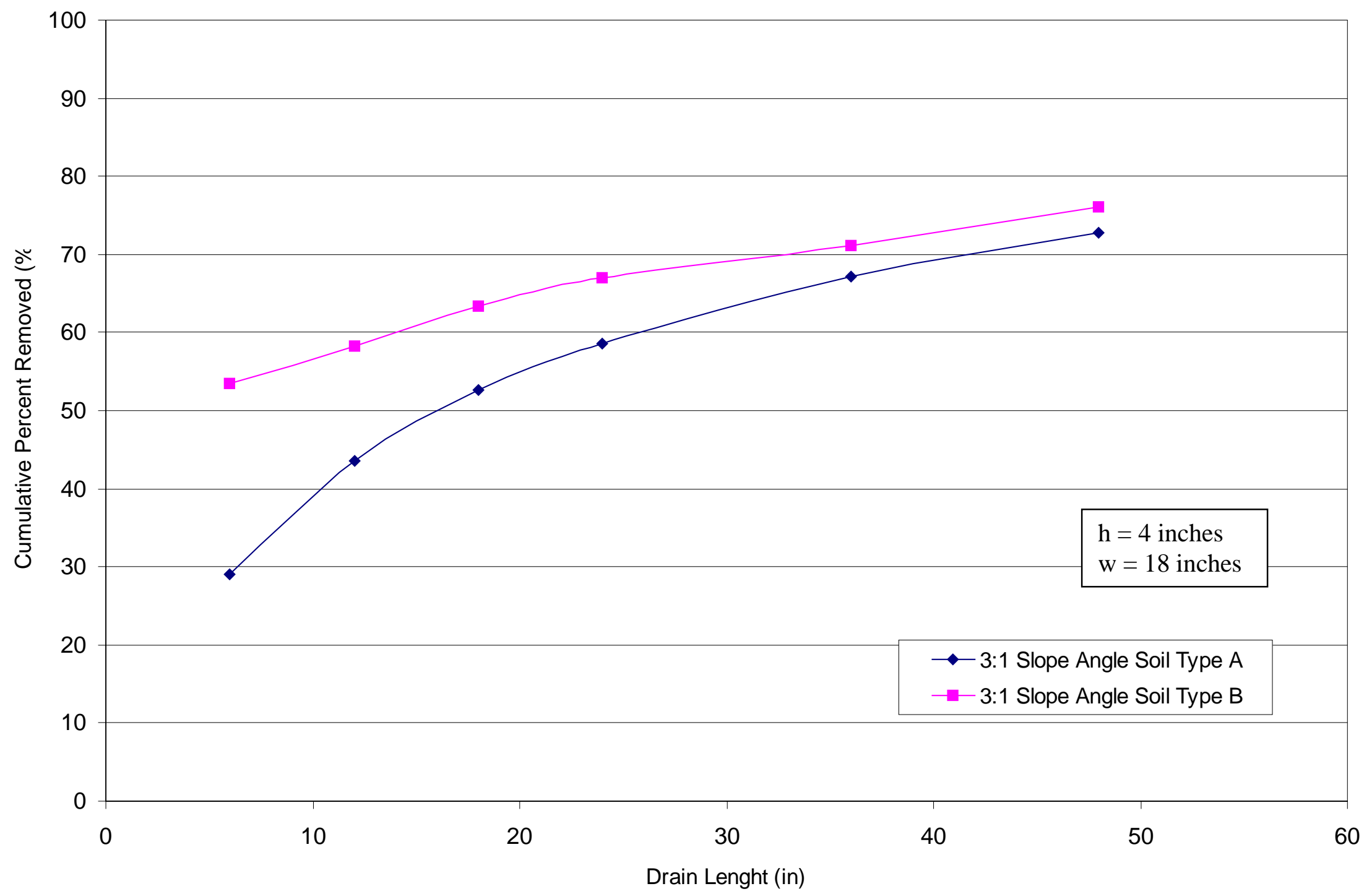

Figure H.15: Influence of Soil Type ( $h=4$ inches, $w=18$ inches). 


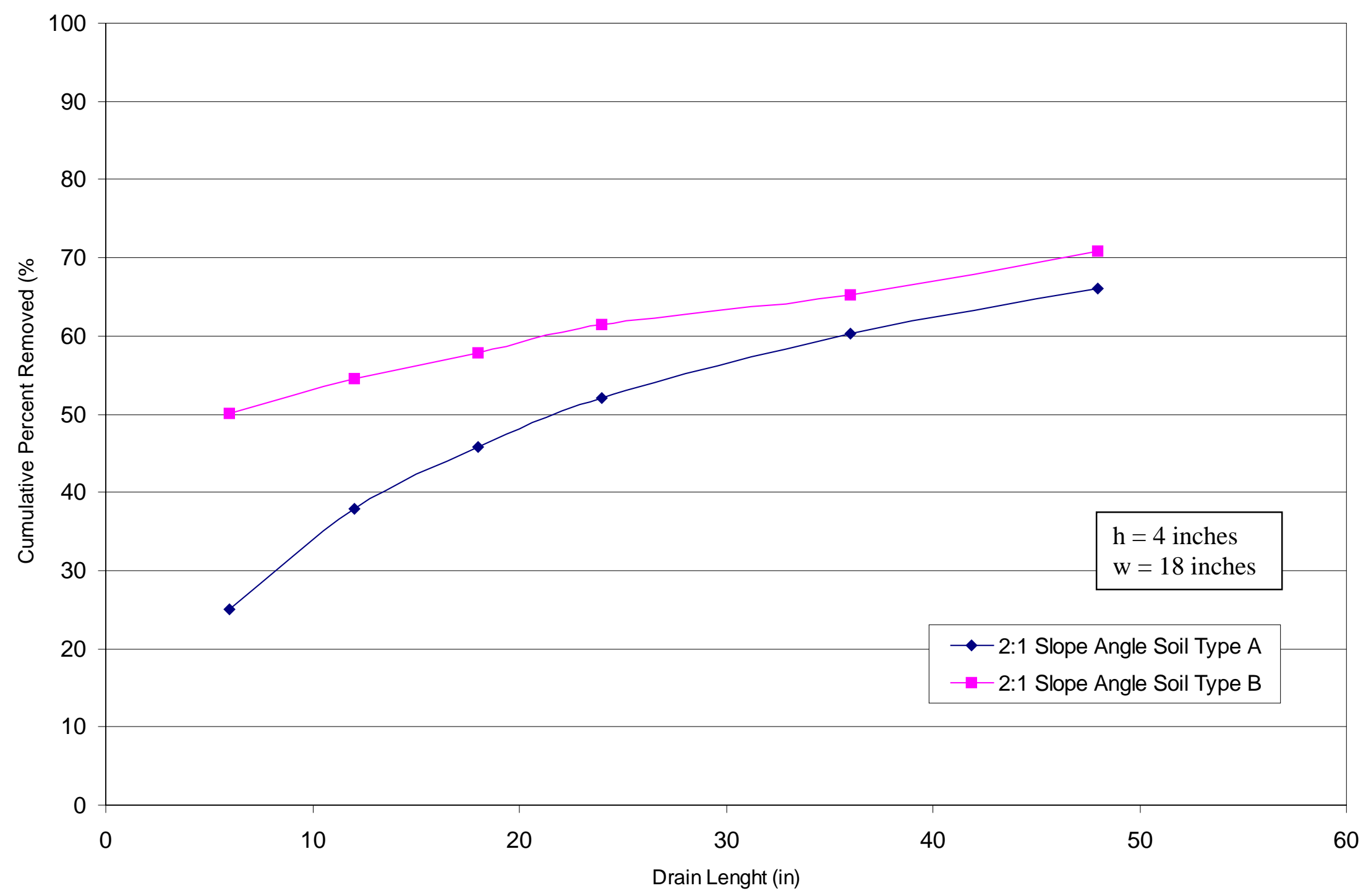

Figure H.16: Influence of Soil Type ( $h=4$ inches, $w=18$ inches). 


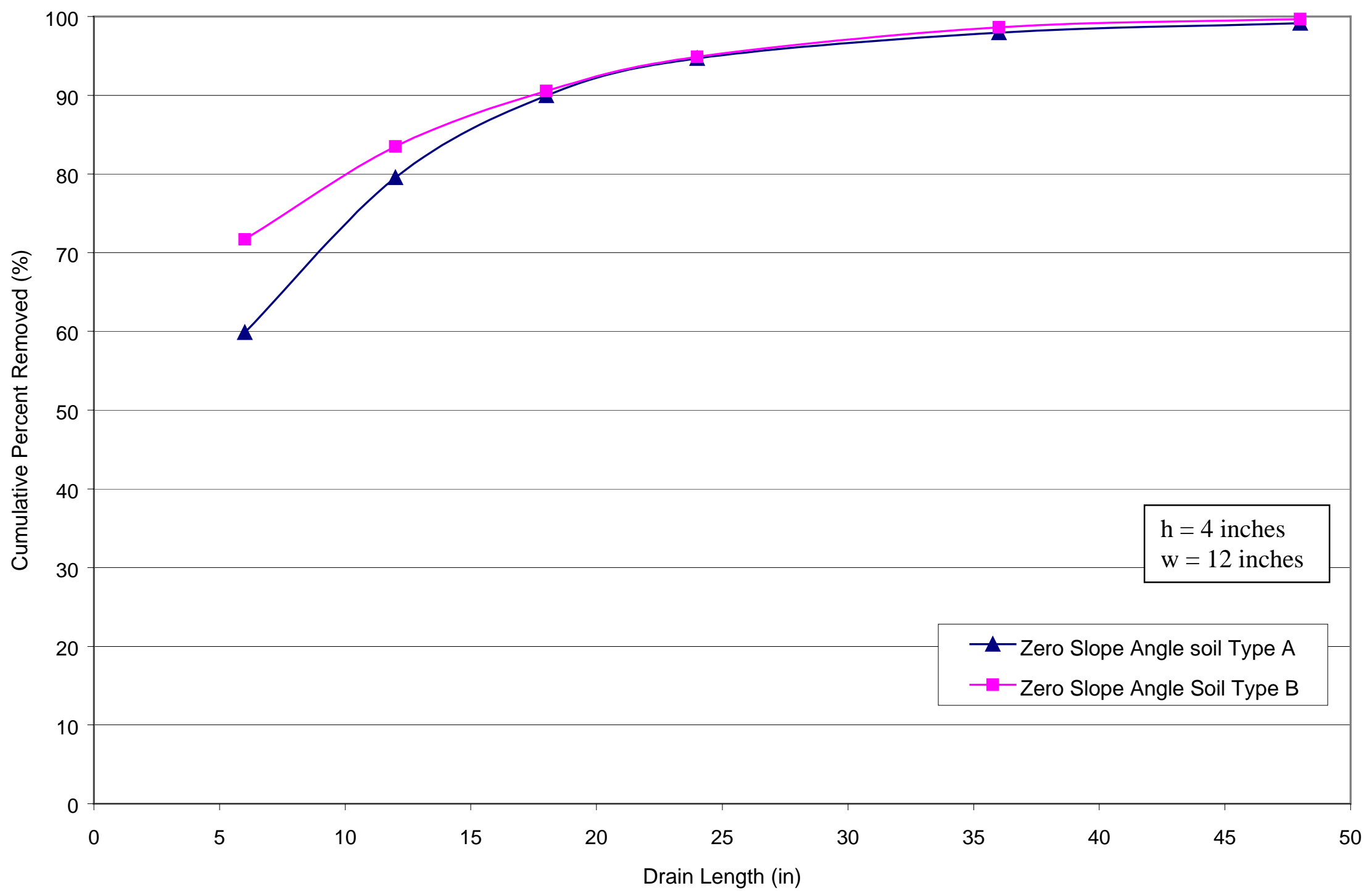

Figure H.17: Influence of Soil Type ( $h=4$ inches, $w=12$ inches). 


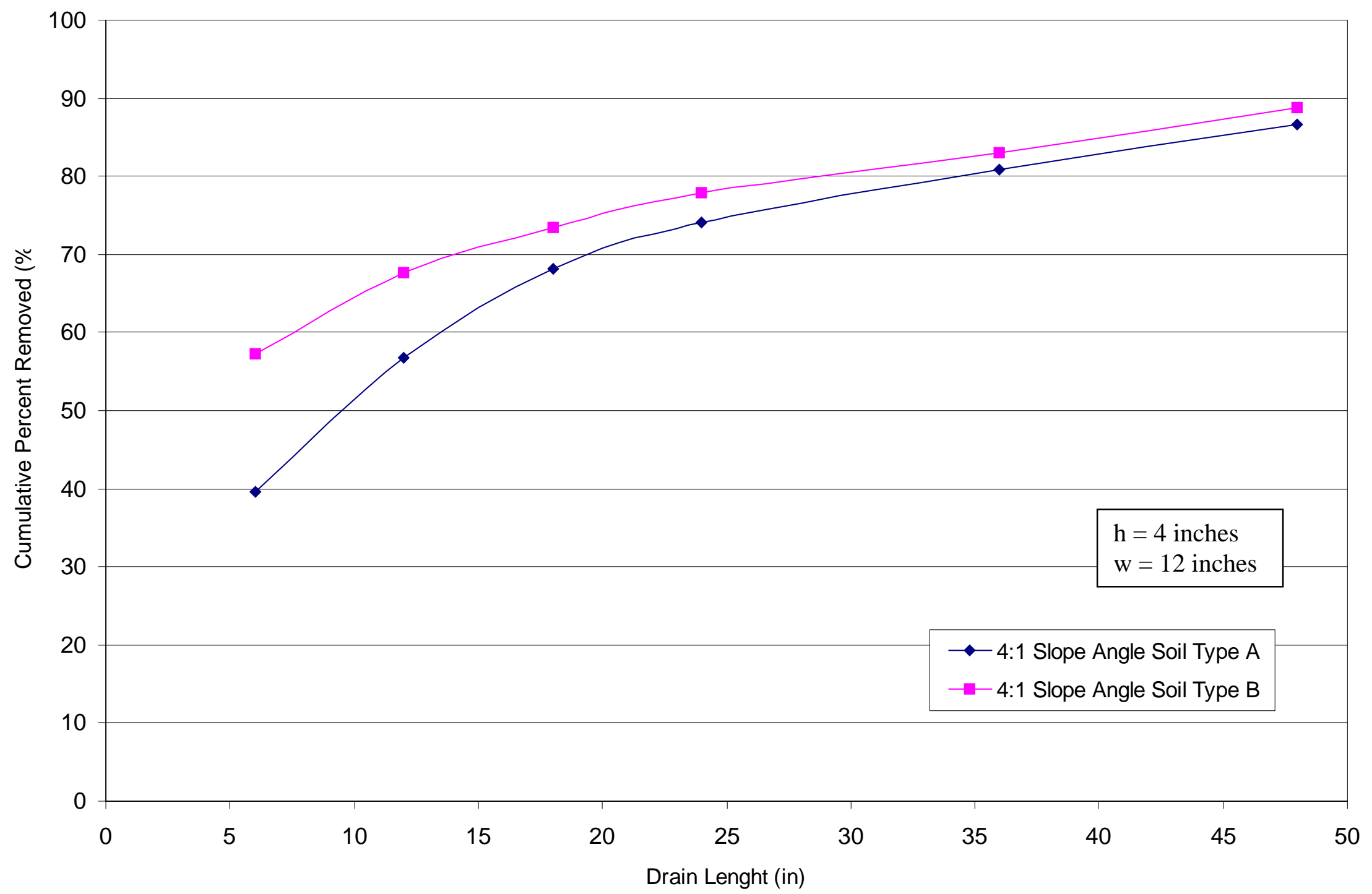

Figure H.18: Influence of Soil Type ( $h=4$ inches, $w=12$ inches). 


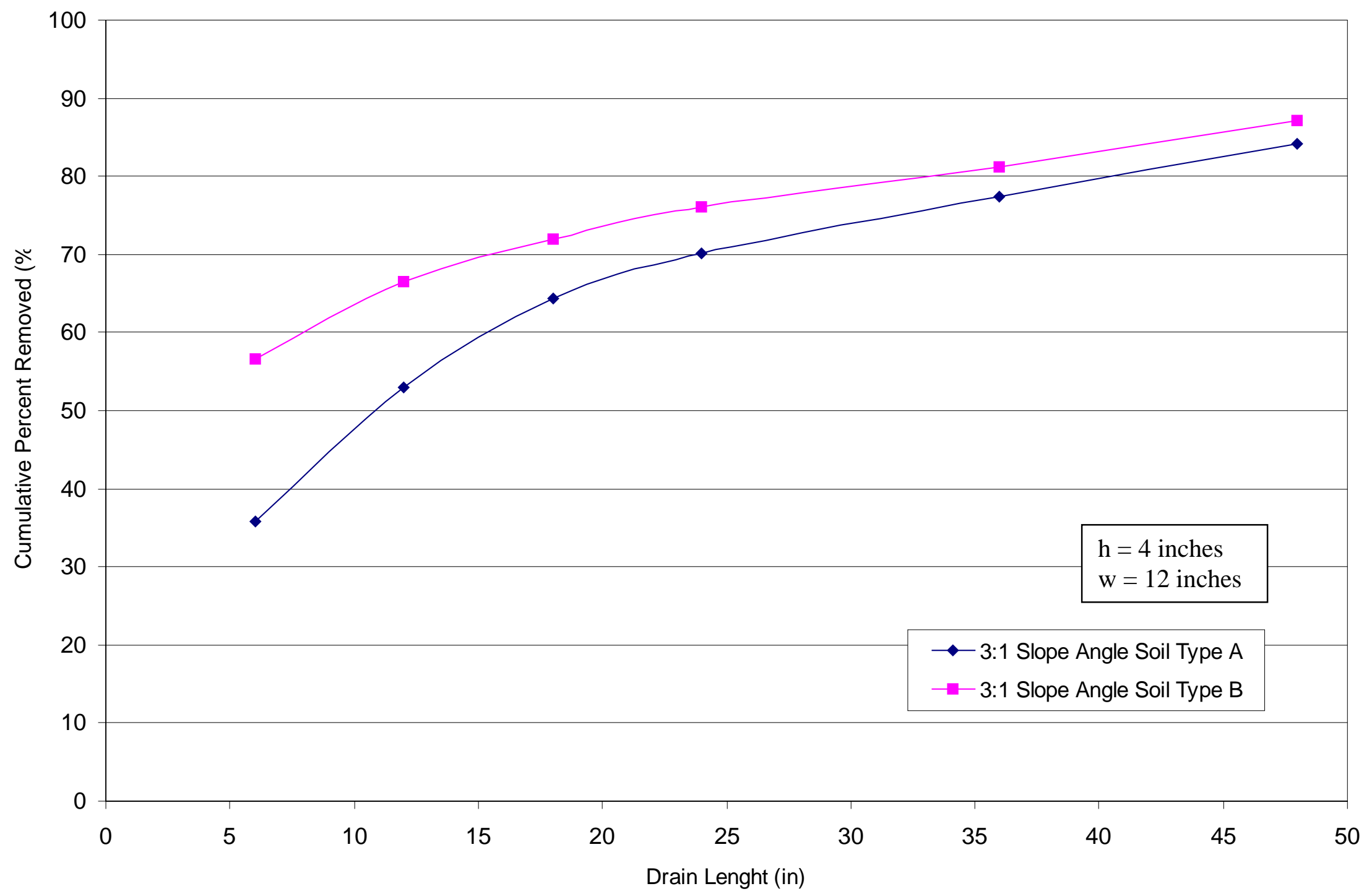

Figure H.19: Influence of Soil Type ( $h=4$ inches, $w=12$ inches). 


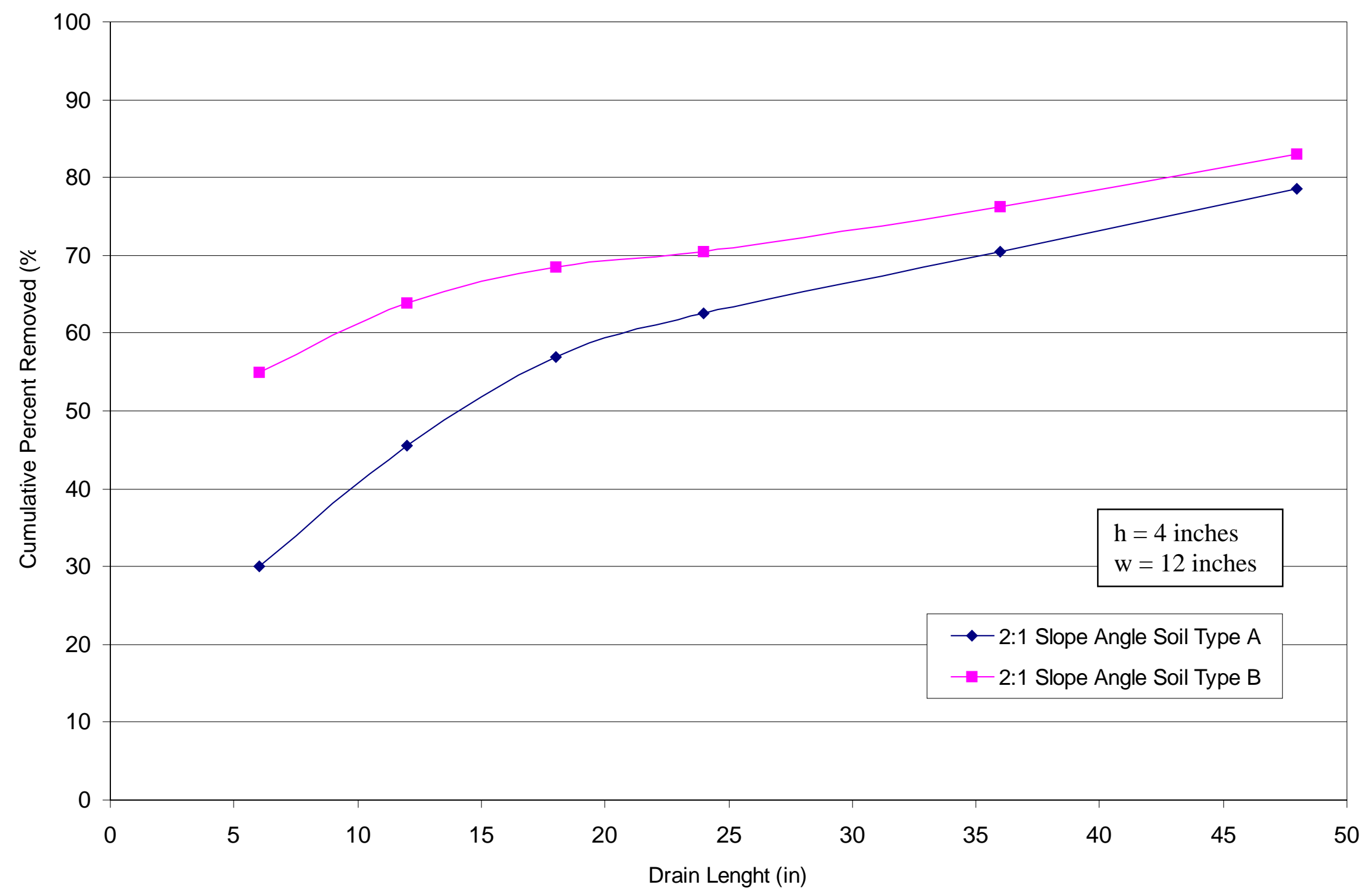

Figure H.20: Influence of Soil Type ( $h=4$ inches, $w=12$ inches). 


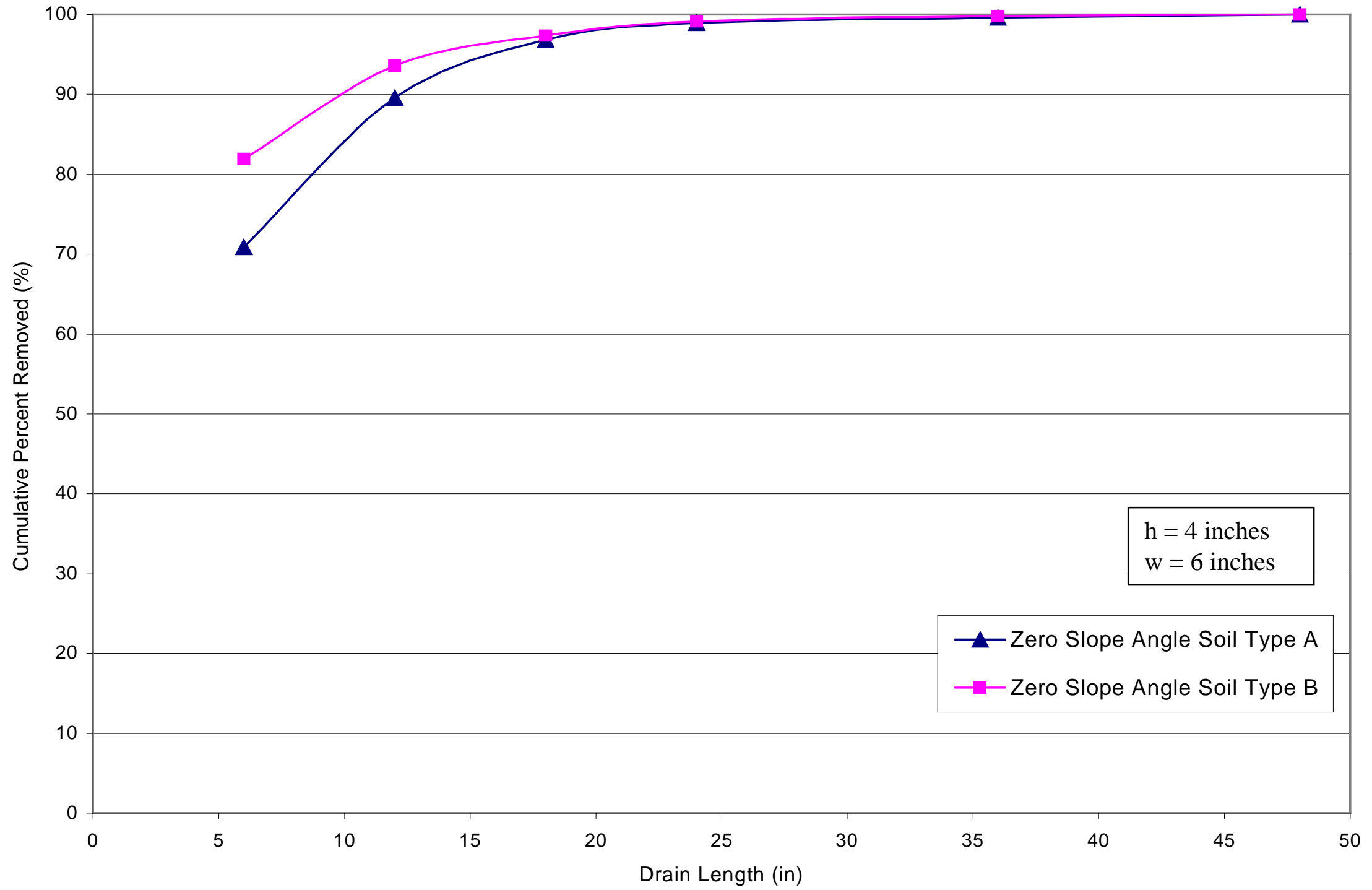

Figure H.21: Influence of Soil Type ( $h=4$ inches, $w=6$ inches). 


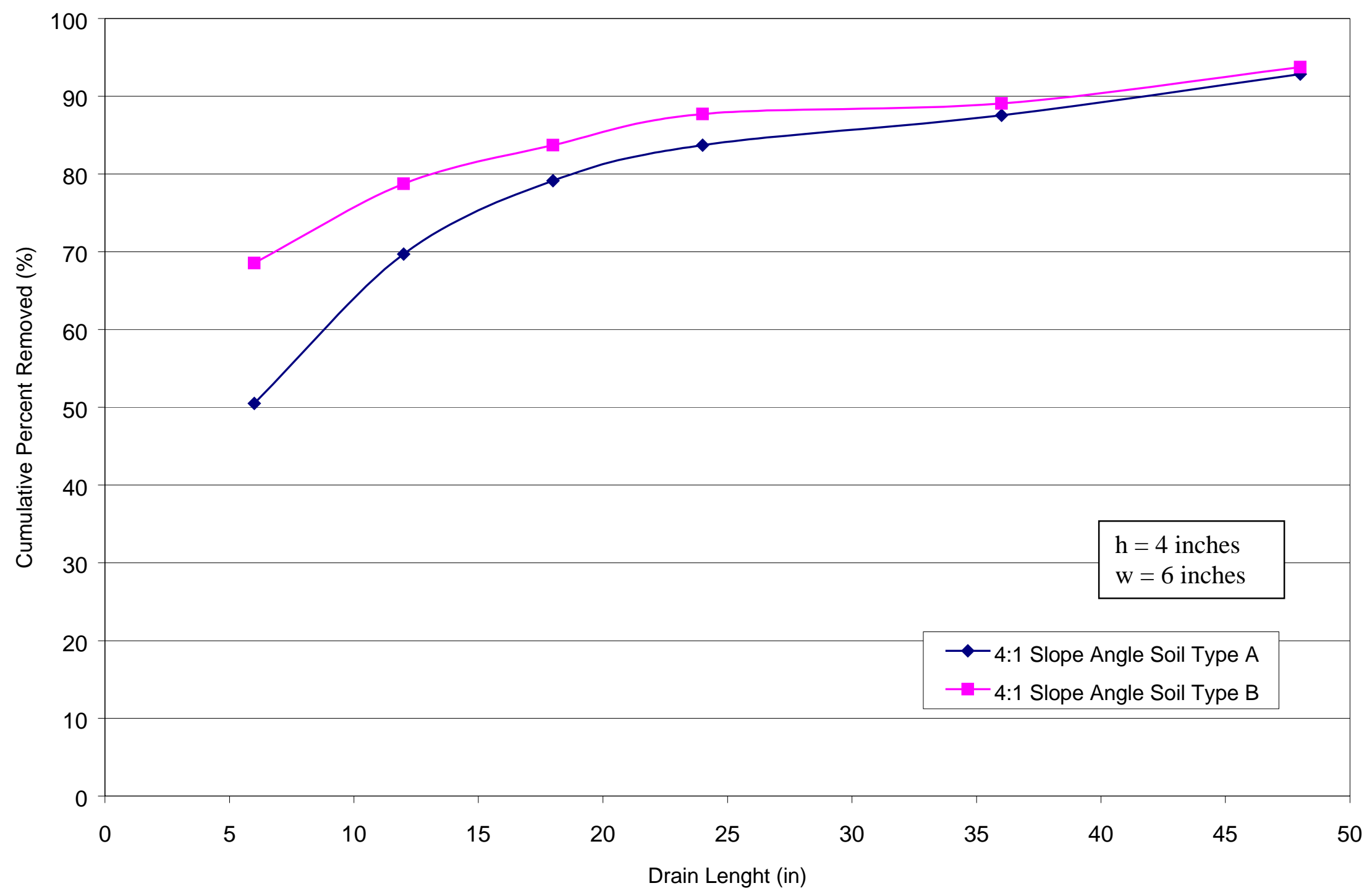

Figure H.22: Influence of Soil Type ( $h=4$ inches, $w=6$ inches). 


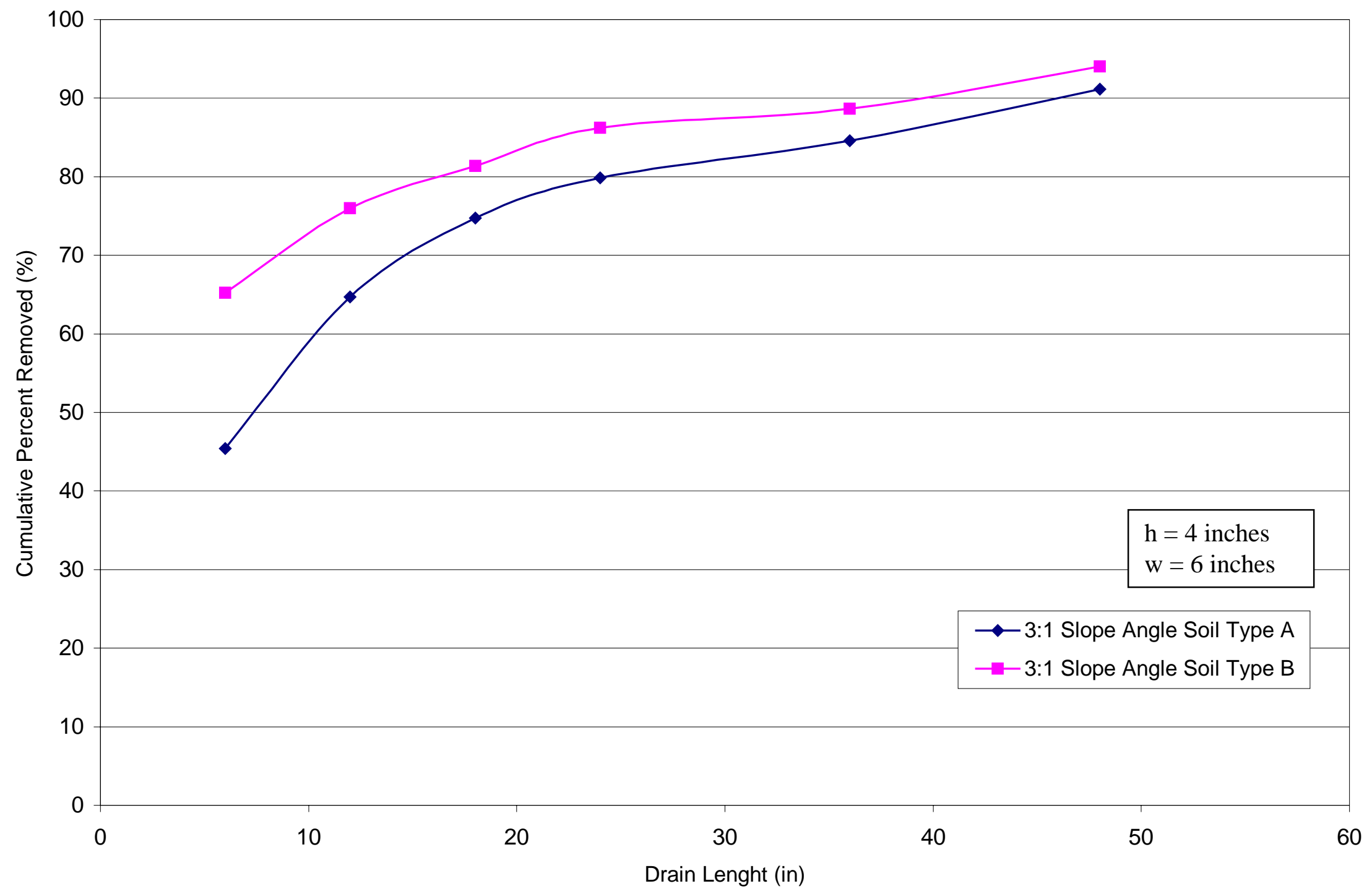

Figure H.23: Influence of Soil Type ( $h=4$ inches, $w=6$ inches). 


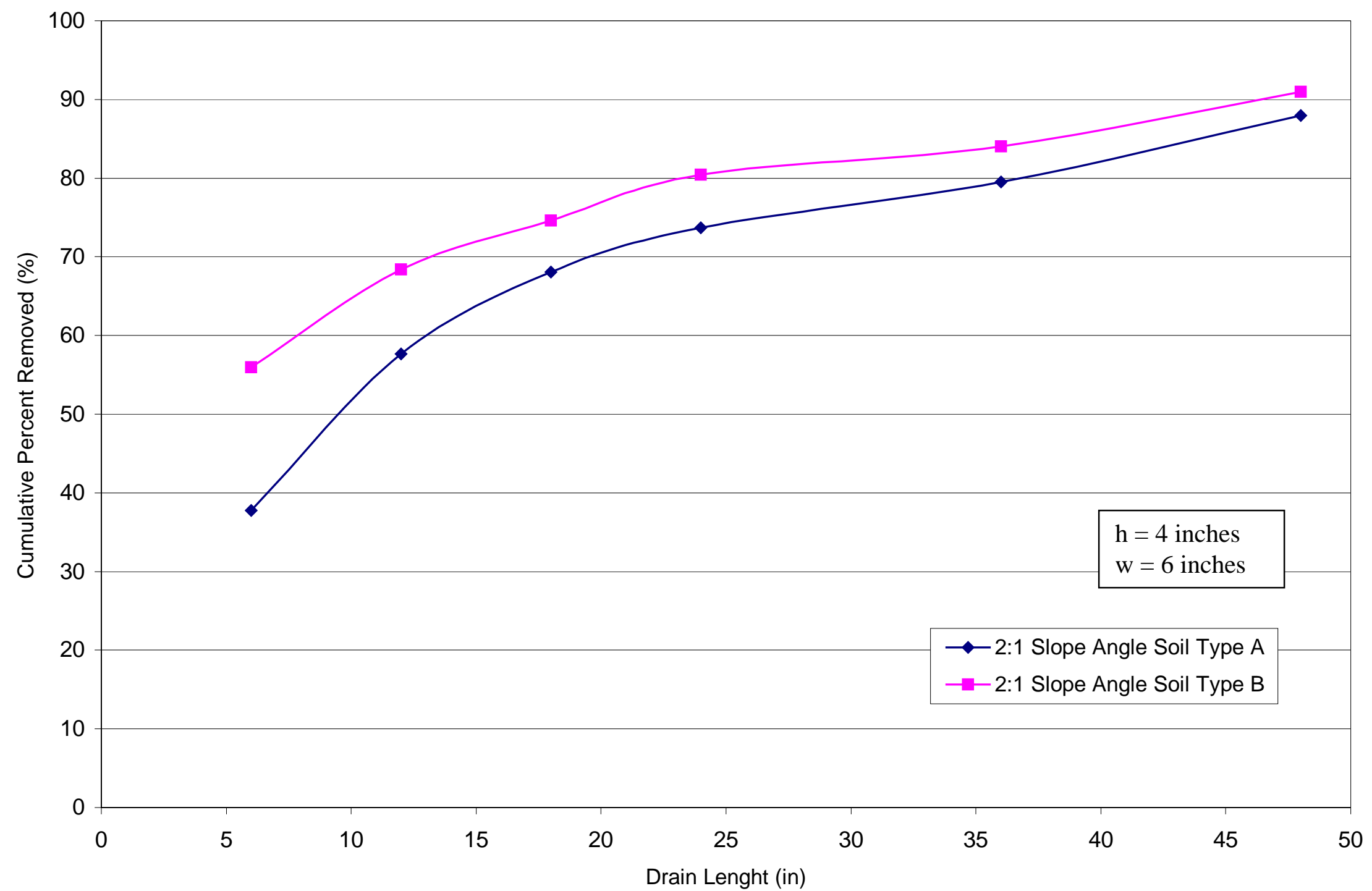

Figure H.24: Influence of Soil Type ( $h=4$ inches, $w=6$ inches). 


\section{APPENDIX I}

\section{Variation of Piezometric Head}

For different

Slope Angle, Trench Spacing and Saturation Depth

Soil Type B (15\% Clay Content) 


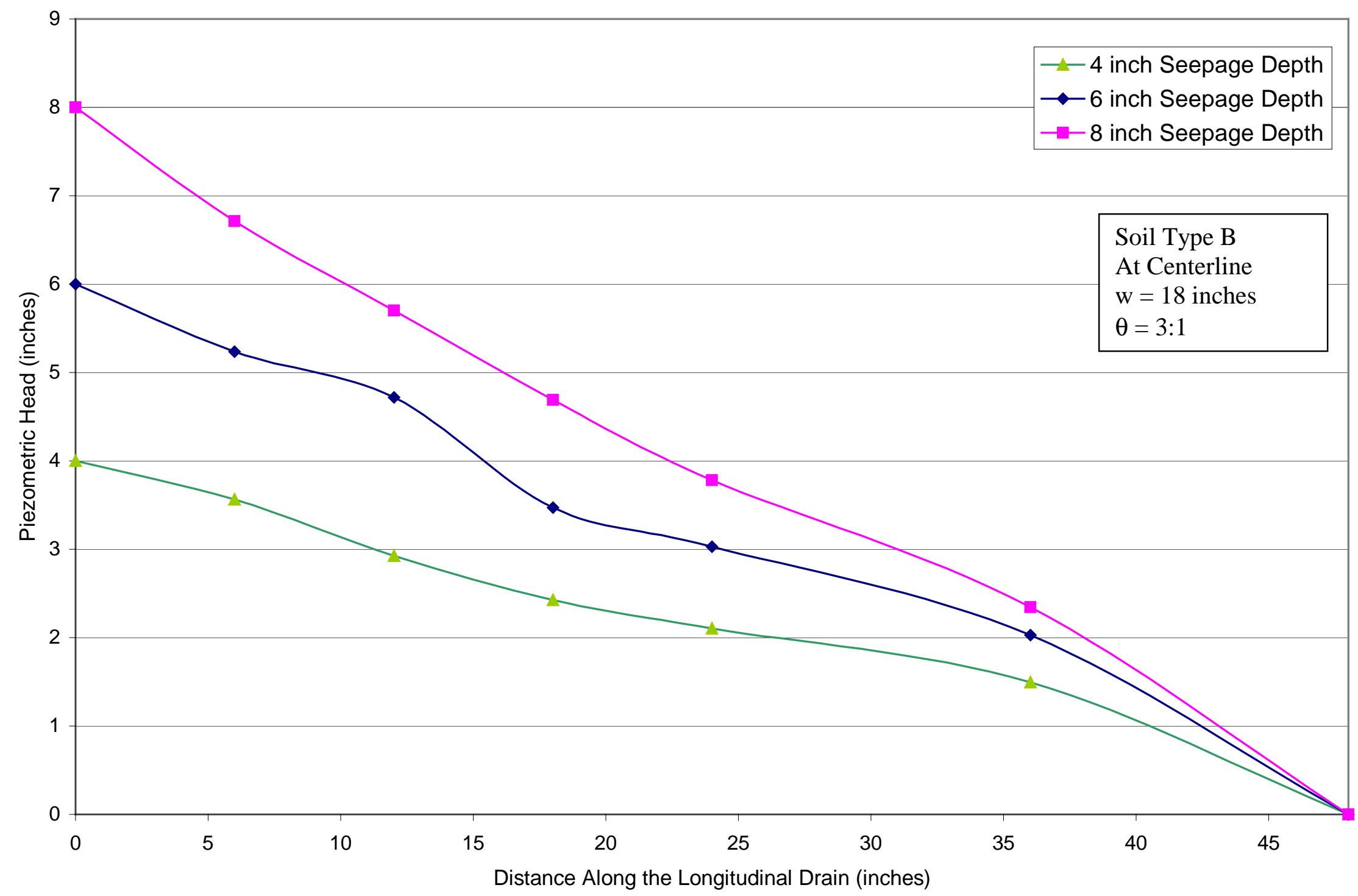

Figure I.1: Influence of Saturation Depth on Piezometric Head at Centerline ( $w=18$ inches, 3:1 Slope Angle). 


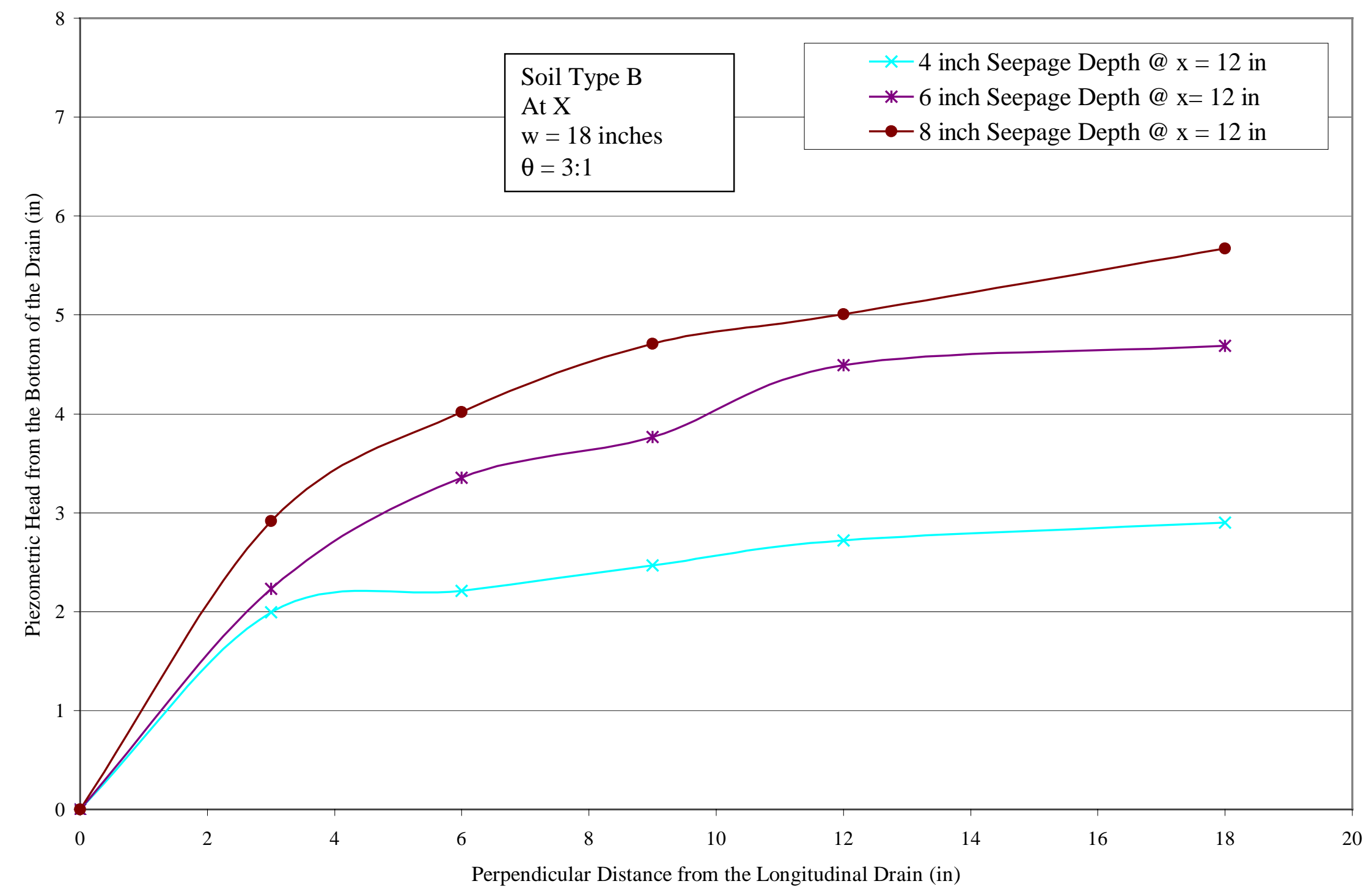

Figure I.2: Influence of Saturation Depth on Piezometric Head at Cross-section X ( $w=18$ inches, 3:1 Slope Angle). 


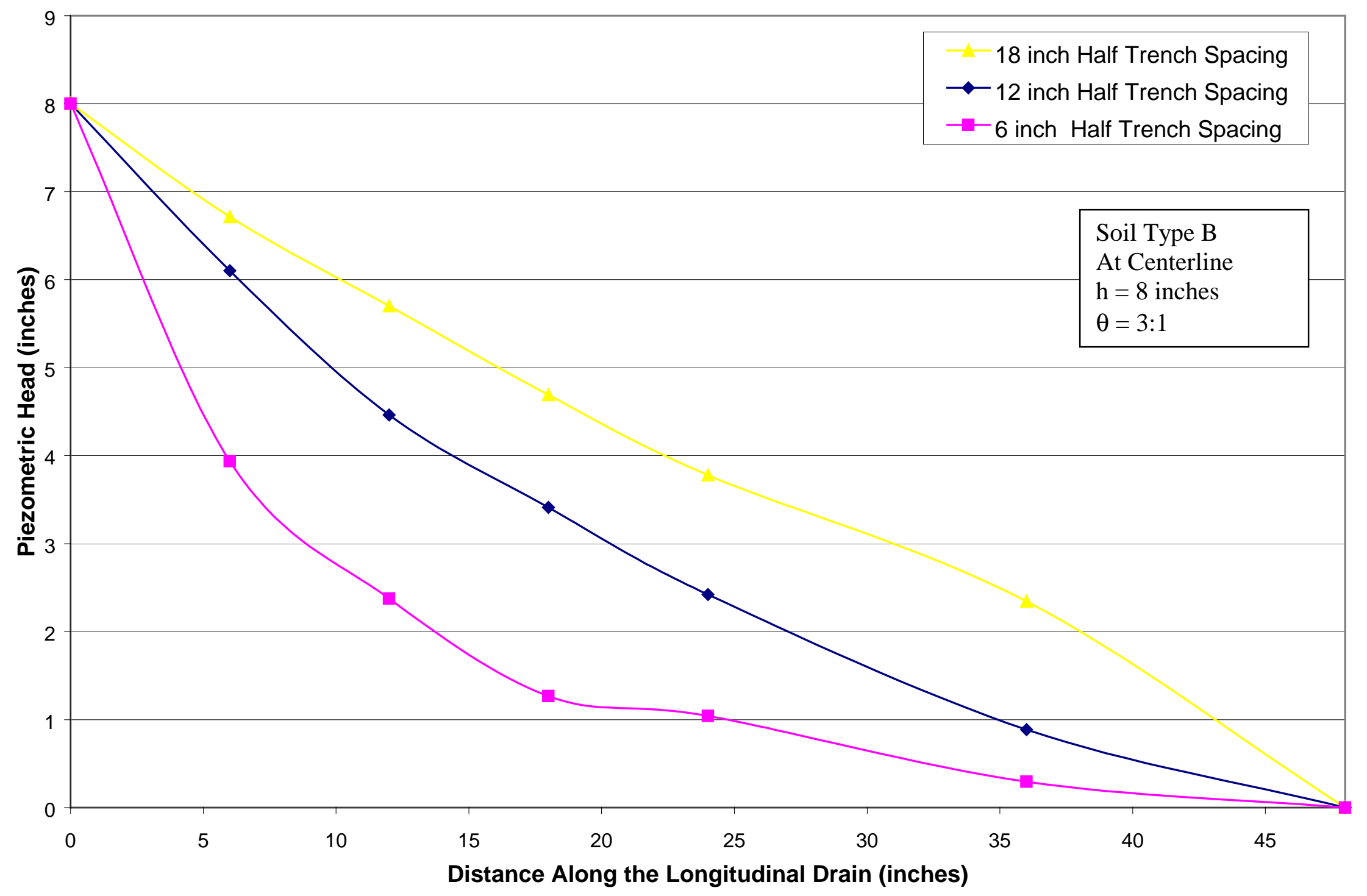

Figure I.3: Influence of Trench Spacing on Piezometric Head ( $h=8$ inches, 3:1 Slope Angle). 


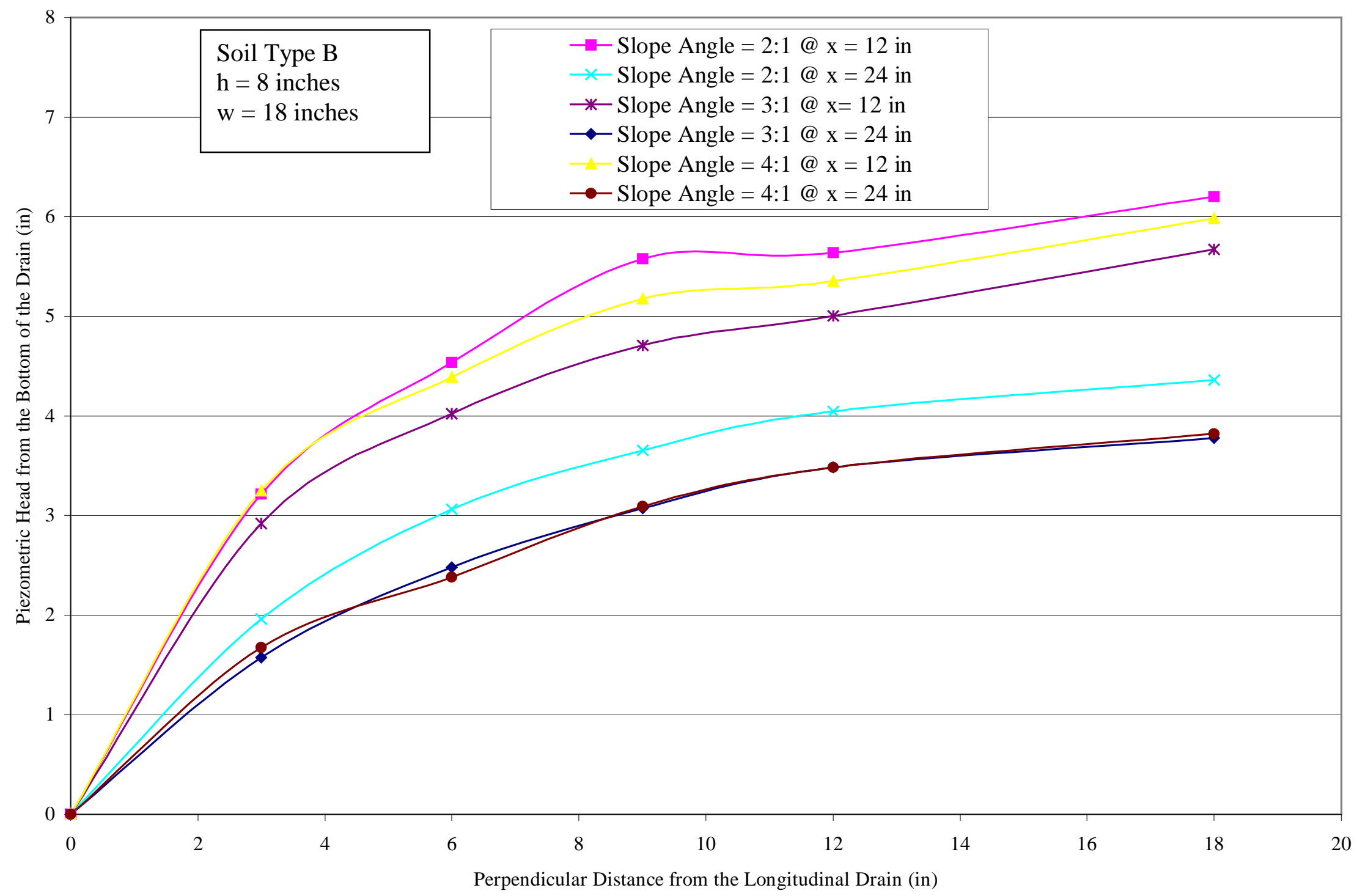

Figure I.4: Influence of Slope Angle on Piezometric Head ( $h=8$ inches, $w=18$ inches). 


\section{VITA}

Ricardo Constantino Kiriakidis Longhi was born in Barquisimeto, Lara State in Venezuela in 1977. He graduated with a Bachelor of Science in Civil Engineering in 1999 from West Virginia University. Currently he is a Masters degree candidate specializing in Geotechnical Engineering at West Virginia University, with aspiration to a doctoral degree in the same area. 